\title{
Effects of Sleeve Blockages on Axial Velocity and Intensity of Turbulence in an Unheated 7 × 7 Rod Bundle
}

January 1976

Prepared for the U.S. Nuclear

Regulatory Commission 


\section{DISCLAIMER}

This report was prepared as an account of work sponsored by an agency of the United States Government. Neither the United States Government nor any agency Thereof, nor any of their employees, makes any warranty, express or implied, or assumes any legal liability or responsibility for the accuracy, completeness, or usefulness of any information, apparatus, product, or process disclosed, or represents that its use would not infringe privately owned rights. Reference herein to any specific commercial product, process, or service by trade name, trademark, manufacturer, or otherwise does not necessarily constitute or imply its endorsement, recommendation, or favoring by the United States Government or any agency thereof. The views and opinions of authors expressed herein do not necessarily state or reflect those of the United States Government or any agency thereof. 


\section{DISCLAIMER}

Portions of this document may be illegible in electronic image products. Images are produced from the best available original document. 
NOTICE

This report was prepared as an account of work sponsored by the United States Government. Neither the United States nor the United States Nuclear Regulatory Commission, nor any of their employees, nor any of their contractors, subcontractors, or their employees, makes any warranty, express or implied, or assumes any legal liability or responsibility for the accuracy, completeness or usefulness of any information, apparatus, product or process disclosed, or represents that its use would not infringe privately owned rights.

PACIFIC NORTHWEST LABORATORY

operated by

BATTELLE

for the

U.S. ENERGY RESEARCH AND DEVELOPMENT ADMINISTRATION

Under Contract E(45-1)-1830

Printed in the United States of America

Available from

National Technical Information Service

U.S. Department of Commerce

5285 Port Royal Road

Springfield, Virginia 2215

Price: Printed Copy $\$ 10.00$; Microfiche $\$ 2.25$ 
J. M. Bates

A. M. Sutey

January 1976

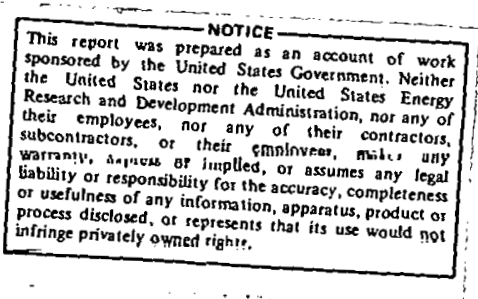

Battelle

Pacific Northwest Laboratories

Richland, Washington 99352 


\section{EXECUTIVE SUMMARY}

An experimental study was performed to investigate the turbulent flow phenomena near postulated sleeve blockages in a model nuclear fuel rod bundle. The sleeve blockages were characteristic of fuel clad "swelling" or "ballooning" which could occur during loss-of-coolant accidents (LOCA) in pressurized water reactors. The study was conducted to provide information relative to the flow phenomena near postulated blockages to support detailed safety analyses of LOCAs. The results of this study are especially useful for verification of the hydraulic treatment of reactor core computer programs such as COBRA.

The experimental flow model was a $7 \times 7$ rod bundle consisting of 0.392 -inch diameter pins with pitches of 0.539 inches. Sleeve blockages were positioned on the center nine rods of the bundle. Area reductions. of 70 and 90 percent were obtained in the center four subchannels of the bundle. These area reductions were not intended to define those expected during a LOCA, but were chosen to provide a severe test for verification of subchannel (core) computer programs. Axial components of local mean' velocity and local intensity of turbulence were measured using a onevelocity component laser Doppler anemometer (LDA). The experiments were performed in water at $85^{\circ} \mathrm{F}$ at Reynolds numbers of $1.4 \times 10^{4}, 2.9 \times 10^{4}$, and $5.8 \times 10^{4}$. The conditions modeled those of steam at a point in time during a postulated LOCA at which all of the flooding water $(0.5,1.0$, and $2.0 \mathrm{in} . / \mathrm{sec}$ ) would be converted to steam.

The experimental results indicated that a 90 percent blockage located midway between two grid spacers created a severe flow disturbance. Axial velocities measured immediately upstream from the blockage cluster were extremely low and flow reversals were detected downstream from the blockage. The recirculation zone existed for approximately five subchannel hydraulic diameters downstream from the blockage axial centerline. Flow recovery was completed approximately fifty subchannel hydraulic diameters downstream from the blockage. The velocity profiles were independent of Reynolds number when normalized to bundle average velocity. Local intensity of 
turbulence values increased by three orders of magnitude near the blockage cluster but the increase was not strongly dependent on Reynolds number.

Data were also obtained with a 90 percent blockage located adjacent to a grid spacer. The results were similar to those obtained with the blockage between spacers; however, flow recovery with the blockage adjacent to a spacer occurred over a much longer length than with the blockage cluster between spacers.

Velocity reductions obtained near a 70 percent blockage located midway between spacers were similar but less severe than those detected near a 90 percent blockage. Flow reversals were detected downstream from the blockage cluster but the recirculation zone persisted for less than three subchannel hydraulic diameters. Local intensity of turbulence values also increased by three orders of magnitude downstream from the cluster.

- The experimental axial velocity data were compared to predictions calculated using the-COBRA computer program. Predicted subchannel averaqe velocities aqreed well with measured values for the cases with the 70 and 90 percent blockages located midway between spacers. Velocity predictions could not be performed using the COBRA program with a 90 percent blockage located adjacent to a spacer since numerical instabilities were encountered. Recent improvements in the COBRA-IIIC program are expected to eliminate this problem. Because of the success of the program in predicting the data for blockages located midway between two spacers, it is recommended that COBRA be used to aid in the definition of future flow blockage experiments.

It is recommended that multi-rod burst experiments be utilized to define "real" flow blockage locations, shapes, and severities expected to occur in nuclear fuel rod bundles during a LOCA. The effects of these "real" blockage configurations on turbulent flow phenomena in rod bundles can then be experimentally evaluated using LDA techniques. In addition, it is recommended that LDA methods similar to those presented herein be used to determine flow distributions near blockages presently being investigated in rod bundle heat transfer studies, such as FLECHT, to aid 
in the selection and placement of thermal instrumentation and to assist with the interpretation of the heat transfer results. Future flow blockage experiments in two-phase flowing media similar to those expected during a LOCA should be conducted as state-of-the-art two-phase flow instrumentation is developed. Experiments of this type are needed to verify and improve core safety analys is computer programs such as COBRA under two-phase flow conditions. It is strongly recommended that laser-optical methods be investigated and developed to permit measurements of velocity, intensity of turbulence, and void fraction in two-phase flows. 


\section{THIS PAGE}

\section{WAS INTENTIONALLY \\ LEFT BLANK}


EXECUTIVE SUMMARY.

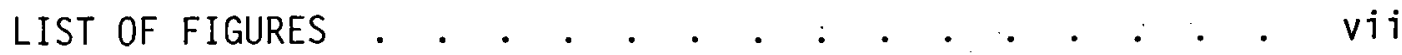

LIST OF TABLES.

1.0 INTRODUCTION

2.0 CONCLUSIONS AND RECOMMENDATIONS . . . . . . . . . . . . .

2.1 Conclusions . . . . . . . . . . . . . . . . 3

2.2 Recommendations. . . . . . . . . . . . . . . 7

3.0 EXPERIMENTAL METHOD . . . . . . . . . . . . . . . . . . . . .

3.1 Equipment. : . . . . . . . . . . . . . . 9

3.1 .1 Test Facility . . . . . . . . . . . . . . . 10

3.1 .2 Test Assembly . . . . . . . . . . . . . 10

3.1.3 Laser Doppler Anemometer . . . . . . . . 19

3.1.4 Signal Processing Instrumentation . . . . . . 24

3.2. Experimental Procedure . . . . . . . . . . 26

3.3 Experimental Data . . . . . . . . . . . . 27

3.3.1 Data Point Locations. . . . . . . . . . 27

3.3.2 Data Reduction Methods . . . . . . . . . 27

3.3.3 Accuracy of Data . . . . . . . . . . . 33

4.0 EXPERIMENTAL RESULTS AND DISCUSSION. . • • • . . . . . . 36

4.1 Bare Rod . . . . . . . . . . . . . . . . . 36

4.1.1 Axial Velocity. . . . . . . . . . . 37

4.1.2 Intensity of Turbulence. . . . . . . . . 37

4.290 Percent Blockage Midway Between Spacers. . . . . 40

4.2.1 Axial Velocity. . . . . . . . . . . . . 41

4.2.2 Intensity of Turbulence. . . • . • • . . 52

4.390 Percent Blockage Adjacent to a Spacer . . . . . 63

4.3.1 Axial Velocity. . . . . . . . . . . 63

4.3.2 Intensity of Turbulence. . . . . . . . . 66

4.470 Percent Blockage Midway Between Spacers. . . . . 69

4.4.1 Axial Velocity. . . . . . . . . . . . 71

4.4.2 Intensity of Turbulence. . . . . . . . . 77 


\section{CONTENTS (Continued)}

4.5 Friction Factors and Loss Coefficients. . . . . $\because 83$

4.5.1 Bare Rod Friction Factor . . . . . . . . 83

4.5.2 Spacer Loss Coefficients . . . . . . . . 83

4.5.3 Blockage Loss Coefficients. . . . . . . . . . 83

5.0 COMPARISONS WITH COBRA PREDICTIONS . . . . . . . . . .

5.1 COBRA Version and Input Model . . . . . . . . . 88

5.2 Subchannel Average Velocity Estimates . . . . . . 90

5.3 COBRA Predictions. . . . . . . . . . . . . 94

5.3.1 70 Percent Blockage Between Spacers. . . . . 94

5.3.2 90 Percent Blockage Between Spacers. . . . . 94

ACKNOHLEDGEMENTS . . . . . . . . . . . . . . . 103 REFERENCES . . . . . . . . . . . . . . . . . 105

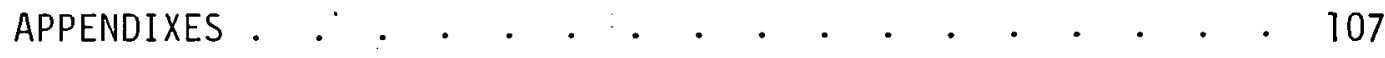

Appendix A, Nomenclature. . . . . . . . . . . A-1

Appendix B, Uncertainty Analysis . . . . . . . . B-1

Appendix C, Tabulation of Reduced Data . . . ... . C-1 


\section{LIST OF FIGURES}

1. Hydraulic Test Facility.

2. Test Assembly Arrangement .

3. Test Assembly Cross Section at the Blockage Axial Centerline . . . . . . . . . . . . . 13

4. Model Rod Bundle.: . . . . . . . . . . . ... . 15

5. Blocked Subchannel Flow as a Function of Bundle Size. . . 16

6. Bundle Tie Plate. . . . . . . . . . . . . . . 17

7. Simple "Egg Crate" Spacer. . . . . . . . . . . . 18

3. Flow Blockage Sleeves . . . . . . . . . . . . 20

9. Differential Doppler LDA System . . . . . . . . . . 22

10. Detail of the Measuring Volume . . . . . . . . . . 23

11. LDA Signal Processing Instrumentation . . . . . . . . 25

12. Blockage and Spacer Axial Locations. . . . . . . . . 28

13. Data Traverse Locations. . . . .. . . . . . . . . 29

14. Laser Beam Deflection from Air to Water . . . . . . 31

15. Bare Rod Velocity Profiles, $U_{B}=5.7 \mathrm{ft} / \mathrm{sec} . . .3 . .38$

16. Bare Rod Intensity Profiles, $U_{B}=5.7 \mathrm{ft} / \mathrm{sec} . .+. \quad . \quad 39$

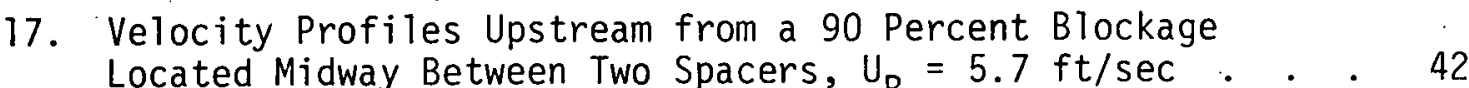

18. Velocity Profiles Immediately Downstream from a 90 Percent Blockage Located Midway Between Two Spacers, $U_{B}=5.7 \mathrm{ft} / \mathrm{sec}$ : . . . . . . . . . . . . . . 43

19. Velocity Profiles Far Downstream from a 90 Percent Blockage Located Midway Between Two Spacers, $U_{B}=2.7 \mathrm{ft} / \mathrm{sec} . \quad$. 44

20. Velocity Profiles Near a 90 Percent Blockage Located Midway Between Two Spacers, $U_{B}=2.7 \mathrm{ft} / \mathrm{sec} . \cdot$. . . 46

21. Velocity Profiles Near a 90 Percent Blockage Located Midway Between Two Spacers, $U_{B}=10.7 \mathrm{ft} / \mathrm{sec}$. . . . . 47

22. Comparisons of Velocity Profiles Near a 90 Percent Blockage Located Midway Between Two Spacers, $U_{B}=2.7,5.7$ and $10.7 \mathrm{ft} / \mathrm{sec}$. . . . . . . . . .

23. Axial Profiles of Subchannel \#1 Center Velocities with a 90 Percent Blockage Located Midway Between Two Spacers .. . 50 


\section{LIST OF FIGURES (Continued)}

24. Velocity Profiles Along Inner Traverses at Data Plane \#5 (+2.0 in.) with a 90 Percent Blockage, $U_{B}=5.7 \mathrm{ft} / \mathrm{sec} .: 51$

25. Velocity Profiles Along Outer Traverses at Data Plane \#5 $\left(+2.0\right.$ in.) with a 90 Percent Blockage, $U_{B}=5.7 \mathrm{ft} / \mathrm{sec} . \quad .53$

26. Intensity Profiles Upstream from a 90 Percent Blockage Located Midway Between Two Spacers, $U_{B}=5.7 \mathrm{ft} / \mathrm{sec}$. . . 54

27. Intensity Profiles Downstream from a 90 Percent Blockage Located Midway Between Two Spacers, $U_{B}=5.7 \mathrm{ft} / \mathrm{sec}$. . . 55

28. Intensity Profiles Near a 90 Percent Blockage Located

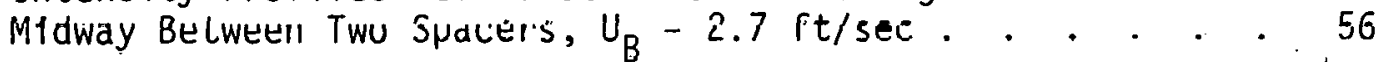

29. Intensity Profiles Near a 90 Percent Blockage Located Midway Between Two Spacers, $U_{B}=10.7 \mathrm{ft} / \mathrm{sec}$. . . . . . 57

30. Intensity Profiles Near a 90 Percent Blockage Located Midway Between Two Spacers," $U_{B}=2: 7,5.7$ and $10.7 \mathrm{ft} / \mathrm{sec}$. . . . . . . . . . . . . . . . 59.

31. Axial Profiles of Subchannel \#1 Center Intensities with a 90 Percent Blockage, $U_{B}=2.7,5.7$, and $10.7 \mathrm{ft} / \mathrm{sec} .:$ : 60

32. Intensity Profiles Along Inner Traverses at Data Plane \#5 $(+2.0$ in. $)$ with a 90 Percent Blockage, $U_{B}=5.7 \mathrm{ft} / \mathrm{sec}$

33. Intensity Profiles Along Outer Traverses at Data Plane \#5 $(+2.0$ in. $)$ with a 90 Percent Blockage, $U_{B}=5.7 \mathrm{ft} / \mathrm{sec} . \quad 62$

34. Velocity Profiles Upstream from a 90 Percent Blockage Located Adjacent. to Spacer \#2, $U_{B}=5.7 \mathrm{ft} / \mathrm{sec} \cdot \cdot$.

35. Velocity Profiles Downstream from a 90 Percent Blockage Located Adjacent to Spacer \#2, $U_{B}=5.7 \mathrm{ft} / \mathrm{sec}$. . .

36. Axial Profiles of Subchannel \#1 Center Velocities with a 90 Percent Blockage Located Between Two Spacers and Located Adjacent to a Spacer, $U_{B}=5.7 \mathrm{ft} / \mathrm{sec} . . . \quad .67$

37. Intensity Profiles Near a 90 Percent Blockage Located Adjacent to Spacer \#2, $U_{B}=5.7 \mathrm{ft} / \mathrm{sec}$

38. Axial Profiles of Subchannel \#1 Center Intensities with a 90 Percent Blockage Located Midway Between Spacers \#1 and $\# 2$ and Located Adjacent to Spacer \#2, $U_{B}=5.7 \mathrm{ft} / \mathrm{sec} . \quad \therefore 70$

39. Velocity Profiles Upstream from a 70 Percent Blockage Located Midway Between Two Spacers, $U_{B}=5.7 \mathrm{ft} / \mathrm{sec}$. . . 72

40. Velocity Profiles Downstream from a 70 Percent Blockage Located Midway Between Two Spacers, $U_{B}=5.7 \mathrm{ft} / \mathrm{sec}$.

41. Axial Profiles of Subchannel \#1 Center Velocities with a 70 and a 90 Percent Blockage Located Midway Between Two Spacers, $U_{B}=5.7 \mathrm{ft} / \mathrm{sec}$. 
42. Velocity Profiles at Data Plane \#15 (+0.8 in.) with a 70 Percent Blockage, $U_{B}=5.7 \mathrm{ft} / \mathrm{sec} . . . . . . .476$

43. Intensity Profiles Upstream from a 70 Percent Blockage Located Midway Between Two Spacers, $U_{B}=5.7 \mathrm{ft} / \mathrm{sec} . . .78$

44. Intensity Profiles Downstream from a 70 Percent Blockage Located Midway Between Two Spacers, $U_{B}=5.7 \mathrm{ft} / \mathrm{sec}$. . . 79

45. Axial Profiles of Subchannel \#1 Center Intensities with a 70 and a 90 Percent Blockage Located Nidway Between Two Spacers, $U_{B}=5.7 \mathrm{ft} / \mathrm{sec} \cdot . \cdot \cdot \cdot \cdot \cdot \cdot$

46. Intensity Profiles at Data Plane \#15 (+0.8 in.) with

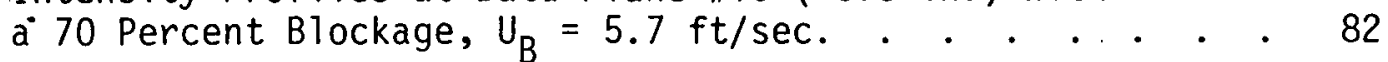

47. Bare Rod Friction Factors . . . . . . . . . . . . 84

48. Spacer \#2 Loss Coefficients . . . . . . . . . . . 85

49. Comparison of Overal1 Bundle Pressure Losses wi.th No Blockage, with a 70 Percent Blockage, and with a

90 Percent Blockage. . . . . . . . . . . . 87

50. COBRA Geometry Mode1. . . . . . . . . . . . . . 91

51. Simplified Subchannel Geometry for Calculating Subchannel Average Velocities. . . . . • . . . . . 92

52. COBRA Velocity Predictions in Subchannels \#1, \#2, and \#3 with a 70 Percent Blockage, $U_{B}=5.7 \mathrm{ft} / \mathrm{sec} \cdot . \cdot e^{\circ} \cdot .95$

53. COBRA Velocity Predictions in Subchannels \#4, \#5, and \#6 with a 90 Percent Blockage, $U_{B}=5.7 \mathrm{ft} / \mathrm{sec} . . . \quad . \quad$. . 96

54. COBRA Velocity Predictions in Subchannels \#1, \#2; and \#3 with a 90 Percent Blockage, $U_{B}=5.7 \mathrm{ft} / \mathrm{sec} \cdot . . . \quad . \quad . \quad 97$

55. COBRA Velocity Predictions in Subchannels \#4, \#5, and \#6 with. a 90 Percent Blockage, $U_{B}=5.7 \mathrm{ft} / \mathrm{sec} . .+. .998$

56. COBRA Velocity Predictions in Subchannels \#1, \#2, and \#3 with a 90 Percent Blockage, $U_{B}=2.7 \mathrm{ft} / \mathrm{sec} . . \quad \cdot . \cdot . \quad .99$

57. COBRA Velocity Predictions in Subchannels \#1, \#2, and \#3 with a 90 Percent Blockage, $U_{B}=10.7 \mathrm{ft} / \mathrm{sec} . .+. . .100$ 
1. Uncertainty Values (Run \#S7-346)... . . . . . . . 34

2. COBRA Input Parameters . . . . . . . . . . . . 89

3. Comparisons of Calculated and Measured Bundle Flowrates . . . . . . . . . . . . . . . . . . 93

C-1 Tabulation of Experimental LDA Data. $\quad . \quad \therefore \quad \cdots \quad \therefore \quad . \quad C-2$

$\mathrm{C}-2$ Tabulation of Pressure Loss Data $\left(T=85 \pm 4^{\circ} \mathrm{F}\right) . \quad . \quad \therefore \quad C-153$ 
EFFECTS OF SLEEVE BLOCKAGES ON AXIAL VELOCITY

AND INTENSITY OF TURBULENCE IN AN UNHEATED

$7 \times 7$ ROD BUNDLE

\subsection{INTRODUCTION}

In the event of a loss-of-coolant accident (LOCA) in a pressurized water reactor (PWR), fuel rod overheating may occur. As clad temperatures increase during a LOCA, internal fuel rod pressures may cause clad "swelling" or "ballooning" which could lead to coolant blockages. It is important that flow and heat transfer phenomena near such blockages are well understood to permit detailed safety analyses to be performed for postulated LOCAs. Consequently, as a first step in gaining such an understanding, a program was initiated to study the effects of blockages on flow distributions in rod bundles. The program objectives were: 1) to evaluate, develop, and apply laser Doppler anemometry (LDA) methods for measurement of flow and turbulence in the vicinity of blockages, and 2) to improve the data base for verification of subchannel (core) programs such as COBRA-IIIC. (1) The intent of the program was to perform a logical sequence of flow blockage experiments using water, air, air-water, and steam-water, in model nuclear fuel rod bundles. Such information was not available for relatively large rod bundles in any of the above mentioned flow media. In addition to providing basic subchannel velocity and turbulence data which could be related to blockages under flowing steam conditions in reactor environments, it was anticipated that the LDA experiments in single-phase water and air could aid in developing state-of-the-art two-phase flow instrumentation. Such instrumentation could subsequently be used in studies using airwater, and finally, using steam-water flow typical of that expected during a LOCA.

The data obtained in blockage experiments of this type are valuable for verification of analytical methods currently being developed for safety analyses. For example, the method of subchannel analysis has recently received rather wide attention as a tool in predicting the hydrautic and 
thermal performance of rod bundle nuclear fuel assemblies during both normal operation and accident conditions. Computer programs such as COBRA-IIIC use the subchannel analysis technique for the hydraulic treatment of reactor cores since the program can be applied to complicated fuel rod configurations with relative ease. However, experimental, verification of such computer codes is required.

The purpose of this report is to present the local velocity and intensity of turbulence results obtained in the the flow blockage experiment: conducted in water. Comparisons of the data with predictions of the COBRA program are provided. An abbreviated follow-on study has been conducted in air to simulate the high quality steam environment expected during a LOCA and will be reported in the near future. Additional experiments should be. performed in two-phase flow environments; however, improved state-of-the-art two-phase flow instrumentation must be developed to permit such studies. 


\subsection{CONCLUSIONS AND RECOMMENDATIONS}

\subsection{CONCLUSIONS}

This experiment provides information regarding the turbulent flow structure resulting from disturbances created by postulated sleeve blockages in a model nuclear fuel rod bundle. The information was obtained with a laser Doppler anemometer by measuring the local mean axial velocity and local intensity of turbulence at selected axial locations in the bundle.

The experimental data indicated that postulated blockages caused severe flow disturbances in the rod bundle. Axially, the flow was not influenced by a 90 percent blockage until the flow reached a location between three and six subchannel hydraulic diameters upstream from the blockage cluster. A recirculation zone existed for approximately five subchannel hydraulic diameters downstream from the cluster. The flow required approximately. 50 subchannel hydraulic diameters to completely recover from the effects of the blockage. Local intensity of turbulence profiles were consistent with velocity profiles in that the intensity was relatively uniform upstream from the blockage, increased by three orders of magnitude downstream from the blockage, and was completely recovered from the blockage disturbance 50 subchannel hydraulic diameters downstream from the cluster. Both the velocity profiles and the intensity profiles were found to be essentially independent of Reynolds number over the range investigated.

In the lateral direction, the gross influence of the blockage was confined to those subchannels containing sleeve blockages. Flow increases were detected in the subchannels adjacent to the blockage cluster since flow was diverted around the blockage.

Effects of axial blockage location were studied by comparing data measured with a 90 percent blockage located midway between two spacers with data obtained with the blockage located adjacent to a spacer. The location of the blockage did not affect the flow in the immediate vicinity of the blockage cluster; however, the downstream recovery profile was influenced. The required flow recovery length with the blockage adjacent to a spacer was significantiy greater than when the blockage was located midway between spacers. 
Blockage severity was investigated by comparing data obtained using 70 percent and 90 percent blockage clusters. The recirculation zone was shorter--approximately 3 subchannel hydraulic diameters compared to approximately 5 diameters--for the less severe blockage. The required flow recovery lengths were essentially the same for the two blockage severities.

COBRA predictions of the experimental velocity data were exceptionally good for the cases with the 70 percent and 90 percent blockages located midway between two spacers. The COBRA program could not predict subchannel velocities when the blockage was located adjacent to a spacer since numerical instabilities were encountered.

The sperifir rnnclusions resulting from this investigation are listed below by experimental condition.

\section{Bare Bundle With No Blockages}

- The peak-to-average velocity ratios in developed flow were approximately 1.18, which agree with turbulent pipe flow theory and other available rod bund?e experimental velocity data. $(2,3,4)$

- The velocity profiles across the bundle cross section were uniform, which justified the assumption of bundle geometric symmetry.

- Local intensity of turbulence values were approximately 0.05 far removed from a spacer and 0.13 one subchannel hydraulic diameter downstream from a spacer. These intensity values are in agreement with existing rod bundle data. $(2,3,4)$

\section{Percent Blockage Between Spacers}

- A 90 percent blockage created severe flow disturbances. Immediately upstream from the binrkage r.luster, extremely low velocities, $U / U_{B} \approx 0.1$, wcre illedsured. Clow reversials, $U / U_{B} \approx-0.2$, were detected downstream from the blockage. The recirculation zone extended approximately five subchannel hydraulic diameters ( 2.5 in.) downstream from the blockage cluster axial centerline. 
- The flow essentially recovered from the blockage influerice fifty subchannel hydraulic diameters downstream from the cluster.

- The normalized velocity profiles, $U / U_{B}$, along the length of the bundle were independent of Reynolds number over the range

.$\quad$ investigated.

- Local intensity of turbulence values upstream from the blockage increased from 0.05 to 0.9 .

- Downstream from the blockage cluster, the turbulence increased to $>10.0$.

- Axial intensity profiles along the length of the bundle were independent of Reynolds number except in the downstream tapered region of the blockage cluster.

90 Percent Blockage Adjacent to a Spacer

- Velocity distributions upstream from the blockage were essentially the same as those obtained with the blockage between spacers.

- Flow reversals, $U / U_{B} \approx-0.2$, were detected downstream from the blockage cluster. The recirculation zone could not be defined since a spacer interfered with LDA measurements.

- The flow recovery length with the blockage cluster adjacent to a spacer was much greater than with the cluster midway between spacers. Uniform flow was not achieved fifty subchannel hydraulic diameters downstream from the blockage.

- Upstream from the blockage, the intensity of turbulence magnitudes were approximately the same as those measured with the blockage midway between spacers.

- Downstream from the blockage, the intensity levels were lower than with the blockage located between spacers, but recovery length was independent of blockage location. 


\section{Percent Blockage Between Spacers}

- A 70 percent blockage did not disturb the flow as severely as a 90 percent blockage. Velocity magnitudes on the order of $U / U_{B} \approx 0.75$ were, measured upstream from the blockage cluster.

- Flow reversals, $U / U_{B} \approx-0.2$, were measured just downstream from the cluster centerline, but the resulting recirculation zone persisted less than three subchannel hydraulic diameters ( 1.4 in.) downstream.

- Although the 70 percent blockage did not disturb the flow as severely as the 90 percent blockage, the required flow recovery length was approximately the same for the two blockage severities.

- Local intensity of turbulence magnitudes measured upstream from the blockage increased from 20.05 to 20.15 .

- Downstream from the blockage cluster, intensity values of 2.0 were meàsured.

\section{Pressure Loss Data}

- The friction factor $\left(f=0.34 \mathrm{Re}^{-0.25}\right.$ ) and spacer loss coefficients $\left(K_{S P} \approx 1.4\right)$ determined from the pressure drop data agreed satisfactorily with expected values.

- $\because$ The loss coefficient for the 70 percent blockage was measured to be approximately zero. The loss coefficient for the 90 percent blockage was determined to be between 0.0 and 0.3 .

In addition, several conclusions regarding predictions of the COBKA computer program emerged from this study.

\section{Percent Blockage Between Spacers}

- The COBRA-IIIC program satisfactorily predicted the velocity data obtained using a 70 percent blockage located midway between two spacers. 
- The locations and magnitudes of the minimum velocity points upstream and downstream from the blockage cluster were predicted exceptionally well.

- The predicted velocity recovery profile closely agreed with the measured profile.

\section{Percent Blockage Between Spacers}

- A modified version of the COBRA-IIIC code accurately predicted the experimental data obtained at three bundle flowrates with a 90 percent blockage located midway between two spacers.

\section{Percent Blockage Adjacent to a Spacer}

- Subchannel velocity predictions could not be performed with the COBRA program when the blockage was adjacent to a spacer. Numerical instabilities were encountered; hence, predictions of the velocity data must await an improved version of COBRA.

\subsection{RECOMMENDATIONS}

After considering the results of this experimental study, it is strongly. recommended that the following investigations be undertaken:

- Multi-rod burst experiments should be performed to define "real" flow blockage locations, shapes, and severities. The effects of "real" blockages on turbulent flow phenomena in rod bundles can then be thoroughly evaluated usiny LDA techniques.

- Although the present experiment provides valuable information on velocity and intensity of turbulence distributions near postulated blockages, the implications concerning heat transfer are inconclusive at this time. Heat transfer experiments in rod bundles containing blockages, such as FLECHT, ${ }^{(5)}$ should be performed and integrated with flow experiments of the type performed in the present study. Flow experiments would aid in the selection and piacement of thermal instrumentation and assist the interpretation of the heat transfer experimental results. 
- The original intent of this experimental program was to perform a sequence of blockage experiments in water, air, air-water, and finally in steam-water. The results of the water experiment are presented herein; an abbreviated air test has been completed and the results will be reported in the near future. Therefore, it is recommended that two-phase flow blockage experiments at expected LOCA conditions be performed once the state-of-the-art advances in two-phase flow measurement techniques.

- It is strongly recommended that laser-optical methods be investigated to advance the stale-uf-the-art. in obtaining local. void fraction and phase velocity measurements in two-phase flow.

- Predictions of the COBRA program should continue to be compared $\because \quad \ldots$ with future flow blockage data and its capability should be improved as a result of the comparisons. Since COBRA has successfully predicted the water velocity data with a biockage located midway between two spacers, it should be used to aid in the definition of future flow blockage experiments. 


\subsection{EXPERIMENTAL METHOD}

Experimental measurements of local axial velocity and local intensity of turbulence were made in a model fuel rod bundle using a laser Doppler anemometer. The $7 \times 7$ rod bundle contained sleeve blockages characteristic of fuel clad "swelling" and/or "ballooning" of the center nine rods. Area reductions of 70 and 90 percent in the center four subchannels were investigated. The experiments were performed in water at $85^{\circ} \mathrm{F}$ at Reynolds numbers of $1.4 \times 10^{4}\left(U_{B}=2.7 \mathrm{ft} / \mathrm{sec}\right), 2.9 \times 10^{4}\left(U_{B}=5.7 \mathrm{ft} / \mathrm{sec}\right)$, and $5.8 \times 10^{4}$ $\left(U_{B}=10.7 \mathrm{ft} / \mathrm{sec}\right)$. These conditions modeled those of steam at a point in time during a postulated LOCA at which all of the flooding water $(0.5,1.0$, and $2.0 \mathrm{in.} / \mathrm{sec}$ ) would be converted to steam.

The model rod bundle was positioned in an existing vertical flow housing. The housing contained windows on the front and back plates to permit a laser beam to pass completely through the rod bundle. Water flow from a hydraulics loop entered the bottom of the test assembly and exited at the top. The LDA system was positioned at desired axial locations with a lift table. Traverses through the bundle along specific subchannel rows were made to obtain local axial velocity and intensity of turbulence profiles.

The following sections describe the equipment required to perform the flow blockage experiment, the experimental procedure, and the experimental data obtained during the testing phase of the study.

\subsection{EQUIPMENT}

The basic equipment used to perform the flow blockage experiment in water consisted of a hydraulic test facility, a test assembly made up of a flow housing and an unheated $7 \times 7$ rod bundle, a laser Doppler anemometer, and signal processing instrumentation. The following sections present detailed discussions of each piece of equipment used in the study. 


\subsubsection{Test Facility}

The flow blockage experiment was performed in the hydraulic facility shown schematically in Figure 1. The facility is an isothermal recirculating flow loop with flow capabilities up to $700 \mathrm{gpm}$, (depending on pump selection), at temperatures ranging from approximately 60 to $180^{\circ} \mathrm{F}$. "In-line flow measurements are performed with an orifice meter and a 4-inch turbine meter. Additional flow sensing capabilities àre provided with a manifold arrangement. Loop water temperatures are controlled with a U-tube heat exchanger which utilizes process water on the secondary side.

Test assemblies are interfaced with the facility through standard 1 -inch piping flanges. The vertical distance between test assembly flow inlets and outlets can be as great as 6.5 feet.

\section{1 .2 Test Assembiy}

Figure 2 shows an assembly view of the test section. In this experiment, water entered the bottom of the flow housing, flowed vertically upward through the test section, emerged at the top of the flow housing, and entered the return piping to the recirculation pumps. Rubber expansion couplers were used at the test section inlet and outlet to aid in isolating the test assembly from the normal vibrations of the flow loop.

An 8-inch long flow conditioning section was placed at the inlet to the test assembly. The flow conditioner consisted of four eccentric perforated plates with $1 / 4$-inch holes (60\% open) in a triangular array followed by a bank of $1 / 4$-inch tubes 3-1/4 inches long. The plates distributed the flow uniformly across the test assembly cross section; the tubes served as flow straighteners to establish a fixed scale of turbulence.

Figure 3 presents a cross sectional view of the tesl assembly at the blockage axial centerline. The flow housing body consisted of front and back plates containing windows and solid stainless steel side platcs containing pressure taps. The back plate contained the inlet and outlet nozzles and was permanently installed in the test facility. The front and back plates were bolted together with the side plates placed between them. 


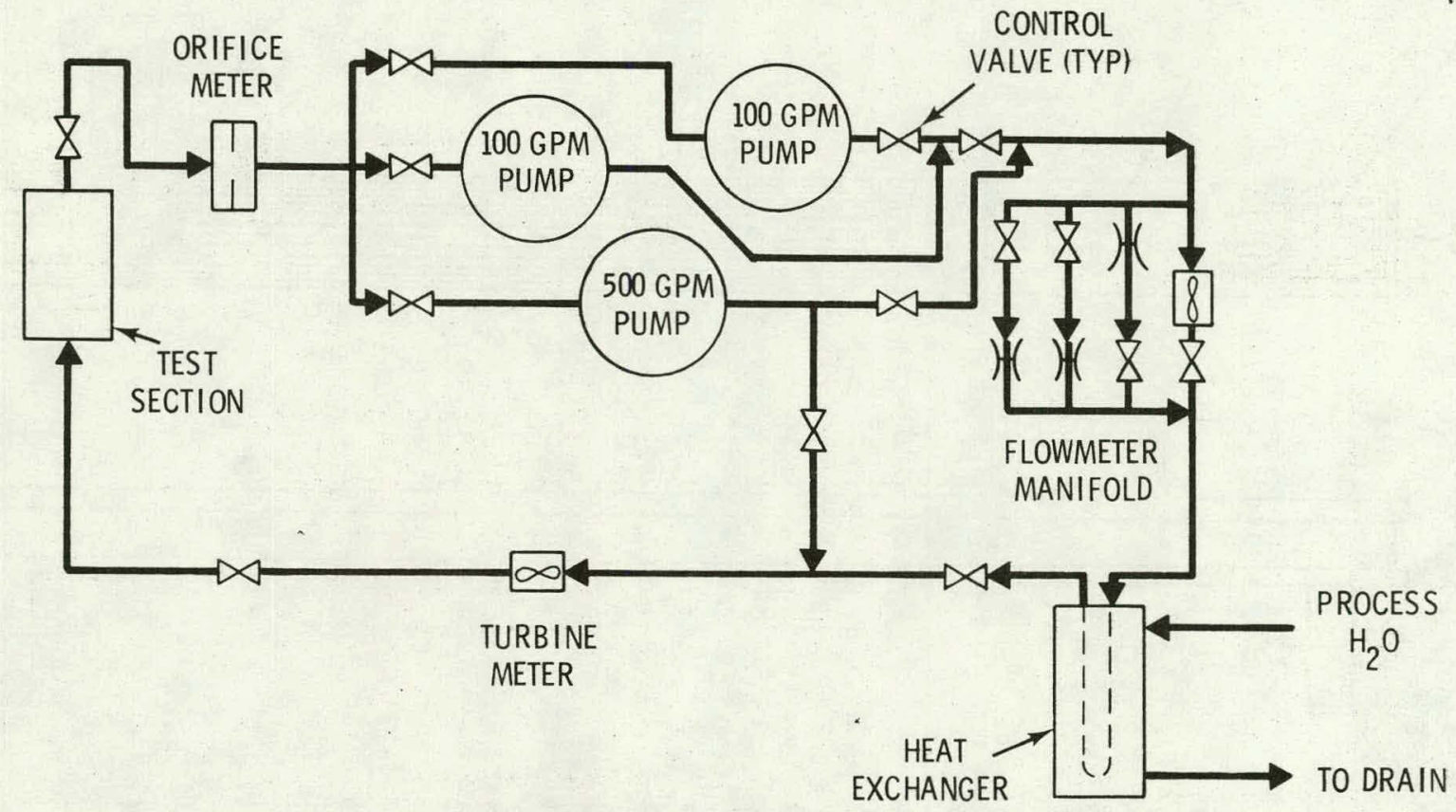

FIGURE 1. Hydraulic Test Facility 


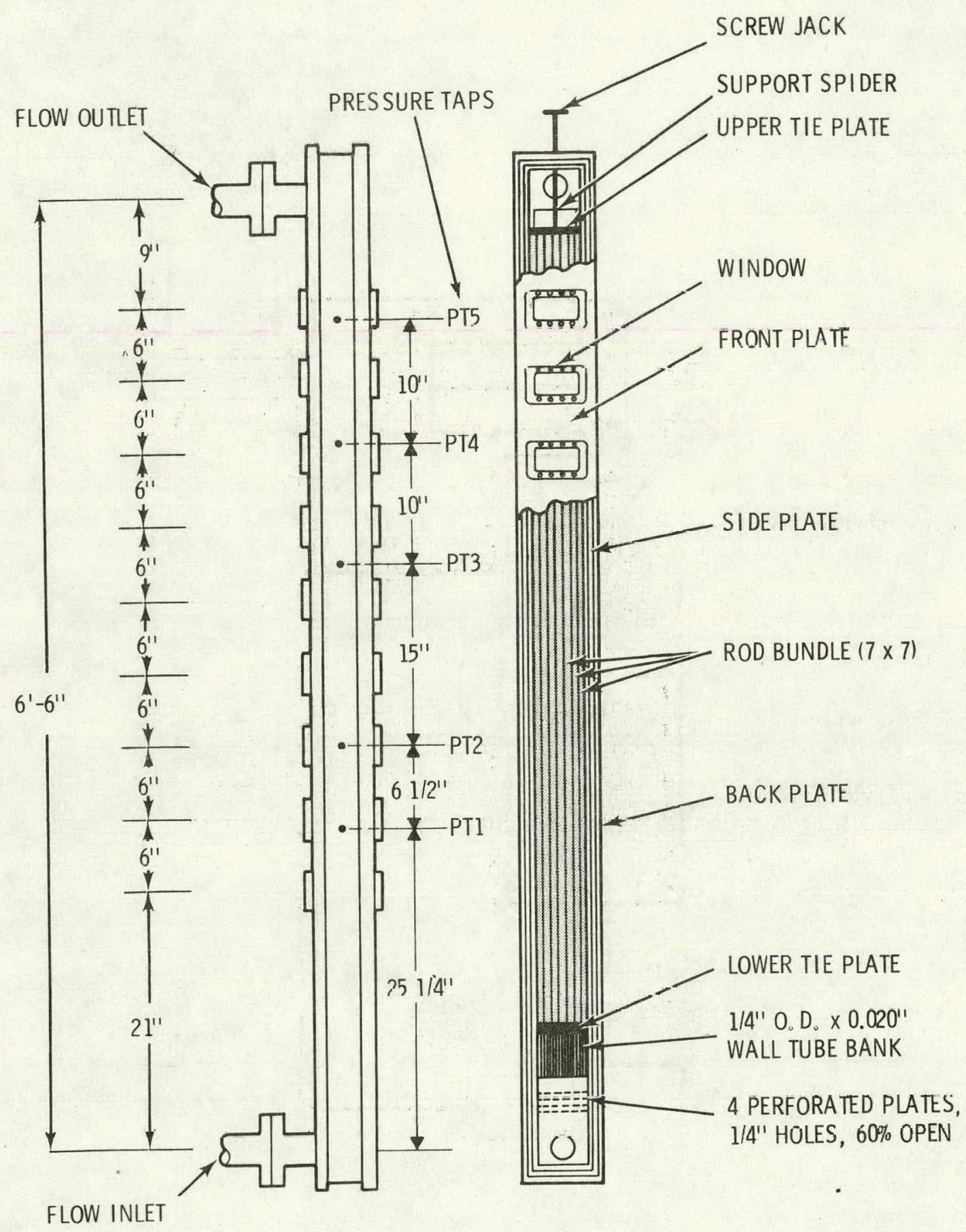

FIGURE 2. Test Assembly Arrangement 


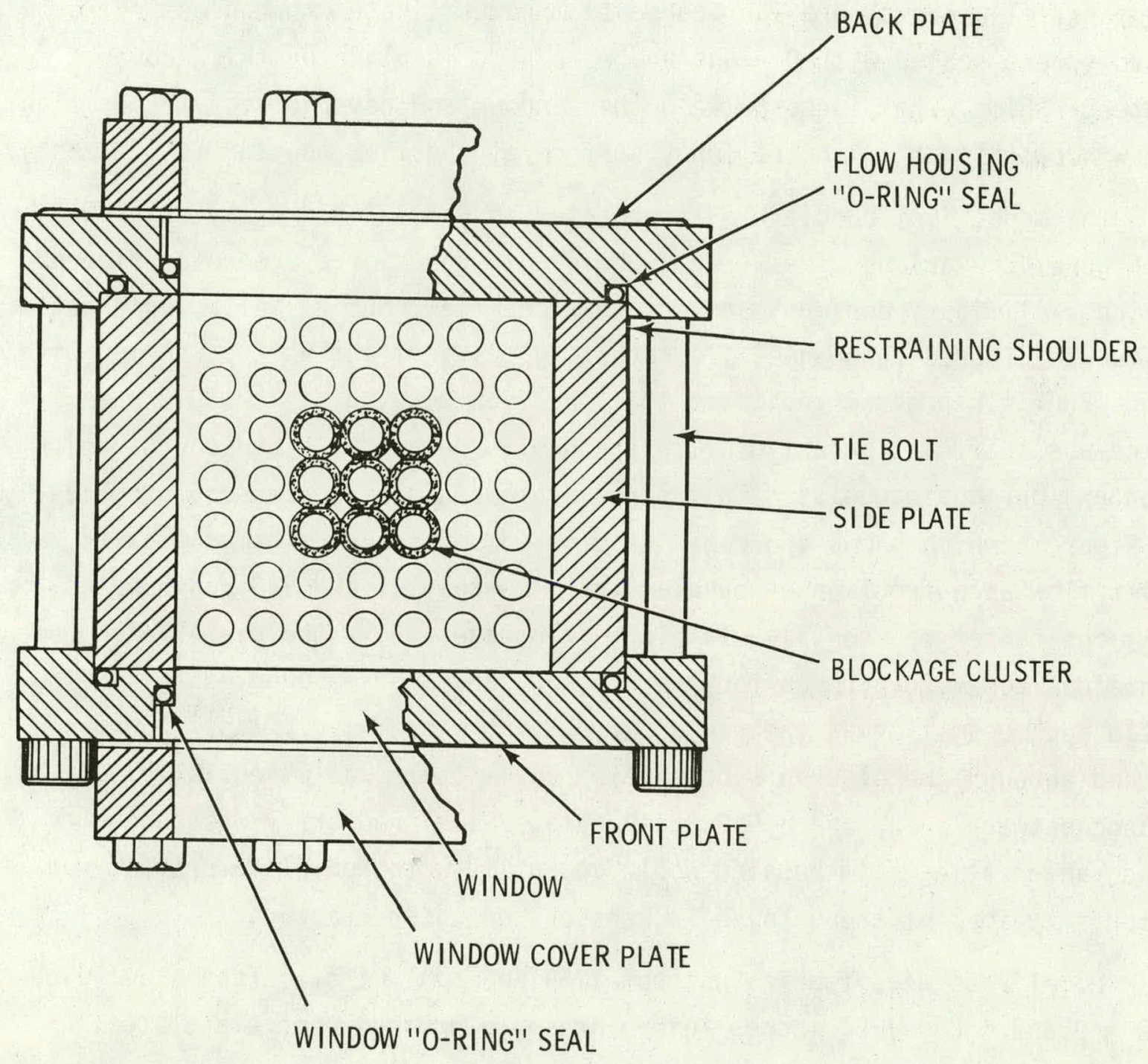

FIGURE 3. Test Assembly Cross Section at the Blockage Axial Centerline 
A continuous 0 -ring sealed the interface between plates. Flow housing internal dimensions ( 4.065 inches square) were maintained by the restraining shoulder next to the 0 -ring groove on the front and back plates.

The front and back plates each contained nine windows, 2 inches high by 4 inches wide, located on 6 -inch axial intervals. The optically flat and parallel windows were fabricated from borosilicate crown glass. The windows were sealed with 0 -rings and were held in place by thick cover plates. Shims were placed between the windows and cover plates to position the windows "flush" with the inner surface of the flow housing $( \pm 0.002$ in.).

The model fuel bundle was an unhcated square $7 \times 7$ rod array as shown in Figure 1. Various sizes (rod numbers) of square arrays were considered during preliminary design to assure that the flow housing walls would not, influence blocked subchannel flowrates. A pre-test analysis per ormed with the COBRA-IIIC program indicated that the flow housing walls would not force a significant amount of flow through 80 percent blocked subchannels (center four subchannels) of a $7 \times 7$ rod bundle. This can be seen graphically in Figure 5 which shows the ratio of blocked subchannel minimum flow to inlet flow as a function of bundle size. In the $1 \times 1$ and $3 \times 3$ rod bundles, only the center rod contained a sleeve blockage, while the center nine rods contained sleeve blockages for the $5 \times 5,7 \times 7$ and $9 \times 9$ rod bundles. The flow ratio became smaller as the rod array was increased, i.e., less flow was forced through the blocked subchannels, until there was essentially no change between a $7 \times 7$ and a $9 \times 9$ rod bundle. A $7 \times 7$ rod array was chosen since an existing flow housing would accept it with rod diameters and rod pitches typical of those found in pressurized water reactors.

Model rods were fabricated from 1/8-inch Sch 10S stainless steel pipe $(O D=0.392$ inches $) 57$ inches long. Brass lower and upper tie plates, shown in Figure 6 , positioned the 49 rods to form the bundle. Flow channels in the tie plates were sized to assure uniform velocity distributions over the cross section of the bundle. A rod pitch of 0.539 inches was maintained with three simple "egg crate" spacers fabricated from brass as pictured in the end view of Figure 7. Four "dimples" contacted each rod to firmly hold it in place. 


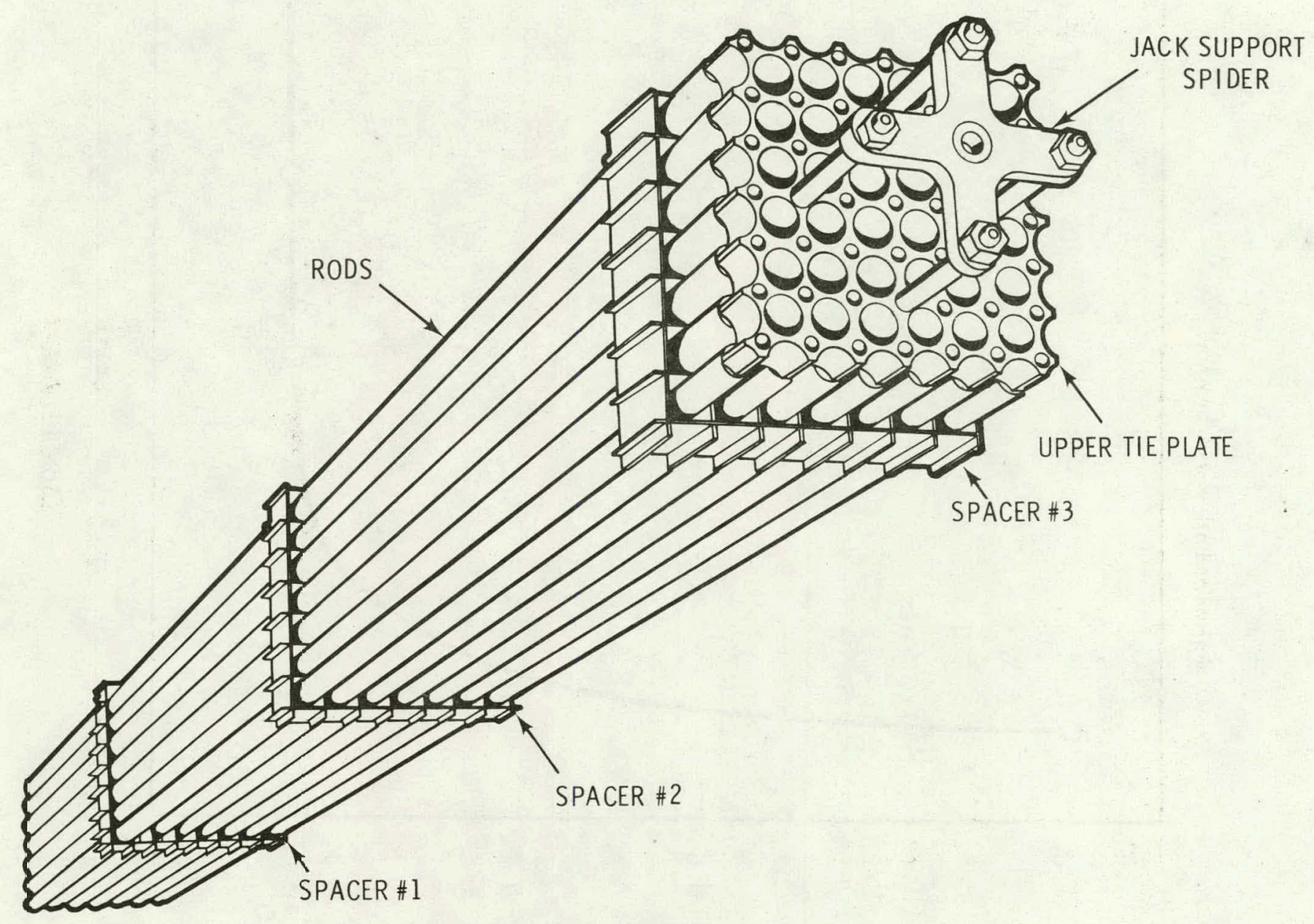

FIGURE 4. Model Rod Bundle 


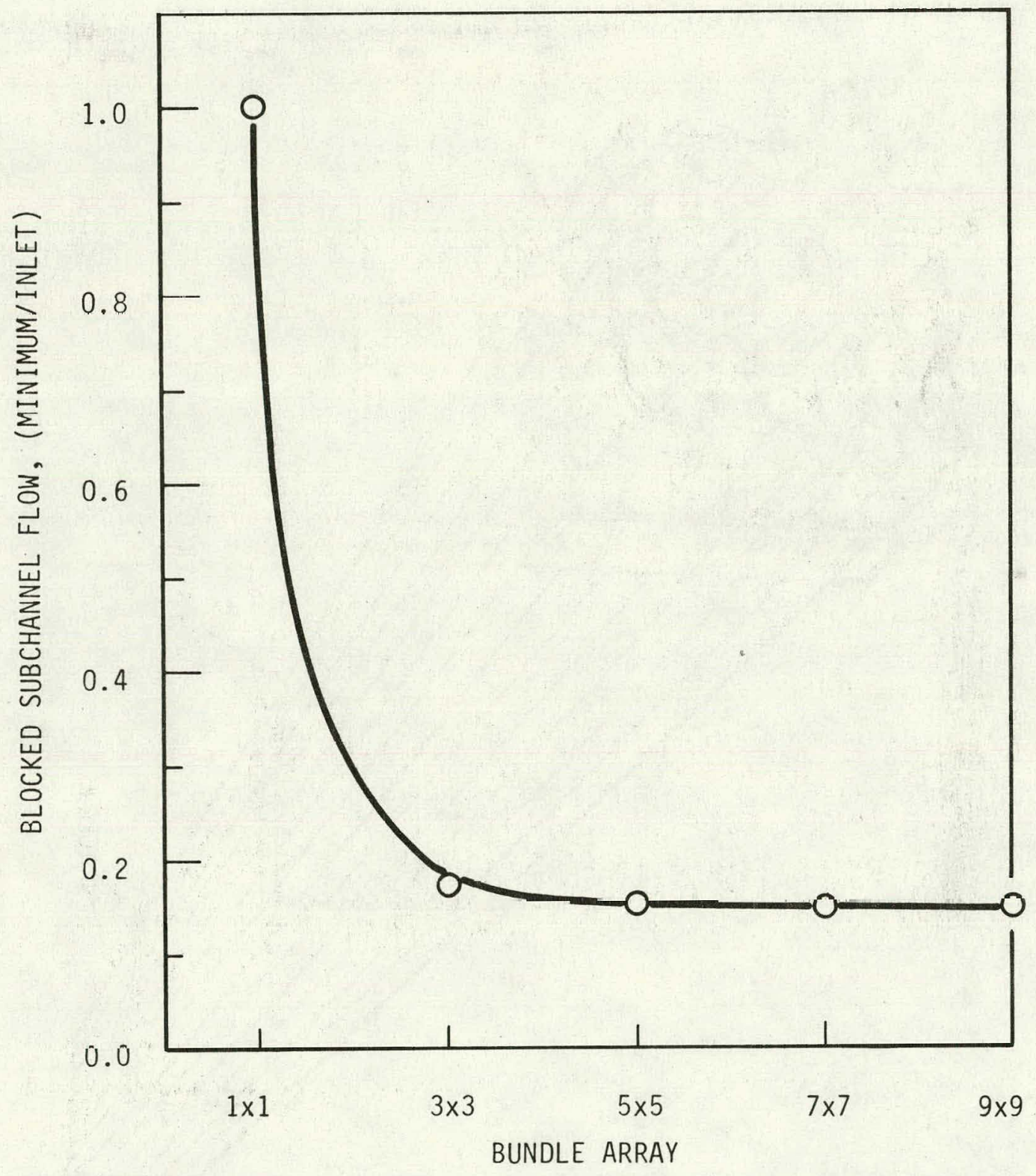

FIGURE 5. Blocked Subchannel Flow as a Function of Bundle Size 


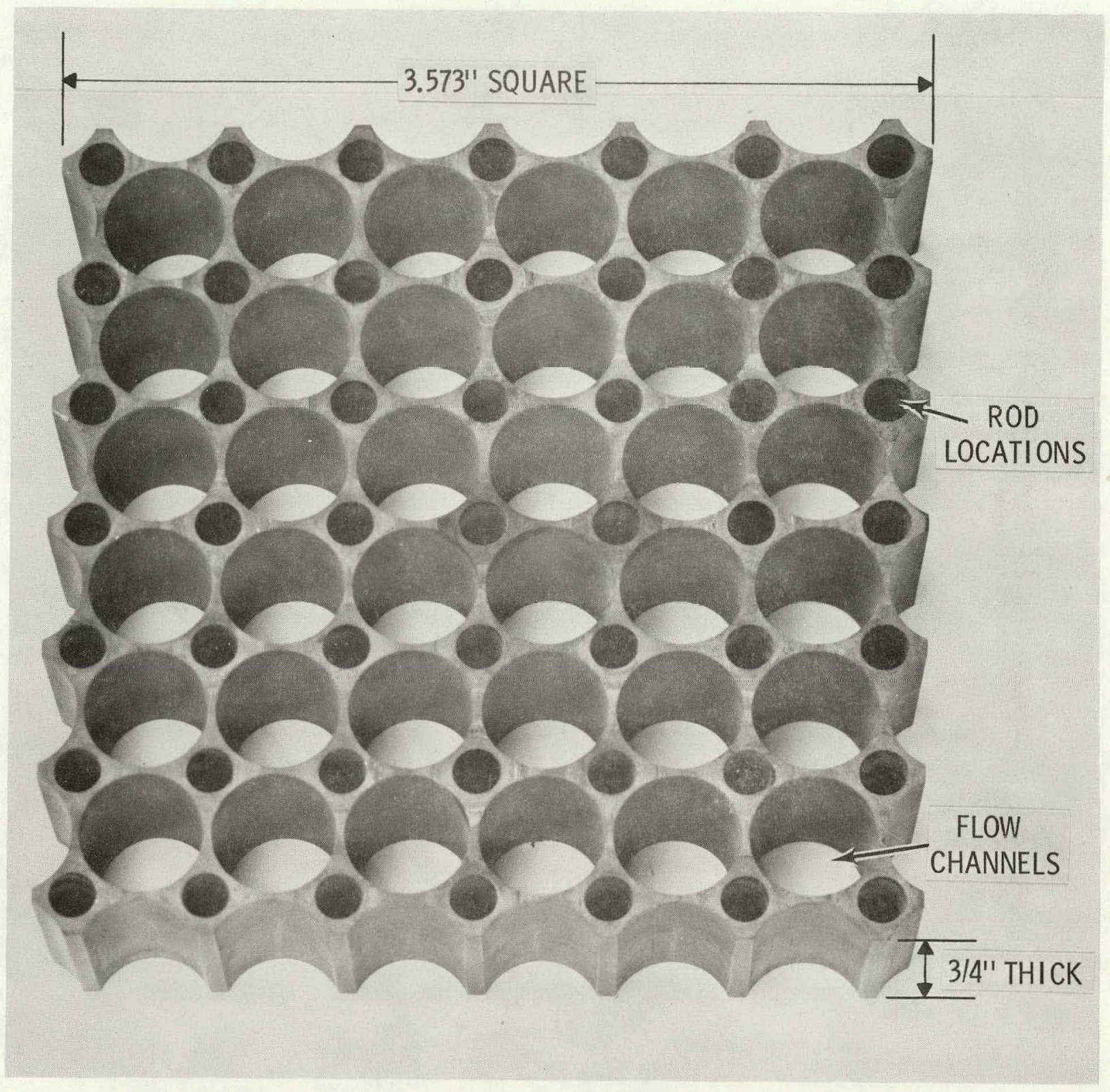

FIGURE 6. Bundle Tie Plate 


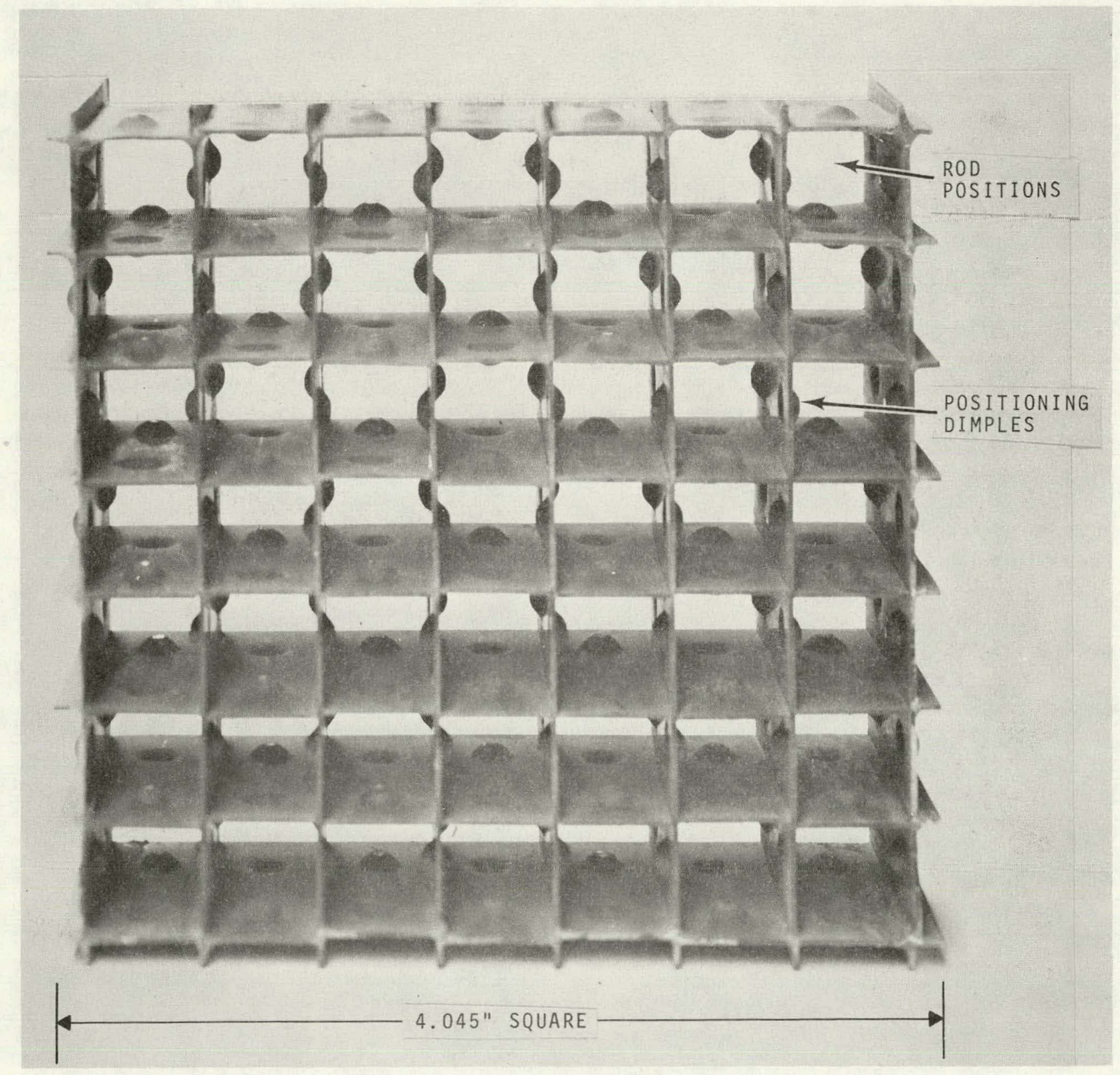

FIGURE 7. Simple "Eqq Crate" Spacer 
Brass flow blockage sleeves shown in Figure 8 were placed on the center nine rods to characterize clad swelling/ballooning. The blockages were 3 inches long with one-jinch tapers at each end. Flow area reductions of 70 and 90 percent could be attained in the center four subchannels. The 70 and 90 percent severities corresponded to area reductions of 35 and 45 percent in the subchannels adjacent to the sides of the cluster and 17 and 22 percent in the subchannels next to the corners of the blockage, respectively. The shape and severity of the blockage clusters used in the present experiment were not intended to define those that would actually exist during a LOCA. The shape of the blockage sleeves was formulated after considering experimental results of high temperature expansion and rupture behavior of Zircaloy tubing. ${ }^{(6)}$ Severities of 70 and 90 percent were chosen to create gross flow disturbances in the rod bundle. Gross flow disturbances were required to adequately test the capability of the COBRA computer program for predicting such maldistributed flow profiles. Two area reductions were investigated to determine severity effects. Determination of prototype LOCA blockage locations, shapes and severities must await results of experiments designed to obtain such information.

A jack support spider was provided at the top of the bundle to permit a screw jack to vertically position the rod bundle in the flow housing. A vertical travel of seven inches was possible and, since the windows were on six-inch centerlines, data at any axial location within the bundle could be obtained.

\subsubsection{Laser Doppler. Animometer}

Turbulent flow measurements were made with a laser Doppler anemometer (LDA). The LDA is a highly advanced system used for obtaining measurements of local mean velocity and intensity of turbulence. The most notable advantage of an LDA system is that the noncontact probing does not disturb the flow. An important feature of all LDA systems is that the output signal is a calibration-free frequency linearly related to flow velocity. Single known components of flow: velocity can be measured independent of other velocity components; further, velocity measurements in reversing flows are possible. 


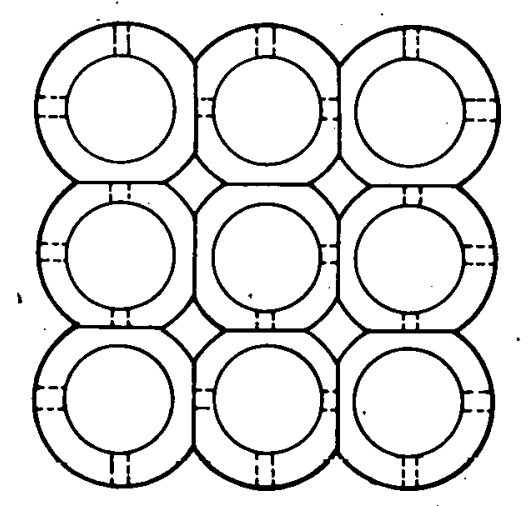

\section{BLUCKAGE CLUUSTER}
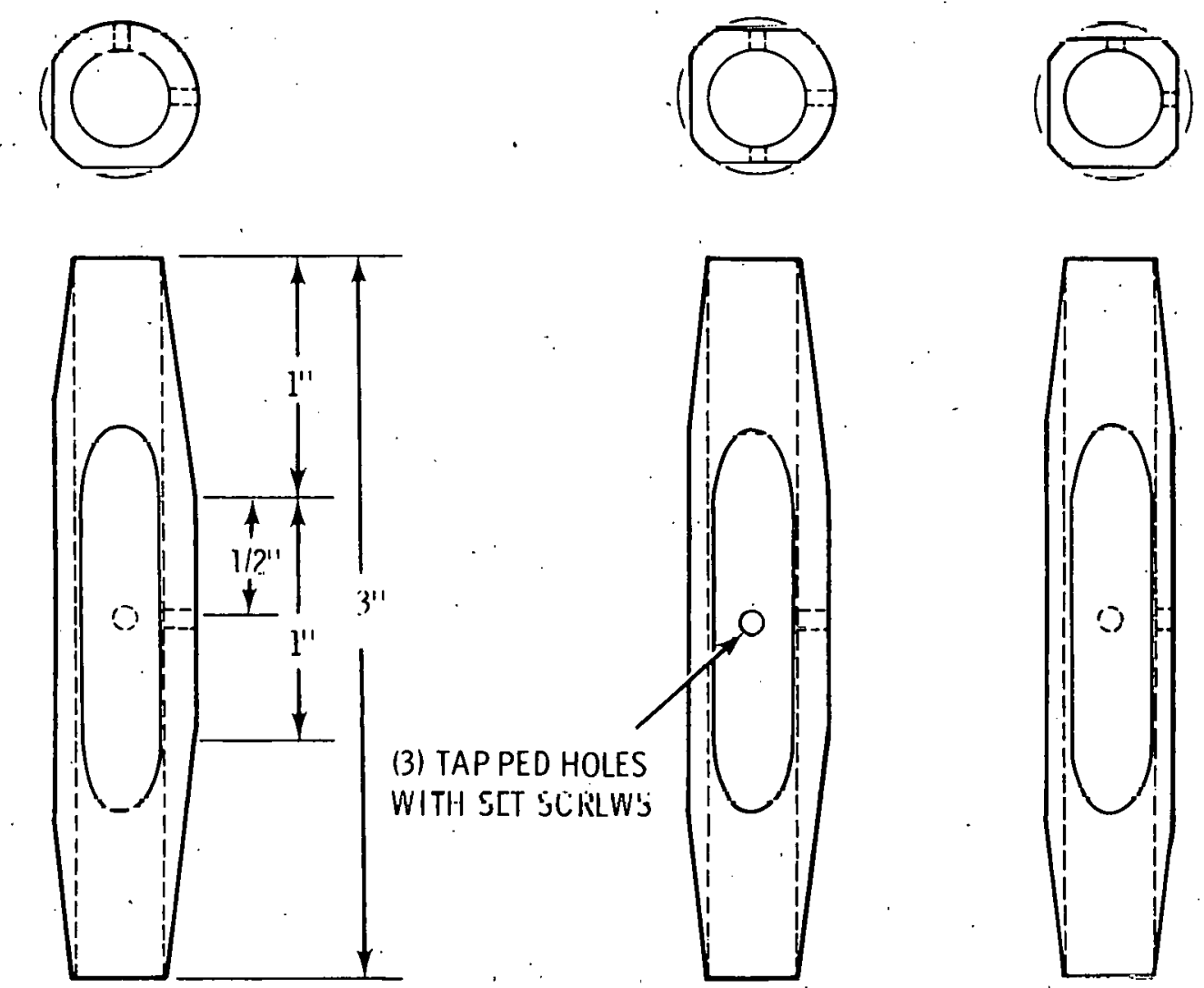

(3) TAP PED HOLES WITH S[T SCLLW'j
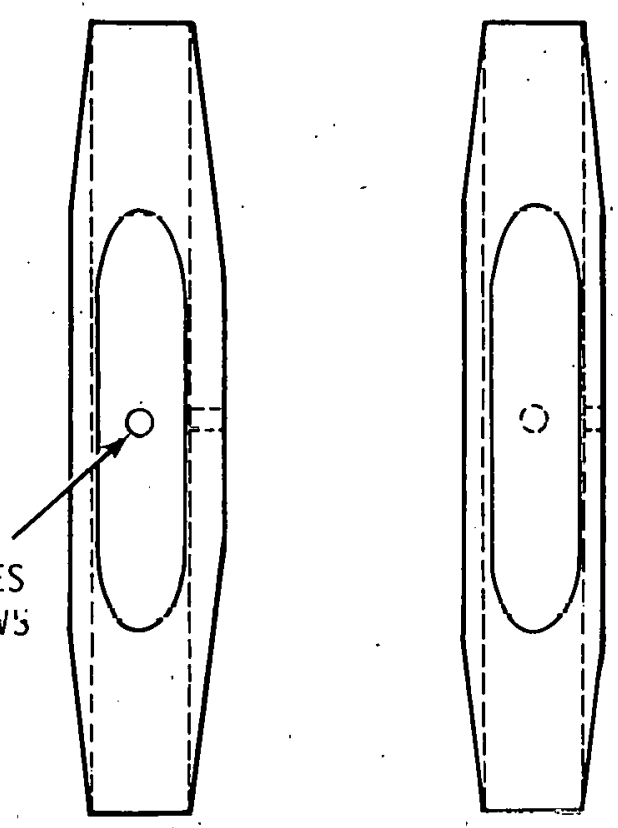

CORNER SLEEVE

SIDE SLEEVE

CENTER SLEEVE

FIGURE 8. Flow Blockage Sleeves 
The LDA system used in the present experiment is shown schematically in Figure 9 and is discussed in detail by Brayton and Goethert. (7) The differential Doppler mode, or "fringe mode," of operation was used since it is easily aligned and operates effectively where the intensity of scattered light is low. Natural contaminants in the loop water were used as light scattering particles in this experiment.

The beam from a $15 \mathrm{MW}$ He-Ne laser was divided with a beam splitter. Each beam was passed through a Bragg Cell where the frequency of one beam was shifted by $44 \mathrm{MHz}$ while the frequency of the other beam was shifted by $45 \mathrm{MHz}$. Frequency shifting was desired to remove the directional ambiguity of the flow measurements, and thereby permit measurements of zero and negative velocities, i.e., the Doppler frequency of scattered light from a particle having zero velocity was $1 \mathrm{MHz}(45-44=1 \mathrm{MHz})$. Negative axial velocities produced Doppler signals with frequencies less than $1 \mathrm{MHz}$ and positive axial velocities produced Doppler frequencies greater than $1 \mathrm{MHz}$.

The two beams were passed through a lens and focused at a point in the flow channel. The intersection volume (measuring volume) formed by the two beams was calculated to be $\sim 0.008$ inches in diameter and ح 0.089 inches in length which indicates the "localized" characteristics. of the measurements. A lens system and $200 \mu$ aperture were used to collect scattered light from particles passing through the measuring volume and to focus the light on the photomultiplier (PM) tube. The aperture eliminated extraneous light from entering the PM Lube. The PM tube collected radiant energy resulting from the scattered light and produced an alternating signal current with a beat, or Doppler frequency, $f_{D}$.

At the intersection volume, the two laser beams created interference ringes as shown in Figurc 10: Bccause the two light beams were mutually coherent and identically polarized, they interfered constructively and destructively to form closely spaced fringes of maximum and minimum illuminating intensity. Simple trigonometry was used to determine the distance between fringes; 


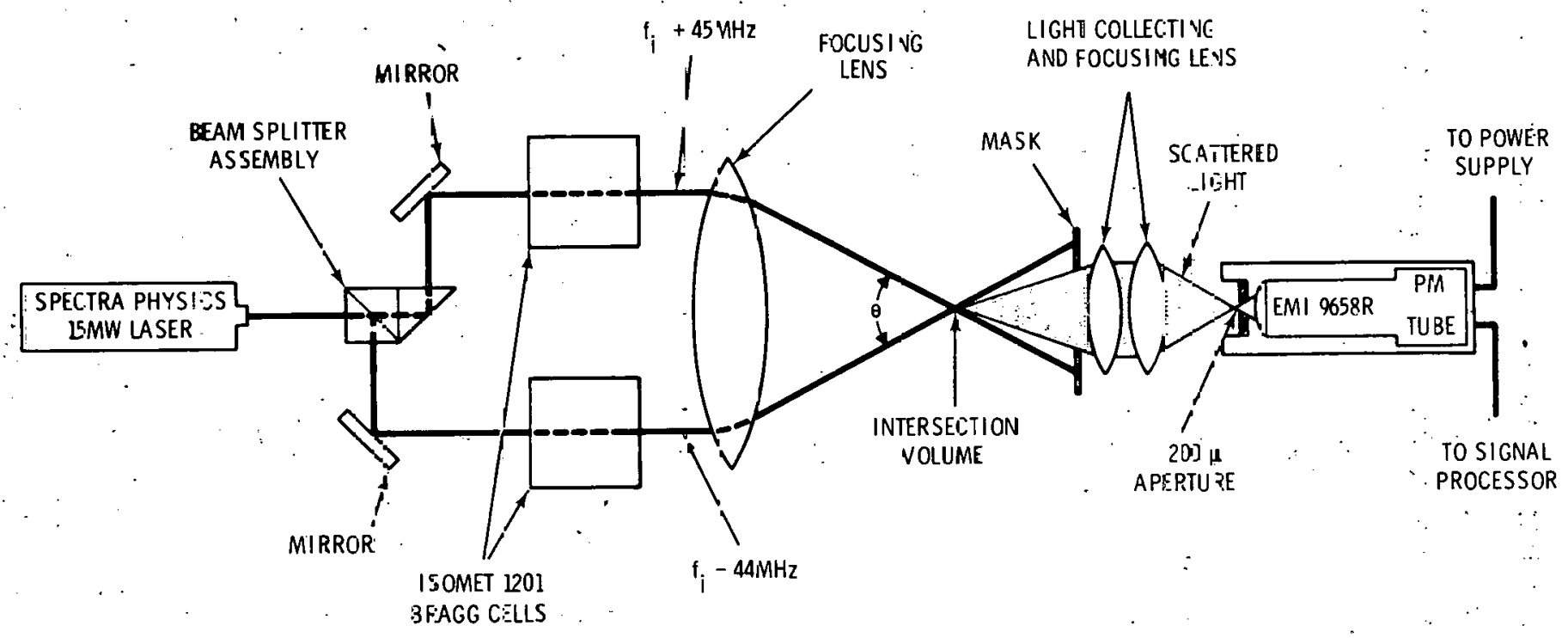

F-GURE 9. Differential Doppler LDA System 


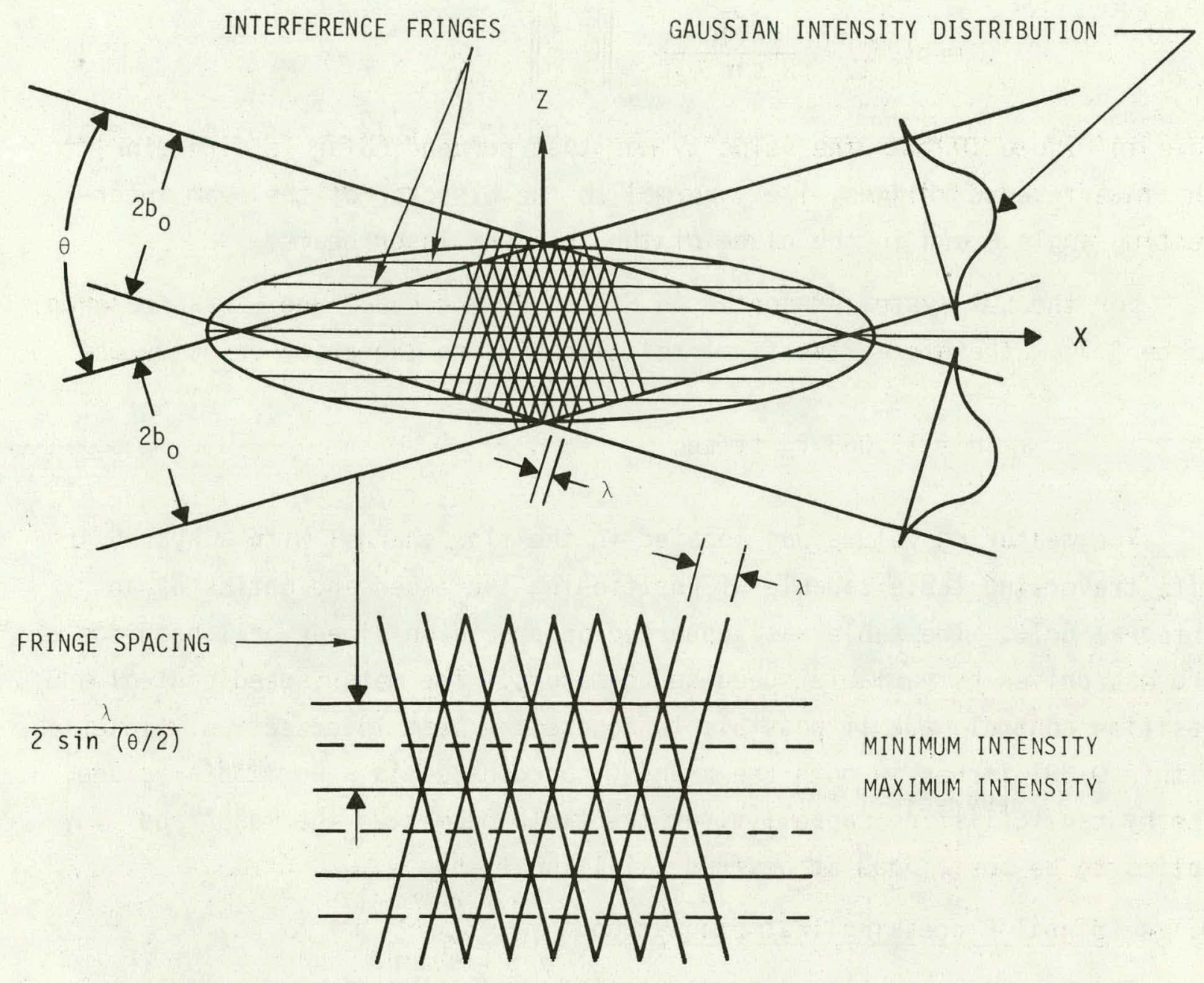

ENLARGEMENT OF INTERFERENCE REGION

FIGURE 10. Detail of the Measuring Volume 


$$
d_{f}=\frac{\lambda}{2 \sin \theta / 2}
$$

Since the product of frequency and distance yields velocity, then

$$
U=d_{f} f_{D}=\frac{\lambda f_{D}}{2 \sin \theta / 2}
$$

Note in Figure 10 that the velocity was that perpendicular (z direction) to the interference fringes, i.e., normal to the bisector of the beam intersecting angle $\theta$ and in the plane of the incident laser beams.

For the LDA system presented in Figure 9, $\lambda=6328 \AA$ and $\theta$ was measured to be $9.7^{\circ}$. Therefore, the final relationship for the axial velocity was

$$
U=13.063 f_{D} \mathrm{ft} / \mathrm{sec}
$$

The measuring volume was located in the flow channel with a hydraulic lift/traversing table capable of positioning the laser and optics as an integral unit. The table was supported on precision linear ball bearings and was driven by variable speed servo-motors. The motor speed control and position control made it possible to locate the beam intersection volume to within 0.001 inches in both the $x$ and $y$ coordinates in a horizontal plane. The hydraulic lifting capability of the table permitted the laser and optics to be positioned at desired axial locations.

\subsubsection{Signal Processing Instrumentation}

The signal processing instrumentation used to condition, interpret, and obtain the axial velocity intensity of turbulence data from the Doppler signal is presented in Figure 11. The system basically consisted of a Doppler signal processor, oscilloscope, digital voltmeter, and rms voltmeter.

The Doppler signal processor consisted of a preamplifier and frequency tracker which improved the signal-to-noise ratio of the Doppler shifted signal and converted the frequency into an analog voltage which was linearly related to local mean axial flow velocity. The processor possessed 


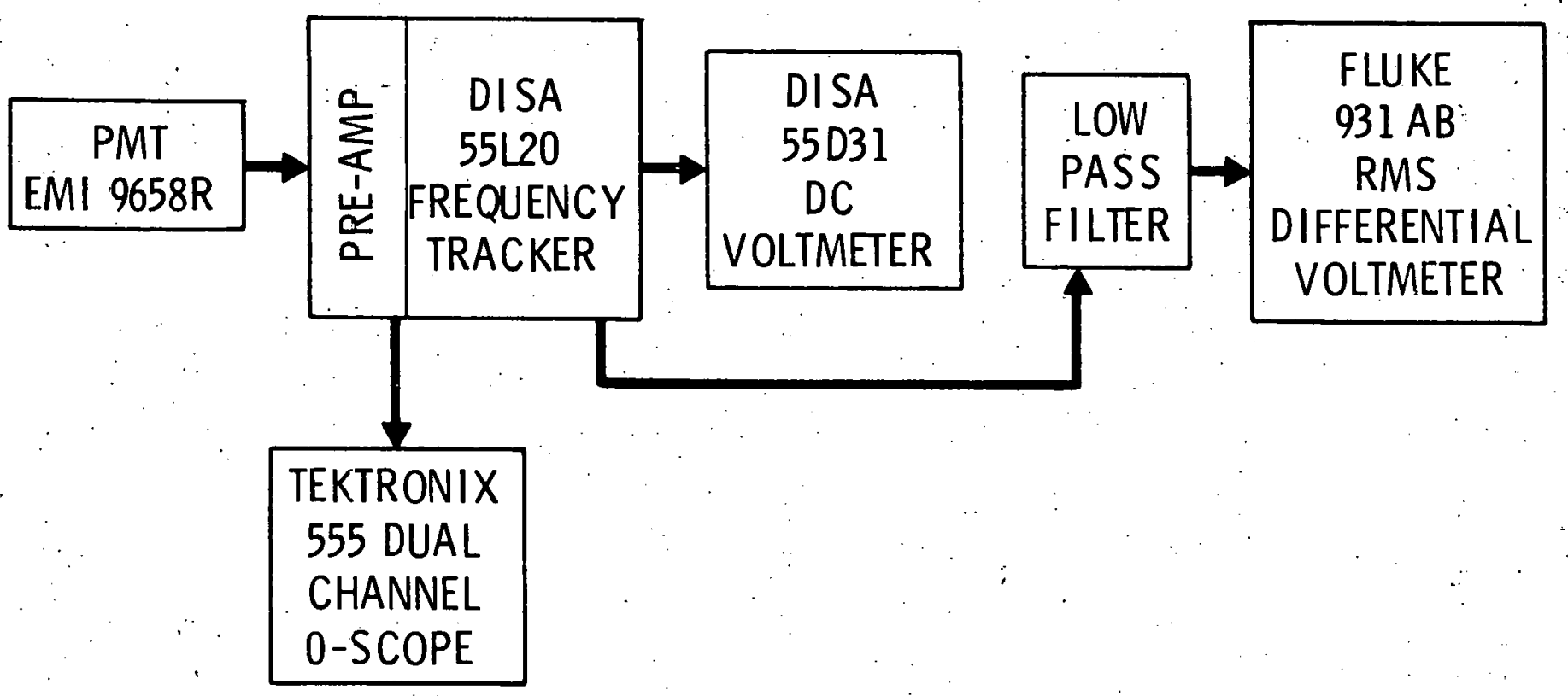

FIGURE 11. LDA Signal Processing Instrumentation 
frequency tracking capabilities; once it was "locked on" to the Doppler frequency it followed frequency fluctuations about the mean within each available frequency range. A meter unit was supplied with the processor to indicate Doppler frequencies. A DC digital voltmeter was used to more accurately determine mean velocities proportional to the voltage output of the signal processor. An rms voltmeter was used to measure the alternating component of the processor output voltage which corresponded to the local rms fluctuating component of axial velocity.

A low pass filter preceded the rms voltmeter to filter higher frequency signals. All data were obtained at a cutoff frequency of $4 \mathrm{kHz}$. This limit was chosen since the intensity of turbulence changed while the cutoff selector was switched between $1 \mathrm{kHz}$ and $3 \mathrm{kHz}$, but negligible changes were observed above $4 \mathrm{kHz}$. Also, the $4 \mathrm{kHz}$ cutoff frequency agrees with that used in Reference 2 for similar flow conditions.

\subsection{EXPERIMENTAL PROCEDURE}

Loop flow and temperature were set at desired values. The loop had very stable flow, pressure, and temperature controls and did not require adjustments during data acquisition:

Once the loop was operating at selected conditions, the LDA optical system was adjusted to produce an optimum Doppler signal as observed on an oscilloscope. The inside surfaces of the windows were located to within \pm 0.045 inches by observing the loss of signal on the oscilloscope as the measuring volume was traversed into the windows. Data acquisition was started approximately 0.100 inches from a window and continued to be taken incrementally, usually every 0.135 inches, along a selected traverse across the rod bundle. The measuring volume was positioned to within 0.001 inches relative to its adjacent data locations with the lift/traversing table.

At each data location, the frequency tracker. (Doppler signal processor) was checked to assure proper adjustment and the rms voltmeter was nulled to the correct value. The $D C$ voltmeter output (voltage representation of the Doppler frequency), the rms output, the $x$ and $y$ locations, and the other pertinent loop information were then recorded. The lift/traversing table was then used to reposition the measuring volume. 
After desired data at one axial location were obtained, the lift/ traversing table was used to raise or lower the LDA optics to a new axial location. The above testing procedure was then repeated.

Pressure loss data between taps $1-2,2-3,3-4,4-5,1-3$, and $1-5$ were obtained intermittently throughout the course of the experiment. Pressure differentials were measured with strain gauge transducers rated at 1 psid and 5 psid.

\subsection{EXPERIMENTAL DATA}

Data obtained during the course of this experimental investigation are presented in Appendix C. The data were reduced to engineering units and tabulated based on run number. The following sections discuss data point locations, data reduction methods, and accuracy of the data.:

\subsubsection{Data Point Locations}

The 70 percent blockage cluster was positioned midway between spacer \#1 and spacer \#2. The 90 percent cluster was positioned midway between spacers \#1 and \#2, and also placed adjacent to and just upstream from spacer \#2. Blockage and spacer locations are shown in Figure 12.

The locations of the traverses performed at any given axial location (data plane): are presented in Figure 13. The bundle cross section symmetry permitted limitation of data acquisition to the indicated quadrant. For wall subchannels ( $y=0.110$ inches), only one measurement was obtained at a location one-half the distance from the wall to the outside edge of the first rod row. Note that partial traverses 0.050 inches. on either side of the $y=1.224$ inch and $y=1.763$ inch traverses were obtained in selected cases. Partial traverses were performed to determine subchannel velocity profiles in the $y$ direction.

\subsubsection{Data Reduction Methods}

A digital. computer program was written to reduce the experimental data to desired engineering units. Plotting routines were used to display a 


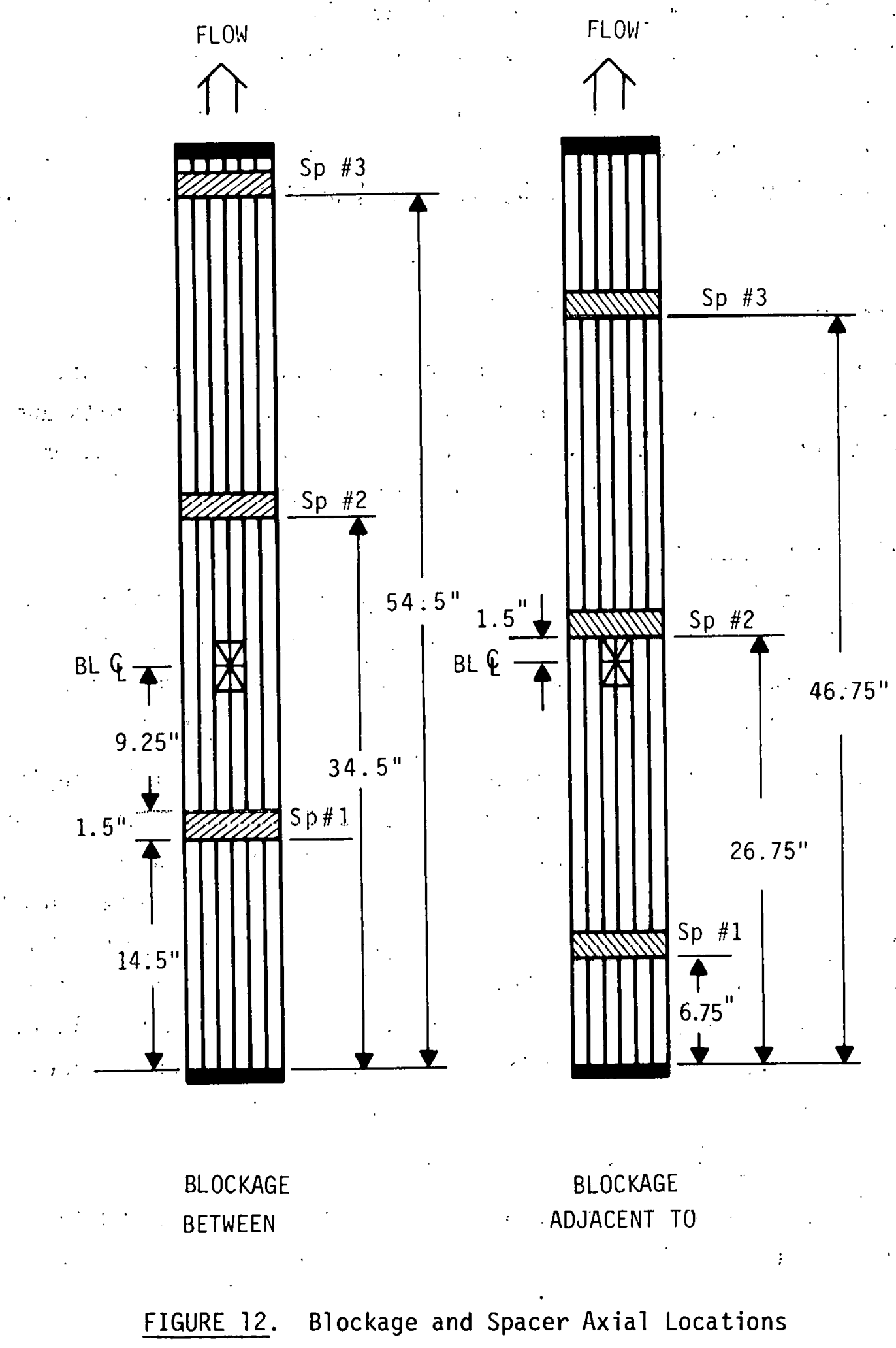




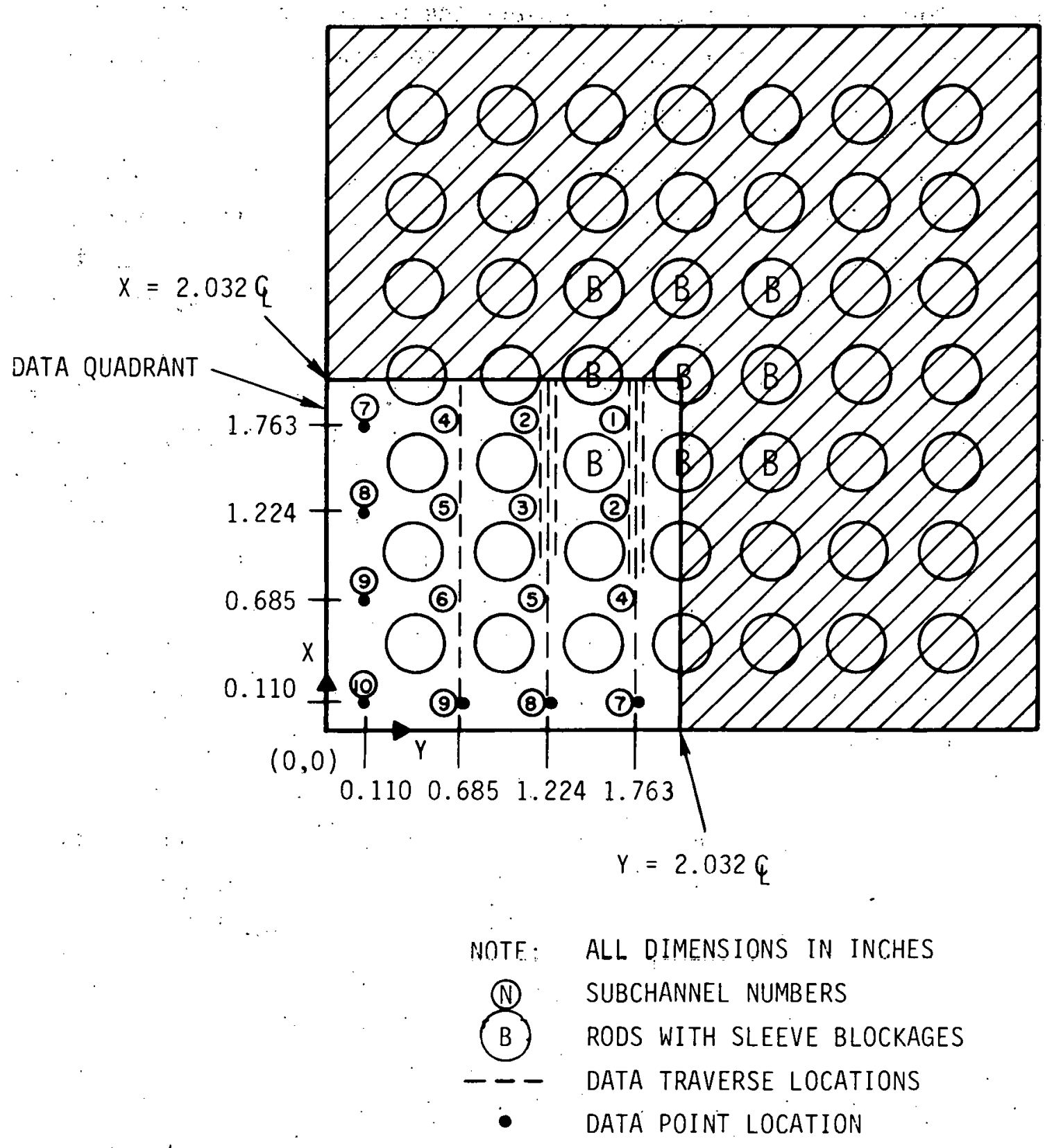

FIGURE 13. Data Traverse Locations 
significant amount of the data. For each data point it was necessary to 1) shift the measurement location to a consistent set of reference coordinates and correct for refractive index; 2) convert the Doppler frequency to mean axial velocity; and 3 ) convert the rms voltage to intensity of turbulence.

\subsubsection{Location Corrections}

The measurement location corrections were made by referencing all $x$ locations to the location $x=1.763$ inches ( $x$ centerline of the subchannei row containing subchannel \#1), and referencing all y locations to the nominal centerlines $y=0.110,0.685,1.224$, and 1.763 inches of the subchannel rows shown in Figure 13. The $x$ locations were referenced to $x=1.763$ inches by examining a particular velocity profile in a data plane and shifting the profile until the peak velocity point in the subchannel containing $x=1.763$ inches corresponded to $x=1.763$ inches. The necessary $x$ shift was then applied to each point obtained in that particular data plane. At most data planes, the velocity profile at $y=0.685$ inches was used to determine the $x$ correction factor. since the velocity profile along the $x$ traverse was very distinct, even near the blockage cluster. The $y$ locations were referenced to the nominal $y$ subchannel row centerlines by simply assuming that the centerline traverses corresponded to the row centerlines.

The measurement locations in the $x$ direction were also corrected for index of refraction to compensate for the varying thickness of water to the measuring volume as shown in. Figure 14. The correction equation

$$
x_{c}=x_{m} \cdot n_{w}
$$

was used and was derived from Snell's law of refraction,

$$
n_{a} \sin \theta_{1}=n_{w} \sin \theta_{2}
$$




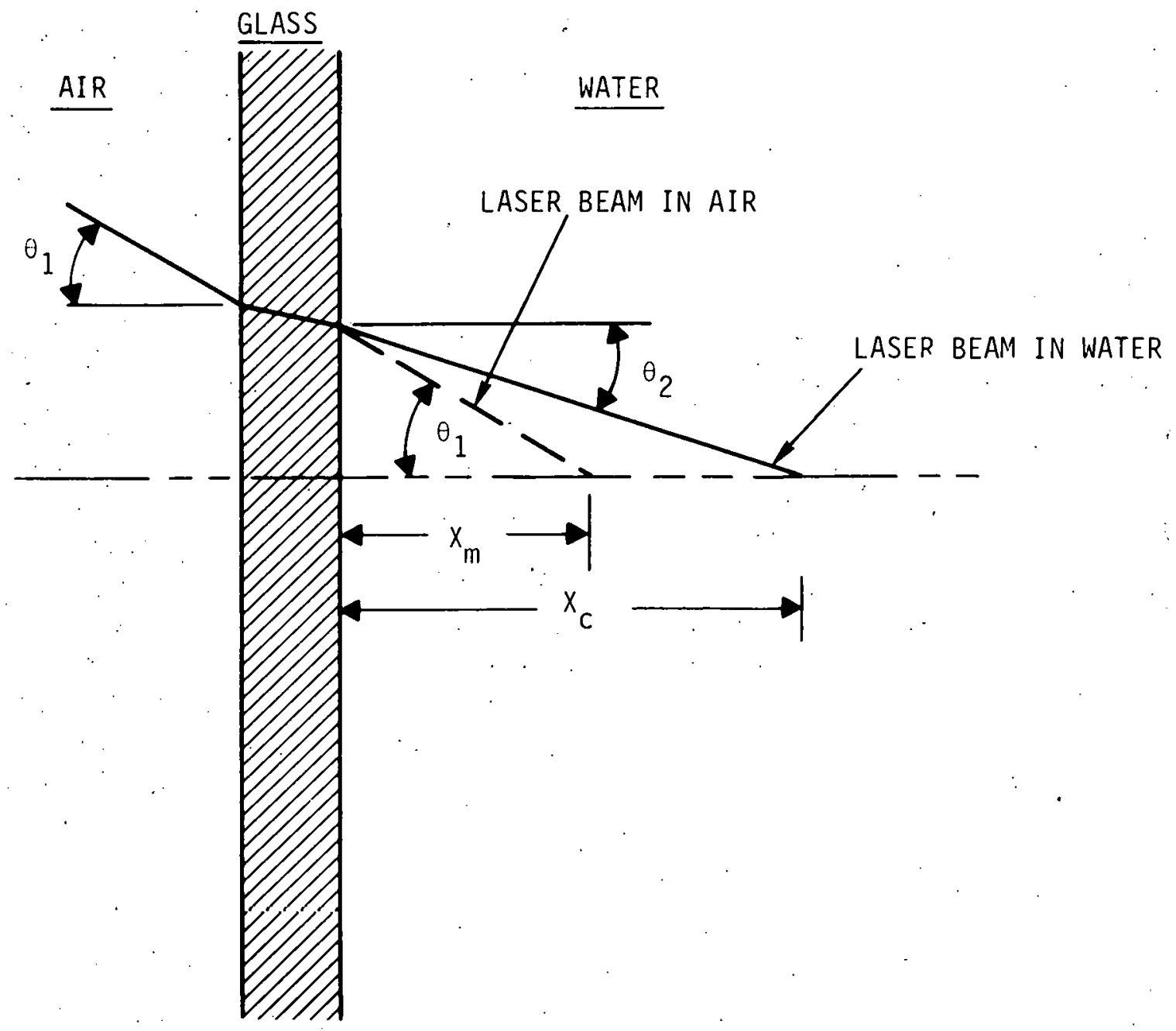

FIGURE 14. Laser Beam Deflection From Air to Water 
For air, $n_{a}=1.0$ and

$$
\theta_{2}=\sin ^{-1}\left(\frac{\sin \theta_{1}}{n_{w}}\right)
$$

where $n_{w}$ is the index of refraction of water. The true position, $x_{c}$, and the measured position, " $x_{m}$ ", were related by

$$
\begin{aligned}
x_{m} \tan \theta_{1}= & x_{c} \tan \theta_{2} \\
& \therefore x_{c}=\frac{x_{n} \tan \theta_{1}}{\tan \left[\sin ^{-1}\left(\frac{\sin \theta_{l}}{n_{w}}\right)\right]}
\end{aligned}
$$

The small angle approximation $\tan \theta=\theta=\sin \theta$ was used to reduce the equation to

$$
x_{c}{ }^{\prime}=x_{m}: n_{w}
$$

\subsubsection{Mean Axial Velocity}

The calculation of mean axial velocity from the Doppler frequency was performed by first converting the voltage output from the $D C$ voltmeter to a frequency. The relationship

$$
f_{D}=\left(E_{D C} \cdot \frac{\text { Range }}{10.0}-f_{S}\right) \quad M H z
$$

was used where

$$
\mathrm{f}_{\mathrm{D}} \text { - Doppler frequency, } \mathrm{MHz} \text {. }
$$

Range - Full scale value of the range used on the frequency. tracker, $\mathrm{MHz}$

$$
E_{D C}-D C \text { voltmeter output, volts }
$$

10.0 - Full scale value of the DC voltmeter, volts

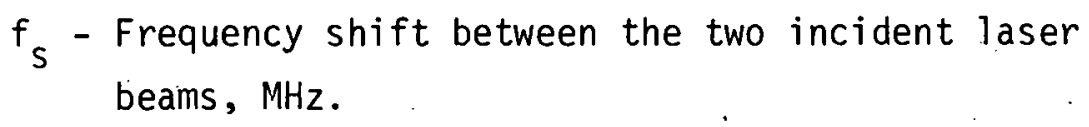


Then, the relationship

$$
U=13.063 \mathrm{f}_{\mathrm{D}} \mathrm{ft} / \mathrm{sec}
$$

was used to determine mean local axial velocity values.

\subsubsection{Intensity of Turbulence}

Local intensity of turbulence values were determined by calculating the ratio of the rms voltmeter output to the $D C$ voltmeter output,

$$
\frac{U^{\prime}}{U}=\frac{E_{r m s}}{E_{D C}-\left(10.0 f_{s} / \text { Range }\right)}
$$

The local rms fluctuating axial velocity component was then found using the expression

$$
U^{\prime}=U \cdot E_{r m s} /\left[E_{D C}-\left(10.0 f_{s} / \text { Range }\right)\right] \mathrm{ft} / \mathrm{sec}
$$

Note that fluctuating components of velocity were normalized with respect to local velocities, not bundle average velocities, to define intensity of turbulence. As local velocities approach zero, local intensity values approach infinity. The infinite intensity values could be eliminated by normalizing the fluctuating velocity component with respect to bundle average velocity. Bundle average velocities were not used since intensity values in regions of low velocities: would remain relatively low and could be misleading when considering possible effects on heat transfer. Therefore, local velority was arbitrarily but consistently chosen for normalizing the fluctuating component of velocity to determine local intensity of turbulence.

\subsubsection{Accuracy of Data}

An uncertainty analysis using the error and uncertainty methods of Schenck ${ }^{(8)}$ was performed to estimate data accuracy. These methods are similar to those of describing uncertainties in single sample experiments presented by $\mathrm{Kline}$ and $\mathrm{McClintock}{ }^{(9)}$ and those of compounding errors presented by Wilson. (10) The methods and analysis are presented and described in detail in Appendix $B$. Table 1 is a summary of the results of the uncertainty analysis based on Run S7-346 of the test matrix presented in Appendix C. 


\subsubsection{Axial Velocity}

Velocity measurements were found to have, an uncertainty of $\simeq \pm 11$ percent. The relatively large error was primarily due to 1 ) the small angle required between the laser beams to permit measurements near the blockage, and 2) the fact that in the vicinity of the blockage, the frequency: tracker would not consistently "hold track" on the $1.5 \mathrm{MHz}$ range; hence, all measurements were obtained on the $5 \mathrm{MHz}$ scale.

TABLE 1. Uncertainty Values (Run \#S7-346)

\begin{tabular}{|c|c|c|c|}
\hline \multirow[b]{2}{*}{ Parameter } & \multirow[b]{2}{*}{ Nominal Value } & \multicolumn{2}{|c|}{ Uncertainty } \\
\hline & & Value & Percent \\
\hline Mean Velocity, U & $5.7 \mathrm{ft} / \mathrm{sec}$ & $\pm 0.62 \mathrm{ft} / \mathrm{sec}$ & \pm 11 \\
\hline Intensity of Turbulence, $U^{\prime} / U$ & 0.132 & \pm 0.022 & \pm 16 \\
\hline x Data Point Location, $x$ & & $\pm 0.001 \mathrm{in}$. & \\
\hline y Data Traverse Location, y & & \pm 0.010 in. & \\
\hline Axial Data Plane Location, $z$ & & $\pm 0.100 \mathrm{in}$. & \\
\hline
\end{tabular}

The error contribution of a small $\theta$ angle is not obvious unless one refers to the detailed uncertainty analysis presented in Apperidix B:: There, it can be seen that the uncertainty is proportional to $1 / \sin (\theta / 2), \csc \theta / 2, \ldots$ and $\cot \theta / 2$ which are relatively large terms when $\theta / 2$ is small.

Since the accuracy of the frequency tracker was based on \pm 1 percent of full scale deflection, being forced to take measurements on the low end the $5 \mathrm{MHz}$ scale accounts for a portion of the velocity uncertainty. All measurements were obtained on the higher range because in nondisturbed flow regions, velocity and turbulence measurements were essentially identical regardless of the range selection. This would lead to the conclusion that the quoted accuracy. of the frequency tracker is conservative.

The uncertainty of $\pm 11 \%$ is considered to be a very conservative estimate of maximum error in absolute local velocity. The data do not exhibit a large amount of scatter as shown by the consistency, $< \pm 5$ percent, from point-to-point throughout any one data traverse. 


\subsubsection{Intensity of Turbulence}

The relatively large uncertainty in the intensity measurements was a result of reading error of the rms voltmeter. The meter was a "null" model, not a time integrating model, and therefore difficult to read in highly turbulent flows. Again, the consistency from data point-to-data point is much less than the \pm 16 percent estimated for absolute uncertainty of intensity.

\subsubsection{Measurement Locations}

Each measurement location was positioned within \pm 0.001 inches of its neighbors in the $x$ direction, and each data traverse was located within \pm 0.010 inches in the $y$ direction relative to the adjacent rod rows. The axial locations of the data planes were known within \pm 0.100 inches relative to the blockage axial centerline. 


\subsection{EXPERIMENTAL RESULTS AND DISCUSSION}

Local axial velocity and intensity of turbulence results of the experiment are presented and discussed in the following sections. In the first section, bare rod results in the absence of a blockage are considered. Bare rod data were obtained in the initial stages of the experiment to verify the correctness of the measurements and to establish a data reference for the study.

In the next section, results obtained with a 90 percent blockage placed midway between two grid spacers are discussed. The data were obtained to compare with the bare rod data and to serve as a blockage data base.

The scctions that follow present comparisons of the results obtained with the 90 percent blockage located midway between spacers to results obtained with the 90 percent blockage located adjacent to a spacer, and to results obtained with a 70 percent blockage located midway between spacers. The comparisons with the 90 percent blockage midway between spacers and adjacent to a spacer were made to investigate blockage location effects on flow distributions within the bundle. Severity effects were determined when the 70 and 90 percent blockage results were compared.

In the final section, friction factors and loss coefficients calculated using experimental pressure loss data are presented. These parameters were required as input to the COBRA computer program to predict experimental velocity data as discussed in section 5.0.

\subsection{BARE ROD}

Axial velocity and intensity of turbulence results obtained with a bare bundle (no blockage cluster) are discussed in the sections to follow. Velocity and intensity profiles obtained in the rod bundle at a Reynolds number of $2.9 \times 10^{4}\left(U_{B}=5.7 \mathrm{ft} / \mathrm{sec}\right)$ were typical of those measured by other investigators. $(2,3,4)$ velocity peak-to-average ratios of $\sim 1.18$ were measured in well-developed flow while ratios of $\sim 1.1$ were detected immediately downstream from a spacer. Intensity of turbulence values of $\sim 0.05$ were measured in well-developed flow regions, but increased to $\sim 0.13$ just downstream from a spacer. 


\subsubsection{Axial Velocity}

Local axial velocity data in the absence of blockages were obtained to verify that the bundle had maintained geometric symmetry during the assembly activity and to establish a data reference case. The velocity profiles presented in Figure 15 indicate bundle symmetry did exist. Ratios of local measured-to-bundle average velocity are shown as a function of distance from the wall ( $x$ traverse). The profiles were obtained at specific axial locations (data planes) along the length of the bundle at $y$ locations of 1.763 or 2.302 inches.

The velocity profile obtained upstream from spacer \#1 shows distinct velocity peaks at the subchannel centers and valleys at rod gaps. Axial velocity peak-to-average ratios of $\sim 1.18$ were measured which agree well with those known to exist in well developed turbulent pipe flow and existing rod bundle data. $(2,3,4)$ The profile also indicates that the flow conditioning section at the entrance to the test assembly distributed the flow uniformly across the bundle cross section.

At an axial location 0.65 inches ( $\sim 1$ subchannel hydraulic diameter) downstream from spacer $\# 1$, the velocity profile indicates the presence of the spacer by its "ragged" appearance and because the peak-to-average velocity ratio decreased to approximately 1.1. A decrease in the velocity ratio could be expected since the spacer created uniform turbulence across the bundle cross section which "flattened" the velocity profile.

Approximately 6 inches downstream ( 212 subchannel hydraulic diameters) from spacer \#1, the velocity profile had nearly recovered from the influence of the spacer. The profiles were completely developed far downstream from spacer \#1. It was concluded that the bundle was geometrically symmetric since the velocity profiles indicated uniformly distributed flow.

\subsubsection{Intensity of Turbulence}

An increase in turbulence downstream from spacer \#1 is shown vividly in Figure 16 where local intensity of turbulence (ratio of local rms fluctuating axial velocity to local mean axial velocity) is presented as a 


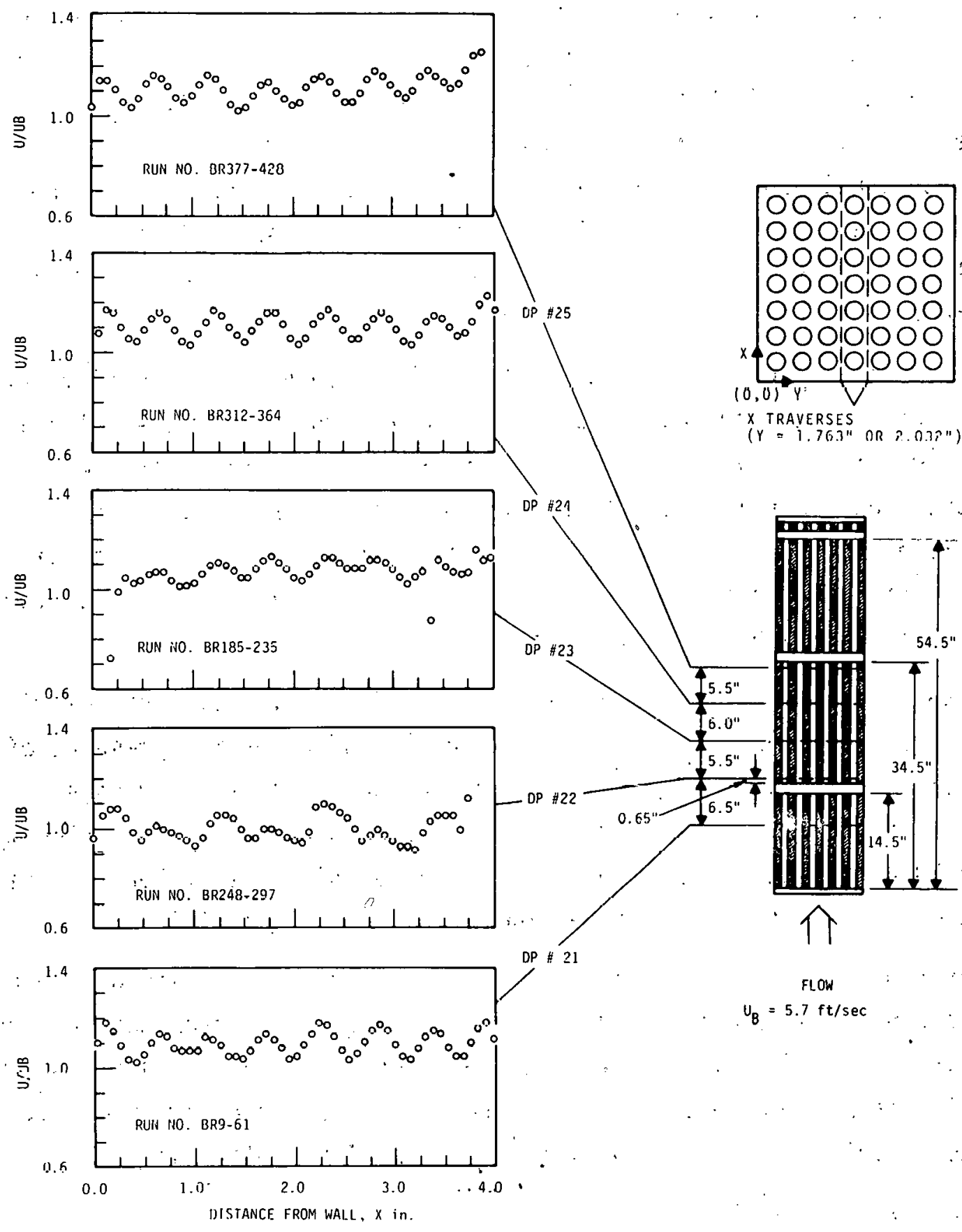

FIGURE 15. Bare Rod Velocity Profiles, $U_{B}=5.7 \mathrm{ft} / \mathrm{sec}$ 


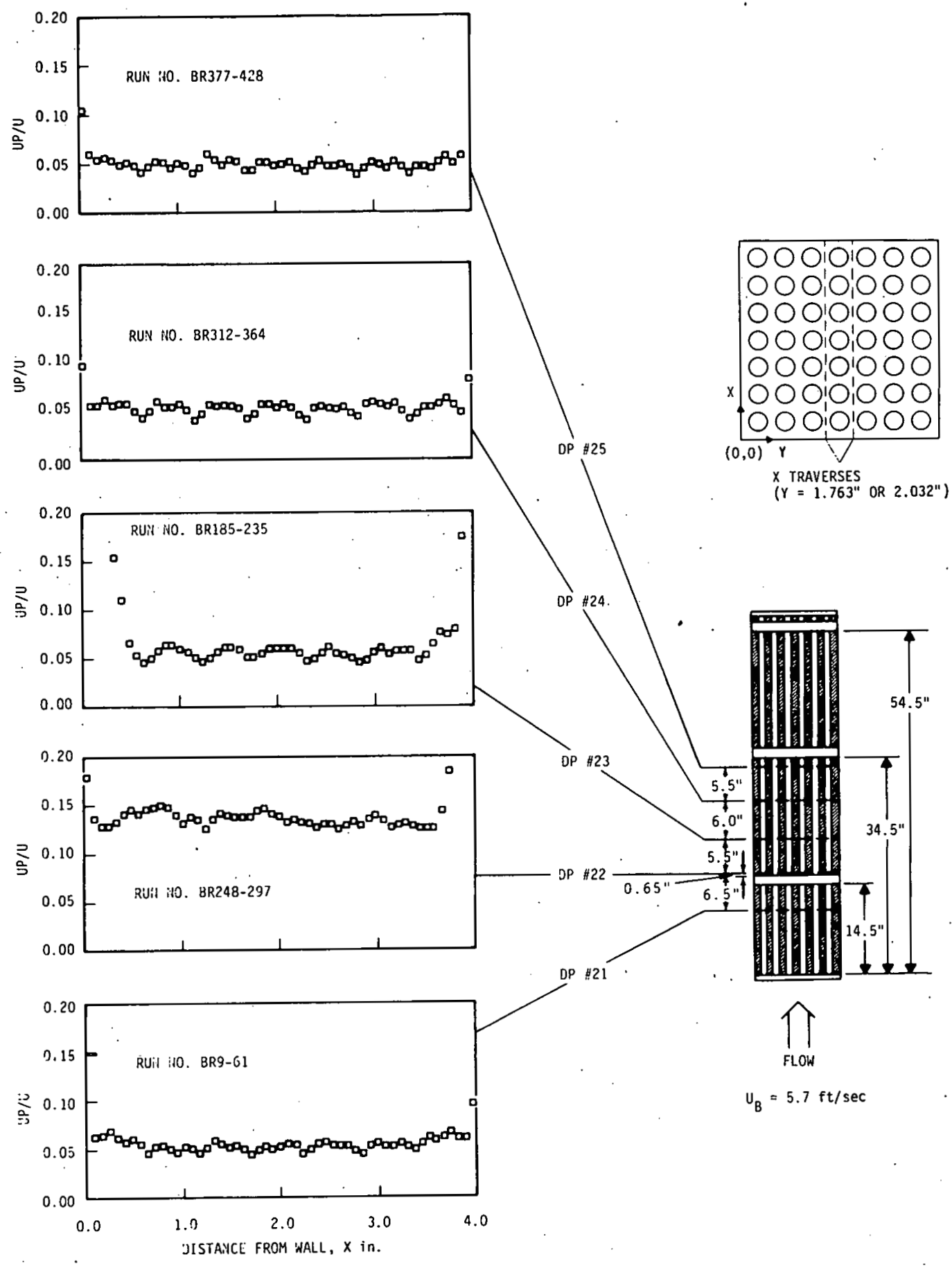

FIGURE 16. Bare Rod Intensity Profiles, $U_{B}=5.7 \mathrm{ft} / \mathrm{sec}$ 
function of distance from the wal1.* Immediately downstream from spacer \# 1 , the measured intensity was approximately three times, 0.005 versus 0.13 , that obtained at the other data planes. The intensity profiles well downstream of spacer $\# 1$ were uniform and indicate that peaks occurred at rod gaps and minima occurred at subchannel centerlines. Local intensity of turbulence values of approximately. 0.05 were measured and agree well with existing rod bundle data. $(2,3,4)$

The occasional spikes in local intensity values obtained near the windows were unreal and were caused by extraneous scattered light from impurities on the windows resulting in erroneous Doppler signals. During the experiments, the occurrence of these spikes could be eliminated by cleaning the test section windows. This occurrence was of minor consequence since only measurements obtained in the close proximity of the windows were affected.

\subsection{PERCENT BLOCKAGE MIDWAY BETWEEN SPACERS}

Results of axial velocity and intensity of turbulence measurements obtained near a 90 percent blockage located midway between two spacers are presented in this section. Data were obtained at three Reynolds numbers, $1.4 \times 10^{4}\left(U_{B}=2.7 \mathrm{ft} / \mathrm{sec}\right), 2.9 \times 10^{4}\left(U_{B}=5.7 \mathrm{ft} / \mathrm{sec}\right)$, and $5.8 \times 10^{4}\left(U_{B}=10.7 \mathrm{ft} / \mathrm{sec}\right)$. The velocity data obtained at selected axial locations along the length of the bundle indicated that a 90 percent blockage created severe flow disturbances. Axial velocities measured immediately upstream from the blockage cluster were extremely low and flow reversals were detected downstream from the blockage. The recirculation zone existed for approximately five subchannel hydraulic diameters downstream from the blockage axial centerline. Flow recovery was completed fifty subchannel hydraulic diameters downstream from the blockage cluster. Flow distributions near the blockage cluster were found to be independent

*See Section 3.3.2.3 for an explanation concerning the choice of normalizing the fluctuating component of velocity with respect to local velocity instead of bundle average velocity to define intensity of turbulence. 
of Reynolds number over the range investigated. Velocity data obtained between each rod row at a single data plane (axial location) showed that the recirculation zone was restricted, in the lateral direction, to the 90 percent blocked subchannels.

Local intensity of turbulence values increased by an order of magnitude (0.05 to 0.8) just upstream from the blockage cluster. Immediately downstream from the blockage, increases in local intensity of three orders of magnitude (>10.0) were detected. A length of approximately 15 subchannel hydraulic diameters was required for intensity values to completely recover from blockage effects. Intensity values upstream and downstream from the blockage cluster were independent of Reynolds number. In the immediate proximity of the cluster, a random dependency on Reynolds number was detected, but no correlation of the data was attempted.

\subsubsection{Axial Velocity}

\subsubsection{Velocity Reduction and Recovery}

Figures 17 through 19 present velocity profiles at specific axial locations along the length of the bundle. The data were obtained with a 90 percent blockage located midway between spacers \#1 and \#2 at an average bundle velocity of $5.7 \mathrm{ft} / \mathrm{sec}\left(\operatorname{Re}=2.9 \times 10^{4}\right)$. Each plot in the figure presents the ratio of local measured axial velocity-to-bundle average velocity as a function of distance from the wall (window). All velocity profiles are presented for an $x$ traverse at $y=1.763$ inches. The numbers in parentheses accompanying the data plane designations indicate respective distances from the blockage axial centerline. The negative sign indicates a particular data plane was located upstream from the blockage.

As shown in Figure 17, the velocity profiles are well developed and very uniform upstream from the blockage cluster. Approximately three subchannel hydraulic diameters (1.8 inches) upstream from the blockage centerline, the influence of the blockage is seen as indicated by the relatively low velocities in the inner subchannels and the higher velocities in the outer subchannels. This trend can be clearly seen in the velocity profile obtained in the tapered region of the blockage 1.3 inches upstream 

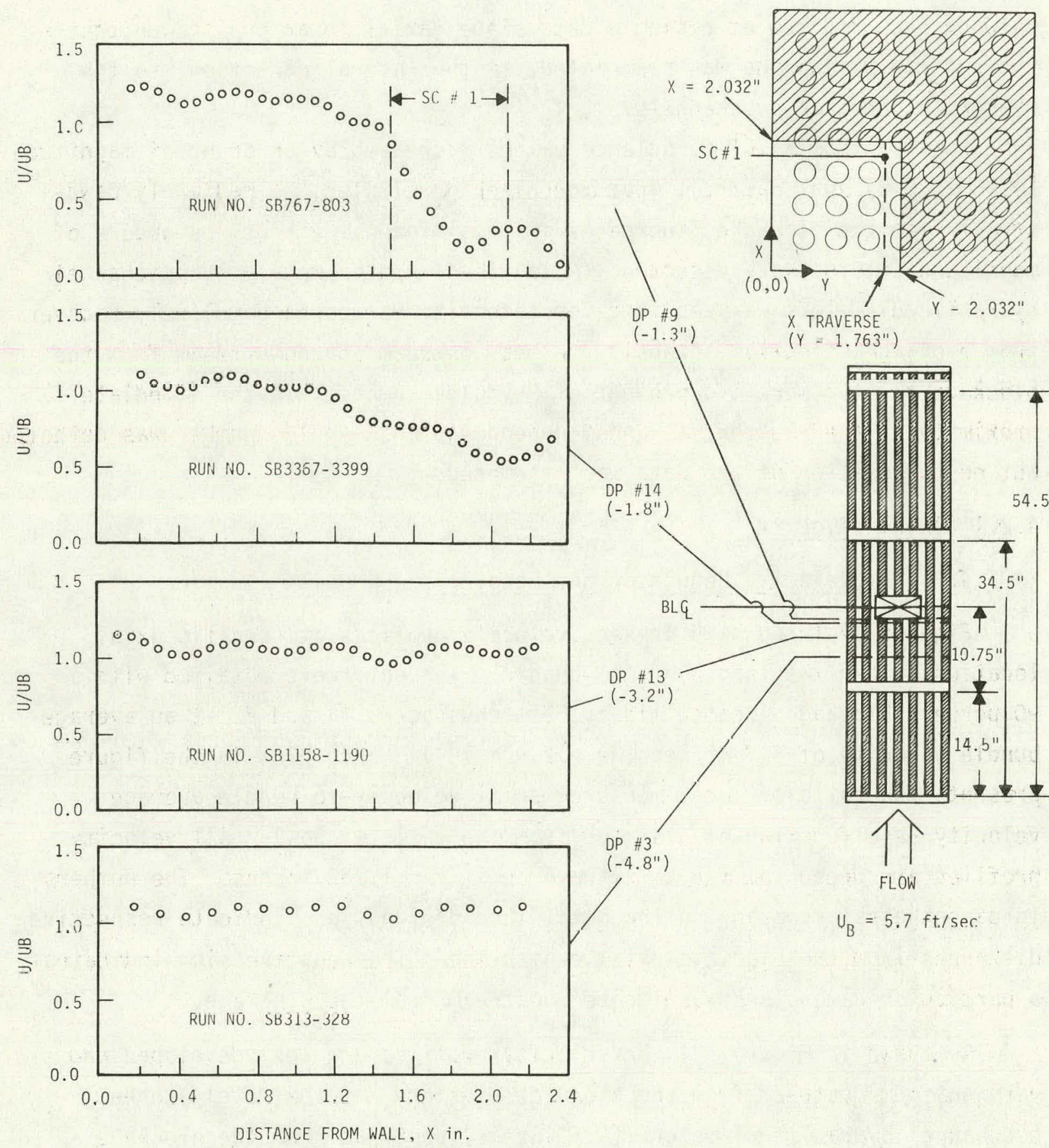

$U_{B}=5.7 \mathrm{ft} / \mathrm{sec}$

FIGURE 17. Velocity Profiles Upstream From a 90 Percent Blockage Located Midway Between Two Spacers, $U_{B}=5.7 \mathrm{ft} / \mathrm{sec}$ 

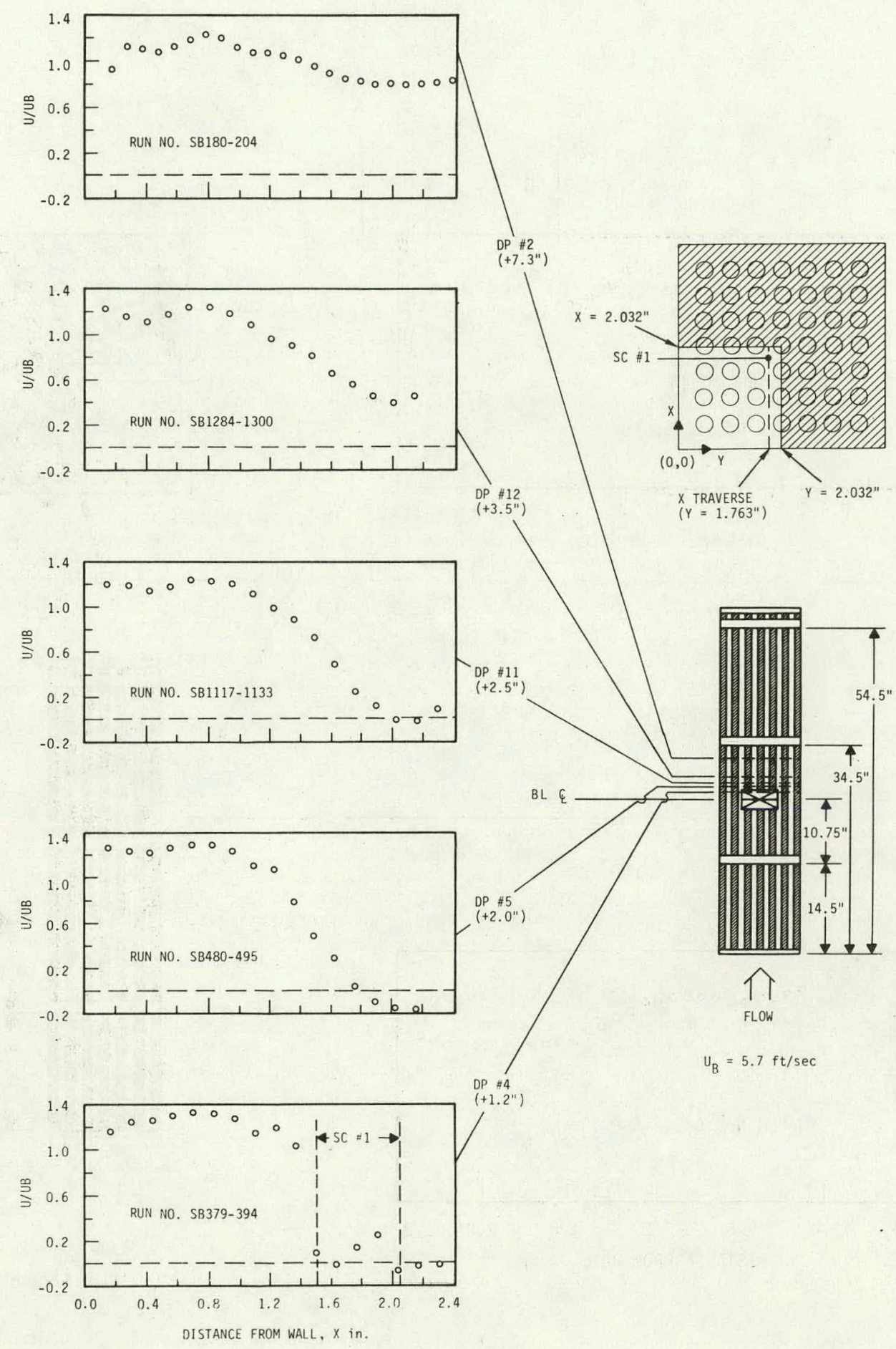

$U_{B}=5.7 \mathrm{ft} / \mathrm{sec}$

FIGURE 18. Velocity Profiles Immediately Downstream from a 90 Percent Blockage Located Midway Between Two Spacers, $U_{B}=5.7 \mathrm{ft} / \mathrm{sec}$ 

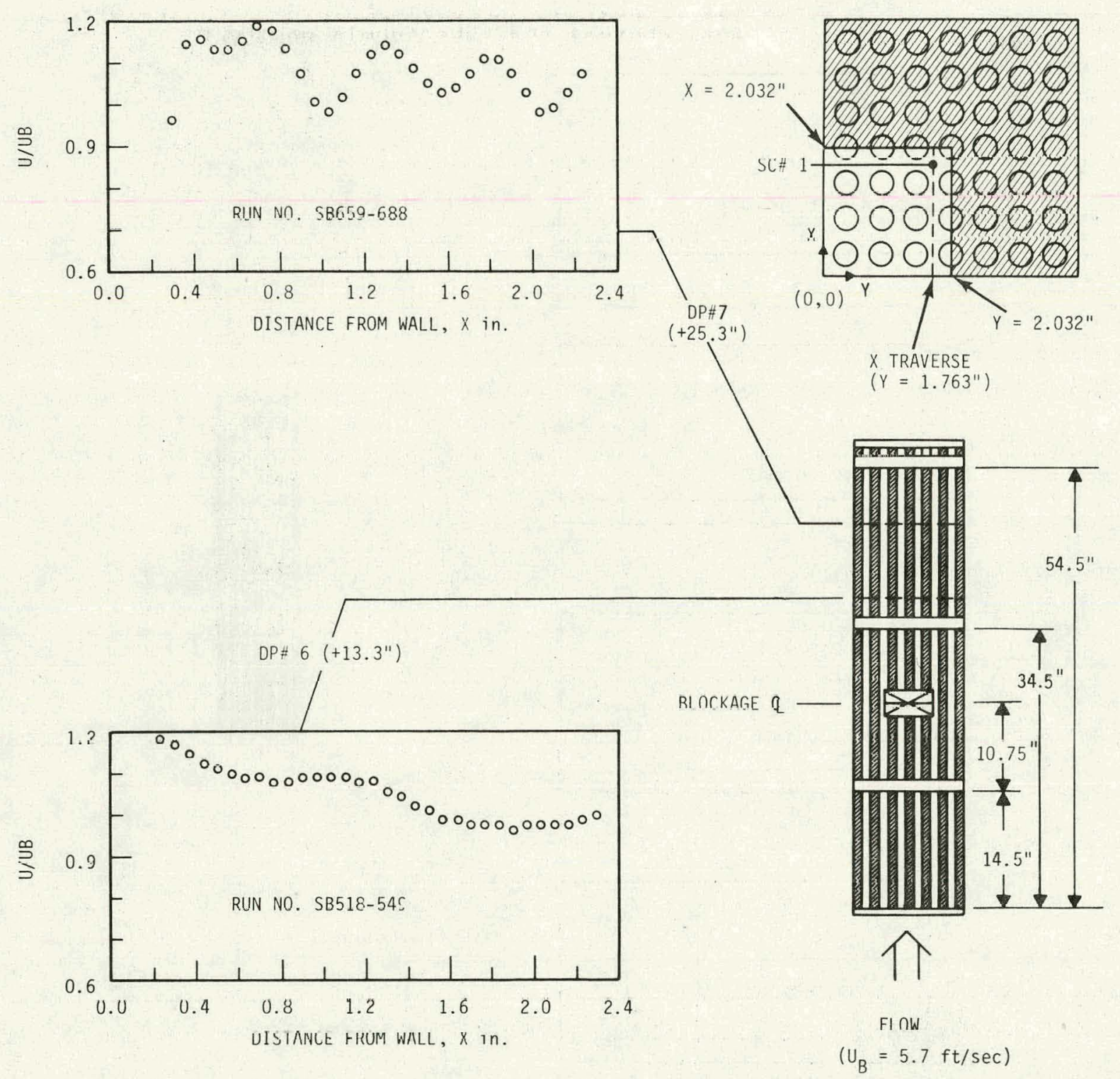

FTGUIRF 19. Velocity Profiles Far Downstream From a 90 Percent Blockage Located Midway Between Two Spacers, $U_{B}=5.7 \mathrm{ft} / \mathrm{sec}$ 
from the blockage centerline. Peak-to-average velocity ratios increased from $\sim 1.1$ to 21.25 in the outer subchannels. Velocity ratios in the inner subchannels decreased, with the most significant decrease occurring in subchannel \#1 (SC \#1). The low velocities are realizable since SC \#1 had an area reduction of 90 percent, whereas the subchannels on the periphery of the blockage cluster were somewhat less restricted as previously discussed in Section 3.1.2.

Figures 18 and 19 present velocity profiles downstream from the blockage; downstream is designated by the plus sign preceding the distance values. Velocity profiles obtained immediately downstream from the blockage, Figure 18, indicate negative flows were measured and a recirculation zone existed. Laterally, the zone was confined to SC \#1. The low inner subchannel velocities were accompanied by relatively high outer subchannel velocities as indicated by the high peak-to-average velocity ratios of 21.3 . Axially, the recirculation pattern persisted for at least 2.5 inches ( 25 subchannel hydraulic diameters) downstream from the blockage centerline.* Flow reversals did not persist 3.5 inches ( $\sim 7$ diameters) downstream from the blockage centerline. At an axial location 7.3 inches downstream from the blockage centerline, the velocity profile began to recover from the influence of the blockage cluster. Additional downstream velocity profiles shown in Figure 19 indicate that, at 213 inches downstream from the blockage, flow recovery continued. At approximately 25 inches or 50 subchannel diameters downstream from the blockage, the velocity profile was essentially recovered from the blockage disturbance.

Velocity profiles at $U_{B}=2.7\left(\operatorname{Re}=1.4 \times 10^{4}\right)$ and $10.7 \mathrm{ft} / \mathrm{sec}$ $\left(\operatorname{Re}=5.8 \times 10^{4}\right)$ were also obtained as shown in Figures 20 and 21. In general, the profiles indicate essentially the same trends as those obtained at $U_{B}=5.7 \mathrm{ft} / \mathrm{sec}$. Figure 22 presents a comparison of the velocity data at the three flowrates. The velocity profiles in the outer subchannel agree exceptionally well. The velocity profiles in the inner subchannels show

*Note that no attempt was made to relate the length of the recirculation zone to a blockage characteristic length. Until sufficient data has been obtained with different blockage severities and dimensions, it is premature to "guess" the best blockage characteristic length that should be used to express the length of the recirculation zone. 

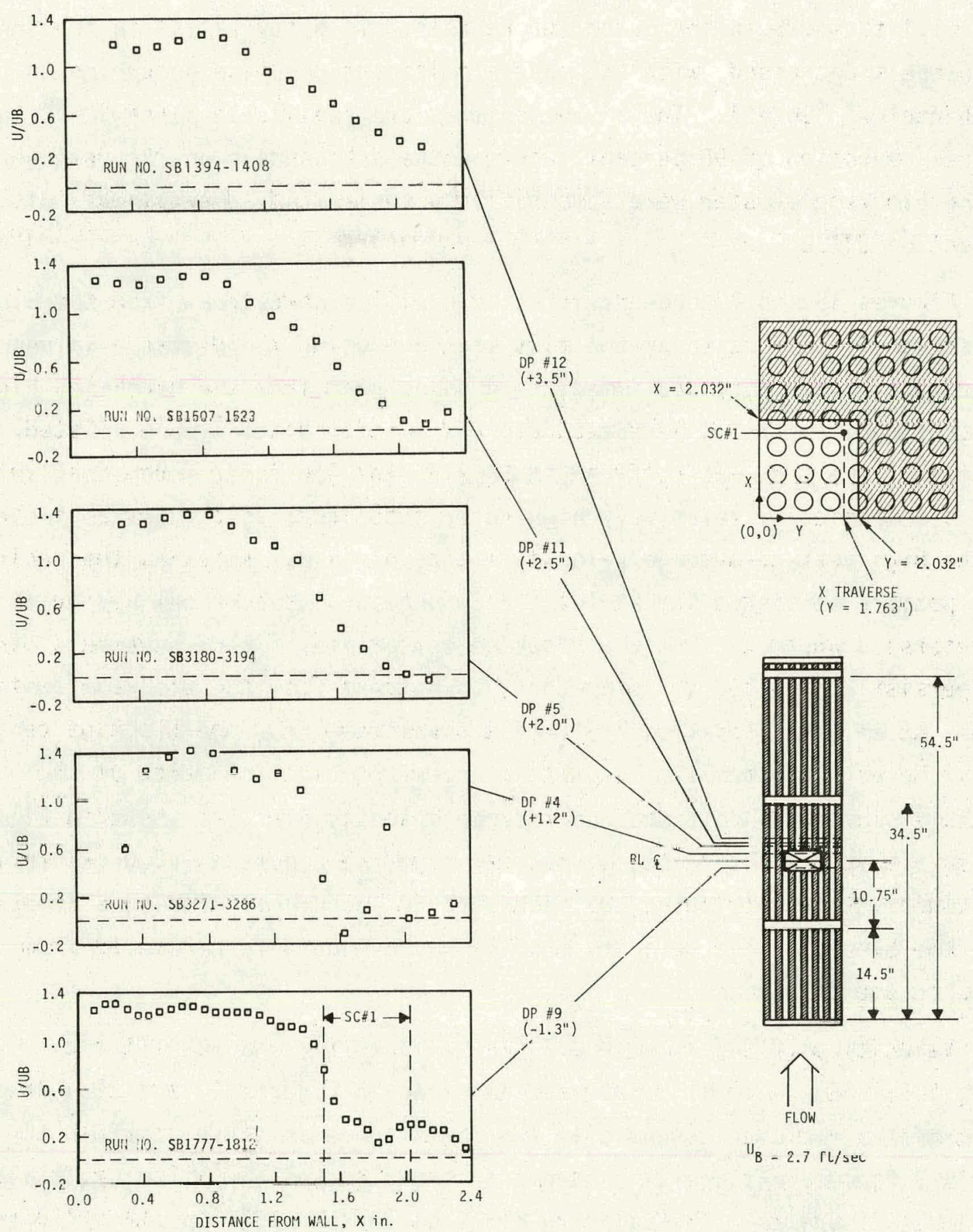

$\mathrm{U}_{\mathrm{B}}-2.7 \mathrm{rL} / \mathrm{sec}$

FIGURE 20. Velocity Profiles Near a 90 Percent Blockage Located Midway Between Two Spacers, $U_{B}=2.7 \mathrm{ft} / \mathrm{sec}$ 

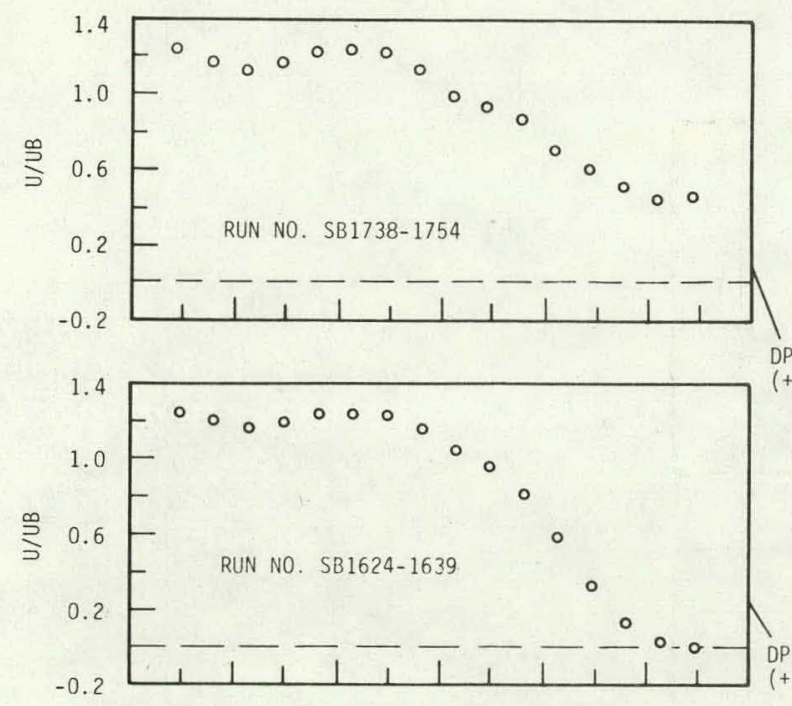

$\mathrm{DP} \# 12$
$\left(+3,5^{11}\right)$
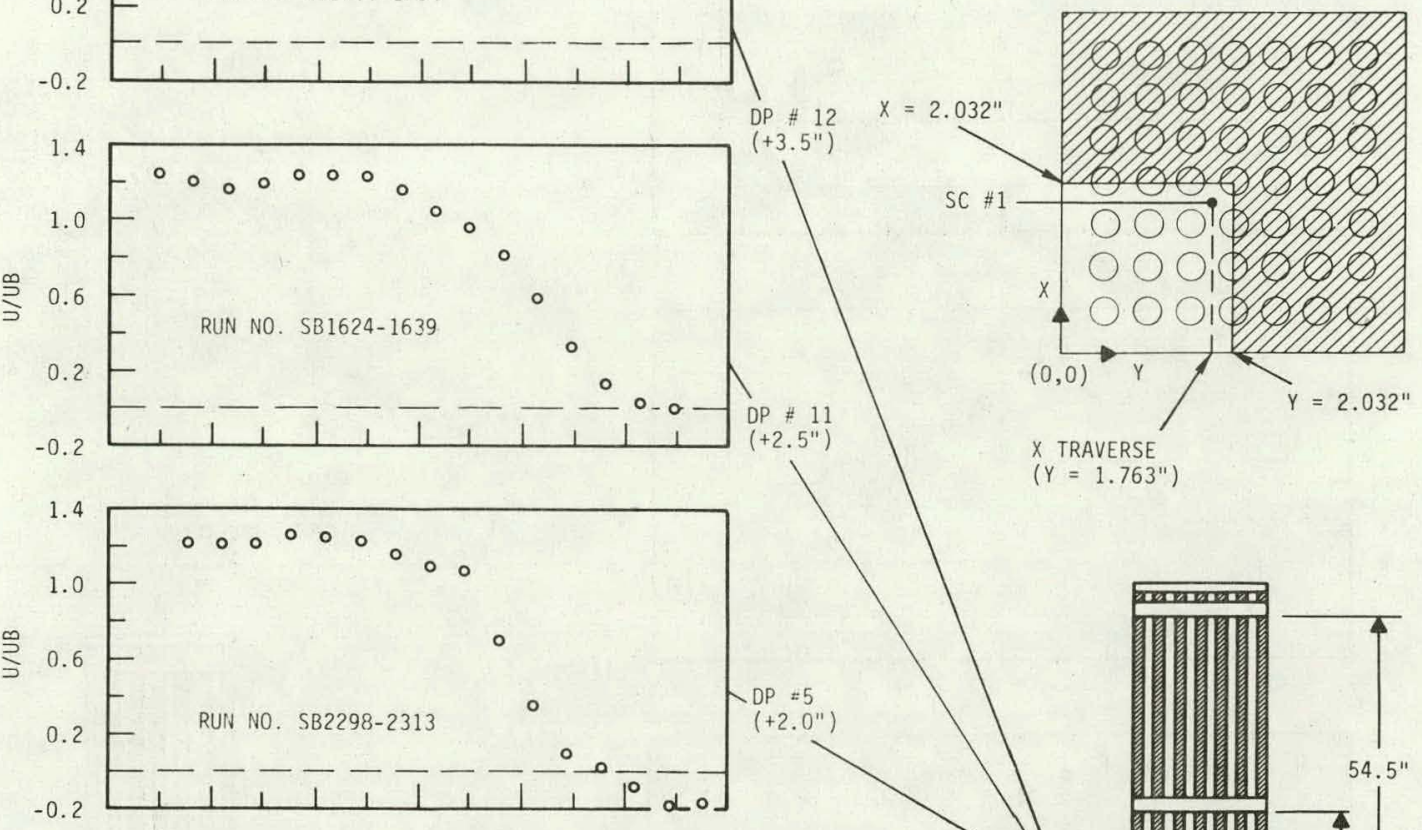

$X$ TRAVERSE

$\left(Y=1.763^{\prime \prime}\right)$
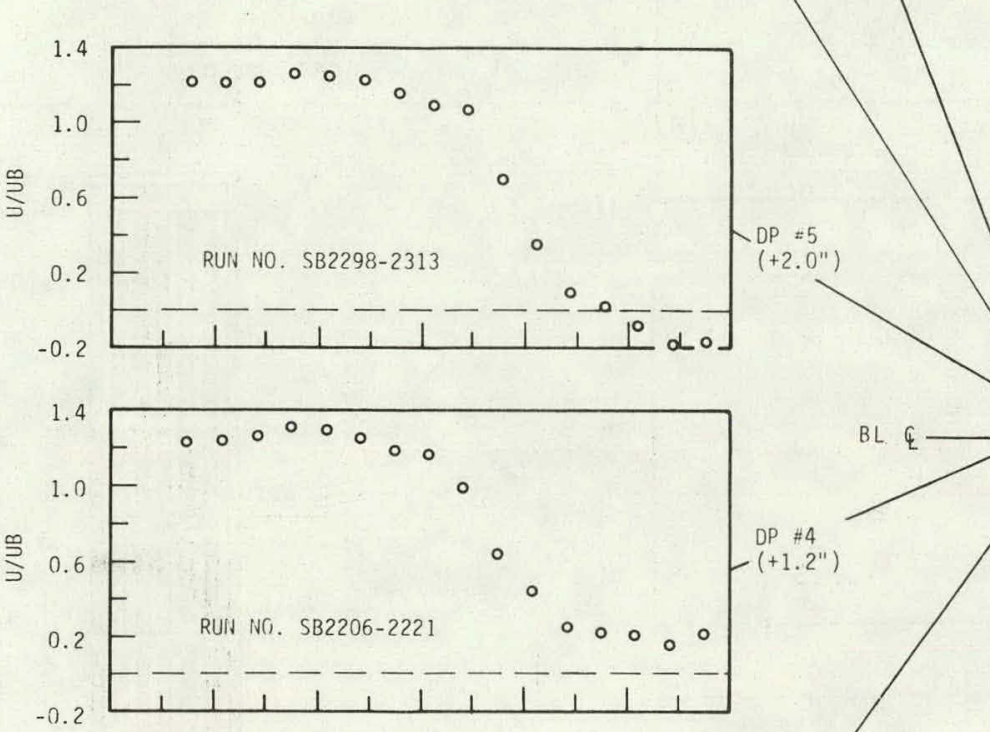

$\left(+2.0^{\prime \prime}\right)$
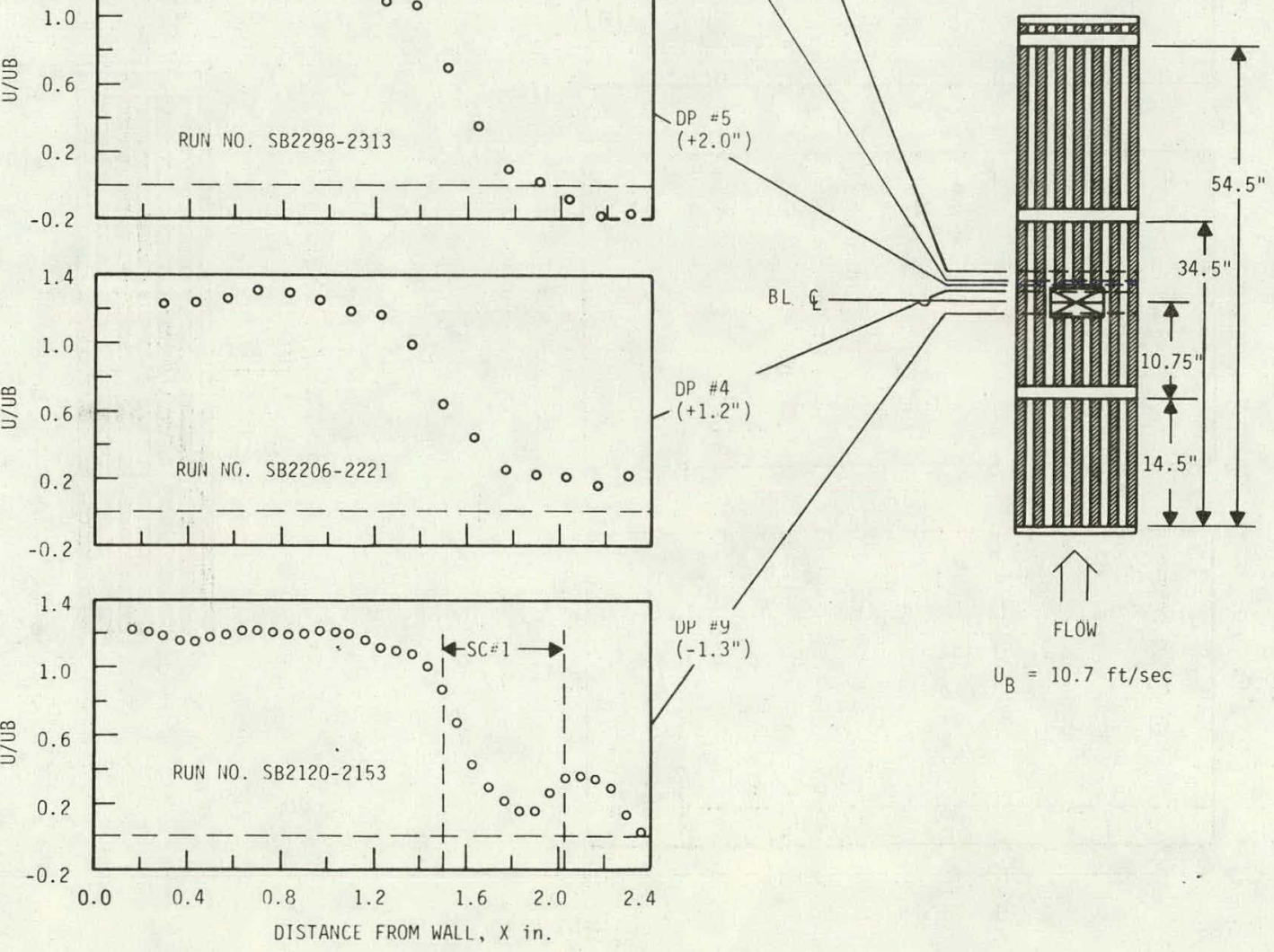

$U_{B}=10.7 \mathrm{ft} / \mathrm{sec}$

FIGURE 21. Velocity Profiles Near a 90 Percent Blockage Located Midway Between Two Spacers, $U_{B}=10.7 \mathrm{ft} / \mathrm{sec}$ 

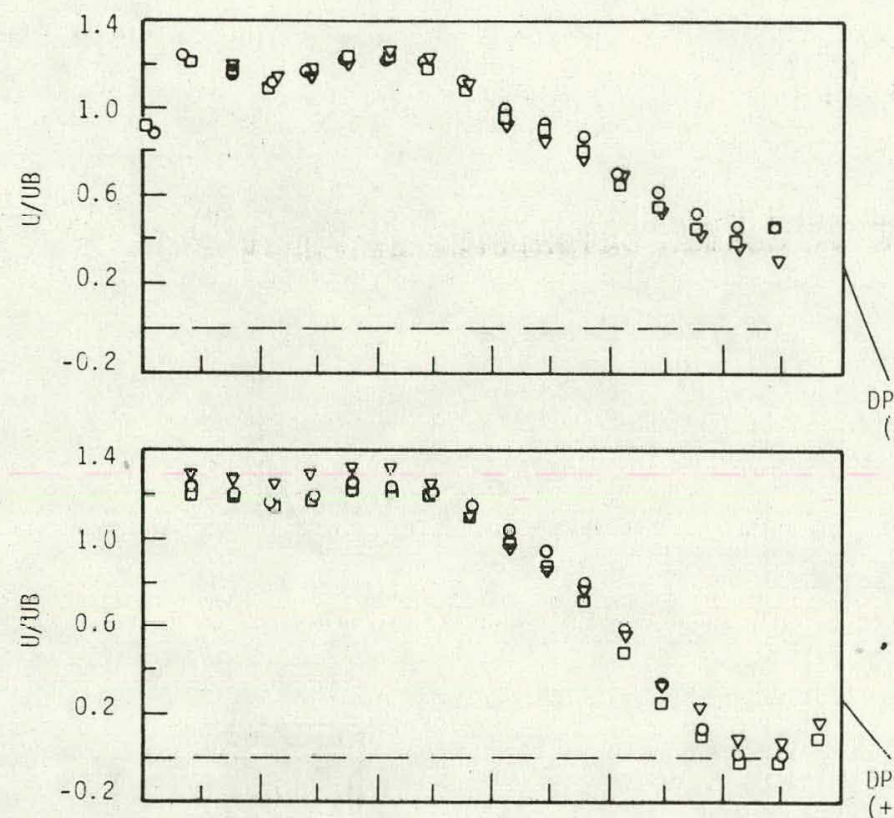

$\mathrm{DP}$ \# 12
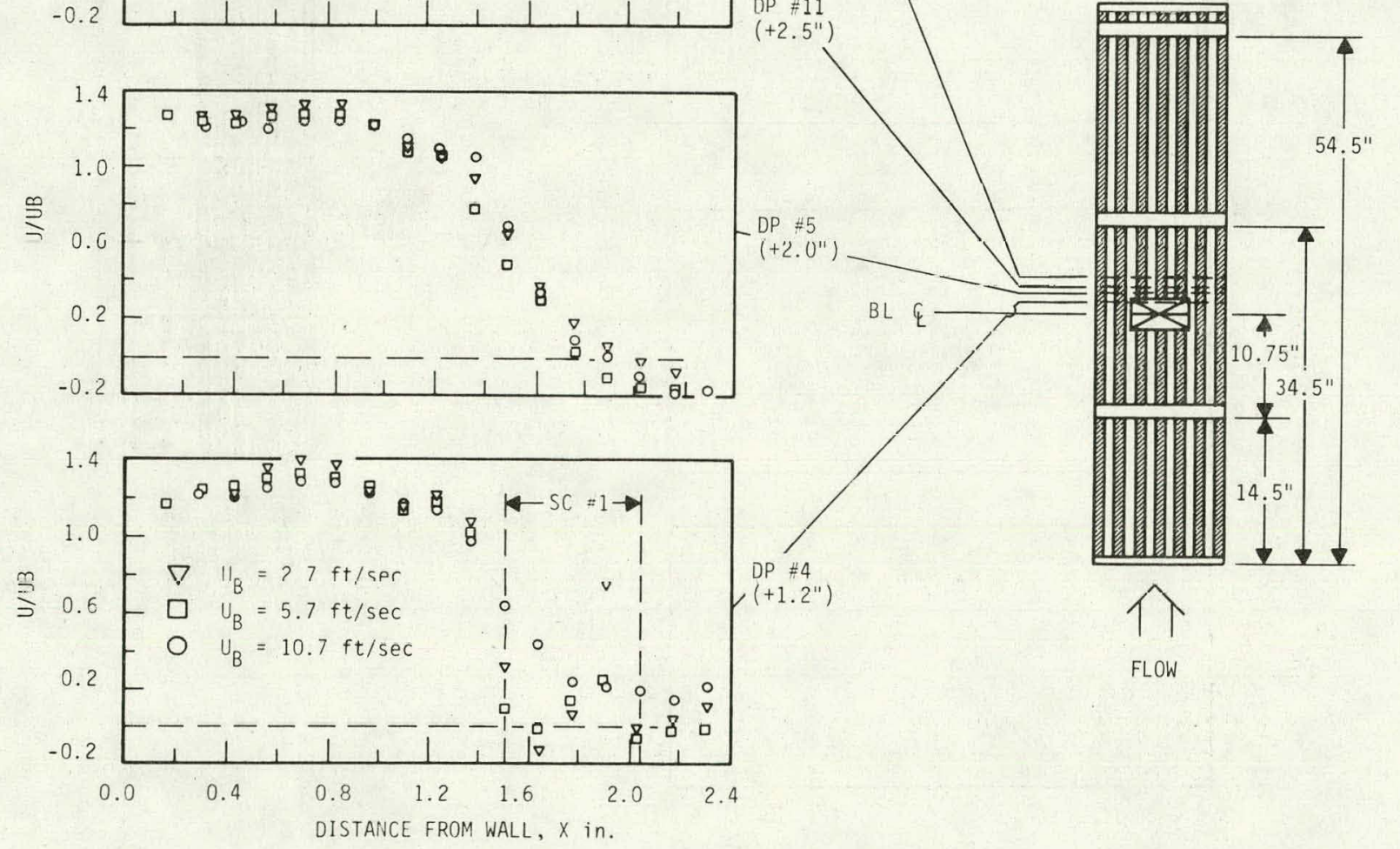

FIGURE 22. Comparisons of Velocity Profiles Near a 90 Percent Blockage Located Midway Between Two Spacers, $U_{B}=2.7,5.7$, and $10.7 \mathrm{ft} / \mathrm{sec}$ 
some scatter in the downstream tapered regions of the blockage. Farther downstream, the three velocity profiles compare surprisingly well. It can be concluded that the velocity distributions resulting from the blockage disturbance were independent of Reynolds number over the range investigated.

Figure 23 presents measured SC \#1 center velocities as functions of axial distance along the bundle at all three flowrates. The overall profiles, which essentially coincide, also indicate that the velocity distributions at the entrance and exit regions to the blockage cluster were not strongly dependent on Reynolds number. The downstream minima were actually "searched out" during data aquisition.

\subsubsection{Typical Data Plane Velocity Profiles}

All velocity profiles obtained at data plane \#5, approximately 2 inches downstream from the blockage axial centerline, are shown in Figures 24 and 25. The data obtained in the inner row, $y=1.763,1.813$, and 1.713 inches, indicate that the subchannel flows were very turbulent since the velocity profiles in the $y$ direction were essentially flat at any $x$ location.

In the subchannel row adjacent to the blockage cluster, $y=1.224$, 1.274 , and 1.174 inches, velocity profiles were present in the $y$ direction. In the inner subchannel, $1.5<x<2.0$ inches, the profiles are very consistent in that the row centerline traverse ( $y=1.224$ inches) and the traverse farthest removed from the blockage cluster ( $y=1.174$ inches) indicated higher velocities than did the traverse made next to the cluster at $y=1.274$ inches. Velocity profiles in the $y$ direction in the outer subchannels, $0.0<x<1.0$ inches, are in good agreement with normal turbulent pipe flow in that velocities along the centerline traverse, $y=1.224$ inches, are higher than the velocities obtained along the adjacent traverses at $y=1.174$ and $y=1.274$ inches. In the transition subchannel between unblocked and 90 percent blocked subchannels, $1.0<x<1.5$ inches, the velocities are random in nature when compared in the $y$ direction. 


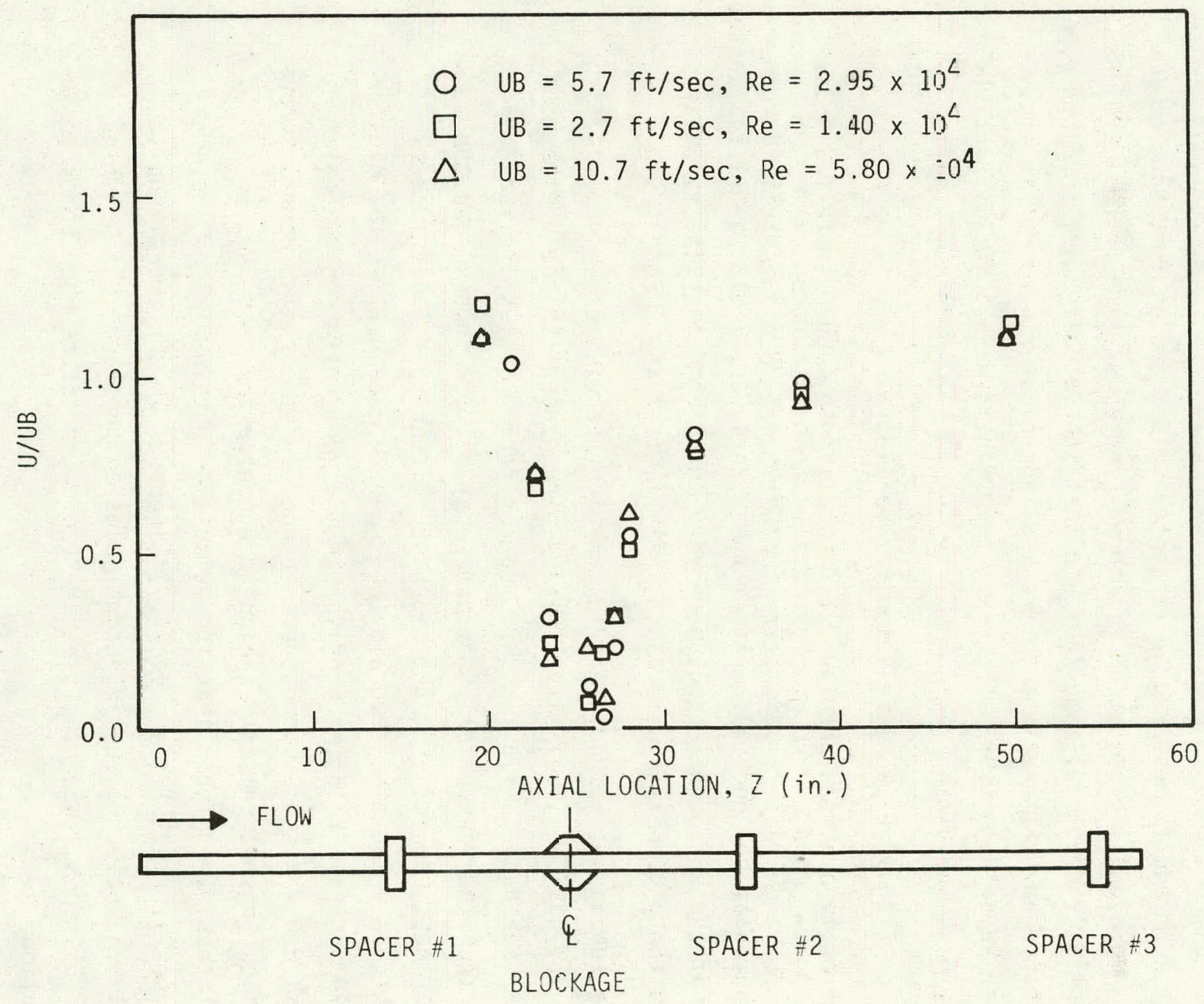

FIGURE 23. Axial Profiles of Subchannel \#l Center Velocities With a 90 Percent Blockage Located Midway: Between

Two Spacers 

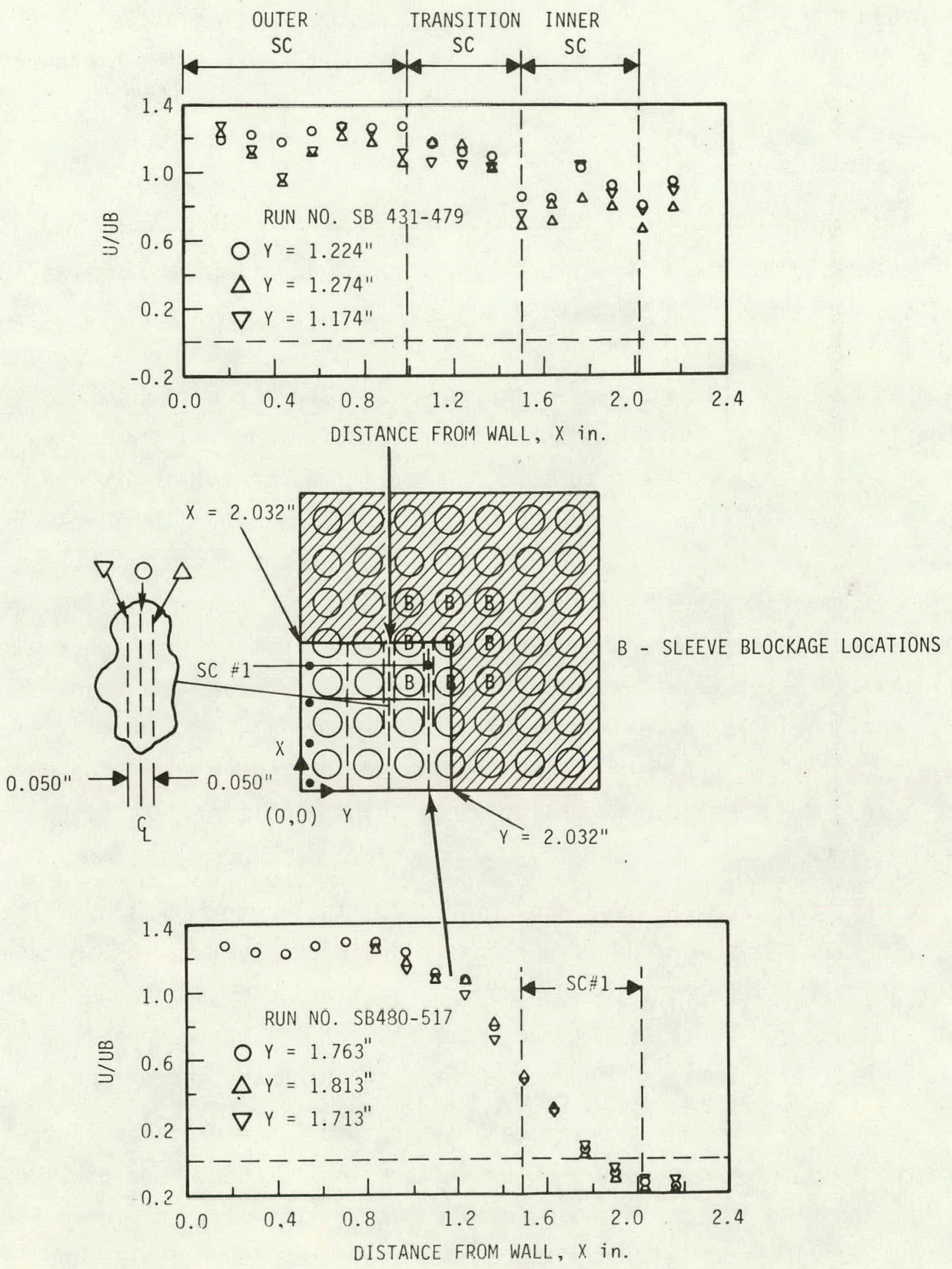

FIGURE 24. Velocity Profiles Along Inner Traverses at Data Plane \#5 (+2.0 in) With a 90 Percent Blockage, $U_{B}=5.7 \mathrm{ft} / \mathrm{sec}$ 
As shown in Figure 25, velocity profiles in the outer subchannel rows, $y=0.685$ and $y=0.110$ inches, indicate developed but relatively high flows, U/UB 27.3 . Higher velocities are reasonable since the blockage cluster diverted flow to the outer subchannels.

\subsubsection{Intensity of Turbulence}

\subsubsection{Intensity Profiles Along the Length of the Bundle}

Intensity profiles at various bundle axial locations and at $y=1.763$ inches are presented in Figures 26 and 27. Local intensity of turbulence values upstream from the blockage cluster $(n 0.05)$ agreed well with those measured with no blockage present, Figure 16. The outer subchannel intensities were 20.04 at the entrance to the blockage, but the intensities measured in SC \# 7 increased to 0.9 . These intensity values are approximately six times those obtained $\sim 7$ subchannel hydraulic diameter downstream from a spacer as presented in Figure 16. Note that in the upstream tapered region of the blockage the intensity values near the center of SC \#I were significantly higher than those in the rod gaps. Generally, higher values of intensity exist in decelerating flows and lower values accompany accelerating flows. By examining the velocity profile of Figure 17, it can be seen that this is precisely the phenomenon that occurred in the upstream tapered region of the blockage since SC \#1 gap velocities were higher than the center velocity.

Downstream from the blockage, Figure 27, the lower intensity values, 20.04, persisted in the outer subchannels and higher values, 210.0 , continued to exist in the innermost subchannels. This trend continued downstream $\sim 2.5$ inches ( $\sim 5$ diameters) but the intensity profile was essentially recovered 3.5 inches ( $\sim 7$ diameters) downstream from the blockage centerline.

Figures 28 and 29 present intensity of turbulence profiles that existed near the 90 percent blockage at $U_{B}=2.7$ and $10.7 \mathrm{ft} / \mathrm{sec}$. The profiles exhibit the same trends as those obtained at $U_{B}=5.7 \mathrm{ft} / \mathrm{sec}$. Relatively high intensities were measured in the blocked inner subchannels, and intensities typical of those obtained in undisturbed well developed flow were measured in outer subchannels. By comparing the profiles at all three 

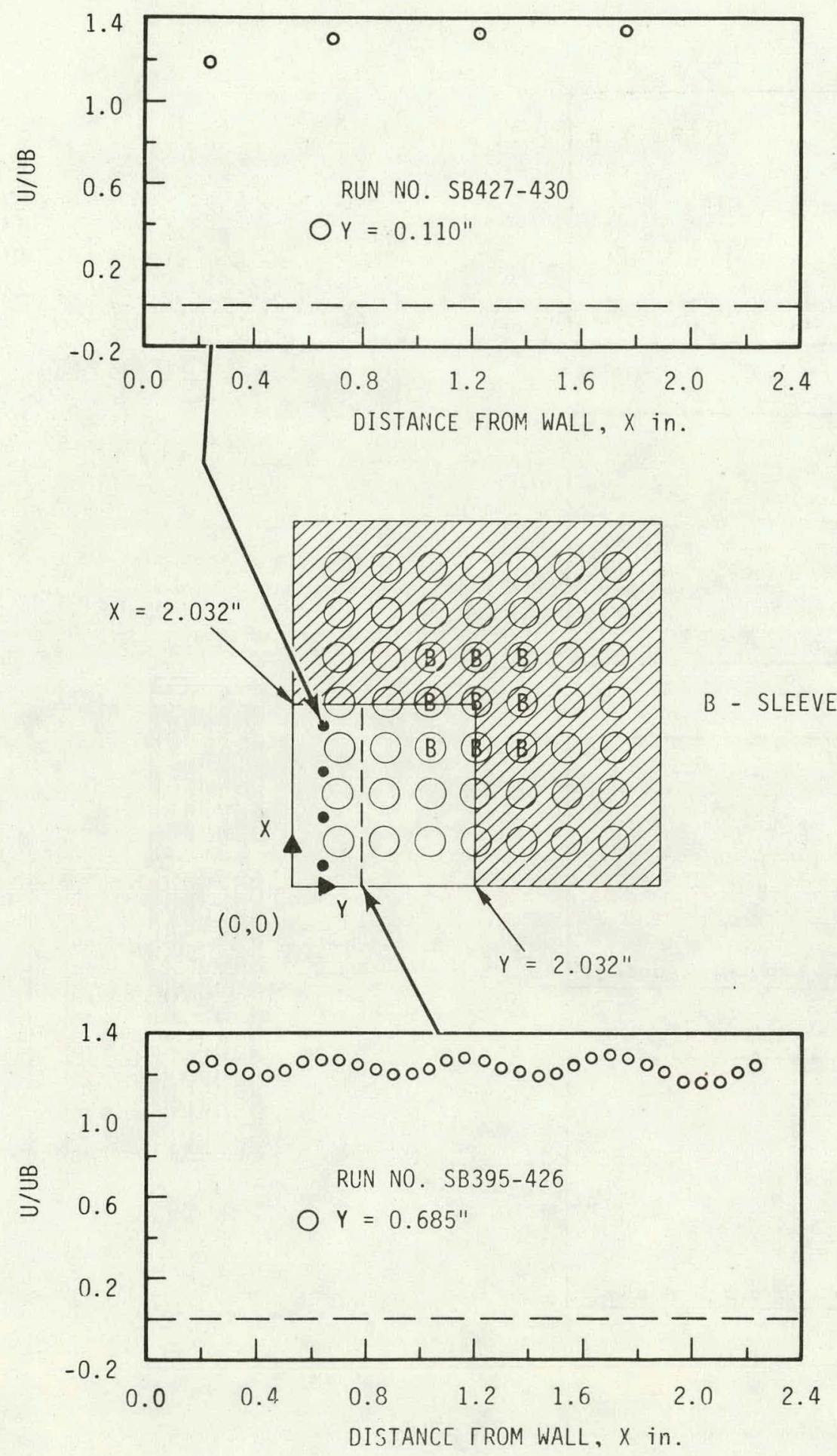

FIGURE 25. Velocity Profiles Along Outer Traverses at Data Plane \#5 (+2.0 in) With a 90 Percent Blockage, $U_{B}=5.7 \mathrm{ft} / \mathrm{sec}$ 

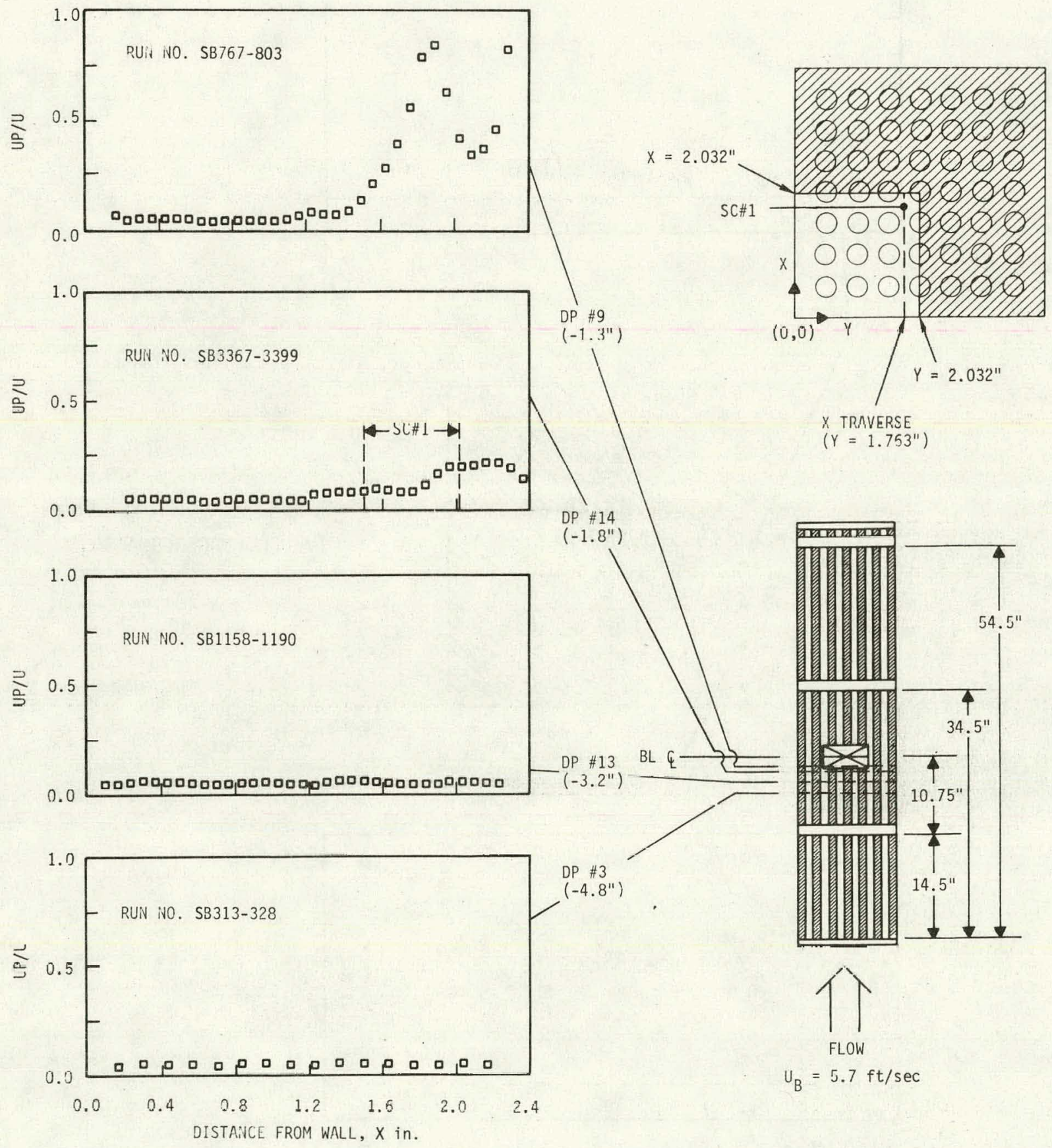

FIGURE 26. Intensity Profiles Upstream From a 90 Percent. Blockage Located Midway Between Two Spacers, $U_{B}=5.7 \mathrm{ft} / \mathrm{sec}$ 

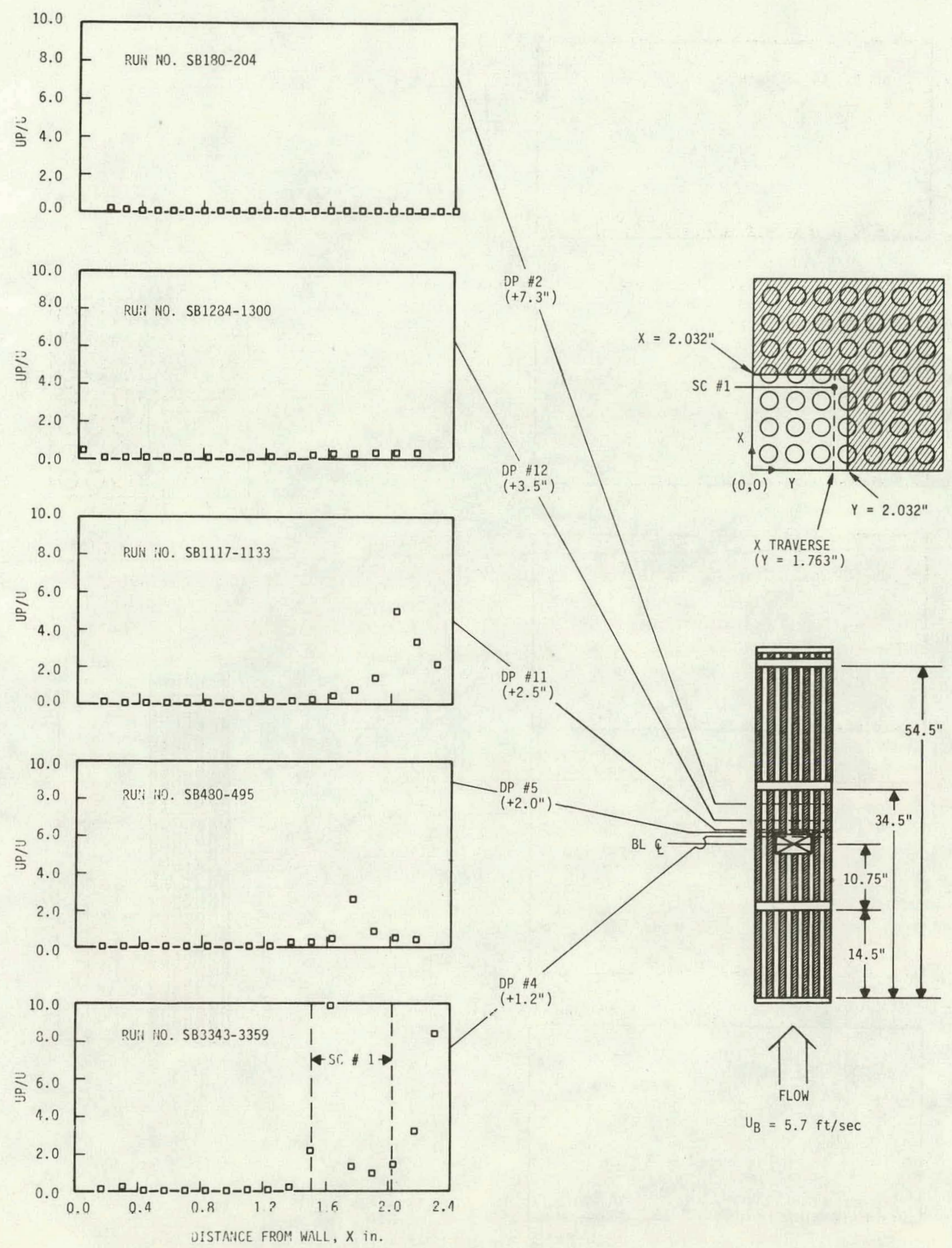

$$
\begin{aligned}
& X \text { TRAVERSE } \\
& \left(Y=1.763^{n}\right)
\end{aligned}
$$
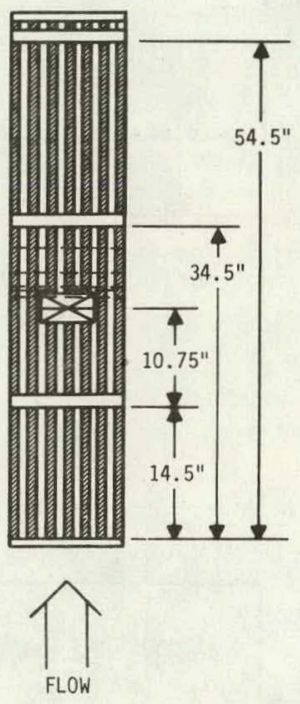

$U_{B}=5.7 \mathrm{ft} / \mathrm{sec}$

FIGURE 27. Intensity Profiles Downstream From a 90 Percent Blockage Located Midway Between Two Spacers, $U_{B}=5.7 \mathrm{ft} / \mathrm{sec}$ 


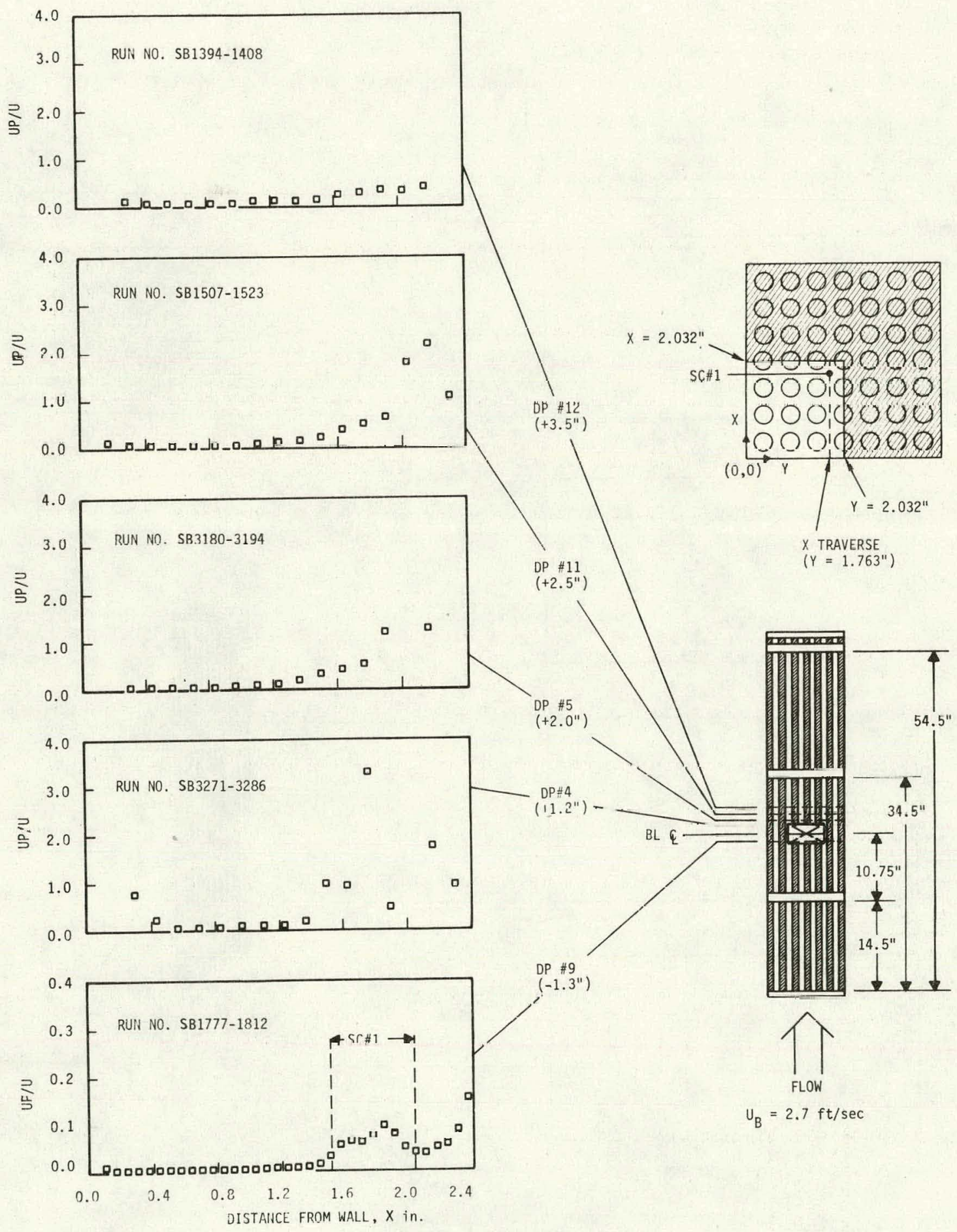

FIGURE 28. Intensity Profiles Near a 90 Percent Blockage Located Midway Between Two Spacers, $U_{B}=2.7 \mathrm{ft} / \mathrm{sec}$ 


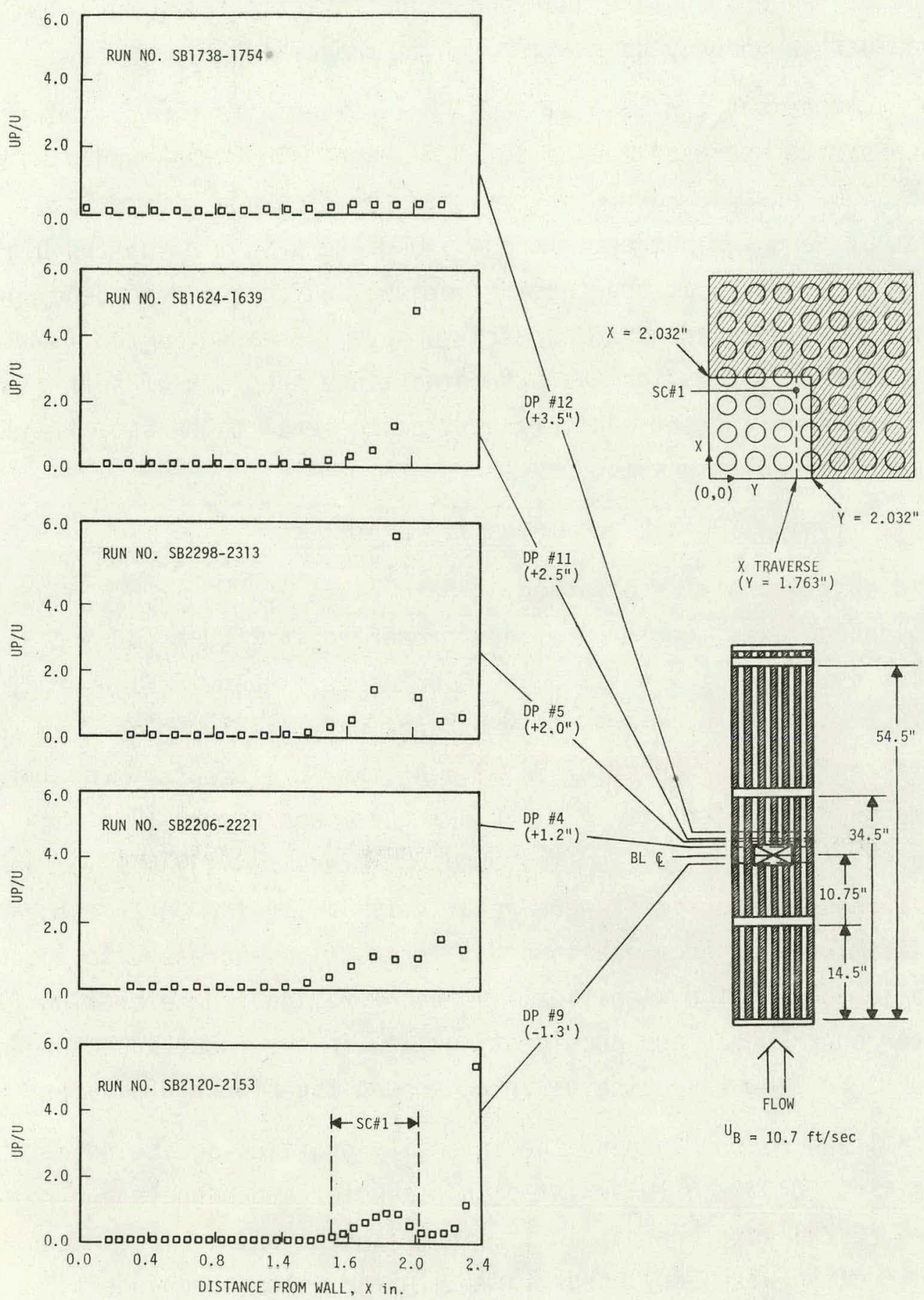

FIGURE 29. Intensity Profiles Near a 90 Percent Blockage Located Midway Between Two Spacers, $U_{B}=10.7 \mathrm{ft} / \mathrm{sec}$ 
flow rates, Figure 30 , it appears that intensity magnitudes were essentially independent of Reynolds number over the range investigated. However, if a Reynolds number dependency does exist, it is random in nature.

Such a comparison can also be made by considering a plot of SC \#1 center intensities as functions of axial distance along the bundle, Figure 31 . Intensity values upstream and downstream of the blockage cluster are independent of Reynolds number. In the immediate proximity of the blockage cluster, intensity data at the three flowrates indicate a dependency on Reynolds number. The intensity appears to have increased as the flow decreased, but nn rnrrelation was attcmptcd since the lack of sufficient data would not permit a satisfactory confidence level to be established for such an empirical relationship.

\subsubsection{Typical Data Plane Intensity Profiles}

A11 intensity profiles obtained at data plane \#5, 2 inches downstream from the blockage axial centerline, are presented in Figures 32 and 33. The profiles obtained at $Y=1.763 \pm 0.050$ inches, shown in Figure 32, indicate that local intensities of turbulence were nearly uniform in the $y$ direction except at the center of SC \#1. At the SC \#1 center, the intensity nearest the bundle centerline, $y=1.813$ inches, was higher than the intensities farther removed from the bundle centerline at $y=1.763$ and $y=1.713$ inches. Intensities were relatively low in the outer subchannels, 0.04, indicating flow acceleration, but intensities increased to approximately 3.5 in SC \#1 which signifies flow deceleration. Accelerating flow in the outer subchannels and decelerating flow in the inner subchannels was reasonable since flow was being diverted around the blockage cluster.

At $y=1.224 \pm 0.050$ inches, the intensity profiles again indicate that low inlensities $(0.05-0.10)$ exisled in the outer subchannels and relatively high values $(0.25)$ were present in the inner subchannels. The intensities in the $y$ direction were very nonuniform. In the outer subchannels, $x<0.8$ inches, the intensities obtained along the row cenlerline traverse, $y=1.224$ inches, were lower $(0.05$ vs. 0.10$)$ than those measured on either side, $y=1.174$ and 1.274 inches. In the inner subchannel, $1.5 \leq x \leq 2$ inches, 


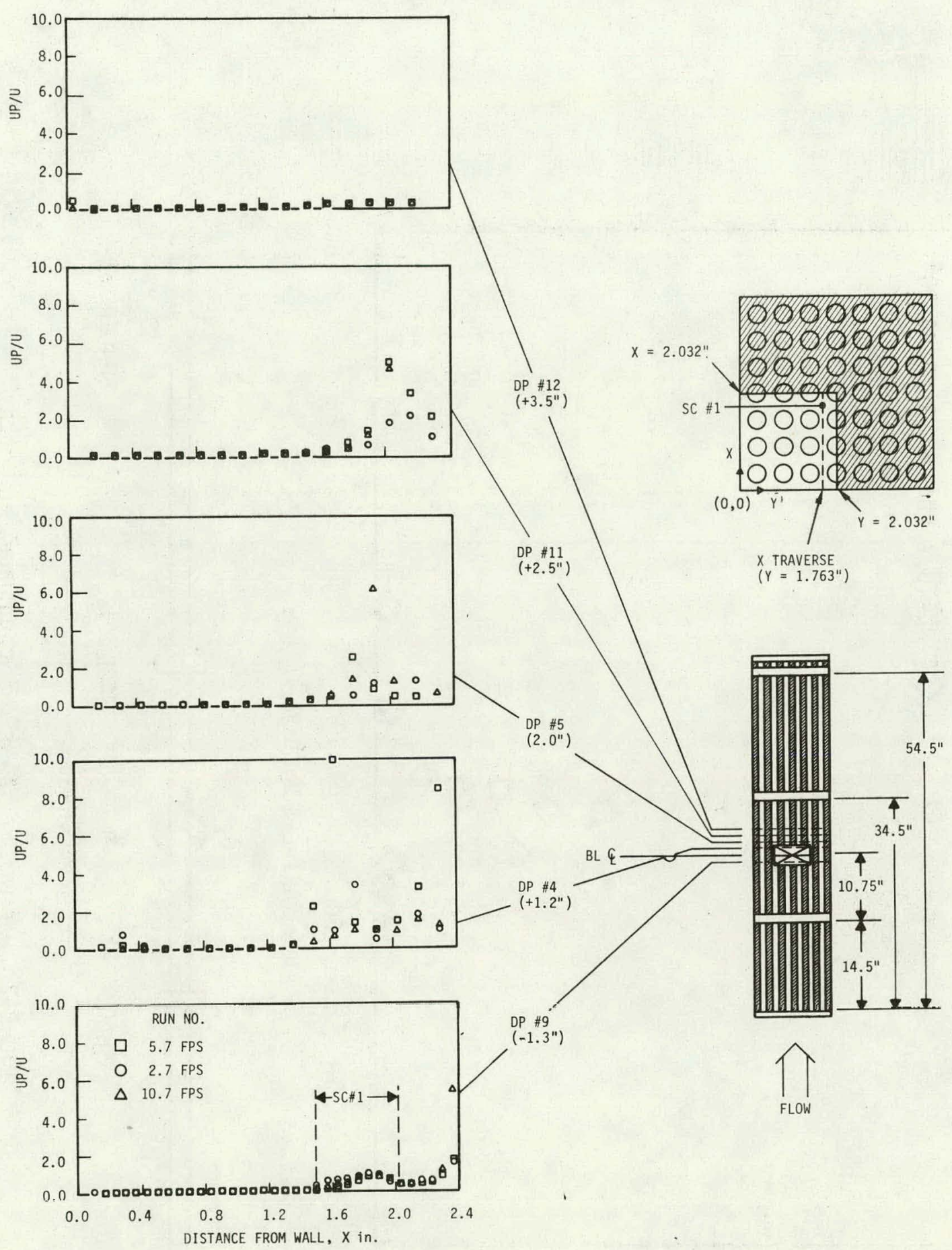

FIGURE 30. Intensity Profiles Near a 90 Percent Blockage Located Midway Between Two Spacers, $U_{B}=2.7$, 5.7 , and $10.7 \mathrm{ft} / \mathrm{sec}$ 

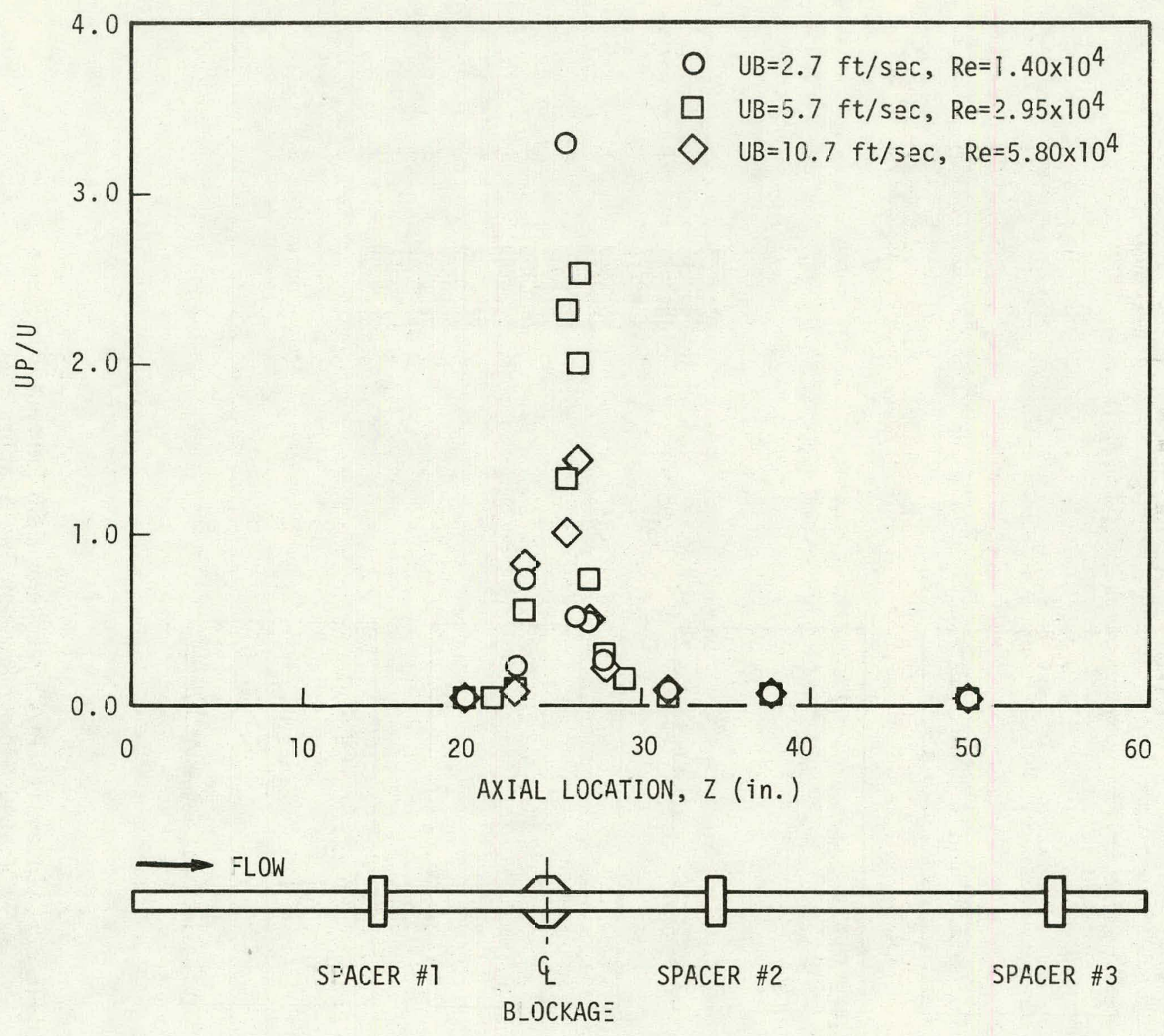

FIGURE 31. Axial Profiles of Subchannel \#1 Center Intersities With a 90 Percent B1 ockage, $U_{B}=2.7,5.7$, and $10.7 \mathrm{ft} / \mathrm{sec}$ 


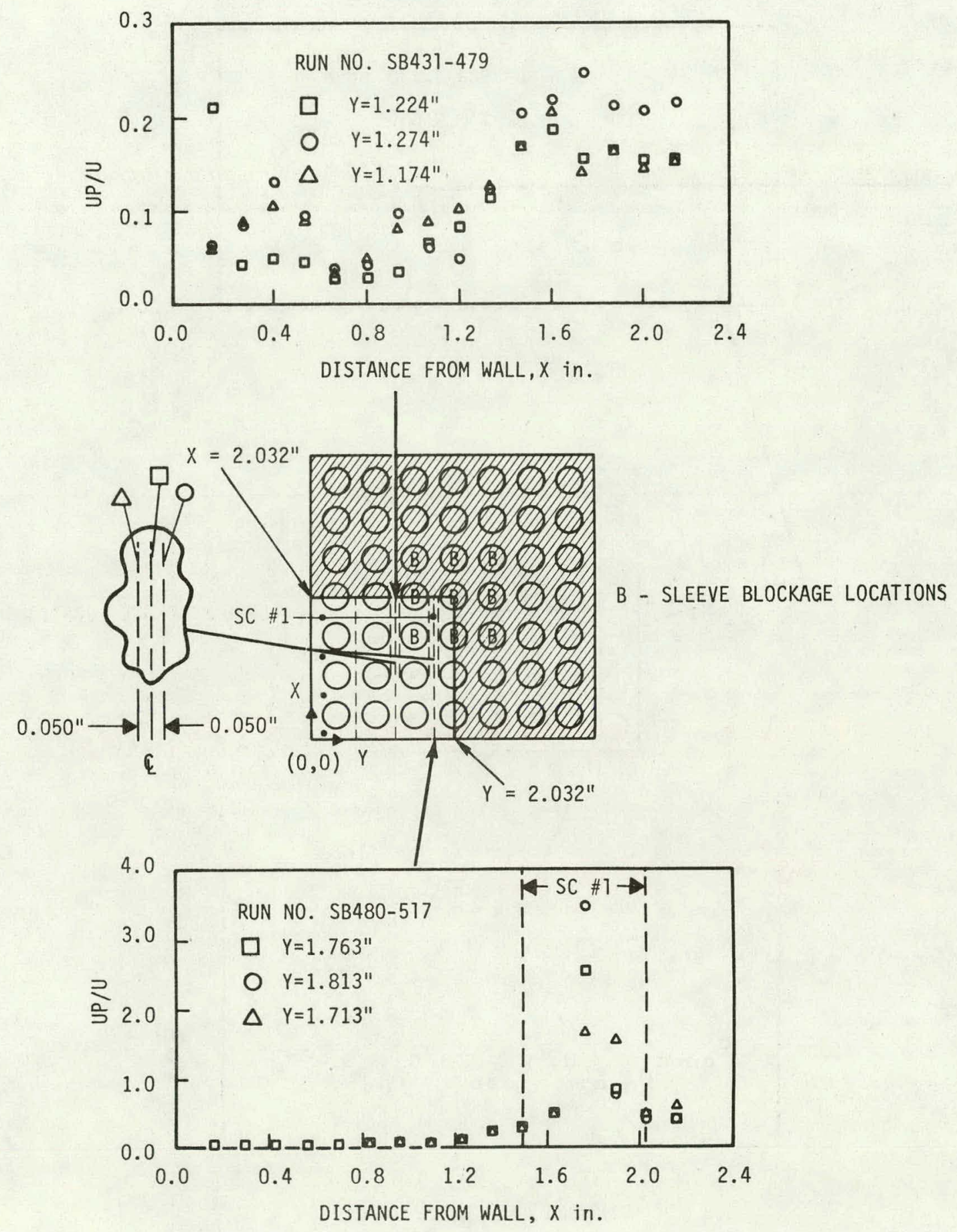

FIGURE 32. Intensity Profiles Along Inner Traverses at Data Plane \#5 (+2.0 in) With a 90 Percent Blockage, $U_{B}=5.7 \mathrm{ft} / \mathrm{sec}$ 


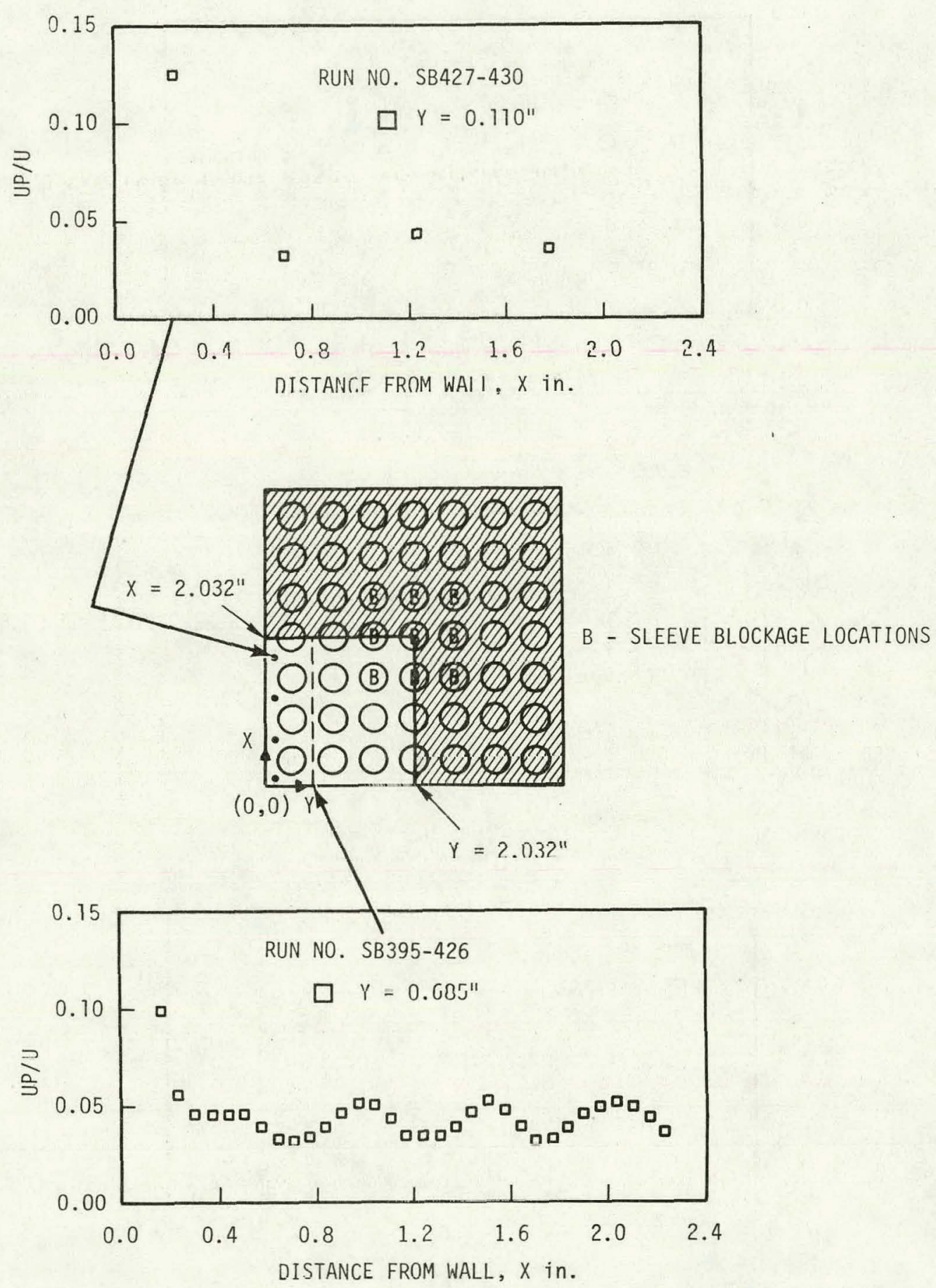

FIGURE 33. Intensity Profiles Along Outer Traverses at Data P1ane \#5 (+2.0 in) With a 90 Percent Blockage, $U_{B}=5.7 \mathrm{ft} / \mathrm{sec}$ 
the intensities measured nearest the blockage cluster, $y=1.274$ inches, are slightly higher than those removed from the blockage, $y=1.224$ and 1.174 inches.

The intensity profiles obtained in the outer subchannels, $y=0.685$ and 0.110 inches, shown in Figure 33, are much lower $(20.03-0.05)$ than those measured in the inner subchannels. The lower values again indicate that accelerating flow existed in the unblocked subchannels.

\subsection{PERCENT BLOCKAGE ADJACENT TO A SPACER}

Velocity and intensity of turbulence results obtained with a 90 percent blockage located adjacent to and upstream from a spacer are discussed in this section. Data at a Reynolds number of $2.9 \times 10^{4}\left(U_{B}=5.7 \mathrm{ft} / \mathrm{sec}\right)$ were obtained. The velocity reduction and recovery profiles resulting from the blockage disturbance were similar to those obtained with the cluster located midway between two spacers. A recirculation zone was detected immediately downstream from the blockage cluster but the exact length of the zone could not be determined since the spacer interferred with LDA measurements. A much longer flow recovery length, > 50 subchannel hydraulic diameters, was required when the blockage was adjacent to a spacer.

Local intensity of turbulence profiles with the blockage adjacent to a spacer were also similar to those detected with the blockage cluster located midway between spacers. Immediately upstream and downstream from the blockage, increases in local intensity from $\sim 0.05$ to $\sim 1.5$ were detected. Even though these intensity values were lower than those measured with the blockage midway between spacers, the recover length was found to be independent of blockage location.

\subsubsection{Axial Velocity}

\subsubsection{Velucity Reduction and Recovery}

Velocity profiles near a 90 percent blockage cluster located just upstream from spacer \#2 are presented in Figures 34 and 35 . The upstream velocity profiles of Figure 34 are similar to those obtained with the 


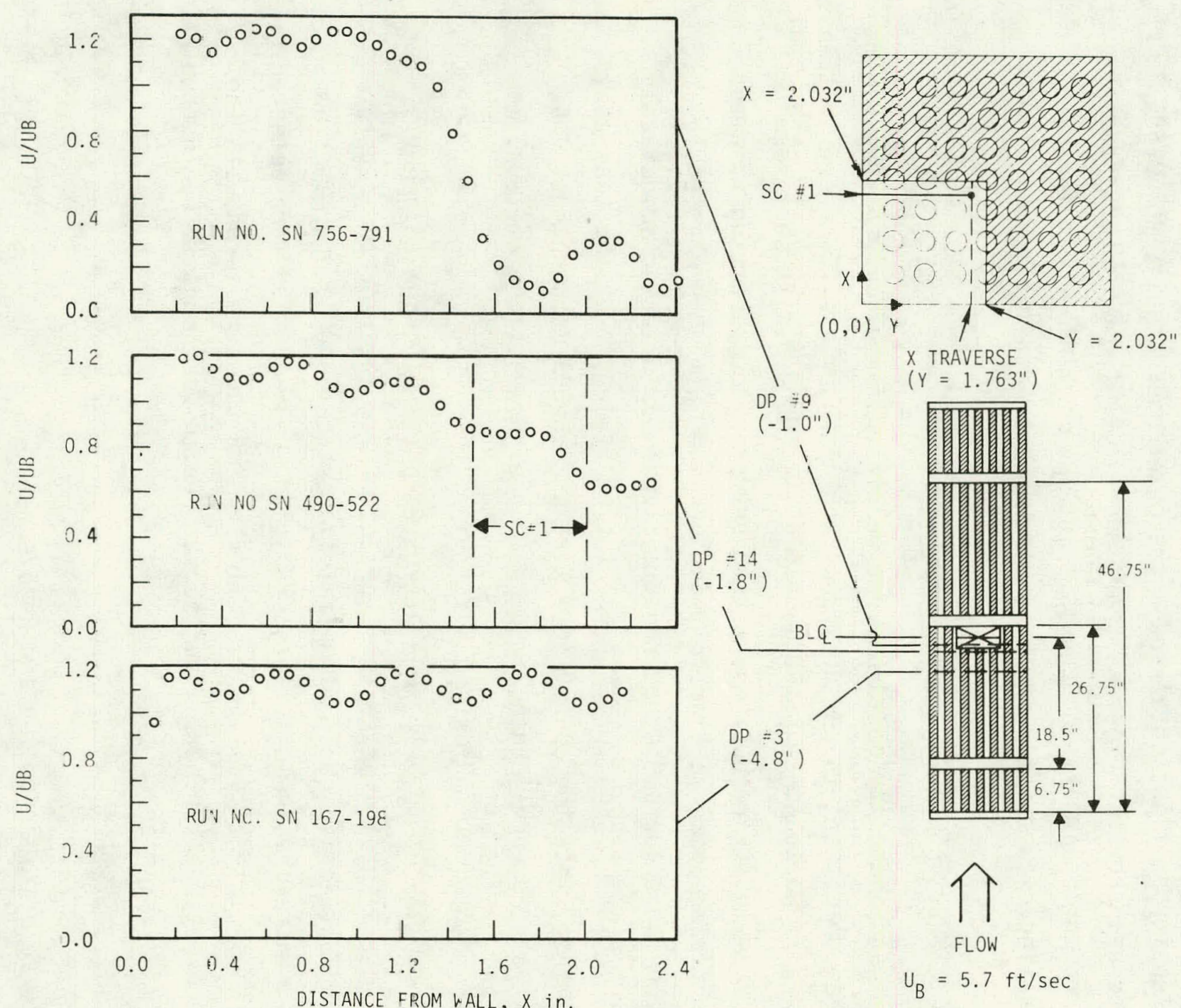

FIGURE 34. Velocity Profiles Upstream Frcm a 90 Percent Blockage Located Adjacent to Spacer \#2, $U_{B}=5.7 \mathrm{ft} / \mathrm{sec}$ 

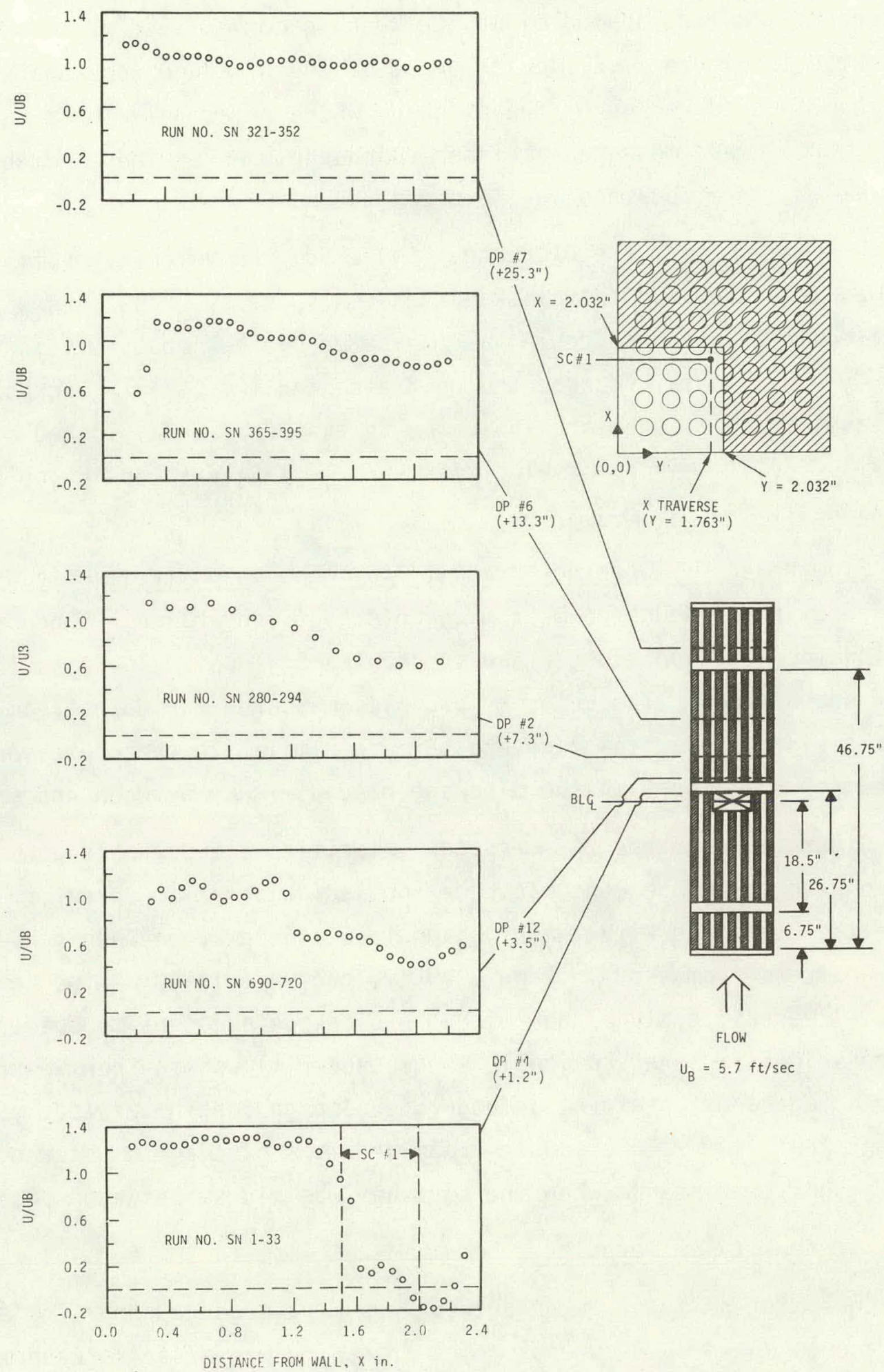

FIGURE 35. Velocity Profiles Downstream From a 90 Percent Blockage Located Adjacent to Spacer \#2, $U_{B}=5.7 \mathrm{ft} / \mathrm{sec}$ 
90 percent cluster located midway between spacers \#1 and \#2 previous $7 y$ presented in Figure 17. The influence of the blockage was apparent in the upstream tapered region of the blockage where relatively low axial velocities $\left(U / U_{B} \approx 0.1\right)$ were measured at inner subchannel centerlines. Higher velocities, $\mathrm{U} / \mathrm{U}_{\mathrm{B}} \approx 1.2$, were obtained in the outer subchannels.

Downstream from the blockage, Figure 35, the velocity profiles appear much as they did with the blockage between spacers. Flow reversals were detected in the tapered region as indicated by the negative velocities $\left(U / U_{B} \approx-0.2\right)$ obtained near the bundle centerline at +7.2 inches. Vivid decreases in velocities are indicated in the 90 percent blocked subchannel $(S C \# 1)$. Relatively high velocities $\left(U / U_{B} \approx 1.3\right)$ existed in the exterior subchannets.

Flow reversals were not present 0.5 inches downstream of spacer \#2, i.c., 3.5 inches downstream from the blockage centerline. Subchannels containing the blockage cluster had substantially lower velocities than the outer subchannels. The velocity profiles measured far downstream from the blockage indicate a flow recovery pattern similar to those previously presented for the case with the blockage placed midway between spacers.

Figure 36 compares SC \#1 center velocities along the length of the bundle with the 90 percent blockage located adjacent to spacer \#2 with velocities obtained with the blockage located midway between spacers \#1 and \#2. Upstream from the blockage cluster, the velocities at the centers of SC \#1 were slightly higher with the blockage adjacent to spacer \#2. Higher velocities are realizable since spacer \#1 was farther upstream from the blockage and therefore, a longer developing length existed. It is evident that flow recovery downstream from the blockage cluster occurred over a shorter distance when the blockage was midway between spacers.

\subsubsection{Intensity of lurbulence}

Local intensity of turbulence values were measured near the 90 percent blockage as shown in Figure 37 . The intensity profiles are essentially the same as those presented in Figures 26 and 27 with the blockage midway between spacers \#1 and \#2. The turbulence upstream from the blockage cluster was 


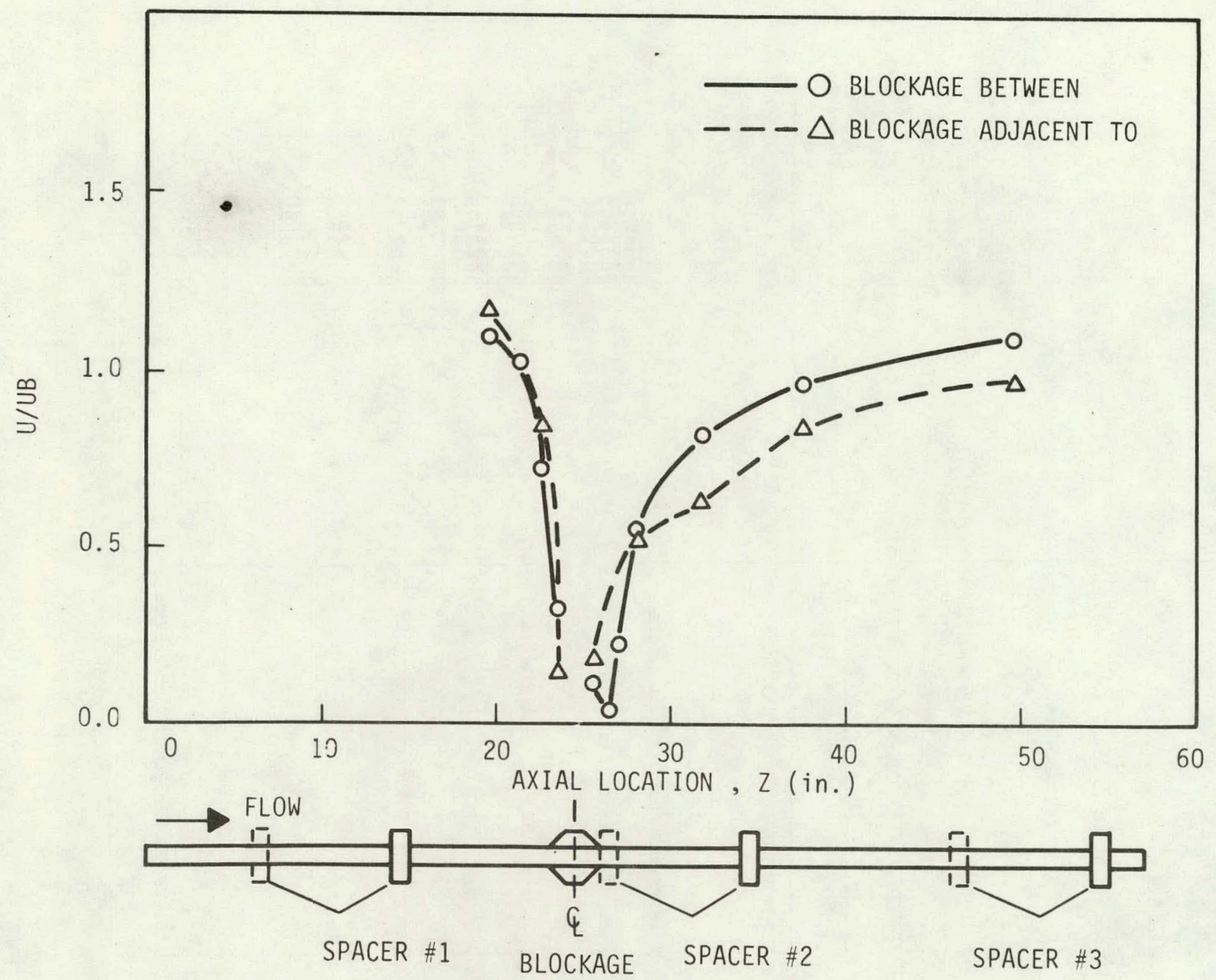

FIGURE 36. Axial Profiles of Subchannel \#1 Center Velocities With a 90 Percent Blockage Located Between Two Spacers and Located Adjacent to a Spacer, $U_{B}=5.7 \mathrm{ft} / \mathrm{sec}$ 


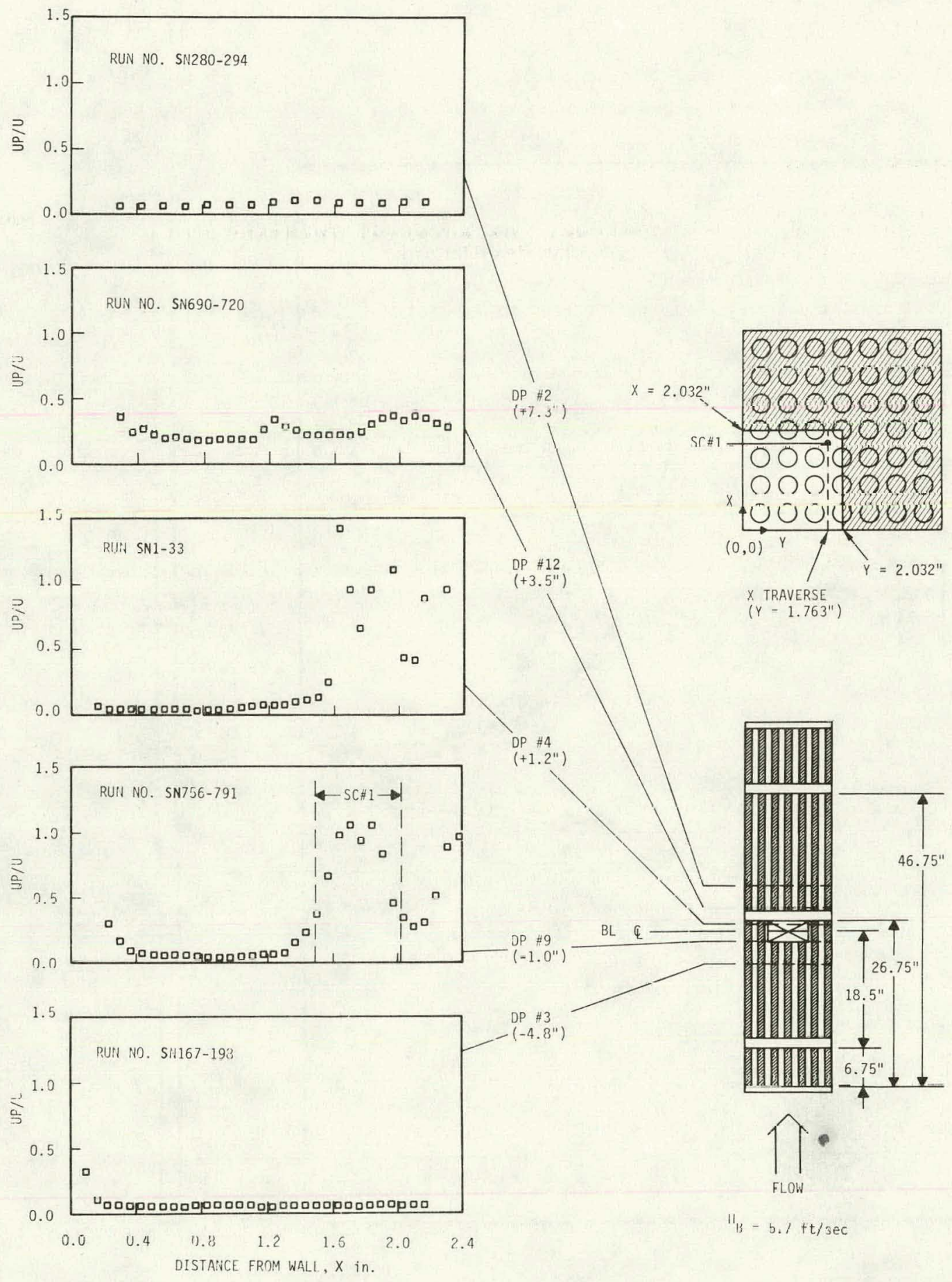

FIGURE 37. Intensity Profiles Near a 90 Percent Blockage Located Adjacent to Spacer \#2, UB $=5.7 \mathrm{ft} / \mathrm{sec}$ 
20.05 which agrees wel1 with the bare rod data of Figure 16. In the tapered region of the blockage both upstream and downstream from the cluster, the intensity increased by a factor of approximately 20 , from 0.05 to 1.0 . Peaks in intensity occurred at the centers of SC \#1 while minima were detected at rod gaps. Farther downstream (+3.5 in.), the intensity began to recover from the effects of the blockage. At an axial location of $+7.3 \mathrm{in}$. the intensity profile was essentially developed.

A comparison of intensities measured at the center of SC \#1 with the blockage located midway between spacers \#1 and \#2 to intensities obtained with the blockage located adjacent to spacer \#2 is presented in Figure 38. For the most part, the turbulence was not dependent on the blockage location relative to the spacers. In the downstream tapered region of the blockage, the intensity with the blockage cluster located midway between spacers was slightly higher than with the blockage adjacent to spacer \#2. The downstream recovery profiles for the two blockage locations were essentially identical.

\subsection{PERCENT BLOCKAGE MIDWAY BETWEEN SPACERS}

Velocity and intensity of turbulence results obtained with a 70 percent blockage located midway between two spacers are presented in the following sections. The velocity profiles measured at selected locations along the length of the bundle indicate that the flow was not influenced by the 70 percent blockage as severely as by the 90 percent blockage. The recirculation zone detected immediately downstream from the blockage cluster extended for less than three subchannel hydraulic diameters. Even thouah the 70 percent blockage did not disturb the flow as severely as the 90 percent blockage, the required flow recovery length was approximately the same for the two blockage severities.

Local intensity of turbulence values increased by as much as two orders of magnitude near the blockage cluster ( 20.05 to $\sim 2.0$ ). The recovery length for intensity was essentially independent of blockage severity even though lower intensity values were measured in the close proximity of the cluster with a 70 percent blockage. 

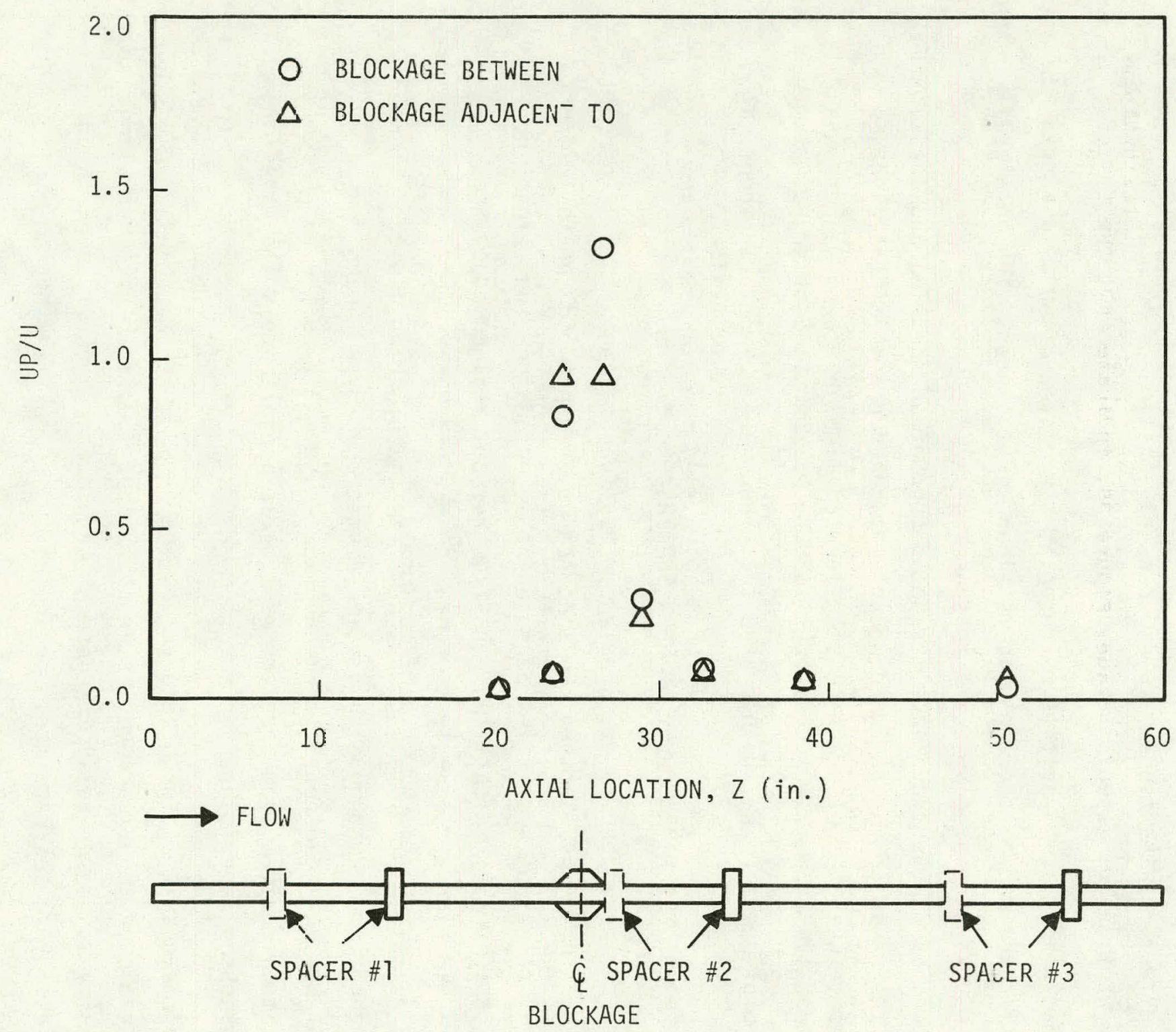

FI3URE 38. Axial Frofiles of Subchannel \#1 Center Intensities With a 90 Percent Blockage Located Midway Between Spacers \#1 and $\# \hat{c}$ and Located Adjacent to Spacer \#2, $U_{B}=5.7 \mathrm{ft} / \mathrm{sec}$ 


\subsubsection{Axial Velocity}

\subsubsection{Velocity Reduction and Recovery}

Figures 39 and 40 present velocity profiles near a 70 percent sleeve blockage located midway between spacers \#1 and \#2. The two velocity traverses obtained upstream from the blockage, Figure 39, indicate that the flow was well developed prior to the cluster and that the influence of the blockage was present 0.8 inches upstream from its axial centerline.

Velocity profiles obtained downstream from the 70 percent blockage cluster are shown in Figure 40. The profile measured in the tapered region of the blockage, 0.8 inches downstream from the axial centerline, indicates flow reversals did occur. The recirculation zone existed for less than 3 subchannel hydraulic diameters downstream from the blockage axial center1ine. Negative flows were detected in the gap regions while jetting was obtained near the centerline of SC \#1. The lack of flow reversals 1.4 inches downstream from the blockage centerline indicates redevelopment of the flow field had been initiated. Evidence that jetting occurred in SC \#1 was sti11 present as indicated by the relatively high velocity at the subchannel center.

Velocity profiles farther downstream from the blockage show flow redevelopment in progress. Jetting in SC \#1 was not present, as indicated by the relatively "flat" velocity profile. Velocity maximums in the outer subchannel centers and minimums in the outer channel gaps were beginning to form. The flow was essentially redeveloped 25.3 inches downstream from the blockage cluster.

The blockage entrance and exit axial velocity profiles are better visualized in Figure 41 where SC \#1 center velocities are presented along the length of the bundle. The axial velocity profile obtained with the 90 percent blockage is included for comparison purposes. The velocity profiles in the entrance region to the blockage cluster were similar for the two blockage severities. The axial location of minimum velocities, which were actually "searched out", appear to coincide. 


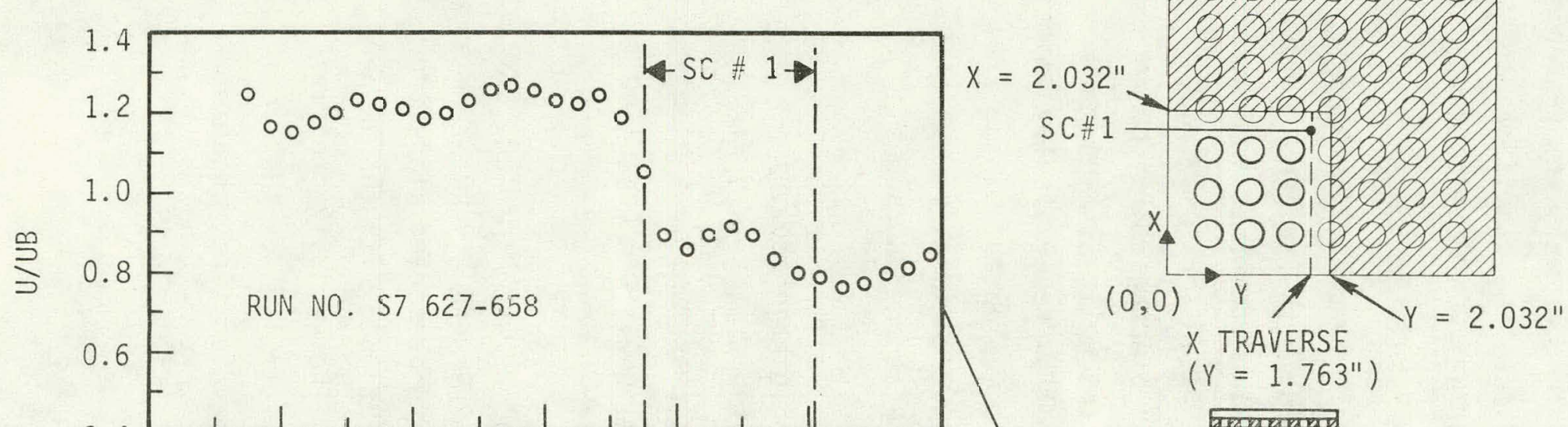

0.4

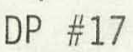

$\left(-0.8^{\prime \prime}\right)$
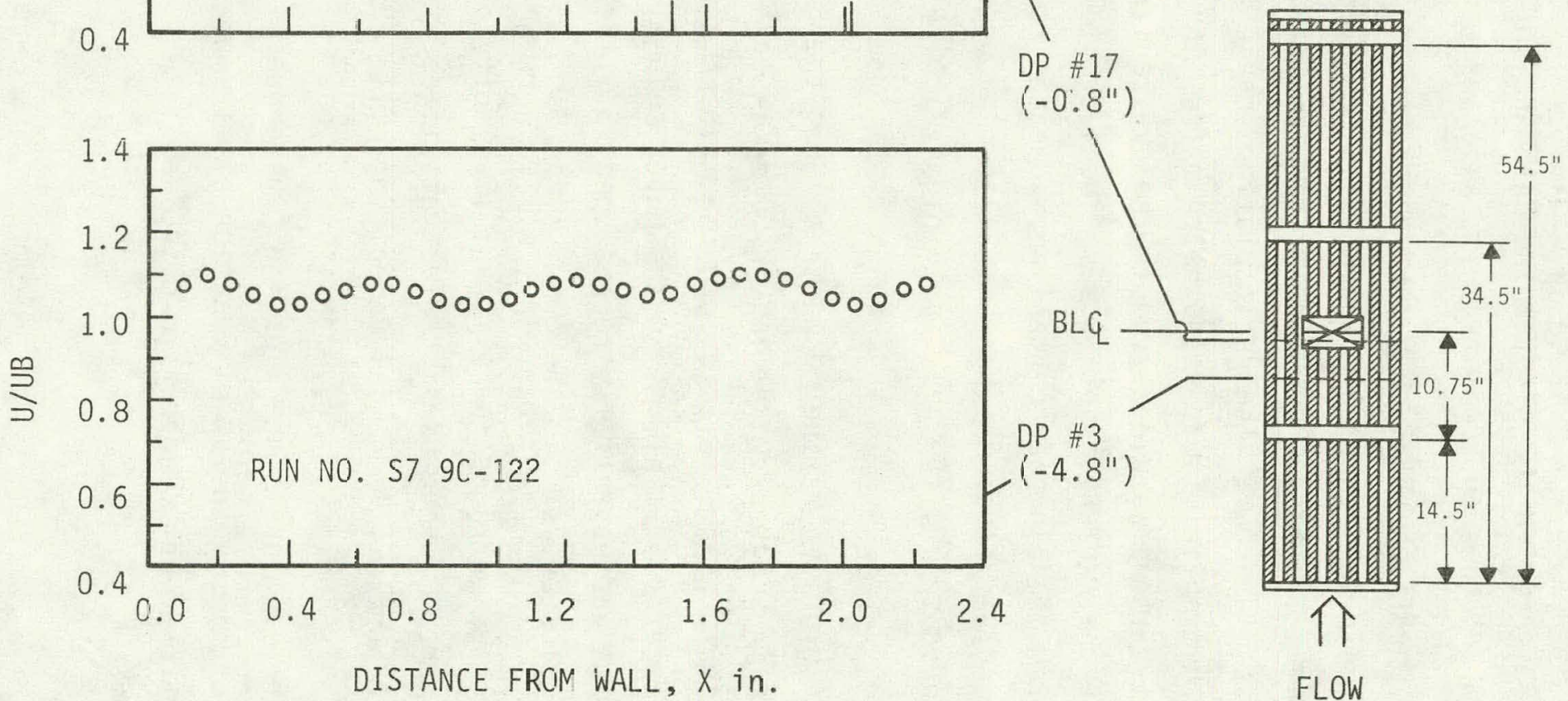

FLOW

$U_{B}=5.7 \mathrm{ft} / \mathrm{sec}$

FIGURE 3c. Velocity Prcfiles Upstream From a 70 Percent Blockage Located Midwãy Between Two Spacers, $U_{B}=5.7 \mathrm{ft} / \mathrm{sec}$ 


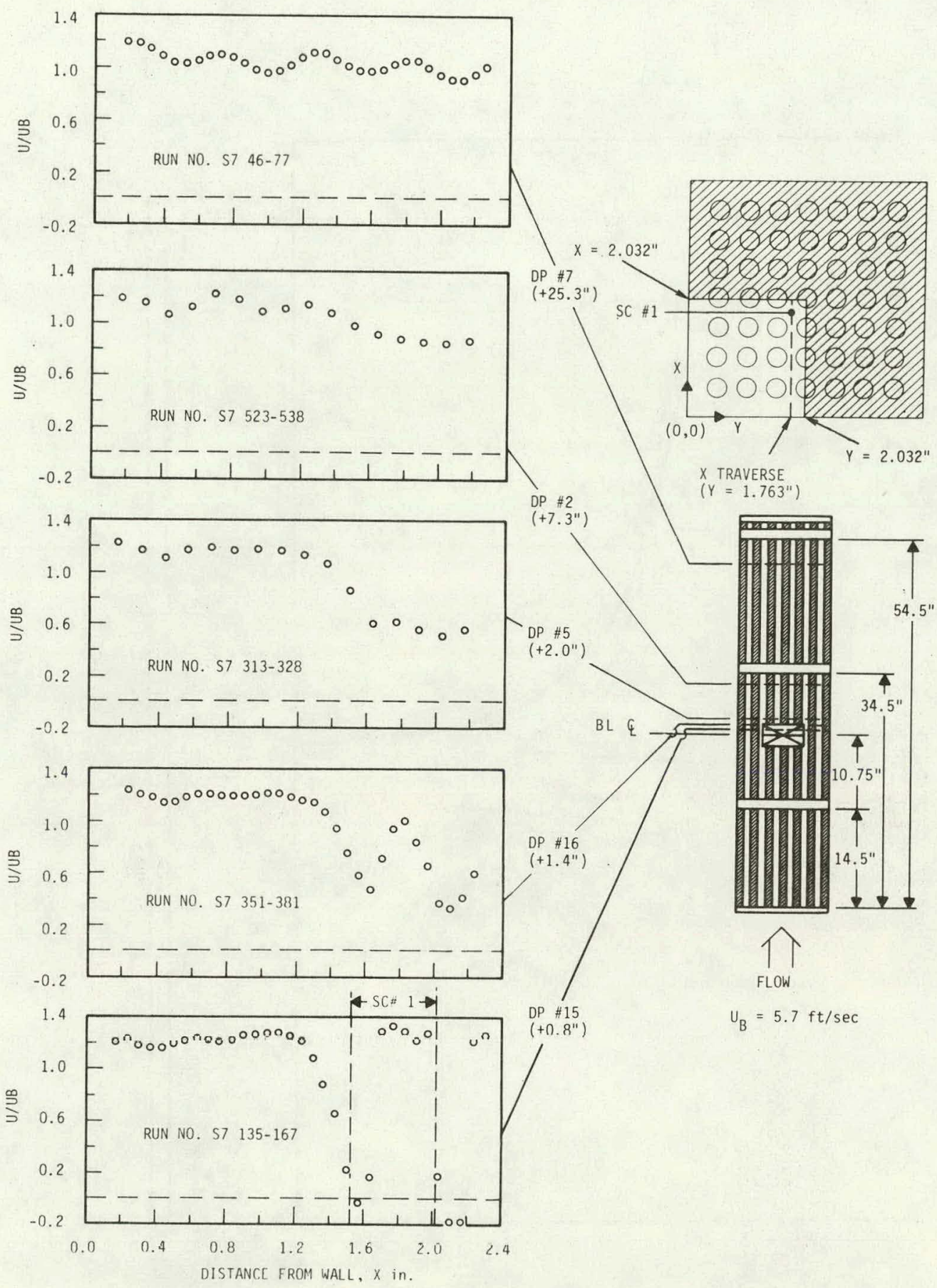

FIGURE 40. Velocity Profiles Downstream From a 70 Percent Blockage Located Midway Between Two Spacers, $U_{B}=5.7 \mathrm{ft} / \mathrm{sec}$ 


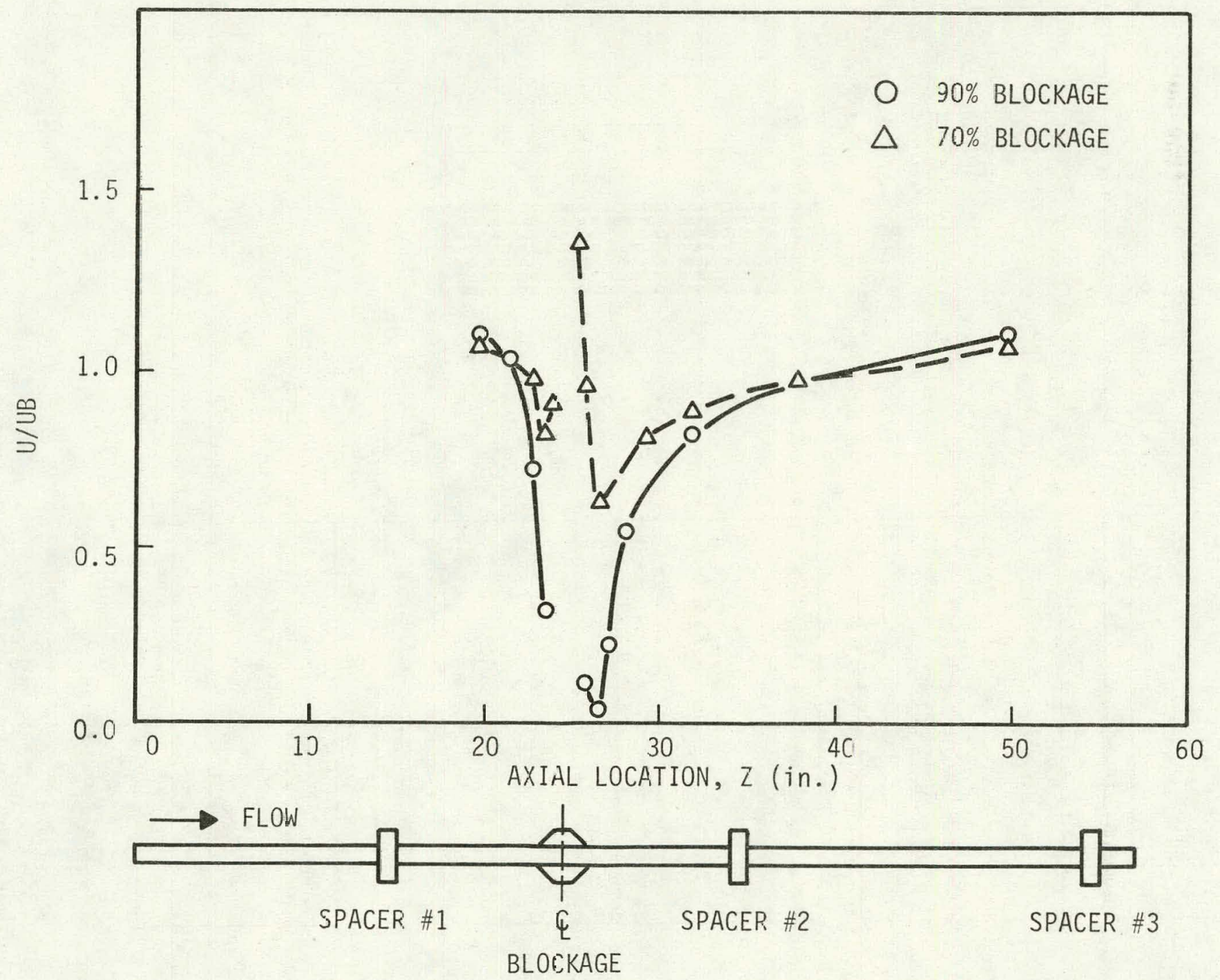

FIGUR $=41$. Axial Profiles of Subchannel \#1 Center Velocities with a 70 and a Si] Percent Blockage Located Midway Between Two Spacers, $U_{B}=5.7 \mathrm{ft} / \mathrm{sec}$ 
At the exit region of the blockage, the velocity profile obtained with the 70 percent blockage exhibits a jetting characteristic that was not measured when using the 90 percent blockage. Jetting may not have been detected with the 90 percent blockage because the measuring volume could not be positioned as close to the blockage axial centerline as was possible with the 70 percent blockage. It was possible to locate a data plane only as close as 1.3 inches above the 90 percent blockage, while the data plane could be positioned as near as 0.8 inches above the 70 percent blockage. The inability to measure velocities closer to the axial centerline of the 90 percent blockage would not appear to completely explain the absence of jetting. Possibly, the flowrates in the 90 percent blocked inner subchannels were extremely low and jetting was minimal or simply did not exist.

The velocity profiles immediately downstream from the blockage cluster indicate that the flow with the 90 percent blockage redeveloped more rapidly than that with the 70 percent blockage when compared on a relative basis; i.e., 1.5 inches from the minimums of the two profiles, the flow with the 90 percent blockage recovered from $U / U B=0.05$ to 0.55 , whereas the flow with the 70 percent blockage recovered from $U / U B=0.62$ to 0.75 . It is assumed that a shorter flow recovery length required for the 90 percent blockage was due to larger driving potentials present with the more maldistributed flow which accompanied the more severe blockage. The influence of the blockage severities was nullified after the flow passed through spacer \#2.

\subsubsection{Typical Data Plane Velocity Profiles}

A comparison of velocity profiles measured at a single cross section (data plane \#15) located 0.8 inches downstream from the 70 percent blockage can be made by referring to Figure 42. The lower plot presents profiles at inner traverses, $y=1.763$ and 1.224 inches. Velocities in the outer subchannels were relatively high for both traverses. Velocity profiles obtained in the inner subchannels indicate that velocities in the subchannel gaps were relatively low but velocities at subchannel centerlines were surprisingly high. Again, the high velocities indicate that jetting occurred in the 70 percent blocked subchannels. 


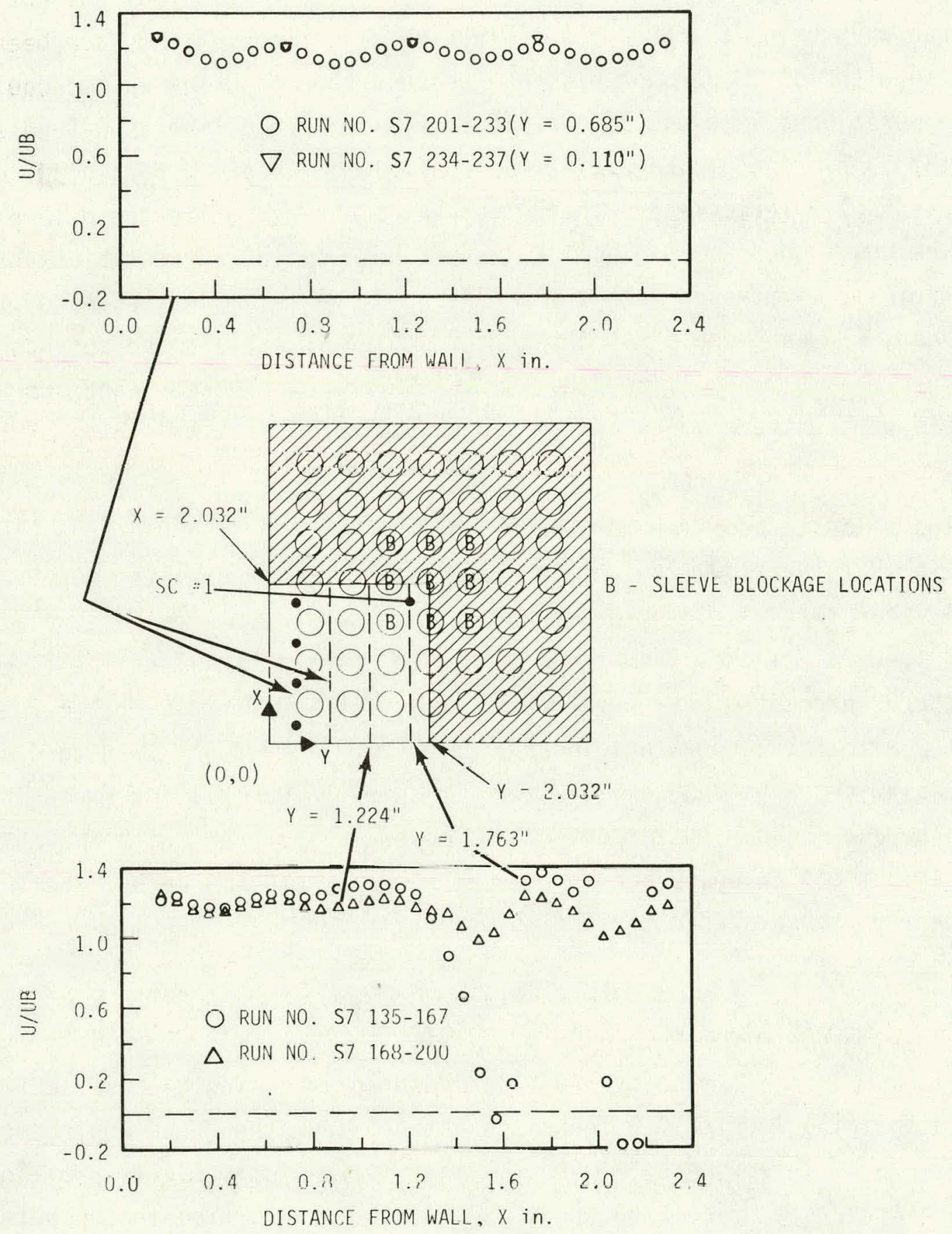

FIGURE 42. Velocity Profiles at Data Plane \#15 (+0.8 in) With a 70 Percent Blockage, $U_{B}=5.7 \mathrm{ft} / \mathrm{sec}$ 
Velocities presented in the upper plot obtained in the outer subchannels, $y=0.685$ and $y=0.110$ inches, are relatively high. The high velocities could be expected since the flow was diverted around the blockage cluster.

\subsubsection{Intensity of Turbulence}

\subsubsection{Intensity Profiles Along the Length of the Bundle}

Local intensities of turbulence measured upstream from the blockage cluster are presented in Figure 43. The flow was well developed 10 hydraulic diameters upstream from the blockage. In the tapered region of the blockage cluster, -0.8 inches, axial intensity values increased in the inner subchannels signifying that deceleration occurred and that the blockage influenced the flow field.

Intensity profiles obtained downstream from the blockage, Figure 44 , indicate the same trends as those received with the 90 percent blockage. Extremely high local intensities, 2 , existed in the inner subchannels of the bundle immediately downstream from the blockage. In the tapered region of the blockage intensity peaks occurred at the gaps of SC \#1 and minimum intensity values were measured at the subchannel center. Low intensity values in the SC \#1 center are reasonable since the velocity profiles of Figure 35 indicated that jetting (accelerating flow) existed. Likewise, low velocities (decelerating flow) were present in the rod gaps which explain the relatively high gap intensities. Intensity magnitudes in the outer subchannels remained at levels comparable to those in the undisturbed flow of data plane $\# 3$.

At an axial location 2.0 inches downstream from the blockage centerline, the turbulent intensity profile was beginning to recover from the blockage disturbance. The profile at +7.3 inches was nearly recovered, and intensities had essentially recovered from the blockage at +25.3 inches downstream from the blockage cluster. 


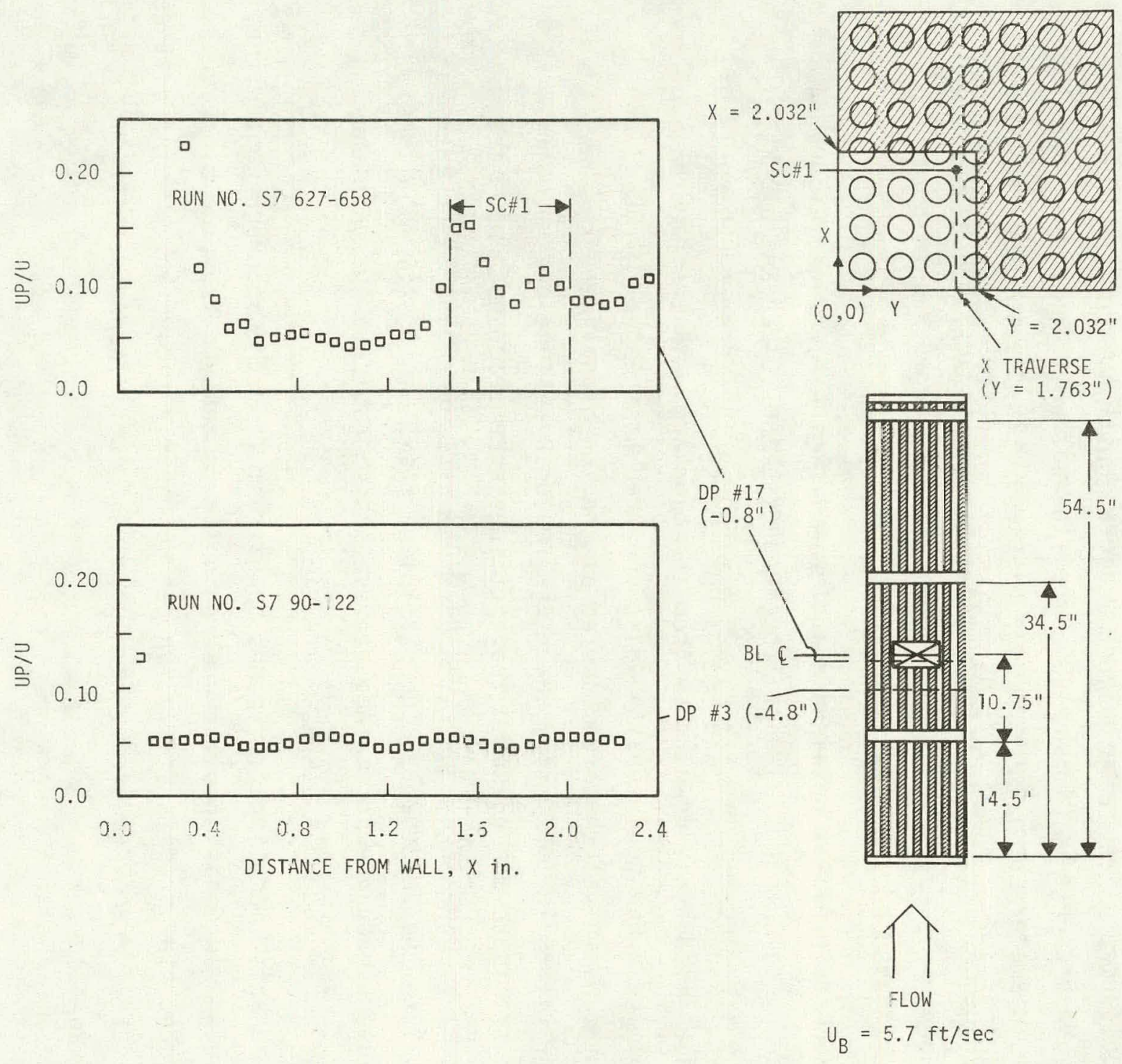

F-GURE 43. Intensity Profiles Upstream From a 70 Percen: B1ockage Located Midway Between Two Spacers, $U_{B}=5.7 \mathrm{ft} / \mathrm{sec}$ 


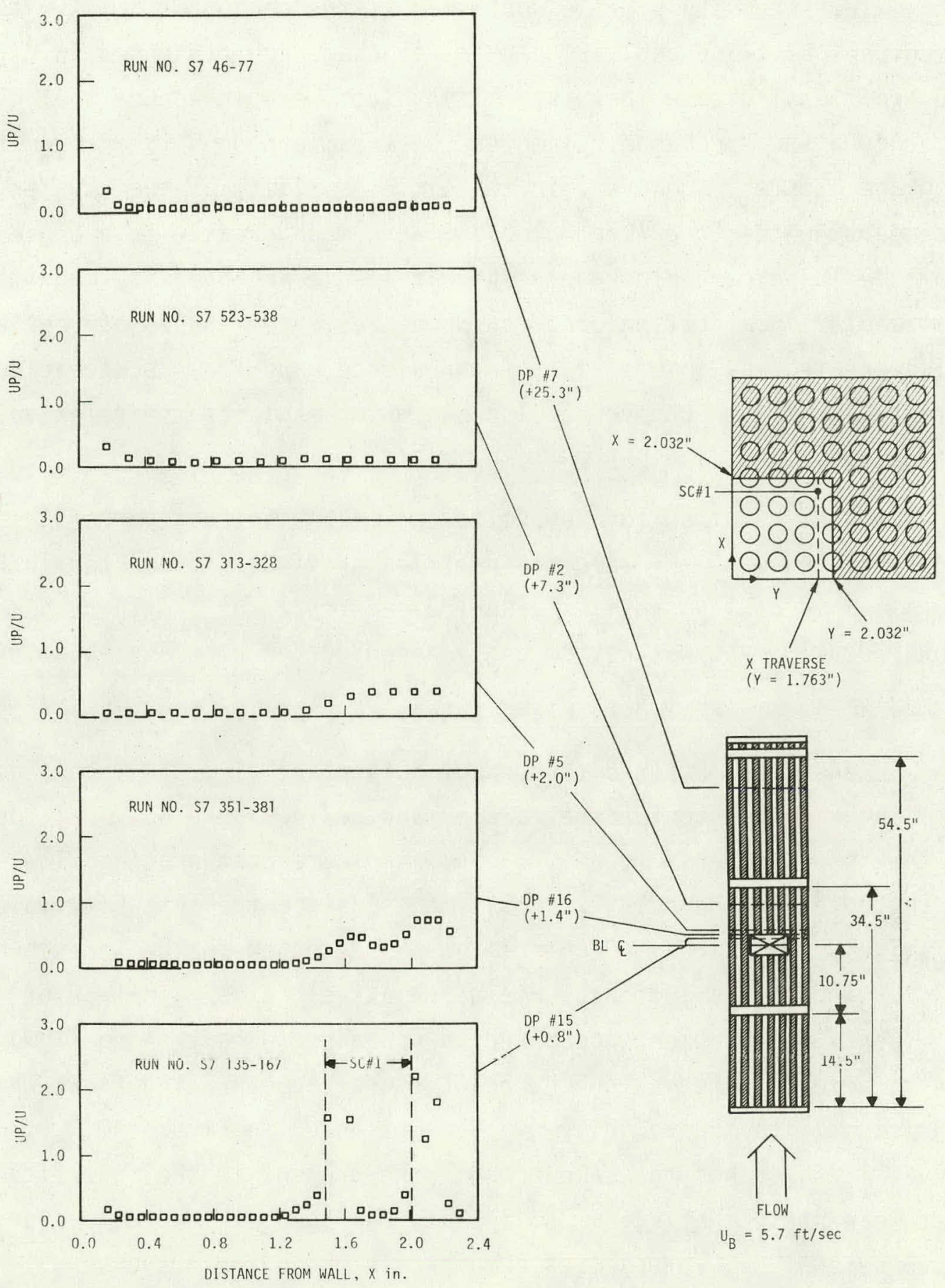

FIGURE 44. Intensity Profiles Downstream From a 70 Percent Blockage Located Midway Between Two Spacers, $U_{B}=5.7 \mathrm{ft} / \mathrm{sec}$ 
Axial intensity profiles obtained at the center of SC \#1 with both a 70 percent blockage and a 90 percent blockage are presented in Figure 45. The profiles indicate that intensity values were independent of blockage severity a few subchannel diameters upstream and downstream from the blockage cluster. However, in the close proximity of the cluster, intensities accompanying the 90 percent blockage were much greater than those resulting from the 70 percent blockage. The difference in intensity magnitudes is realizable since jetting occurred downstream from the 70 percent blockage which created low intensities of turbulence, ard flow deceleration was detected near the 90 percent blockage which explains the relatively high intensity values.

Lengths required for redevelopment of the intensity profiles corresponded to those of the velocity profiles previously presented in Figure 41. The axial intensity profiles also indicate that the length required for flow redevelopment was not strongly dependent on blockage severity.

\subsubsection{Typical Data Plane Intensity Profiles}

Intensities measured throughout data plane \#15, 0.8 inches downstream from the blockage centerline, are presented in Figure 46. Data obtained in the inner traverse $(y=1.763 \mathrm{in}$.) indicate accelerating flow existed in the outer subchannels, $x<1.2$ inches, since the intensity values were relatively low, 20.04 . Chaotic flow was detected in the inner subchamels, $x>1.2$ inches, as indicated by the relatively high magnitude of intensity, 2. Peaks in turbulence occurred in rod gaps (decelerating flow) and minima were detected at subchannel centers (accelerating flow) which is consistent with the velocity profile presented in Figure 40. At $y=1.224$ inches the same trends were present in the intensity profile that were present at $y=1.763$ inches, but the peaks were less severe ( 0.25 versus 2$)$. Intensities obtained in the outer traverses, $y=0.685$ inches and $y=0.110$ inches, again indicate that the flow in the outer subchannels was accelerating, which is logical since flow was being diverted around the blockage cluster. 


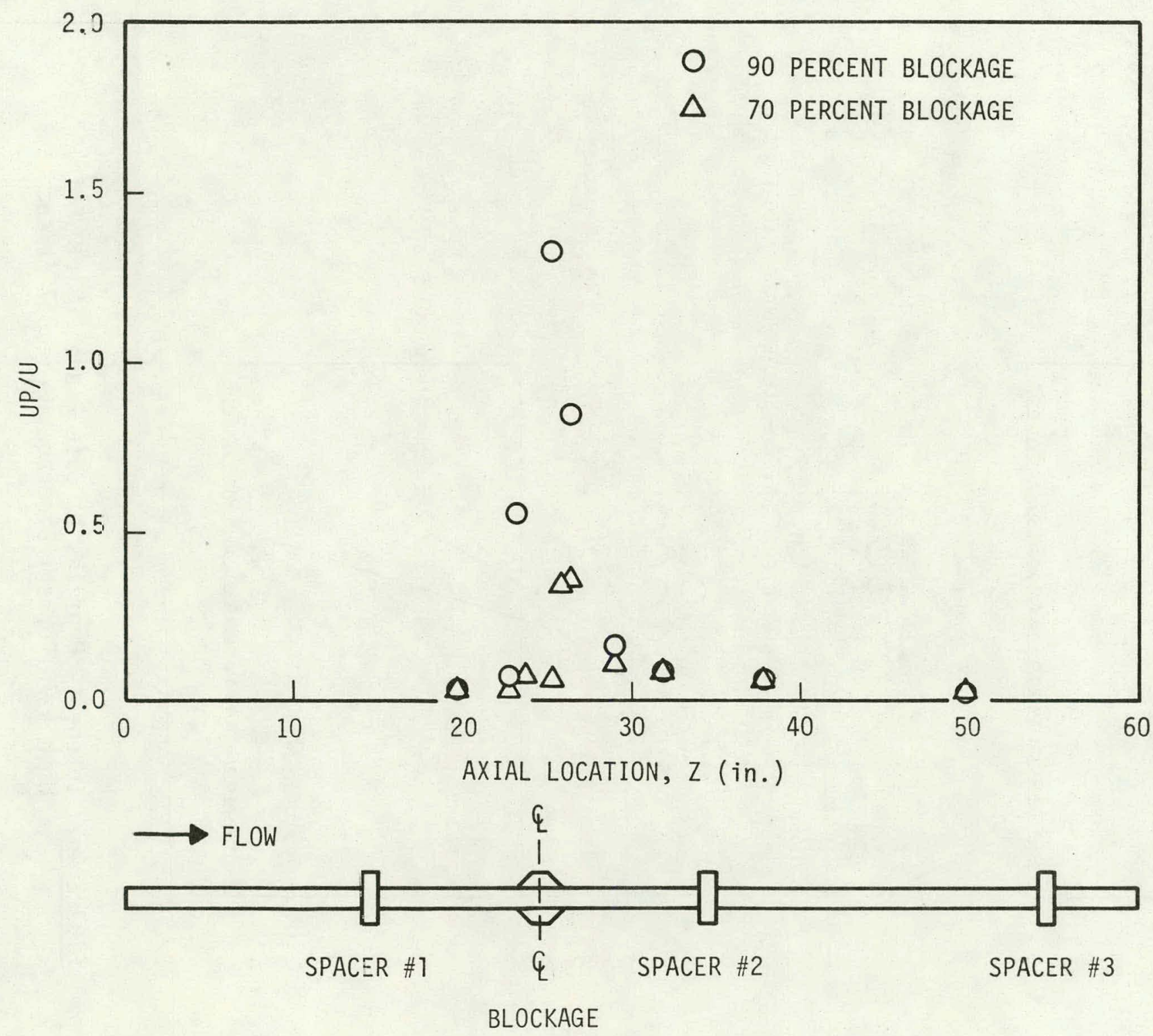

FIGURE 45. Axial Profiles of Subchannel \#1 Center Intensities With a 70 and a 90 Percent Blockage Located Midway Between Two Spacers, $U_{B}=5.7 \mathrm{ft} / \mathrm{sec}$ 


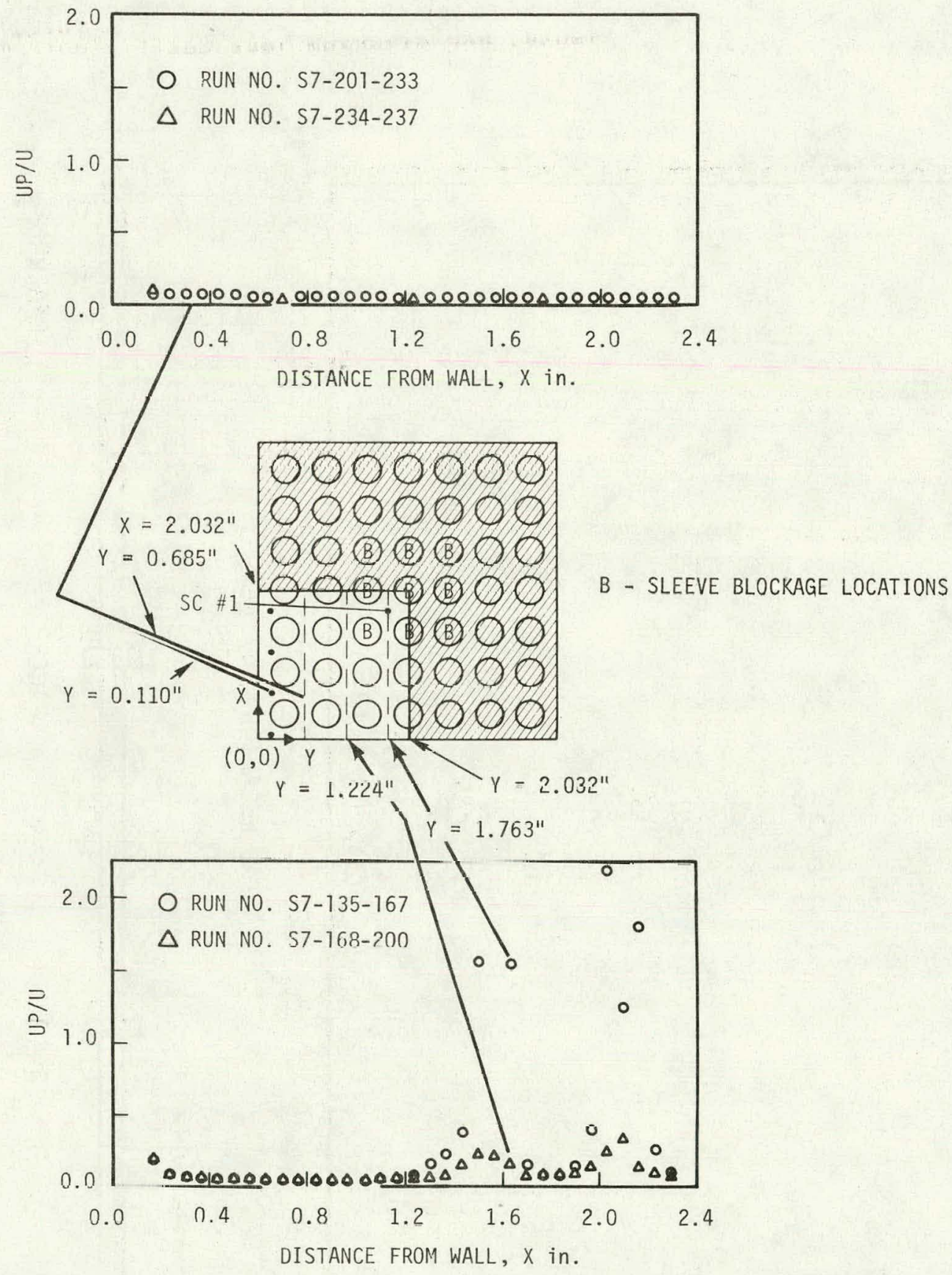

FIGURE 46. Intensity Profiles at Data Plane \#15 (+0.8 in) With a 70 Percent Blockage, $U_{B}=5.7 \mathrm{ft} / \mathrm{sec}$ 


\subsection{FRICTION FACTOR AND LOSS COEFFICIENTS}

Pressure loss data presented in Appendix $C$ were obtained along the length of the bundle at pressure tap locations 1 through 5 previously identified in Figure 2. The data were required to calculate friction factors, spacer loss coefficients, and blockage loss coefficients making up the input to the COBRA computer code.

\subsubsection{Bare Rod Friction Factor}

Pressure losses between taps 4 and 5 were used to obtain bare rod friction factors presented in Figure 47 . The experimental friction factor curve lies approximately 15 percent above the smooth tube curve. A least squares fit of the friction factor data was performed to obtain the coefficient $(0.34)$ and the exponent $(-0.25)$ presented in the friction factor relationship. The relationship agrees well with those determined in the past for similar rod bundles.

\subsubsection{Spacer Loss Coefficients}

Pressure losses resulting from spacer \#2 were obtained by subtracting frictional losses from the pressure losses measured between taps 3 and 4 . The friction factor relationship presented above was used to predict friction pressure losses. Spacer loss coefficients presented in Figure 48 were then calculated from the standard relationship

$$
K_{S P}=2 g \Delta P_{S P} / \rho U_{B}^{2}
$$

Since $K_{S P}$ was based on $U_{B}$, the loss coefficient is a bundle average value, not a subchannel value. The slight slope of the loss coefficient curve indicates that minor friction losses existed. However, the curve is characteristic of other spacer loss coefficient curves obtained in rod bundles.

\subsubsection{Blockage Loss Coefficients}

Pressure losses due to blockages were determined by subtracting the overall bundle pressure loss (taps 1 to 5 ) with a blockage from the overall 


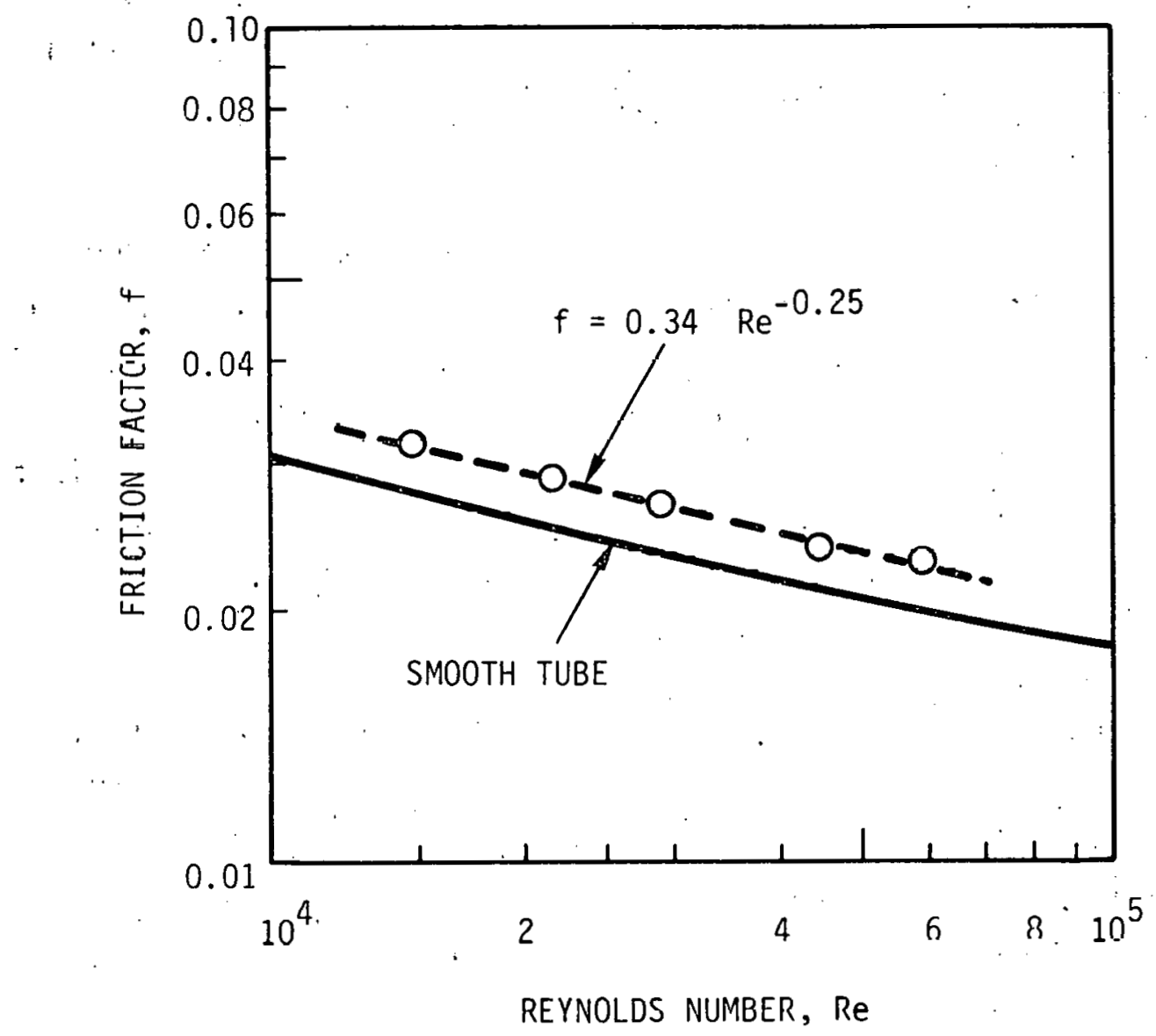

FIGURE 47. Bare Rod Friction Factors 


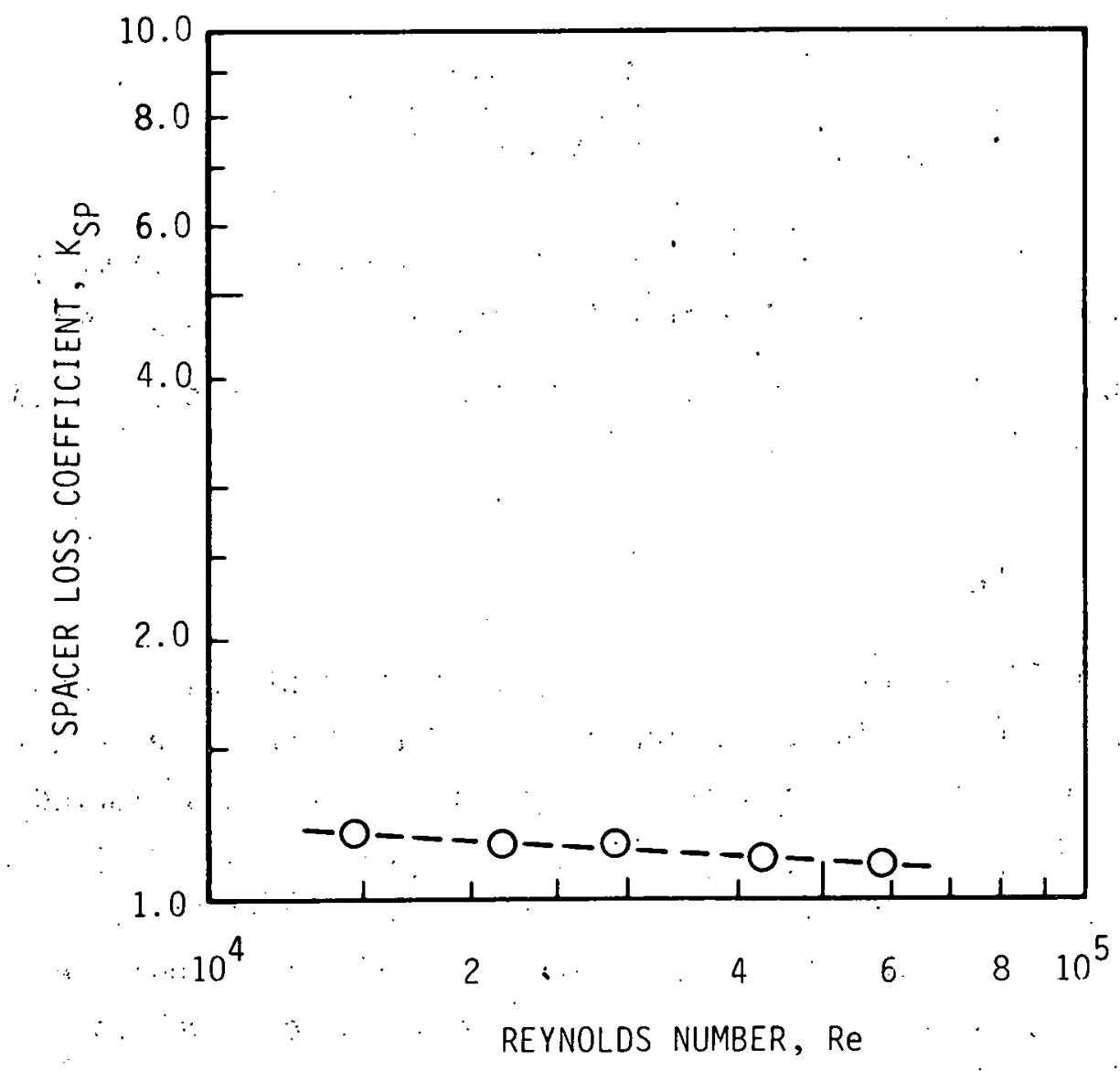

FIGURE 48. Spacer \#2 Loss Coefficients 
loss in the absence of a blockage. Pressure losses in the presence of blockages were normalized to bare bundle flow conditions by considering the $\Delta P$.- flow relationship presented in Figure 49, i.e., $\Delta P \propto U_{B}{ }^{1.82}$ in all cases.

Therefore,

$$
\Delta \mathrm{P}_{\text {Norm }}=\Delta \mathrm{P}_{1-5}\left[\frac{U_{B}^{1.82} \text { (wi thout blockage) }}{U_{B}^{1.82} \text { (with blockage) }}\right]
$$

The pressure drop curves indicate that very little form loss was present since their slopes are near 1.8 (all friction) instead of 2.0 (all form).

Blockage loss coefficients were also based on $U_{B}$ and were calculated using the relationship

$$
K_{B L}=2 g \Delta P_{B L} / \rho U_{B}^{2} \text {. }
$$

In the case of the 70 percent blockage, the loss coefficient was assumed to be zero since the blockage did not increase the overall bundle pressure loss, Figure 49. Figure 49 indicates that the 90 percent blockage contributed slightly $(0.01$ to $0.04 \mathrm{psi})$ to the overall pressure loss. Blockage loss coefficients ranging from 0.03 to 0.27 were calculated using these pressure losses. An order-of-magnitude scatter in the loss coefficient indicates that accuracies of pressure loss measurements were not good enough to accurately predict the low pressure losses due to the blockage. Therefore, the 90 percent blockage loss coefficient was ranged from 0 to 0.5 in the COBRA predictions as presented and discussed in the following section. 


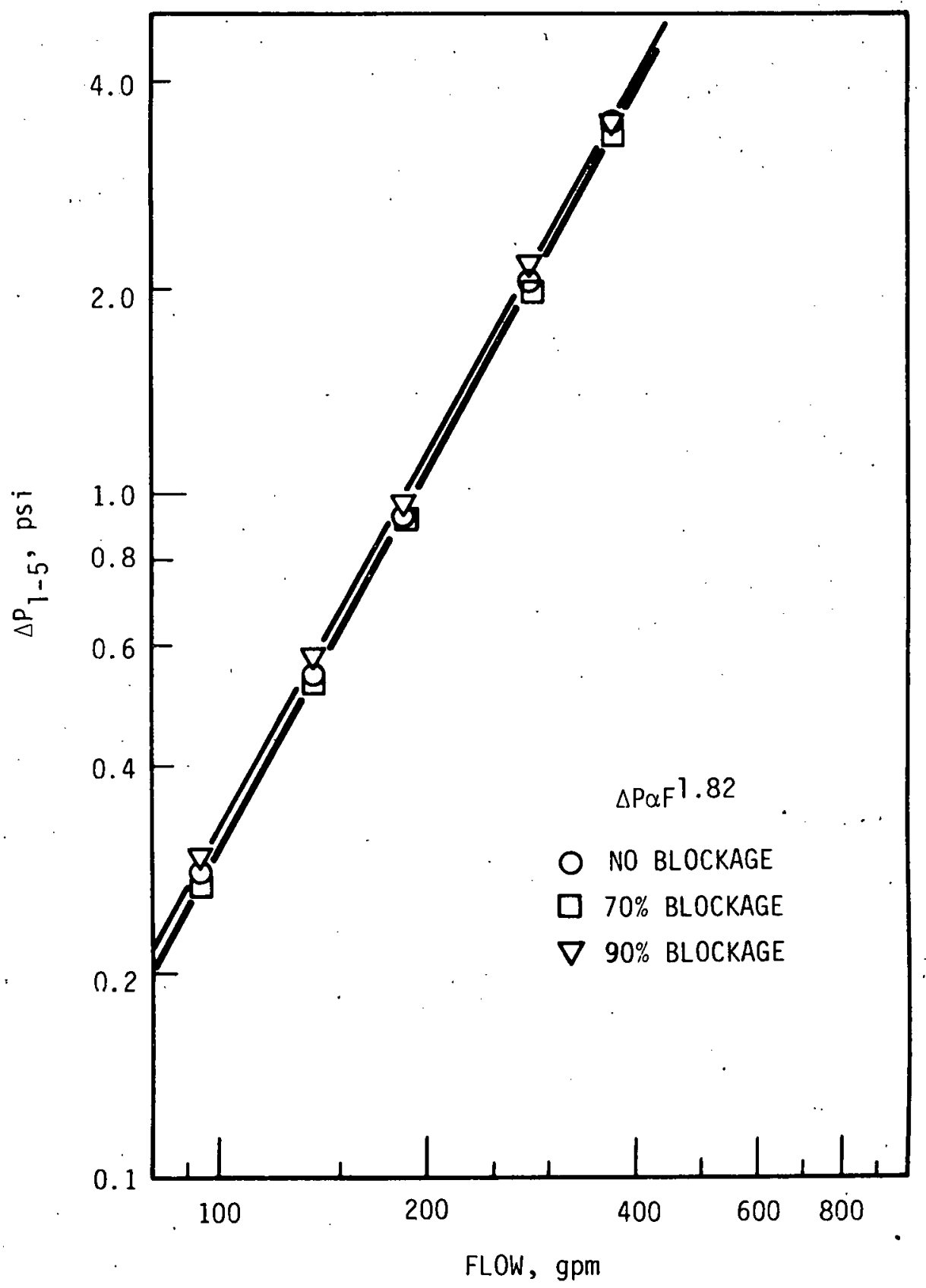

FIGURE 49. Comparison of Overall Bundle Pressure Losses With No Blockage, With a 70 Percent Blockage and With a 90 Percent Blockage 


\subsection{COMPARISONS WITH COBRA PREDICTIONS}

Comparisons of the measured velocity data with predictions obtained using the COBRA program are presented in this section. The comparisons are of major importance in the continuing verification and development of the COBRA program for subchannel (core) analyses at postulated nuclear reactor accident conditions.

The methods used to compare COBRA predictions with the experimental velocity data will be presented in this section. The COBRA versions used to perform the predictions and the input models will be discussed first. The technique used to estimate subchannel average velocities from measured local axial velocity values will then be presented. Finally, COBRA velocity predictions will be compared to measured values for a 70 and a 90 percent blockage positioned midway between spacers \#1 and \#2. COBRA velocity predictions with the blockage cluster located adjacent to spacer \#2 were unsuccessful due to numerical instabilities. Therefore, predictions of that data will be performed with future improved versions of the COBRA code.

\subsection{COBRA VERSION AND INPUT MODEL}

Predictions of the data obtained with the 70 percent blockage were performed using COBRA-IIIC. (1) Data obtained near the 90 percent blockage. could not be predicted with COBRA-IIIC using standard steady-state techniques since instabilities in the numerical solution were encountered. Therefore, predictions of the 90 percent data were perforllied with a modified version of COBRA-IIIS. using a "two step" approach as fulluws:

(1) Steady-state predictions with a 70 percent blockage were performed.

(2) A transient solution, which extended the 70 percent blockage solution to a 90 percent blockage solution, was then performed. During each transient time increment, a slightly greater blockage severity was introduced into the input geometry. After a 
90 percent severity had been obtained, sufficient time steps were completed to assure convergence to the correct solution. It is important to note that the solution was transient with respect to blockage severity only, and that all other input parameters remained constant with time.

The input parameters used to predict the axial velocity data are summarized in Table 2. As indicated, the values of the parameters are typical of those commonly used in nonheated bundle predictions. The blockage loss coefficient was varied from subchannel to subchannel and ranged from 0 to 0.5 depending on subchannel location relative to the blockage cluster.

TABLE 2. COBRA Input Parameters

Parameter

Cross Flow Resistance

Transverse Momentum

Turbulent Momentum Factor

Bare Rod Friction Factor

Subchannel Spacer. Loss Coefficient

Subchannel Blockage Loss Coefficient

For Subchannel \#

For Subchannel \#2

Other Subchannels

Model Length (in.)

Calculation Increment (in.)

Total Transient Time (sec)

Turhulent Mixing

Temperature $\left({ }^{\circ} \mathrm{F}\right)$
COBRA

Symbol

$k_{i j}$

$s / \ell$

$f t$

$f$

$k_{\text {sl }}$

$K_{s 2}$

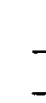

0.02

0.25

1.0

$0.34 \operatorname{Re}^{-0.25}$

1.14

0.5

0.0

0.0

40

$\Delta \mathbf{z}$

$\mathrm{t}$

$\beta$

$T$
0.5

0.0

0.02

85.0 $70 \%$
Value

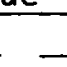
$90 \%$ 0.02 0.25 1.0 $0.34 \mathrm{Re}^{-0.25}$

1.14

0.5

0.05

0.0

40

0.5

2.0

0.02

85.0 
The geometry model presented in Figure 50 identifies the location of the subchannels. The model was a one-eighth sector of the total bundle cross section and was justifiable based on geometric symmetry. Dimensions of the model were as-built dimensions measured during and after bundle assembly. The rod diameters were measured to be 0.392 inches. The rod pitch was 0.539 inches and the rod-to-wall spacing was 0.220 inches. The sleeve blockages were modeled as flow area reductions. The area reductions in the tapered region of the blockage sleeves. were assumed to vary "linearly along the length of the tapers.

\subsection{SUBCHANNEL AVERAGE VELOCITY PREDICTIONS}

Prior to comparing the measured axial velocity profiles with COBRA predictions, the local measured velocity data were used to calculate subchannel average velocities. Subchannel average velocities were required since the COBRA code computes average values only.

For subchannels \#1, \#2, and \#3, an area-weighting approach in conjunction with the assumption of highly turbulent flow was used to calculate subchannel average velocities from experimental local velocity data. Thé subchannel cross sections were simplified by replacing the round ruds with square rods of equal area as shown in Figure 51. This simplified the areaweighting calculations greatly without altering the actual cross sectional subchannel flow areas. Inner sub-area boundaries were defined as being one-half the distance between a data location and its adjacent neighbors. Similarly, wall sub-areas were defined as being midway between the wall and an adjacent data location. Weighting factors for each sub-area were: obtained by dividing the appropriate sub-area by the total subchannel flow area.

Suhchannel average vcloclties were calculated by summing the products of the weighting factors and corresponding measured velocities. The velocity used with a wall sub-area was one-half the value of the velocity of the adjacent sub-area, e'.g., nne-half the velocity corresponding lu sub-area 8 was assumed to exist in sub-area 12. This velocity decay assumption roughly approximated that obtained using the universal "law of the wall." 


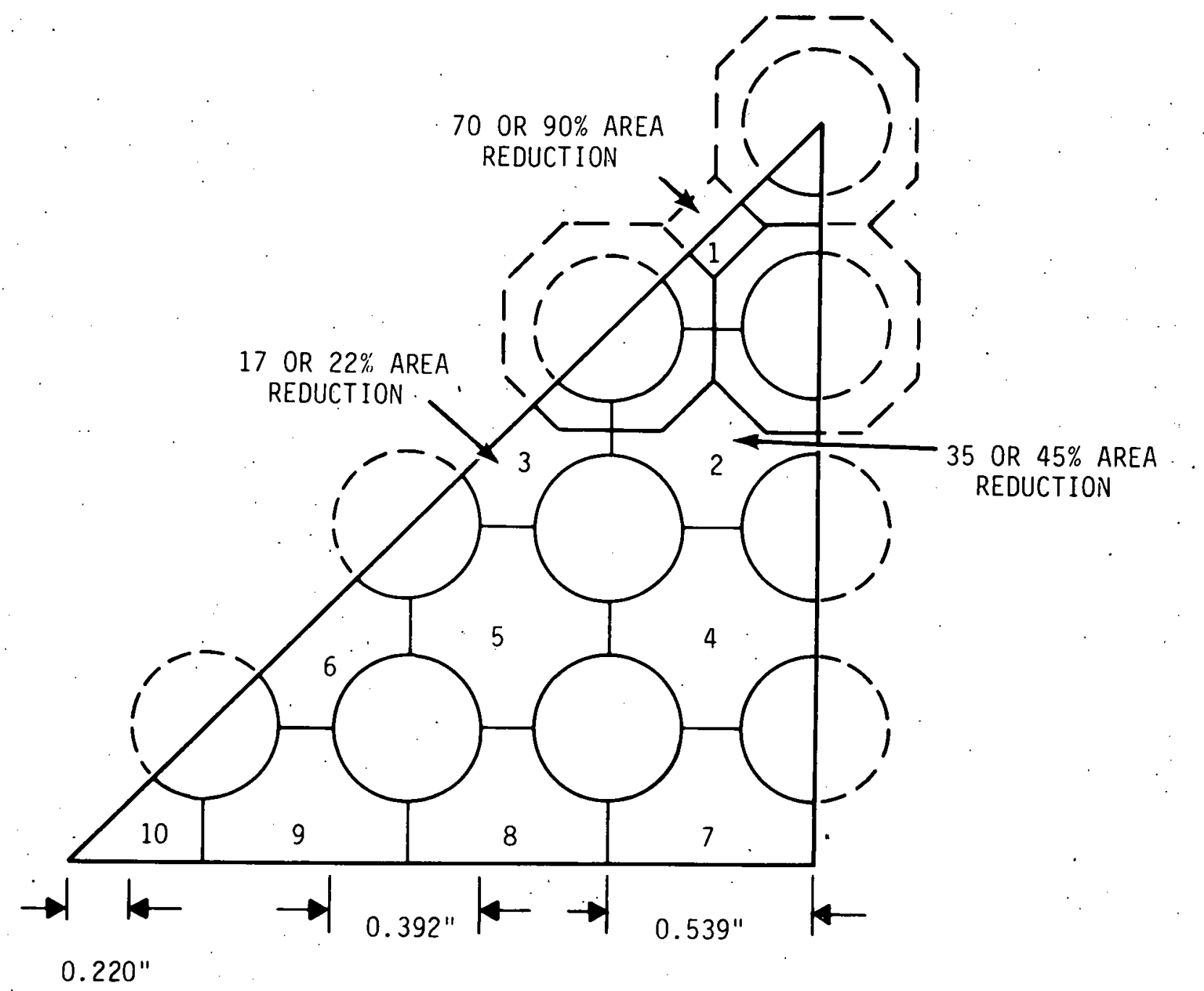

FIGURE 50. COBRA Geometry Mode] 


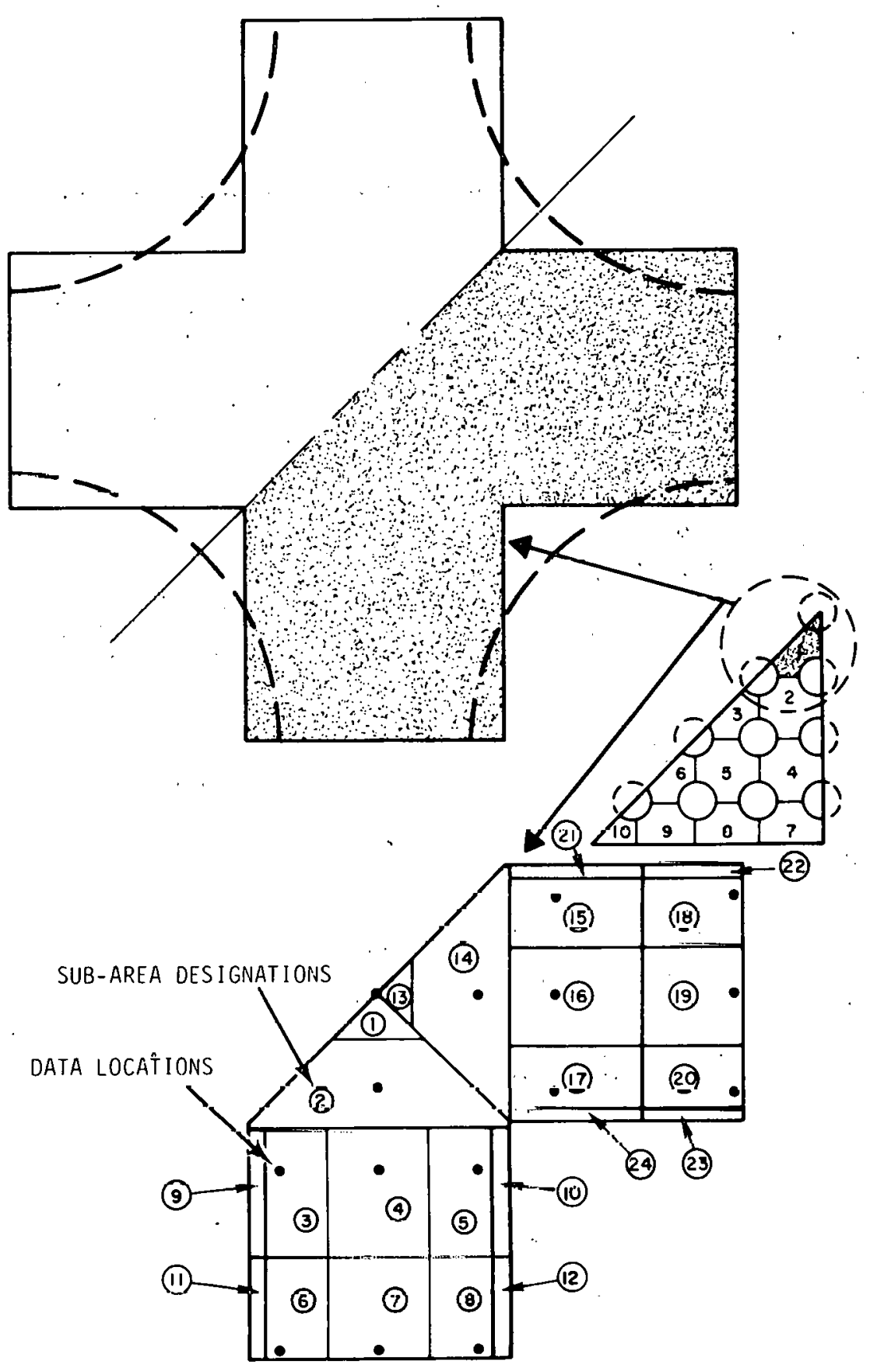

FIGURE 57. Simplified Subchannel Geometry for Calculating Subchannel Average Velocities 
Average velocities for subchannels \#4 through \#10 were determined by inspecting the velocity profiles at nondisturbed data planes, e.g.; \#3, and estimating the ratio of the average subchannel velocity to the centerpoint subchannel velocity. Average subchannel velocities at undisturbed data planes were known to be approximately equal to the average bundle velocity. This approach was also used for subchannels \#1, \#2, and \#3 at locations not influenced by the blockage cluster.

In Table 3, a selected number of calculated bundle flowrates determined using the measured LDA velocity data are compared to bundle flowrates measured with the loop turbine meter. Calculated flows were determined by summing the flowrates, in each subchannel, $F \alpha \sum_{S}^{10} U_{S C} A_{S C}$, and multiplying the sum by eight to account for all eight sectof ${ }^{\delta}=1$ making up the bundle cross section. As indicated, the calculated flowrates agreed exceptionally we.11, \pm 5 percent, with the measured flowrates.

\section{TABLE 3. Comparisons of Calculated and} Measured Bunule Flowrates

\begin{tabular}{|c|c|c|c|}
\hline $\begin{array}{c}\text { Data Plane } \\
\text { No. }\end{array}$ & $\begin{array}{l}\text { Calculated } \\
\text { Flow, gpm }\end{array}$ & $\begin{array}{l}\text { Measured } \\
\text { Flow, gpm }\end{array}$ & $\begin{array}{l}\text { Percent Diff. } \\
\left(\frac{F_{m}-F_{c}}{F_{. m}}\right) 100\end{array}$ \\
\hline$\# 3(-4.8$ in. $)$ & 187.6 & 187.5 & -0.1 \\
\hline$\# 9(-1.2$ in.) & 194.4. & 188.5 & -3.2 \\
\hline$\# 4(+1.2$ in. $)$ & 177.6 & 186.5 & +4.8 \\
\hline$\# 5(+2.0$ in. $)$ & 184.9 & 186.0 & +1.4 \\
\hline$\# 12(+3.5$ in. $)$ & 197.3 & 187.9 & -5.0 \\
\hline$\# 7(+25.3$ in. $)$ & 189.1 & 186.1 & -1.6 \\
\hline$\# 3(-4.8$ in. $)$ & 353.7 & 353.2 & -0.1 \\
\hline$\# 9(-1.2$ in.) & 366.3 & 354.5 & -3.3 \\
\hline$\# 5(+2.0$ in. $)$ & 350.3 & 355.0 & +1.3 \\
\hline$\# 7(+25.3$ in. $)$ & 355.0 & 354.2 & -0.2 \\
\hline
\end{tabular}




\subsection{COBRA PREDICTIONS}

\subsubsection{Percent Blockage Midway Between Spacers}

COBRA-IIIC predictions of the velocity data obtained with the 70 percent blockage located midway between spacers \#1 and \#2 are presented in Figures 52 and 53 . In each figure, the ratio of average subchannel velocity to bundle average velocity is presented as a function of axial location along the bundle. The measured data points are actually subchannel average velocities calculated using measured local axial velocities as discussed in the previous section.

Predicliuns of. the velocity data obtained in subchannels $\# 1$, \#2, and \#3 are shown in Figure 52. COBRA predicted the axial velocity profiles upstream of the blockage cluster extremely well. The predicted locations of the minimum velocity points were in excellent agreement with the experimental data.

Downstream from the blockage, the predicted locations and magnitudes of the minimum velocity points were also in good agreement with measured values. The jetting predicted by COBRA was measured experimentally in the downstream tapered region of the blorkage. The flow rccovery profiles were in good agreement with measured profiles.

Figure 53 presents COBRA predictions of SC \#4,5 and 6 average velocities. As indicated, the predicted subchannel velocities agree satisfactorily with measured values. COBRA predictions of SC \#7 through \#10 velocities, not presented herein, were also in exrellent agreement with the experimental dald.

\subsection{2 g0 Percent Blockage Midway Between Spacers}

COBRA predictions of the velocity data obtained with the 90 percent blockage localed midway between spacers \#1 and \#2 are presented in Figures 54 through 57 . Figures 54 and 55 are comparisons of COBRA predictions with measured data at an average bundle velocity of $5.7 \mathrm{ft} / \mathrm{sec}$. The predictions for SS. \#1 through \#6 are in excellenl agreement with the 


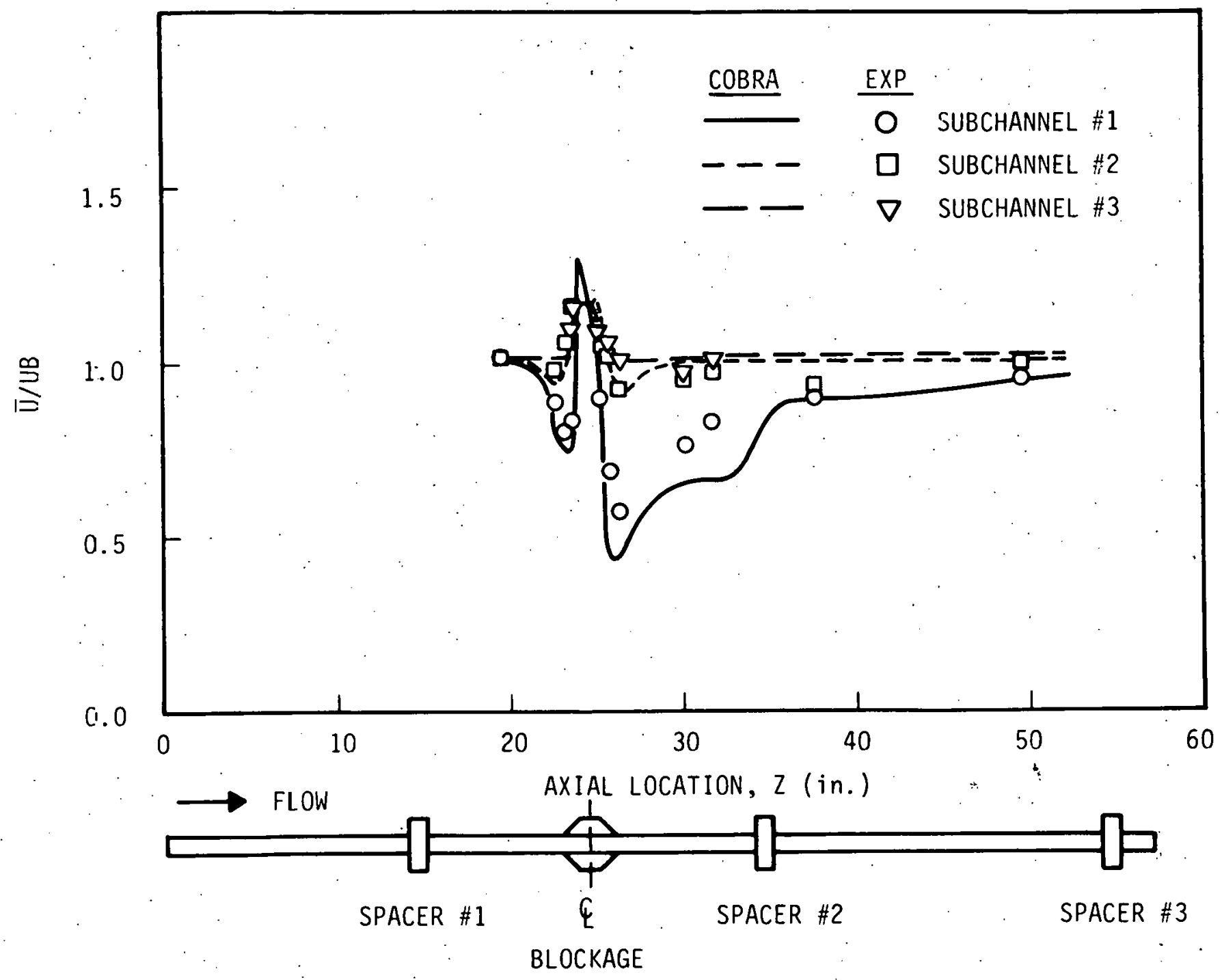

FIGURE 52. COBRA Velocity Predictions in Subchannels \#1, \#2, and \#3 With a 70 Percent Blockage, $U_{B}=5.7 \mathrm{ft} / \mathrm{sec}$ 

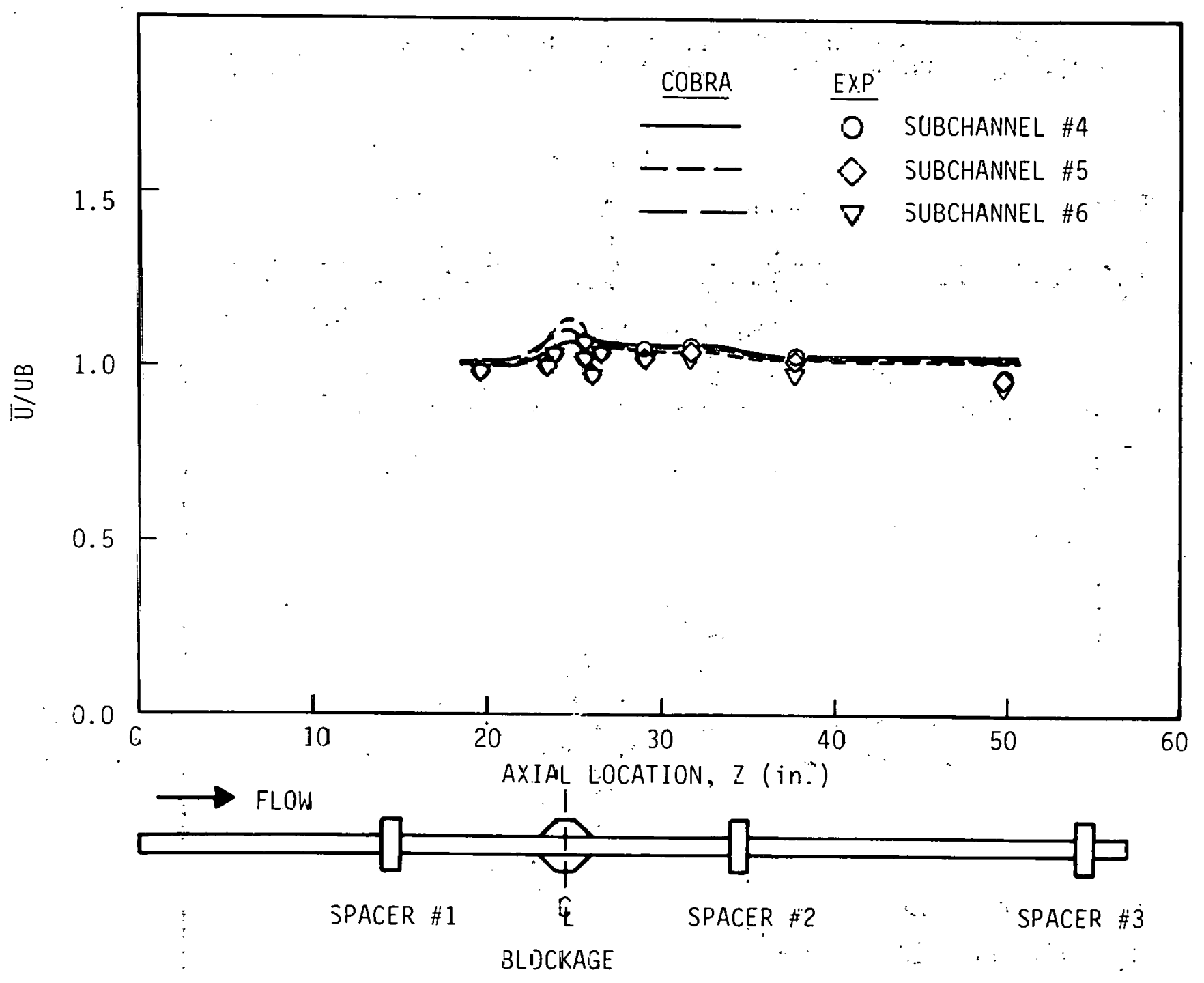

FIGURE 53. COBRA Velocity: Predictions in Subchanneis \#4, \#5, and \#6 With a 70 Percent Blockage, $U_{B}=5.7 \mathrm{ft} / \mathrm{sec}$ 


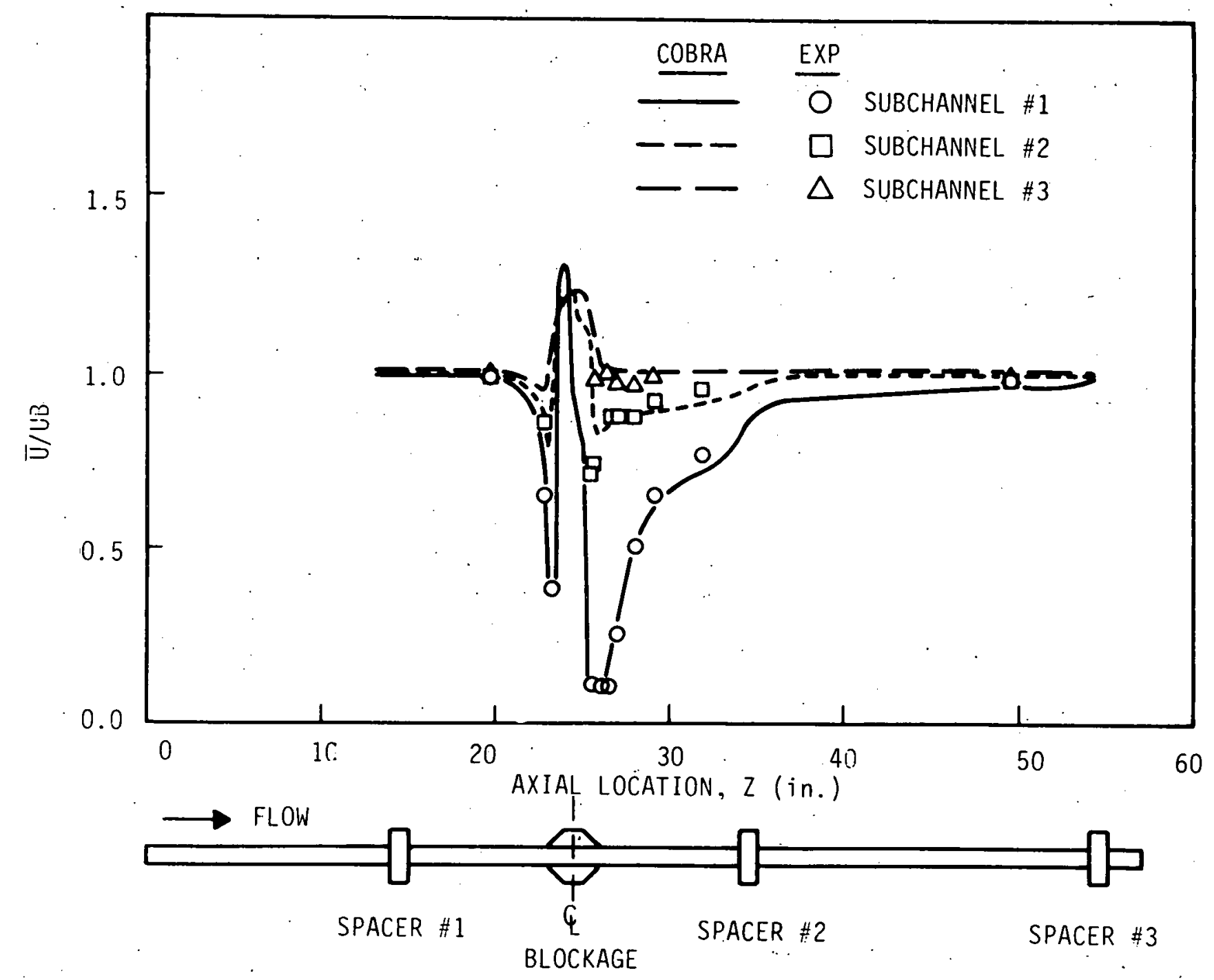

FIGURE 54. COBRA Velocity Predictions in Subchannels \#1, \#2, and $\# 3$ With a 90 Percent Blockage, $U_{B}=5.7 \mathrm{ft} / \mathrm{sec}$ 


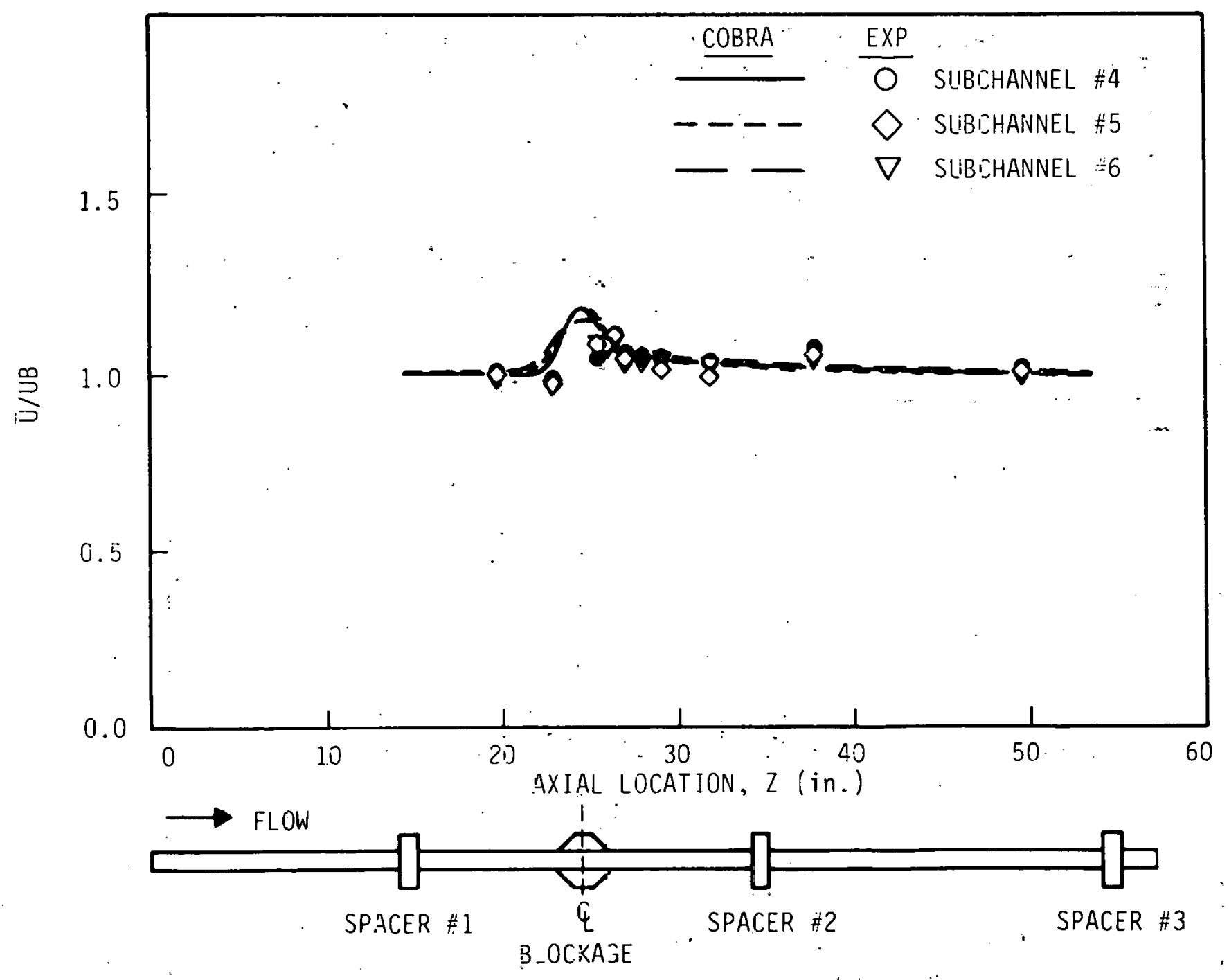

FIGURE 55. COBRA Velocity Predictions in Subchannels: $\# 4,75$, and \#6 With a 95 Percent B.lockage, $U_{B}=5.7 \mathrm{ft}$; sec 


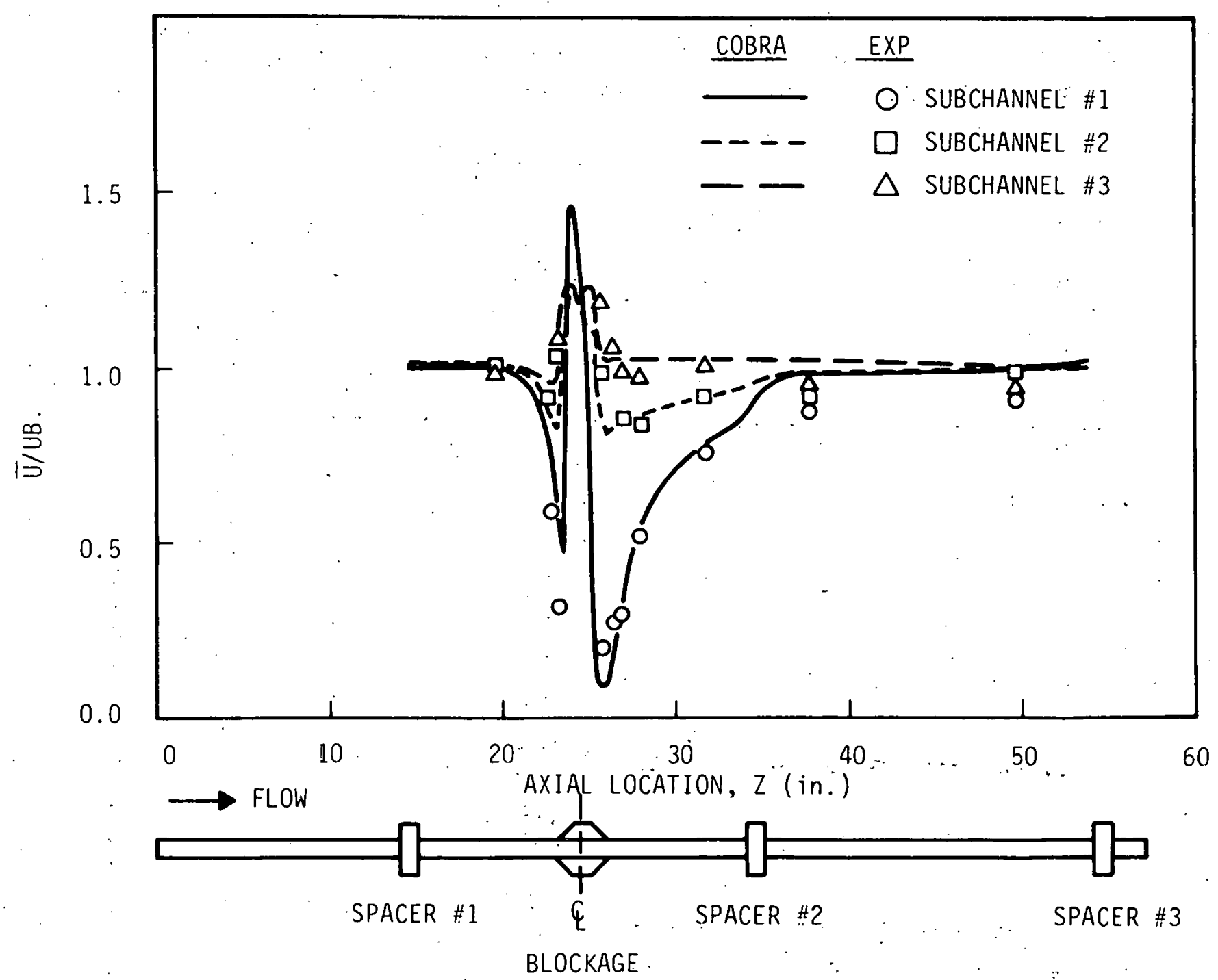

FIGURE 56. COBRA Velocity Predictions in Subchannels \#1, \#2, and \#3 With a 90 Percent Blockage, $U_{B}=2.7 \mathrm{ft} / \mathrm{sec}$ 


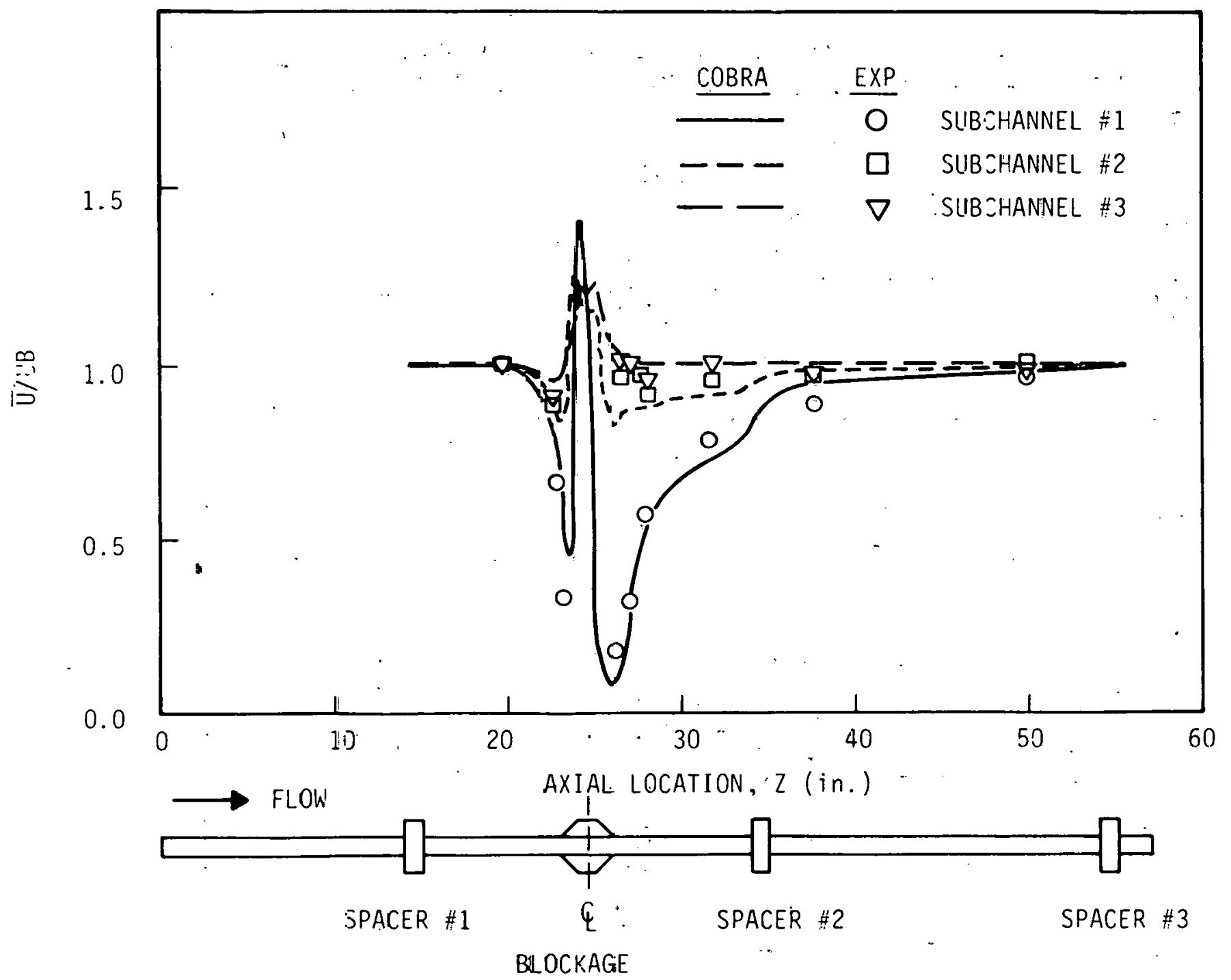

FIGURE 57. COERA Velocity Predictions in Subchannels \#1, 72 , and \#3 With a 90 Percent Blockage, $U_{B}=10,7 \mathrm{ft} / \mathrm{sec}$ 
experimental data. Upstream from the blockage cluster in SC \#1, Figure 54, COBRA predicted the location and magnitude of the severe velocity reduction, but the jetting effect predicted by COBRA was not detected experimentally. Two possible reasons for the jet remaining undetected experimentally were:

- the measuring volume could not be positioned in the "core" of the blockage cluster, i.e., close to the blockage axial centerline. This was caused by the geometrical restraint created by the angle between the laser beams and the restriction of the tapered region of the blockage cluster; and

- jetting may not have actually existed since the severity of the blockage in the center four subchannels may have "choked" the flow and forced the majority of the flow into the outer subchannels.

COBRA predictions agreed exceptionally well with experimental data. obtained downstream from the blockage cluster. The predicted velocity recovery profiles in the reported subchannels \#1 through \#6 essentially coincide with the experimental data. The velocity minimum measured in SC \#1 was actually "searched out" and agrees nicely with the predicted location and value. COBRA predictions of SC \#7. through \#10 velocities, not presented in this report, essentially coincided with the experimental data.

COBRA predictions with experimental data obtained at average bundle velocities of 2.7 and $10.7 \mathrm{ft} / \mathrm{sec}$ are presented in Figures 56 and 57 , respectively. The comparisons in SC \#1 through \#3 are again good, and are similar to the comparisons at $U_{B}=5.7 \mathrm{ft} / \mathrm{sec}$. The minimum velocity locations upstream from the blockage were predicted satisfactorily, but the predicted magnitudes differed slightly from the measured values. Again, the upstream jetting phenomenon predicted in SC \#1 was not detected experimentally as previnusly discussed when $U_{B}=5.7 \mathrm{ft} / \mathrm{sec}$.

- COBRA predicted the downstreám velocity profiles satisfactorily. The locations of the velocity minima were predicted very accurately, but the measured minimum magnitudes (actually "searched out") were slightly greater than COBRA predictions. It is interesting to note that COBRA predicted a shorter flow recovery length than was obtained experimentally at $U_{B}=2.7 \mathrm{ft} / \mathrm{sec}$. No obvious reason for this discrepancy has been formulated. 


\section{THIS PAGE}

\section{WAS INTENTIONALLY \\ LEFT BLANK}




\section{ACKNOWLEDGEMENTS}

Appreciation is extended to Dr. Joe Hopenfeld of ERDA/RRD for initial sponsorship of the flow blockage study, and to Dr. Stan Fabic and Dr. L. S. Tong of NRC/RSR for their continued support. The study was truly a team effort and the authors wish to acknowledge the outstanding efforts of the other team members: A. J. Anthony for equipment design, K. D. Hinkle for fabrication, assembly, and installation of equipment, R. A. McBride for instrumentation setup, loop operation, and data acquisition, J. D. Smith for LDA setup and data acquisition, C. A. McMonagle for COBRA velocity predictions, R. R. Dohaniuk for preparation of illustrations, F. Ono for secretarial assistance, and the graphics and technical publications sections of BNW for preparation of the final report. 
THIS PAGE

WAS INTENTIONALLY

LEFT BLANK 


\section{REFERENCES}

1. D. S. Rowe, COBRA-IIIC: A Digital Computer Program for Steady-State and Transient Thermal - Hydraulic Analys is of Rod Bundle Nuclear Fuel Elements, BNWL-1695, Battelle-Northwest, Richland, WA, March 1973.

2. D. S. Rowe, Measurement of Turbulent Velocity, Intensity, and Scale in Rod Bundle Flow Channels, BNWL-1736, Battelle-Northwest, Richland, WA, May 1973.

3. D. S. Rowe and C. C. Chapman, Measurement of Turbulent Velocity, Intensity, and Scale in Rod Bundle Flow Channels Containing a Grid Spacer, BNWL-1757, Battelle-Northwest, Richland, WA, June 1973.

4. B: Kjellström, Studies of Turbulent Flow Parallel to a Rod Bundle of Triangular Array, A. B. Atomenergi, Studsvik, 61101 Nyköping, Sweden. STU 68-263/U210, 1971.

5. J. 0. Cermak et al., PWR Full Length Emergency Cooling Heat Transfer (FLECHT) Group I Test Report, WCAP-7435, Westinghouse Atomic Power Division, Pittsburgh, PA, 1970.

6. D. G. Hardy, High Temperature Expansion and Rupture Behaviour of Zircaloy Tubing, Proceedings of Topical Meeting on Water Reactor Safety, CONF-730304, Salt Lake City, UT, March 1973.

7. D. B. Brayton and W. H. Goethert, "A New Dual-Scatter Laser DopplerShift Velocity Measuring Technique," ISA Transactions, vol 10, pp 40-50, 1971.

8. Hilbert Schenck, Jr., Theories of Engineering Experimentation, McGraw-Hill Book Company, New York, p 40, 1961.

9. S. J. Kline and F. McClintock, "Describing Uncertainties in Single Sample Experiments," Mech Engr., January 1953.

10. E. Bright Wilson, Jr., An Introduction to Scientific Research, McGraw-Hill Book Company, New York, p 272, 1952.

11. W. M. Kays, Convective Heat and Mass Transfer; McGraw-Hi11 Book Company, New York, $P$ 69, 1966. 
THIS PAGE

WAS INTENTIONALLY

LEFT BLANK 
APPENDIXES 
APPENDIX A

NOMENCLATURE 


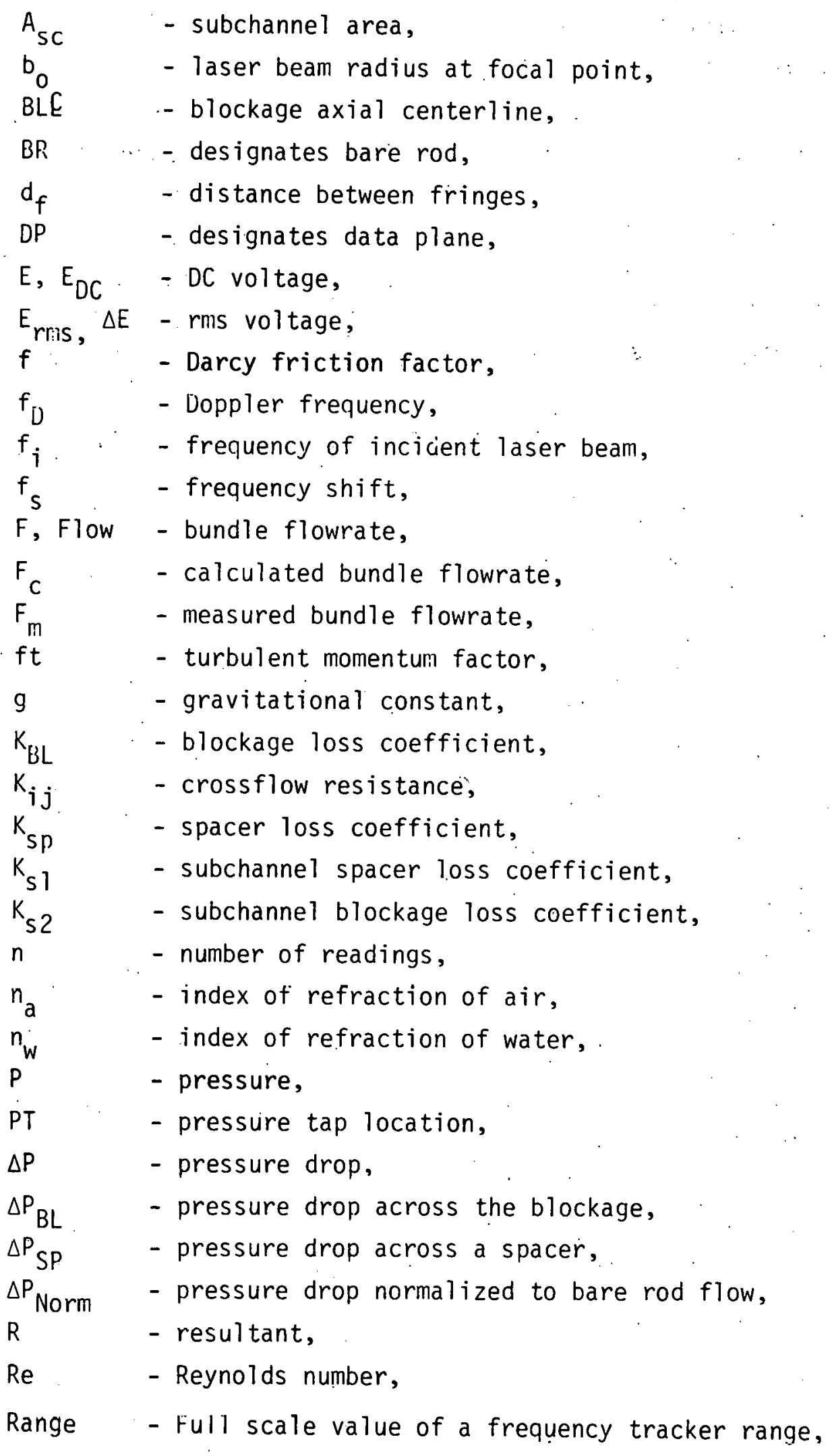


$\mathrm{s}$

$s / \ell$

$\mathrm{SB}$

SN

S7

$t$

\section{$T$, Temp}

$U, U_{\text {local }}$

$\cup_{B}, \cup B$

$U / U_{B}$, VRATIO

$U_{S C}, \bar{U}$

$U^{\prime}, U P, U_{\text {FluC }}$

U'/U,UP/U

I, Turb

$W$

$x$

${ }^{x}$

$x_{m}$

$x_{1}, y_{1}, r_{1}$

${ }_{C}, Y_{C}$

$y$.

$\mathrm{y}_{\mathrm{T}}$

$\Delta y$.

$z$

$\triangle 7$

$\beta$

$\lambda$

$\rho$

$\theta$

$\theta_{1}, \theta_{2}$
- standard deviation,

- transverse momentum,

- designates a 90 percent blockage midway between spacers,

- designates a 90 percent.blockage adjacent to a spacer,

- designates a 70 percent blockage midway between spacers,

- time,

- temperature,

- local measured mean axial velocity,

- bundle average velocity,

- ratio of local mean velocity to bundle average velocity,

- subchannel average velocity,

- rms fluctuating component of velocity,

- intesity of turbulence,

- uncertainty,

- x coordinate,

- corrected $x$ location,

- lieasured x lucalion,

- deviations from a correct reading,

- measured variables.

- y coordinate,

- y traverse location,

- incremental length in y direction

$=z$ coordinate;

- calculation increment,

- turbulent mixing,

- wavelength,

- density,

- angle between incident laser beams,

- angles of deflection. 
APPENDIX B

UNCERTAINTY ANALYSIS 


\section{APPENDIX B - UNCERTAINTY ANALYSIS}

THEORETICAL APPROACH

Accuracies of the results of the blockage study were estimated using the uncertainty method presented by Schenck. (8) Consider the general case of a result $R$, which is a function of the two measured variables $X_{C}$ and $Y_{C}$ :

$$
R+r_{1}=f\left(x_{c}+x_{1}, Y_{c}+y_{1}\right) \text {. }
$$

If this function is continuous and has derivatives, it can be expanded in a "Taylor series," using the first two terms only:

$$
R+r_{1}=f\left(X_{C}, Y_{c}\right)+\left[\left(\frac{\partial R}{\partial X_{C}}\right)_{y} \frac{X_{c}+x_{1}-X_{c}}{1 !}+\left(\frac{\partial R}{\partial Y_{c}}\right)_{x} \frac{Y_{c}+y_{1}-Y_{c}}{1 !}\right] .
$$

Or, since $R=f\left(X_{C}, Y_{C}\right)$ :

$$
r_{1}=\left(\frac{\partial R}{\partial X_{c}}\right)_{y} x_{1}+\left(\frac{\partial R}{\partial Y_{c}}\right)_{x} y_{1}
$$

where the lower case letters $\left(r_{1}, x_{1}\right.$, and $\left.y_{1}\right)$ apply to deviations from the correct readings, and

$$
\sum r_{1}^{2}=\left(\frac{\partial R}{\partial X_{c}}\right)_{y}^{2} \sum x_{1}^{2}+2\left(\frac{\partial R}{\partial X_{c}}\right)_{y}\left(\frac{\partial R}{\partial Y_{c}}\right)_{x} \sum_{\cdot} x_{1} y_{1}=\left(\frac{\partial R}{\partial Y_{c}}\right)_{x}^{2} \cdot \sum v_{1}^{2}
$$

$\sum x_{1} y_{1}$ tends to zero and $s_{r}^{2}=\Sigma r_{1}^{2} / n$ (standard deviation) so that

$$
s_{r}^{2}=\left(\frac{\partial R}{\partial X_{c}}\right)_{y}^{2} s_{x}^{2}+\left(\frac{\partial R}{\partial Y_{c}}\right)_{x}^{2} s_{y}^{2}
$$

and, for the uncertainty interval $\mathrm{H}$

$$
u_{r}^{2}=\left(\frac{\partial R}{\partial X_{c}}\right)^{2} H_{x}^{2}+\left(\frac{\partial R}{\partial Y_{c}}\right)^{2} w_{y}^{2}
$$

where $W$ for this analysis is that precision index enclosing 95 percent of all readings or values. 


\section{ANALYSIS DETAILS}

\section{Velocity Uncertainty}

The uncertainty of the local axial velocity measurements can be estimated by referring to the relationship,

$$
\begin{aligned}
U & =\lambda f_{D} / 2 \sin \Theta / 2 \\
\therefore W_{u}^{2} & =\frac{\partial U}{\partial \lambda}^{2} W_{\lambda}^{2}+\frac{\partial U}{\partial f D}^{2} W_{f D}^{2}+\frac{\partial U}{\partial \Theta / 2}{ }^{2} W_{\Theta / 2}^{2}
\end{aligned}
$$

It can be assumed that the uncertainty of the wavelength of the laser light is negligible. It was estimated, by considering instrument accuracies, that the Doppler frequency uncertainty was $W_{f D} \approx \pm 0.05 \mathrm{MHz}$. The half angle uncertainty was calculated to be $0.06^{\circ}$ using the above uncertainty methods. Since $\lambda=6328 \AA, \theta=9.7^{\circ}$, and let $f_{D}=0.44 \mathrm{MHz}$ (Run S7-346) then,

$$
\begin{aligned}
w_{u}^{2} & \left.=\operatorname{fog}^{2} \sin \theta / 2\right)^{2} w_{\lambda}^{2}+(\lambda / 2 \sin \theta / 2)^{2} w_{f D}^{2} \\
& +\left(\frac{-\lambda f_{D}}{2} \csc \theta / 2 \cdot \cot \theta / 2\right)^{2} w_{\Theta / 2}^{2} .
\end{aligned}
$$

The uncertainty term associated with $\lambda$ goes to zero since $W_{\lambda} \approx 0$. Therefore,

$$
\begin{aligned}
w_{u}^{2} & =\left(2.1 \times 10^{-6} / 2 \cdot 0.0846\right)^{2}\left(0.05 \times 10^{6}\right)^{2} \\
& +\left(-2.1 \times 10^{-6} \cdot 0.44 \times 10^{6} / 2 \cdot 11.83 \cdot 11.79\right)^{2} 0.001^{2} \\
w_{u}^{2} & =0.385+0.004 \\
w_{u} & =+0.624 \mathrm{ft} / \mathrm{ser} . \mathrm{nr} . \\
w_{u} / U & =0.624 / 5.7 \approx \pm 11 \% .
\end{aligned}
$$


Intensity of Turbulence Uncertainty

The uncertainty in local intensity can be determined using the relationship,

$$
\begin{aligned}
I=U & \cdot U=E_{r m s} / E_{D C} \\
\therefore & W_{I}^{2}=\left(\frac{\partial I}{\partial E_{r m s}}\right)^{2} W_{E r m s}^{2}+\left(\frac{\partial I}{\partial E_{D C}}\right)^{2} W_{E D C}^{2} \\
& W_{I} 2=\left(1 / E_{D C}\right)^{2} W_{E r m s}^{2}+\left(-1 E_{r m s} E_{D C}^{-2}\right)^{2} W_{E D C}^{2} .
\end{aligned}
$$

The accuracy of the $D C$ voltage was specified to be $\sim \pm 0.11 v$ and the accuracy of the rms voltage was $\sim \pm 12 \mathrm{mv}$. The rms uncertainty consisted of instrument error $( \pm 2 \%)$, readability error $( \pm 10 \mathrm{mv})$, noise $( \pm 5 \mathrm{mv})$, and Doppler broadening $( \pm 2 \%)$. A detailed discussion on error due to Doppler broadening is presented in Reference 2. Therefore, for Run No. S7-346,

$$
\begin{aligned}
W_{I}^{2} & =(1 / 0.87)^{2} 0.012^{2}+\left(-0.115 \cdot 0.87^{-2}\right)^{2} 0.11^{2} \\
W_{I}^{2} & =0.00019+0.00028 \\
W_{I} & = \pm 0.0217 \\
W_{I} / I & =0.0217 / 0.132 \approx \pm i 6 \%
\end{aligned}
$$

\section{Data Point Location Uncertainty}

The uncertainty in the location of a particular data point relative to its neighbors in the $x$ direction (parallel to the laser beam) was \pm 0.001 inches. This uncertainty is essentially that of the positioning capability of the $1 \mathrm{ift} /$ traversing table.

Uncertainties of the locations of the data traverses in the $y$ direction (perpendicular to the laser beam) relative to adjacent rod rows can be estimated as follows:

$$
y_{T}=\Delta y / 2
$$


where

$$
\begin{aligned}
& y_{T}=y \text { location of the data traverse } \\
& \Delta y=\text { distance between rod rows as measured with the LDA. }
\end{aligned}
$$

The uncertainty of measuring the distance between rods was estimated to be \pm 0.020 inches. Therefore,

$$
\begin{aligned}
& w_{y T}^{2}=\left(\frac{\partial^{y} T}{\partial \Delta y}\right)^{2} w_{\Delta y}{ }^{2} \\
& w_{y T}^{2}=(1 / 2)^{2} w_{\Delta y}^{2} . \\
& w_{y T}^{2}=1 / 4 \cdot 0.020^{2}=0.0001 \\
& w_{y T}= \pm 0.010 \text { inches. }
\end{aligned}
$$

The axial location of a particular data plane relative to the blockage axial centerline could be determined within $\sim \pm 0.100$ inches. This uncertainty estimate was determined by considering measurement accuracy and trueness of the horizontal travel of the lift/traversing table during any one data traverse. 


\section{APPENDIX C \\ TABULATION OF \\ REDUCED DATA}




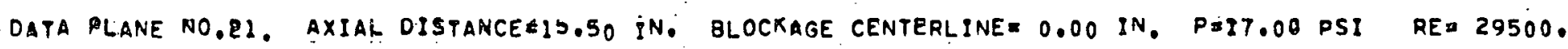

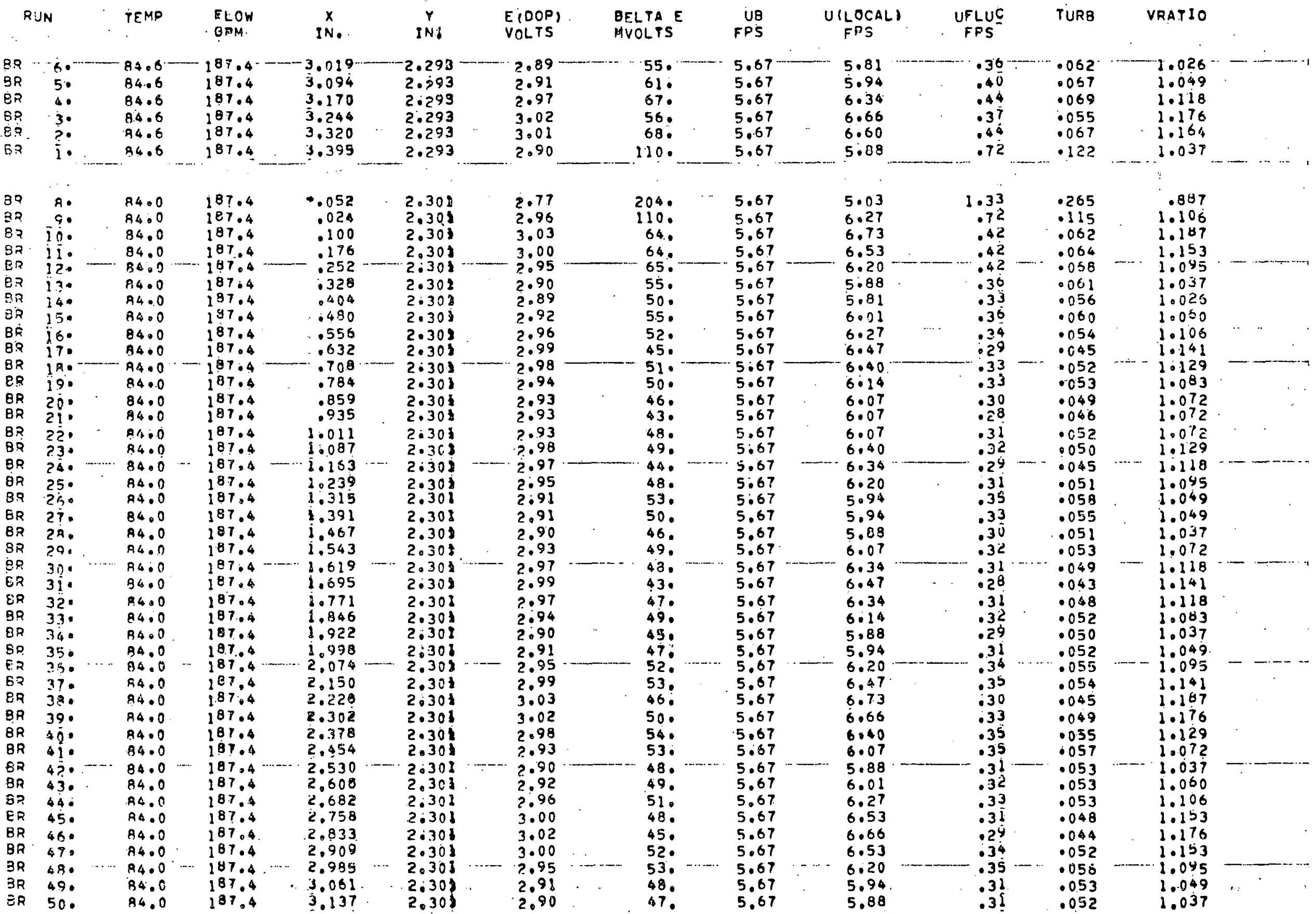




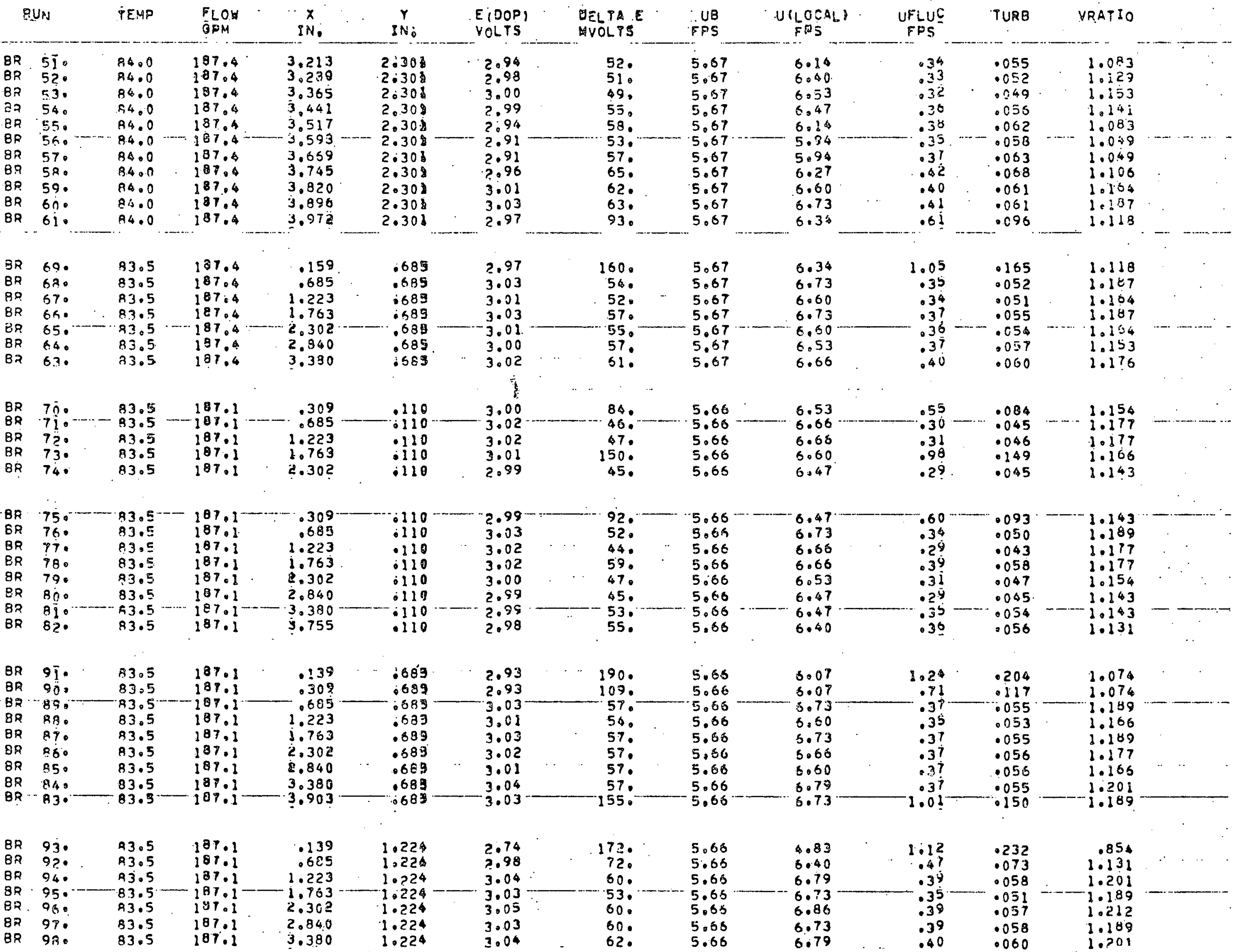




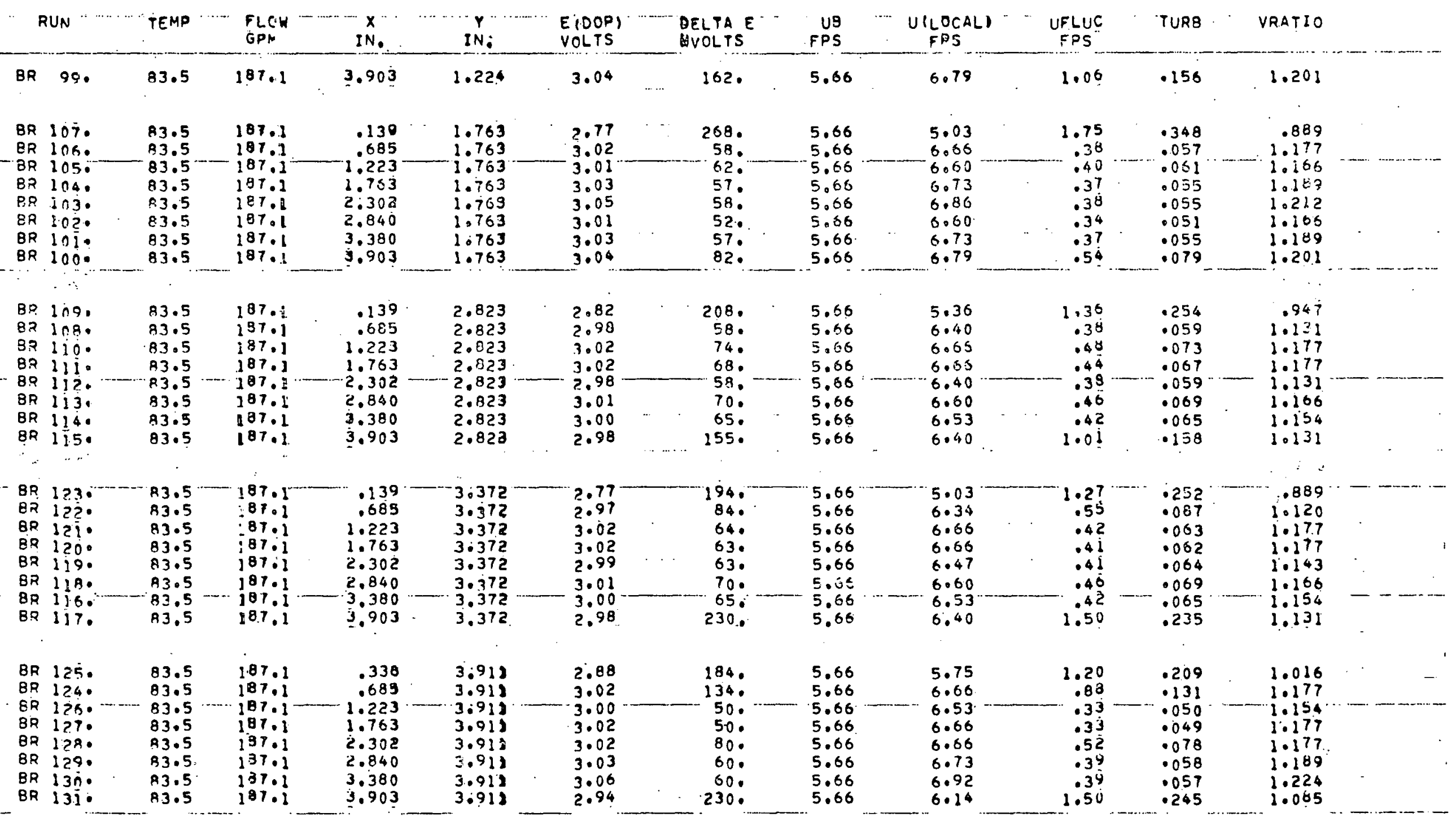


OATA PLANE No.23. AXIAL OISTTANCEF27.50 IN. BLOCKAGE CENTERLINE= 0.0n IN. P=17.00 PSI REa 29200.

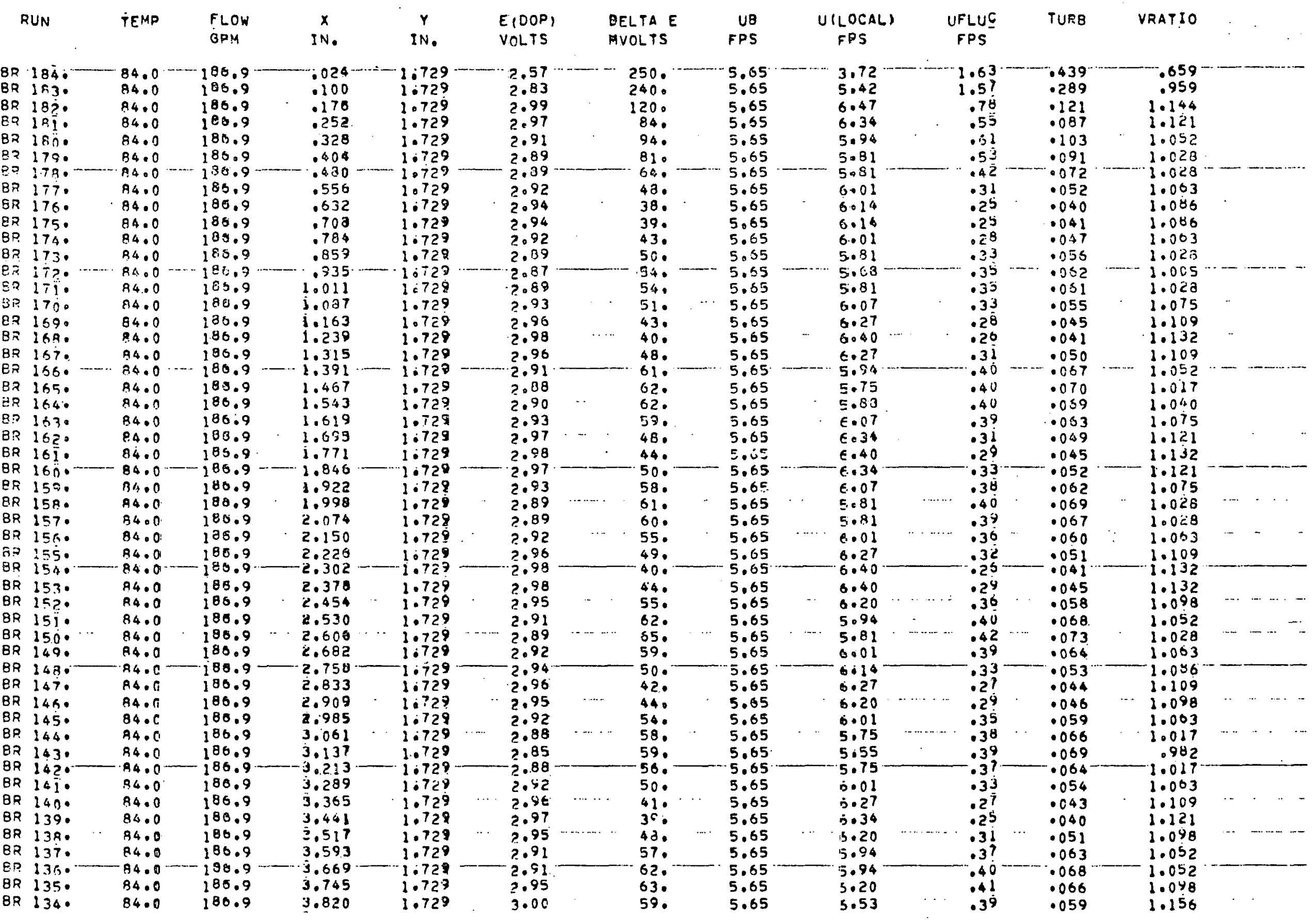




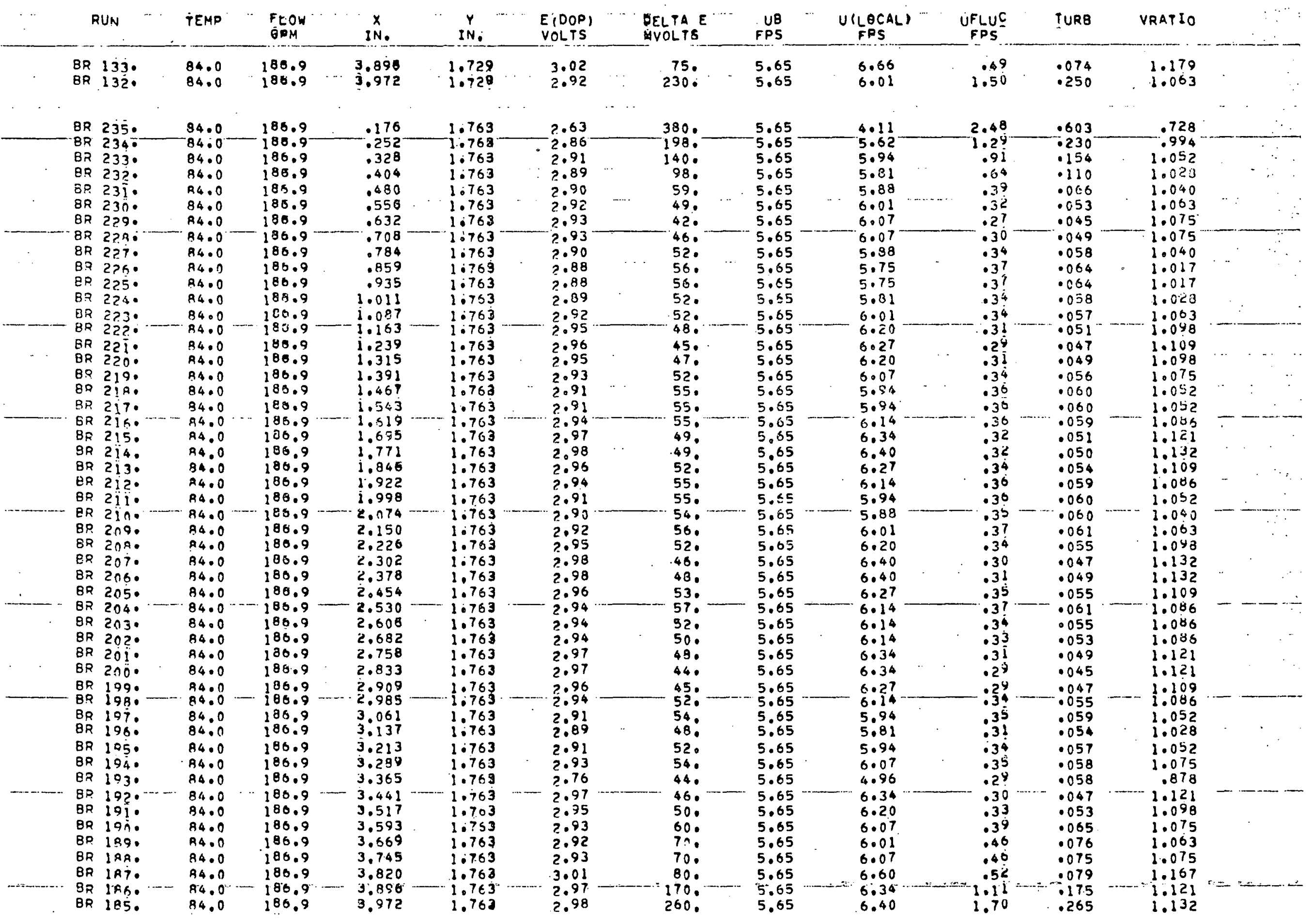




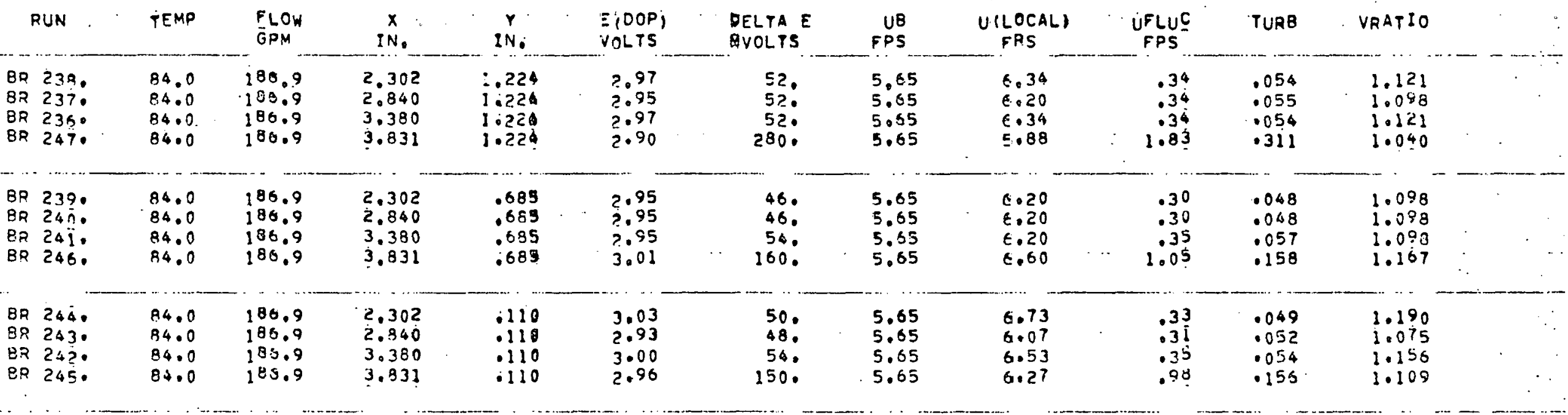




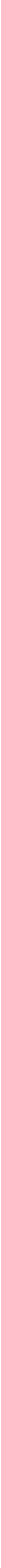




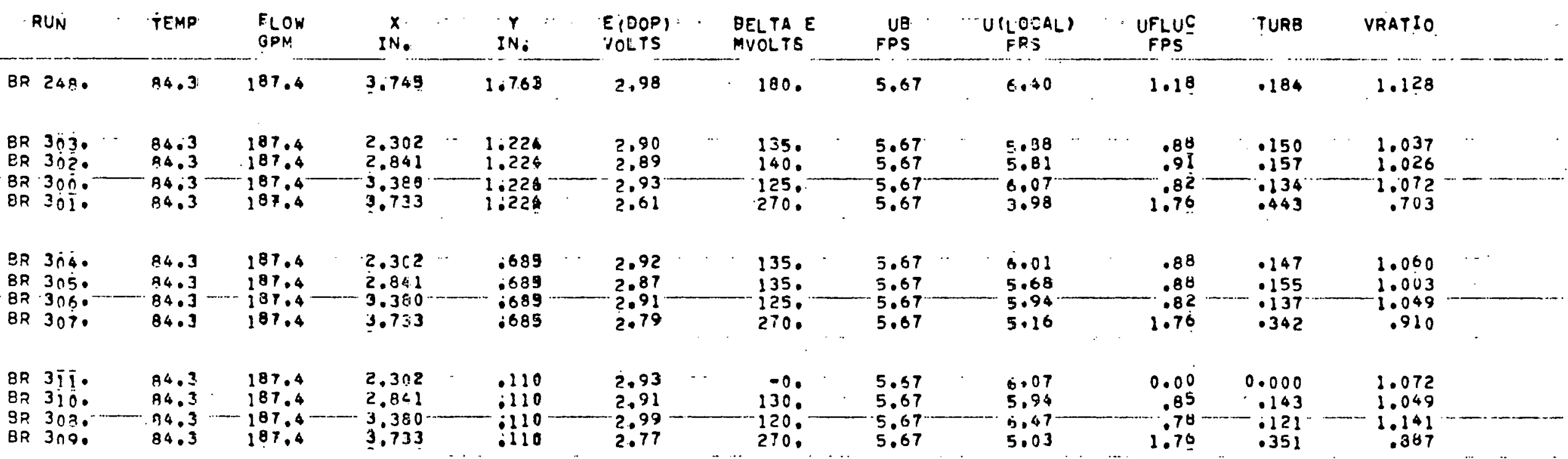


TABLE :CEI. TABULATION OR EXPERIMENTAL LDA OATA

dATA PLANE N0.24. AXIAL DISTANCE 33.50 IN. BLOCKAGE CENTERLINE= 0.00 IN. PEI7.00 PSI RE= 29400.

RUN TEMP FLOW

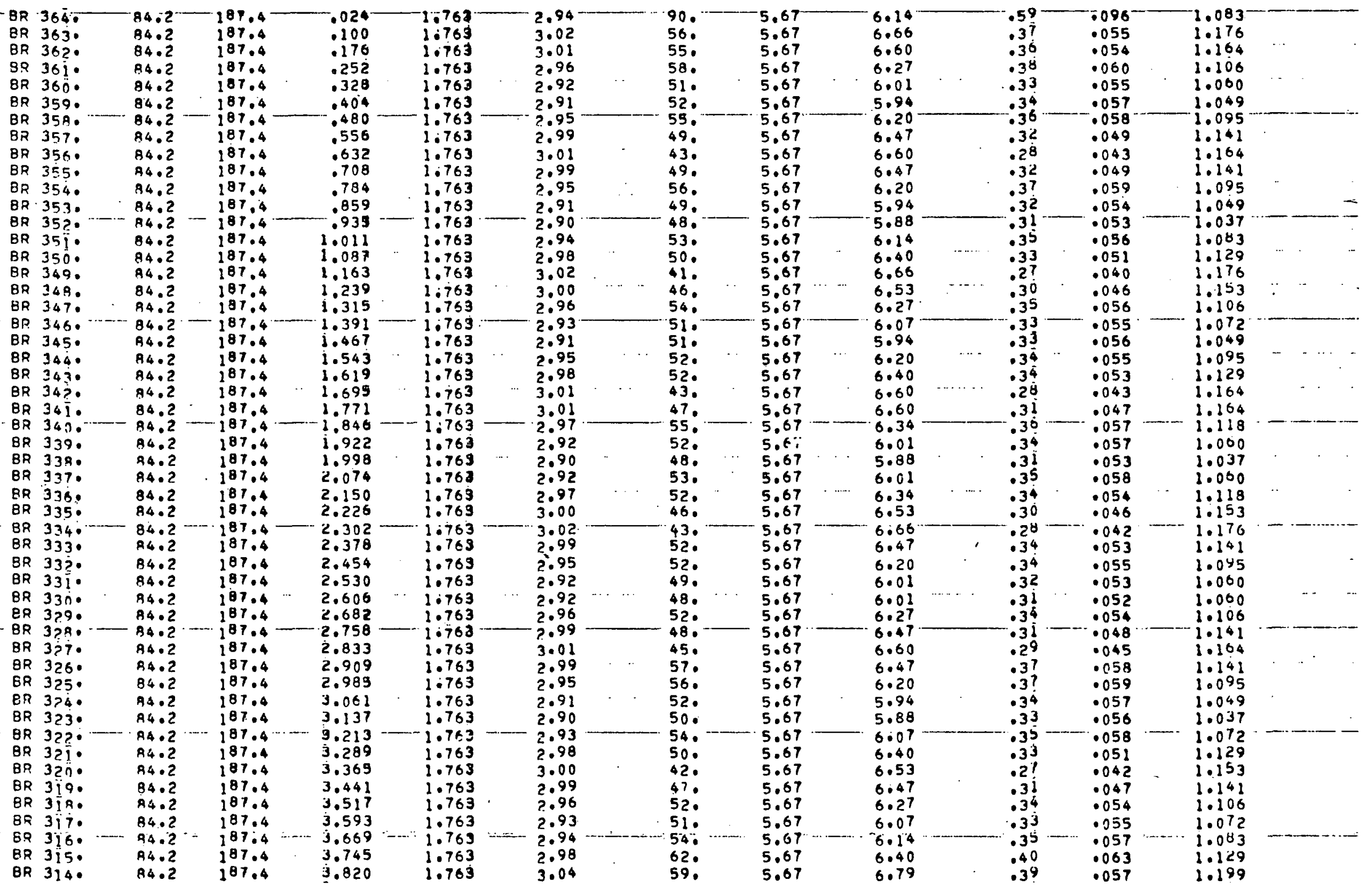




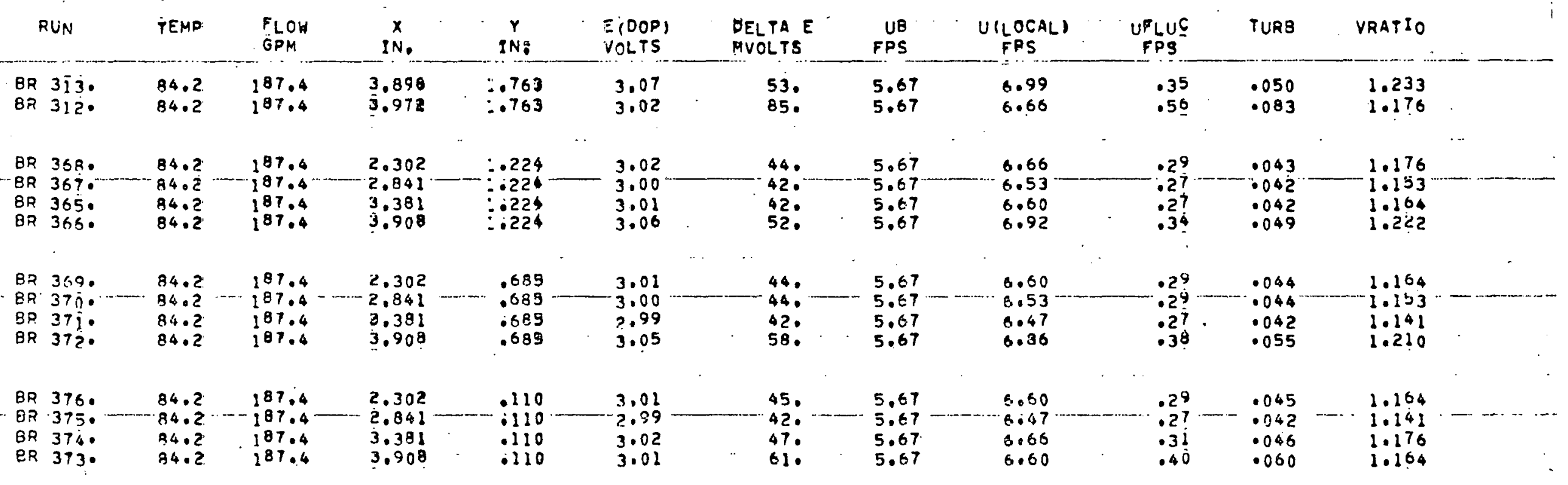


TSBLE CEI. TABULATION OR EXPERIMENTAL LDA DATA

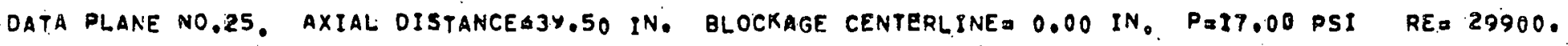

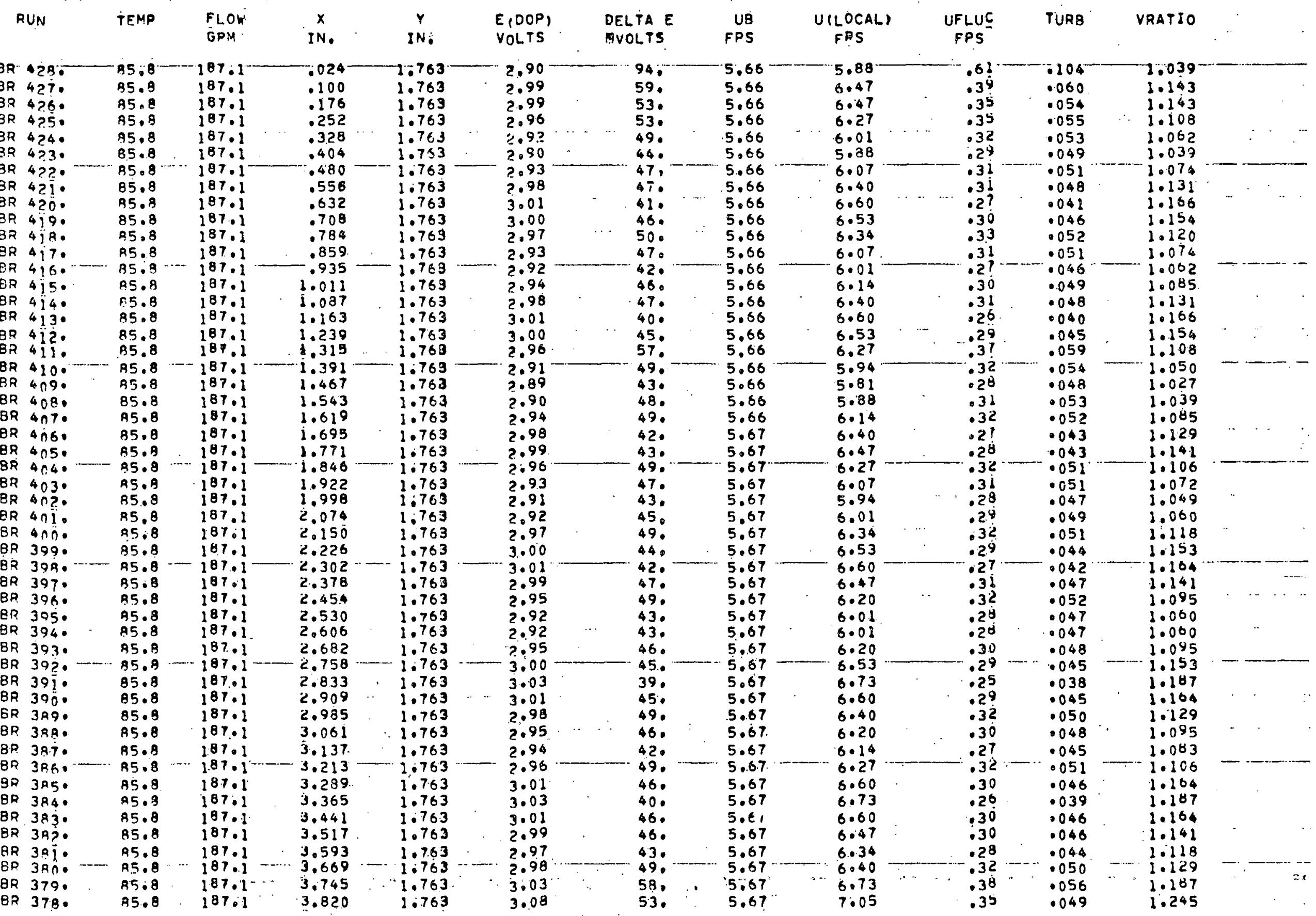




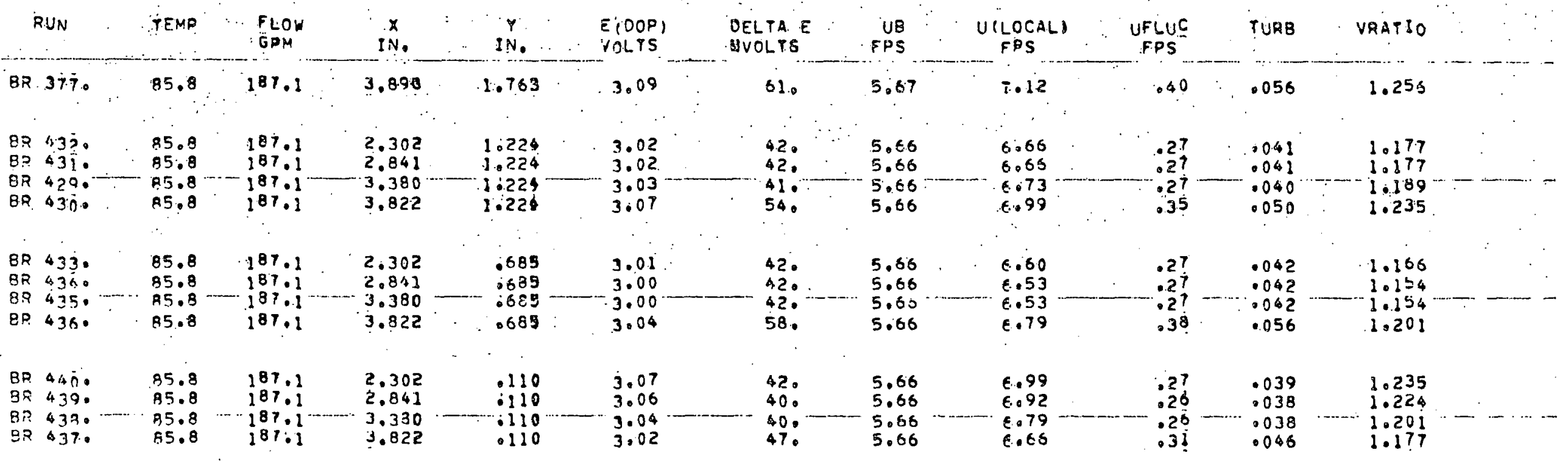




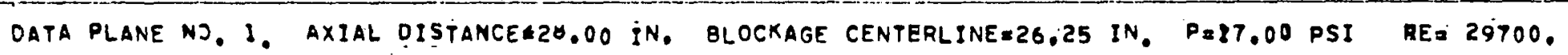

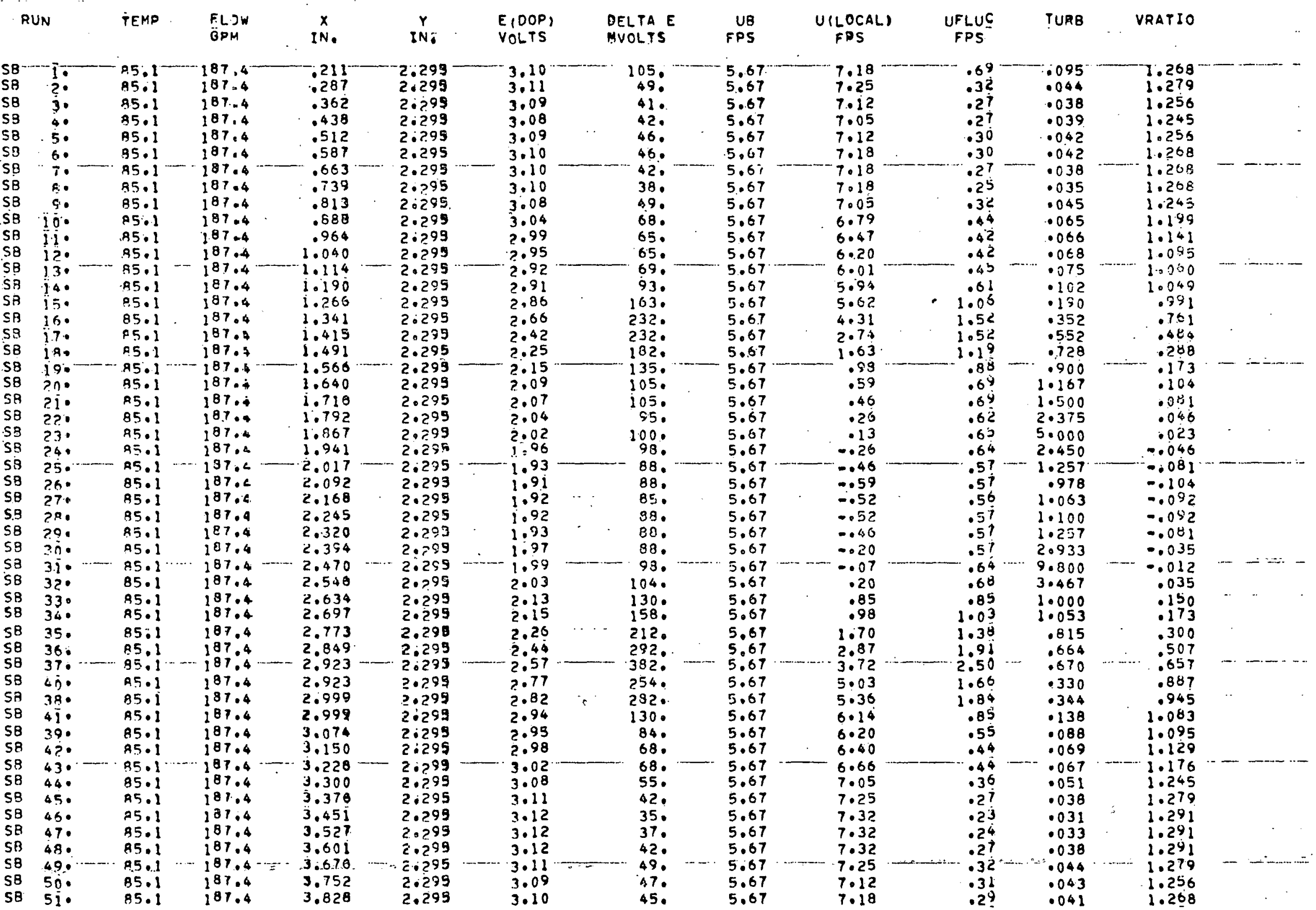




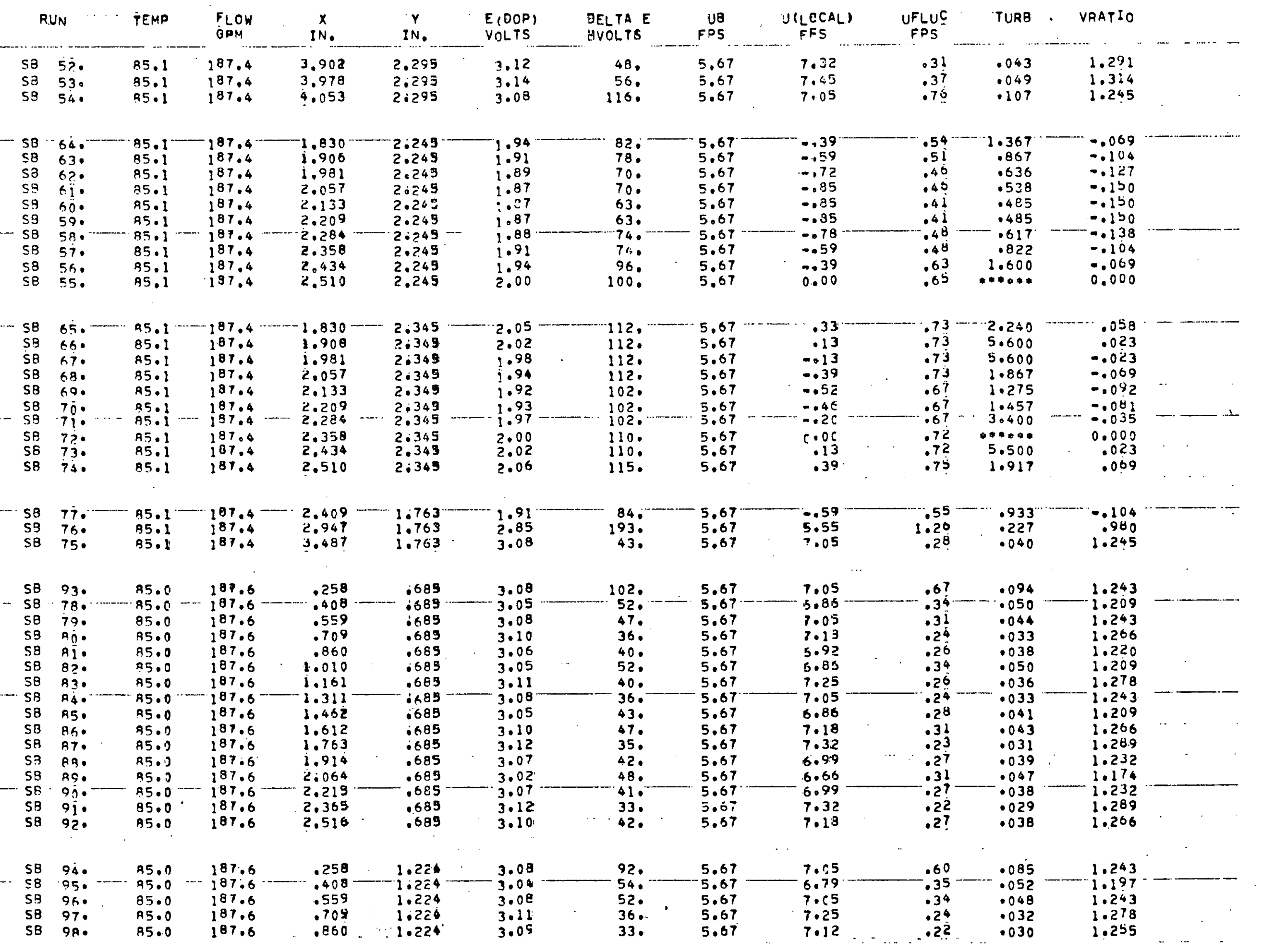




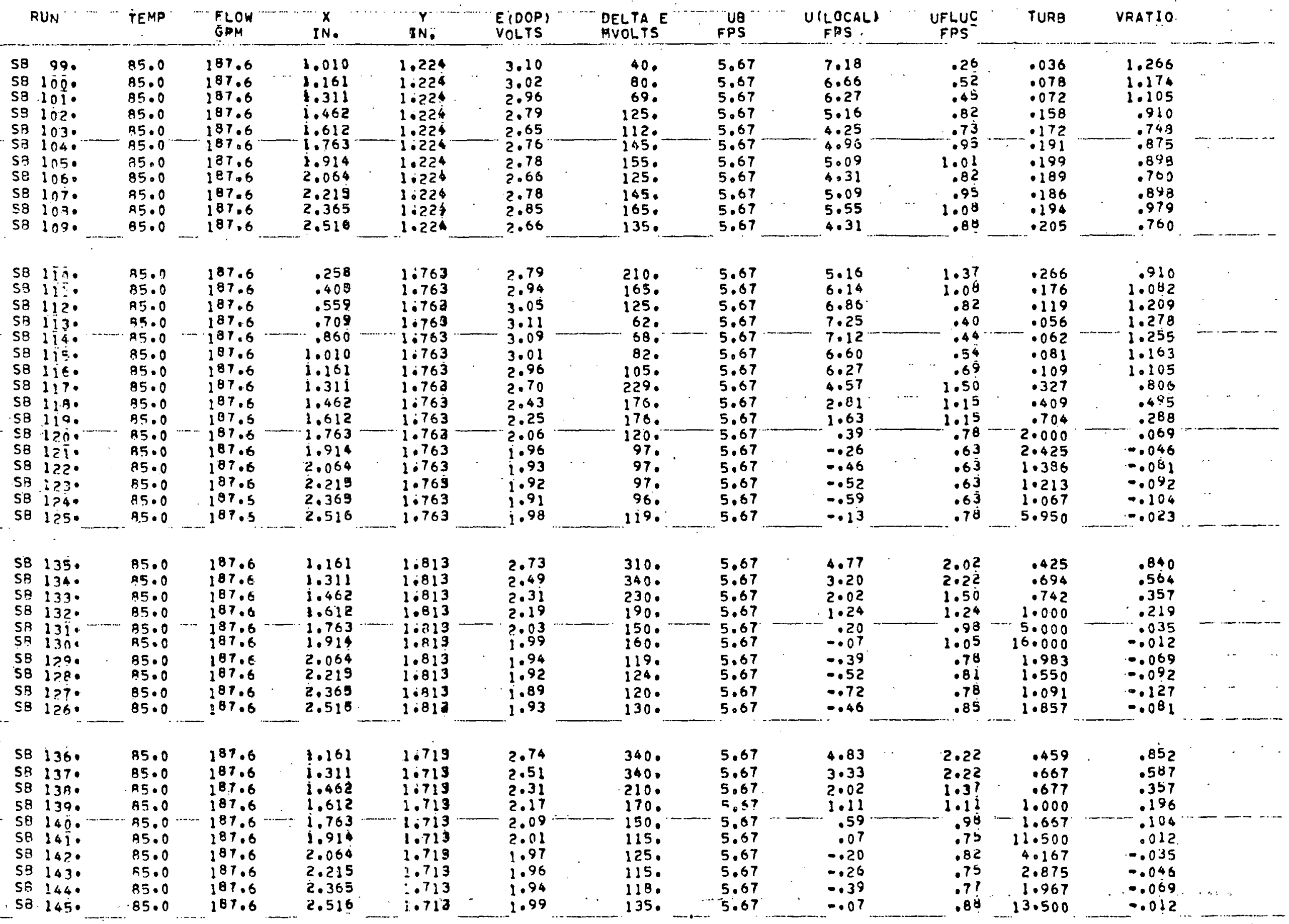


TABLE Cal. TAJULATION OF EXPERIMENTAL LDA DATA

DatA PLANE No, 1. AXIAL DISTANCE\$20.00 iN, BLOCKage CENTERLINE=26.25 IN. Pa87.00 PSI RE= 29800 .

RUN

FLOW
GFM

IN.

Y

E'DOP)
VOLTS

BELTA E
MVOLTS

UB
FPS

ULLOSAL)

UFLUC
FPS

TURB

VRATIO

$58-155^{\circ}$
$58154^{\circ}$

$\begin{array}{lll}85.2 & 187.9 & 1.010 \\ 85.2 & 187.9 & 1.161\end{array}$

$58153^{\circ}$

58152

$5315 i^{\circ}$

Sa $150^{\circ}$

SA 142.

581460

$85 \cdot 2$
85.2

187.9

1.274

$3.04 \cdot$

54.

5.63

$6: 70$

\subsection{0}

$.052 \cdots-1: 195-\cdots$

$18.5 \quad 1.462 \quad 12274$

$\begin{array}{llll}85.2 & 187.9 & 1.612 & 1.270 \\ 85.2 & 187.9 & 1.763 & 1.27\end{array}$

$85.2 \ldots 187.9 \ldots 1.914 \ldots 1.270$

$0=03 \quad 187.7 \quad 3.064$

$6502 \quad 187$.

85.? 187.9

2.064

2. 369

1.274

1.274
1.276

2.79

2.59

127.

125.

5.68
5.69

5.69
5.69

5.68

5.68

1610

2.72
2.59

2.59
2.68

$1.27 A$

2.79

110.

$150 \circ$

5.68

5.68

5.68
5.68

6.79
6.53

5.16

3.85

4.38

$3 i .85$

4.64

$5 \cdot 18$
$4 \cdot 11$

.35
.35
.83

.83
.82

1.01

1.05

126.

.98

1.03
.82

$\begin{array}{rr}.053 & 1.149 \\ .161 & .908\end{array}$

$\begin{array}{ll}.161 & .908 \\ .212 & .678\end{array}$

.231 .0770

$.224 \quad . .823$

.676

.221
.199

.179
$.200 \quad .724$

$\begin{array}{ll}S 2 & 1560^{\circ} \\ 59 & 157^{\circ} \\ 58 & 150^{\circ} \\ 53 & 159^{\circ} \\ 53 & 160^{\circ} \\ 58 & 161^{\circ} \\ 58 & 162^{\circ} \\ 58 & 163^{\circ} \\ 58 & 164^{\circ} \\ 53 & 155^{\circ}\end{array}$

$\begin{array}{ll}95.2 & 187.9 \\ 85.2 & 187.9 \\ 85.2 & 197.9 \\ 85.2 & 197.9 \\ 85.2 & 187.9 \\ 85.2 & 137.9 \\ 85.2 & 187.9 \\ 85.2 & 187.9 \\ 85.2 & 187.9 \\ 85.2 & 187.9\end{array}$

1.010
1.161
1.311

$10170-2.91-$

79.

$5.68 \ldots$

5.94

1.178

1.178

1.462

1.612

1.763

1.174

1.17 .

1.914

1.174

$? .94$
2.76

2.61

2.81
2.80

1.174

2.219

1.174

2.06
2.75

2.88

92.

5.68

5.58

130.

139.
146.

5.68
5.68

5.68
5.68

6.14
6.96

6.96
3.98

5.68

3.98
5.29

5.29
5.23

107.

5.68

5.88

5.23
4.91

130.

137 .

5.68

5.75

5.75
6.51

$\begin{array}{lll}.52 & .087 & 1.046 \\ .60 & .098 & 1.050 \\ .93 & .187 & .874 \\ .85 & .213 & .701 \\ .91 & .172 & .931 \\ .95 & .183 & .920 \\ .70 & .162 & .759 \\ .83 & .169 & .802 \\ .83 & .148 & 1.012 \\ .89 & .199 & .793\end{array}$


TABLE CI. TABULATION OF EXPERIMENTAL LOA DATA

DATA PLANE NO, 2. AXIAE DISTANCEE33.50 IN. BLOEKAGE CENTERLINE=26.25 IN. PaIT.00 PSI RE 29800 .

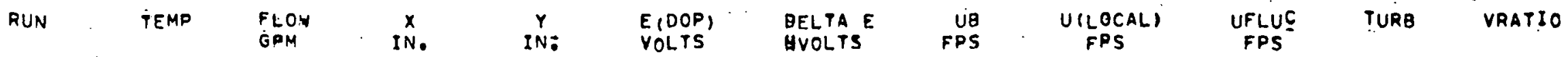

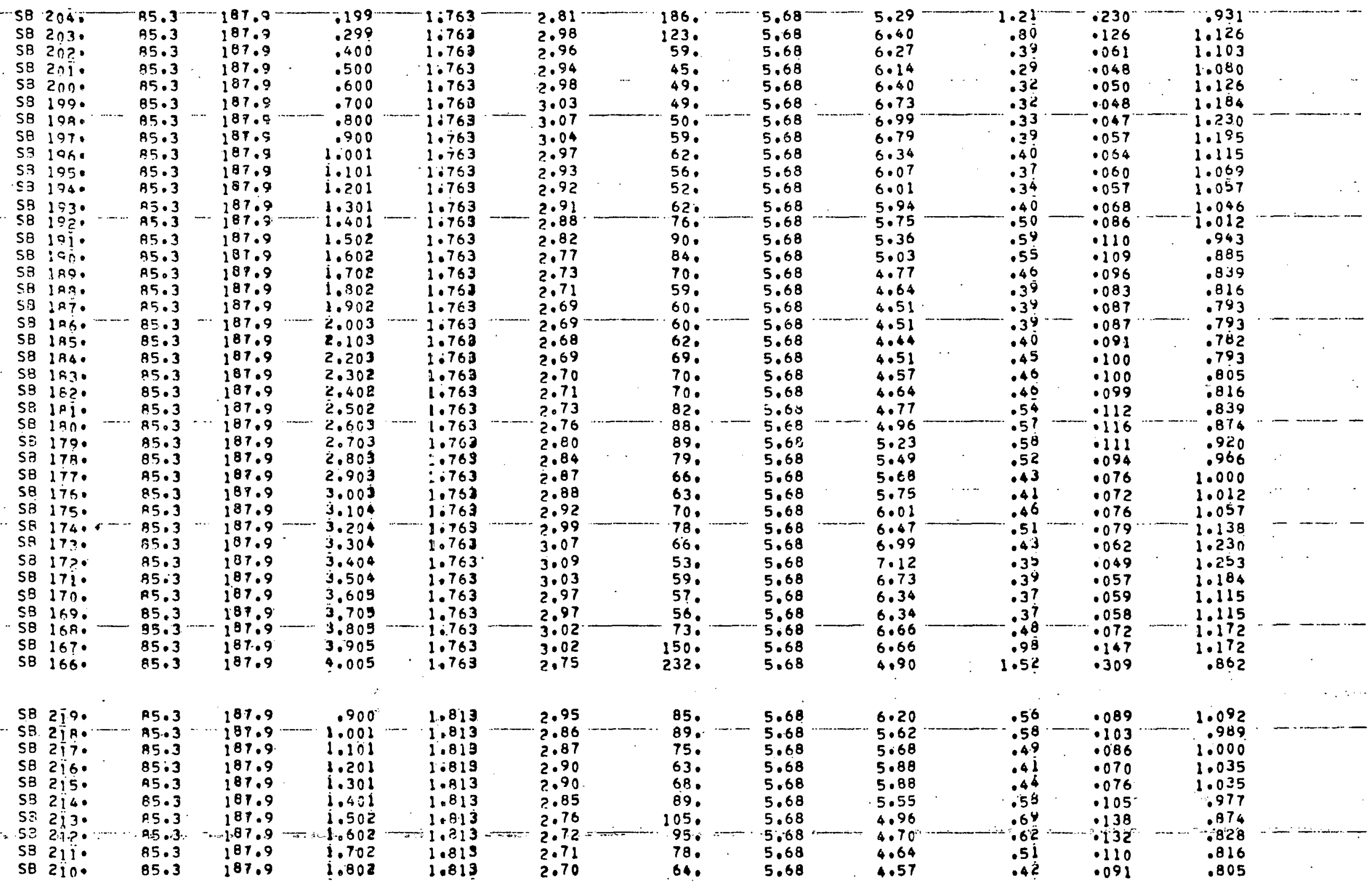




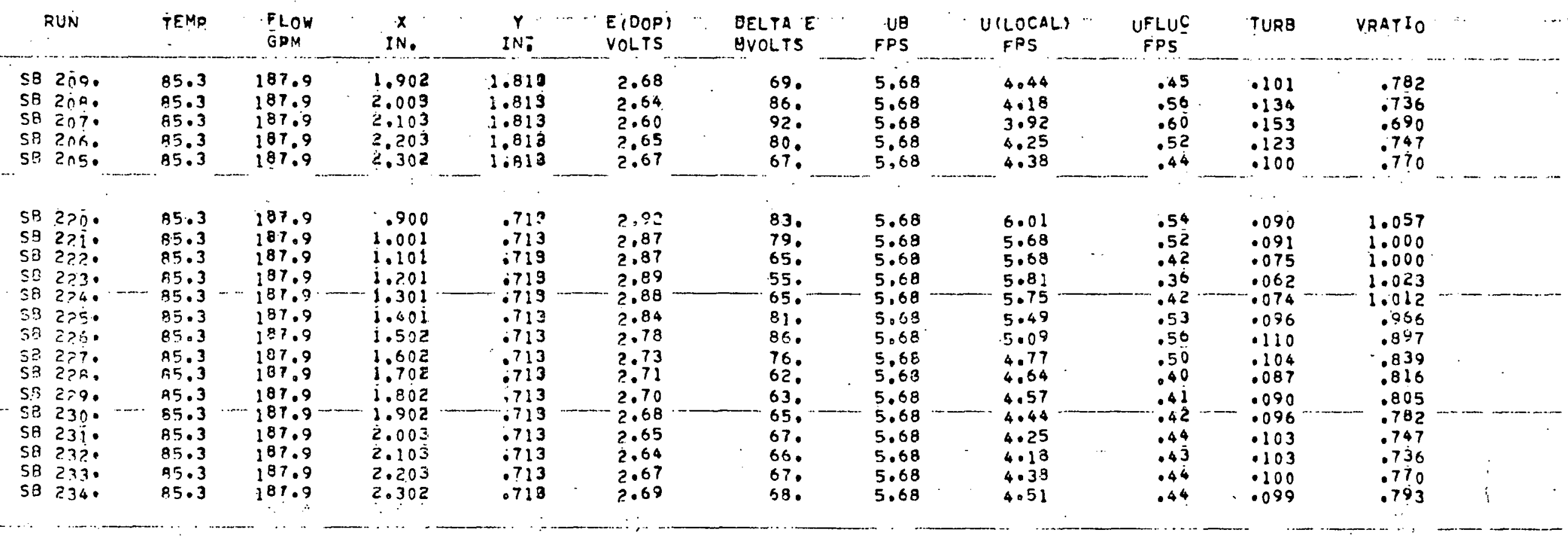


OATA PLANE NO. 2. AXIAL DISTANCE\$35.50 IN. BLOCKAGE CENTERLINE=26.25 IN. P=17.00 PSI RE= 29800.

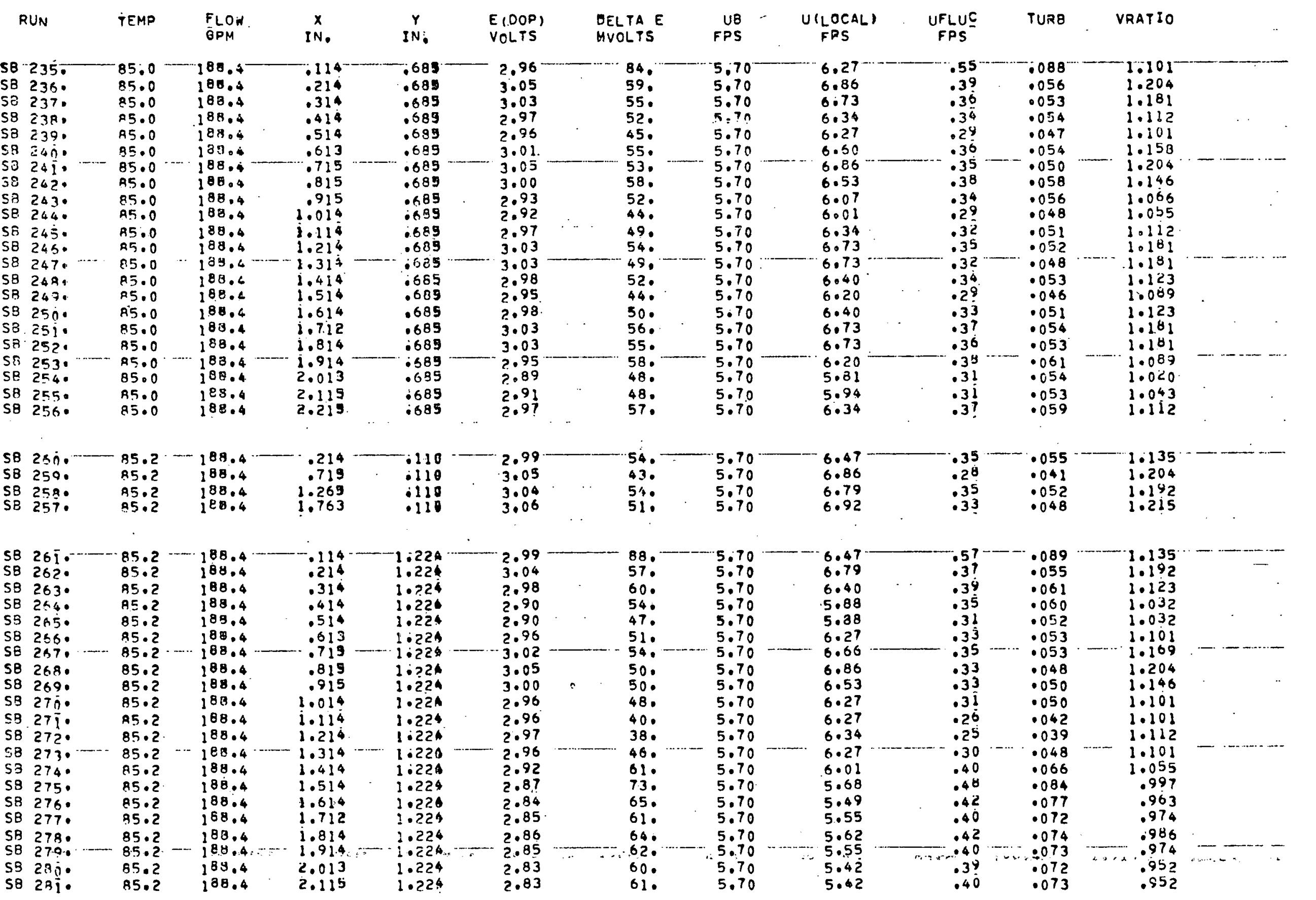




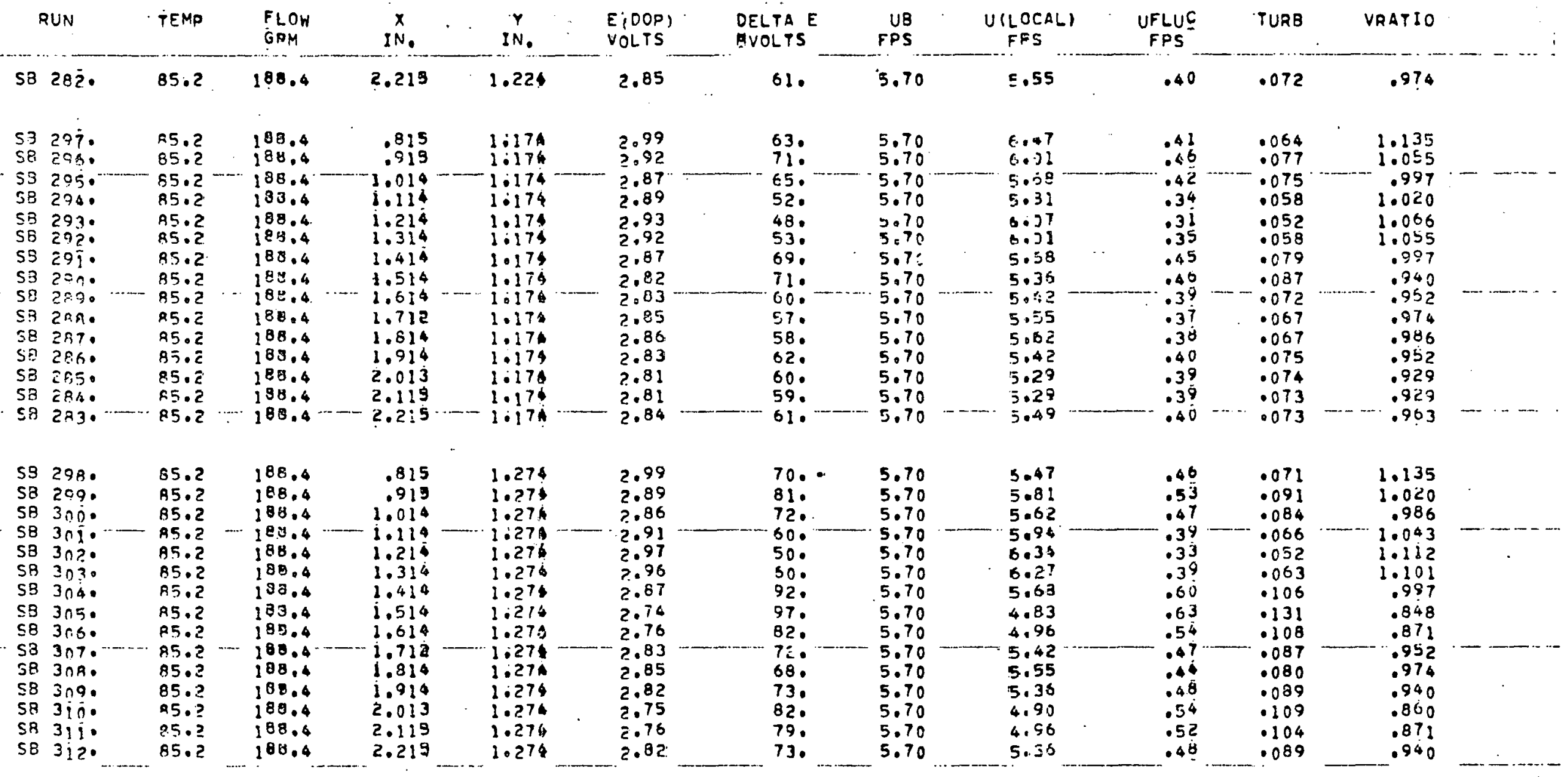


TABLE CII. TABULATION OF EXPERIMENTAL LOA OATA

DATA PLANE MO, 3. AXIAL DISTANCE 21.55 IN. BLOCKAGE CENTERLINE=26.25 IN. Pa17.00 PSI REa 29400.

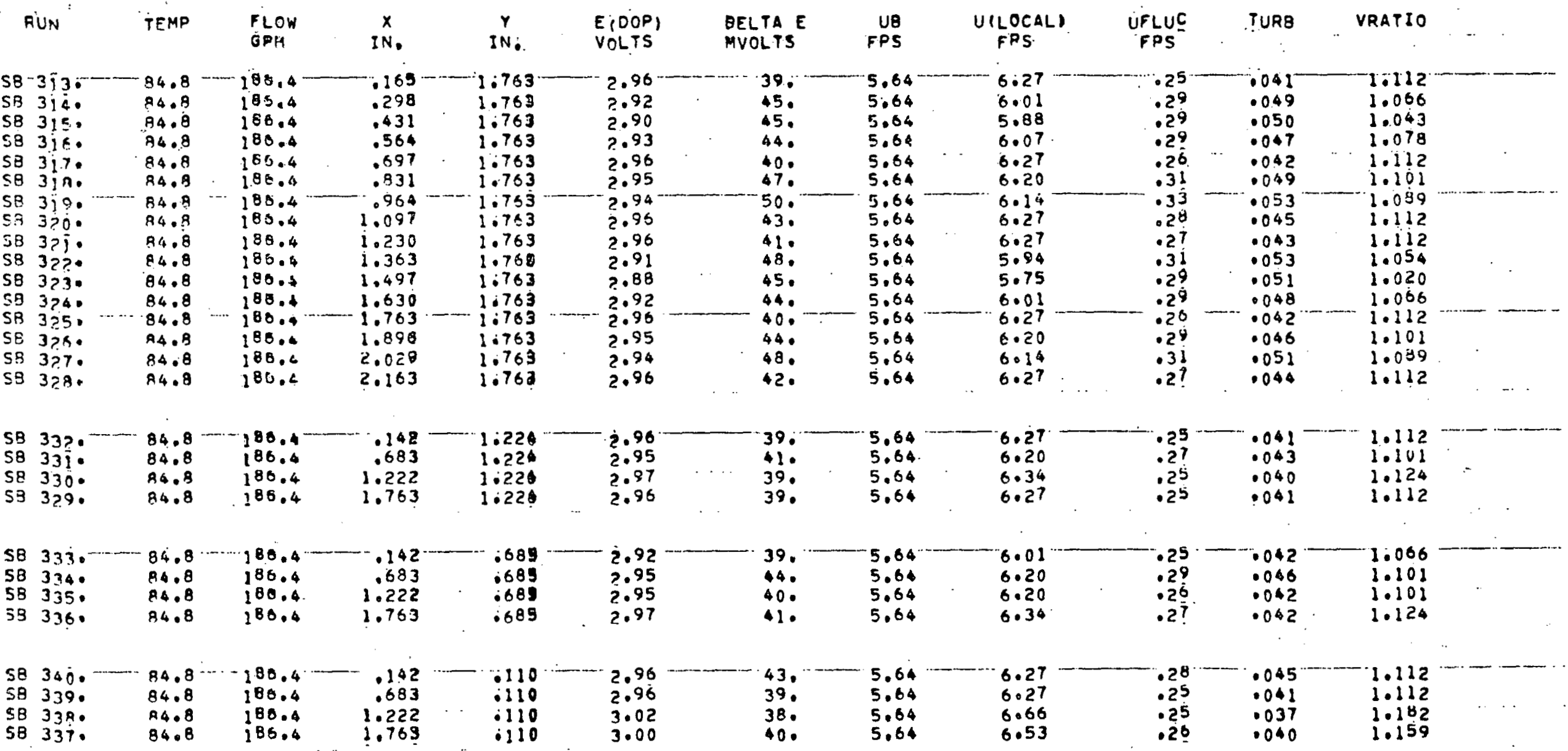




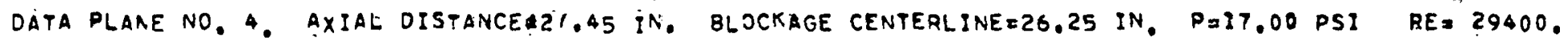

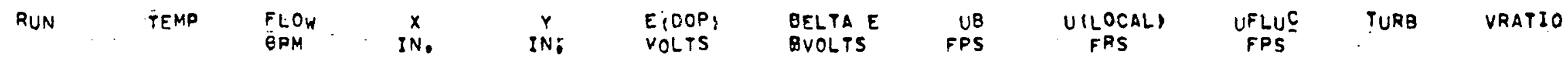

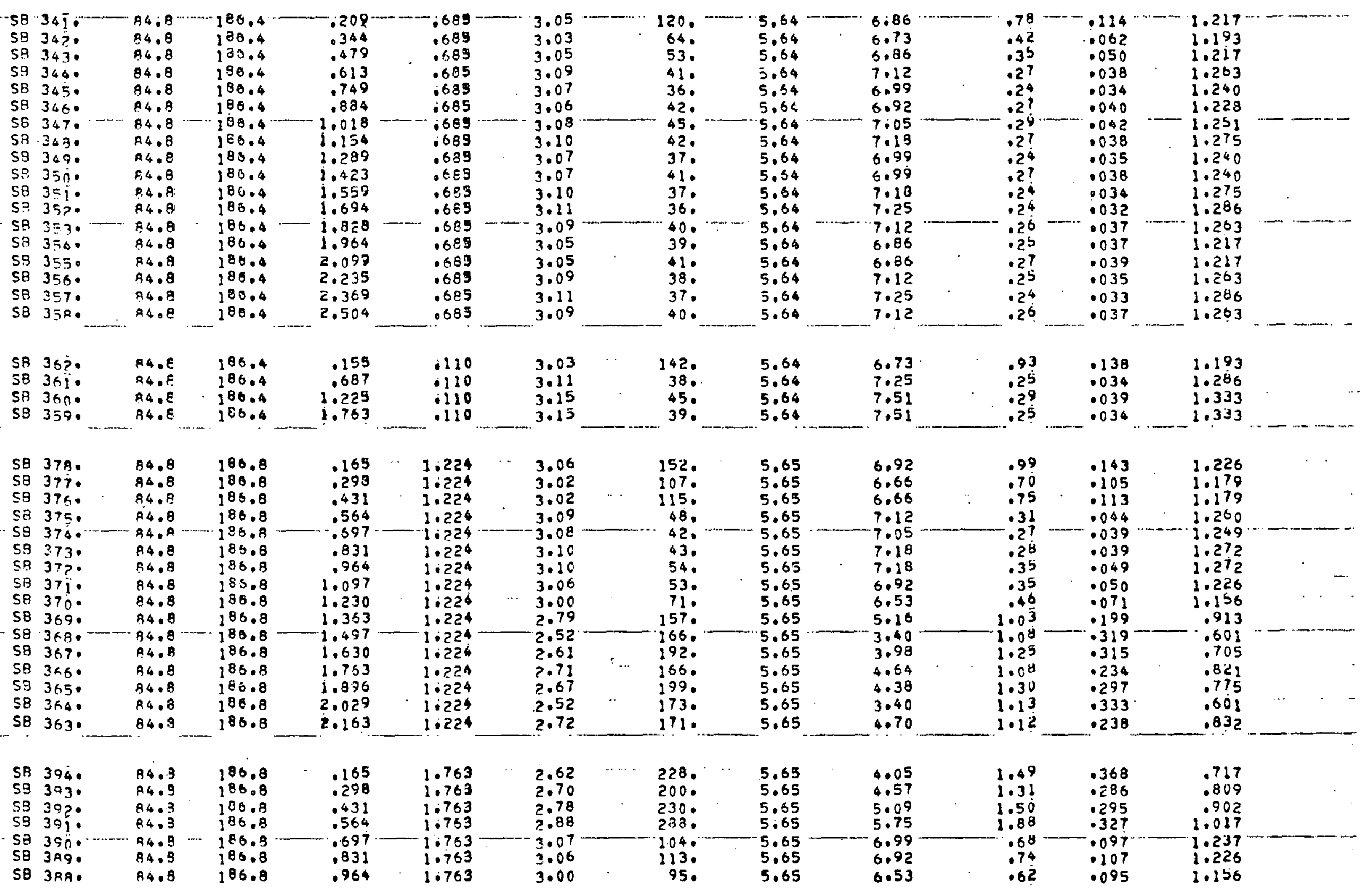




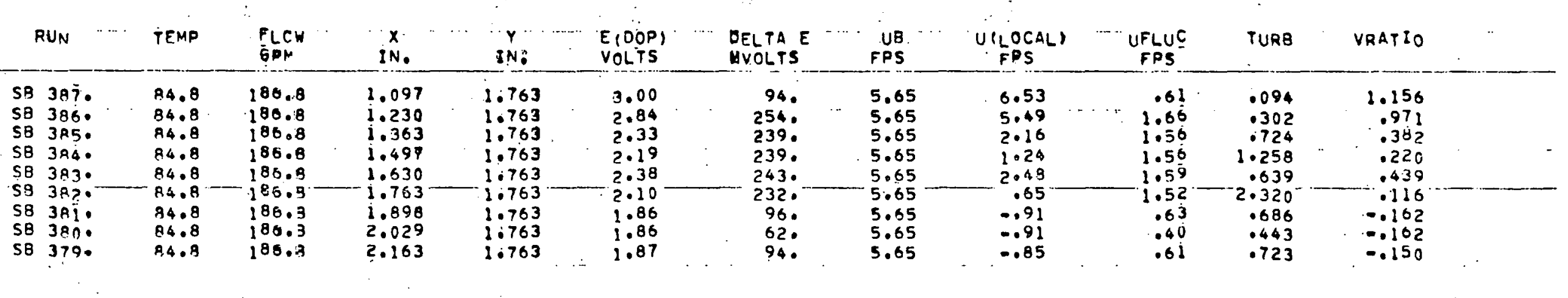


DATA PLANE NO. 5. AXIAL OISTARCE\$20.20 IN. BLOCKAGE CENTERLINE=26.25 IN. PEI7.j0 PSI REz 29400.

RUN TEMP FLOW G

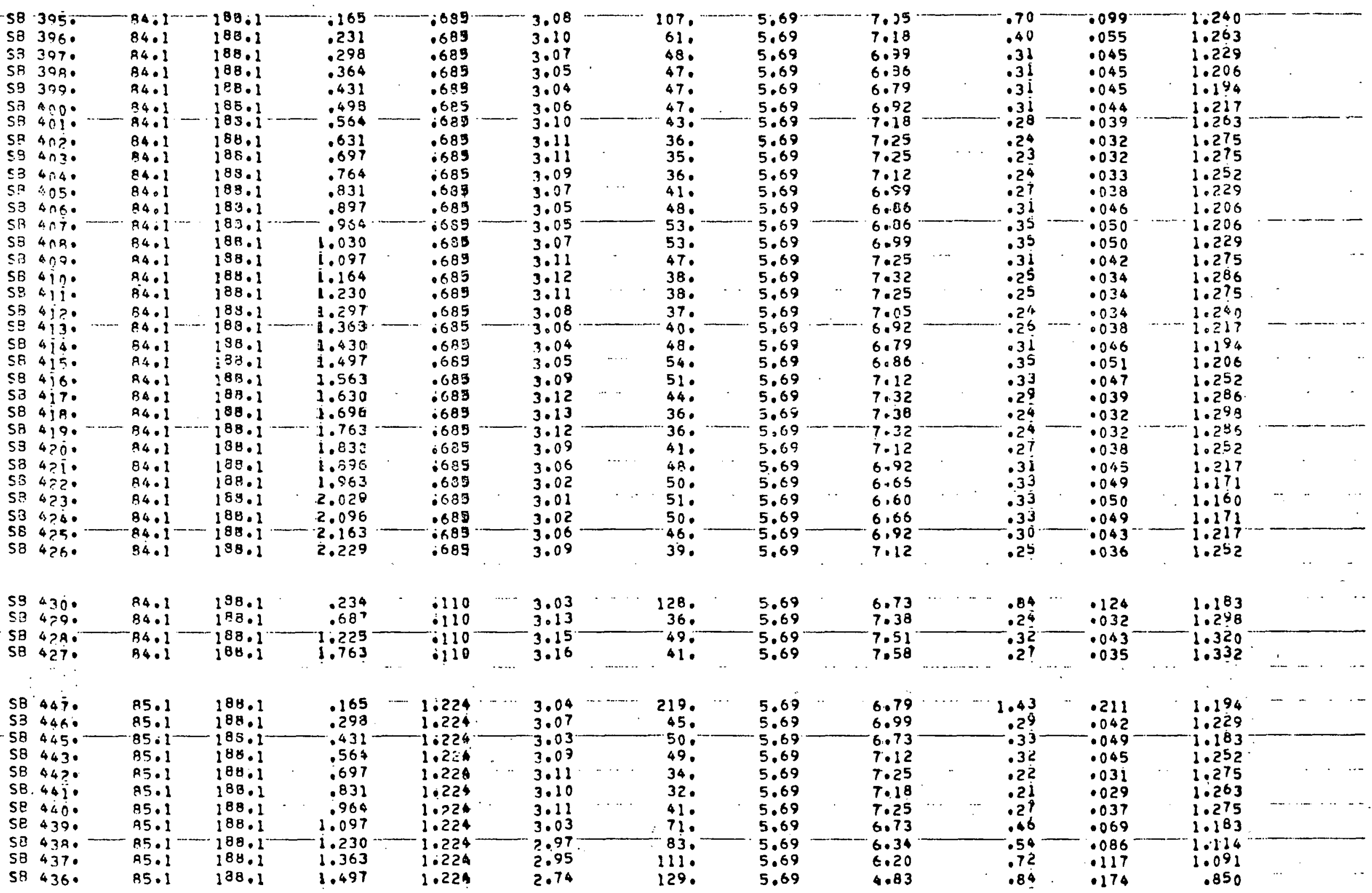




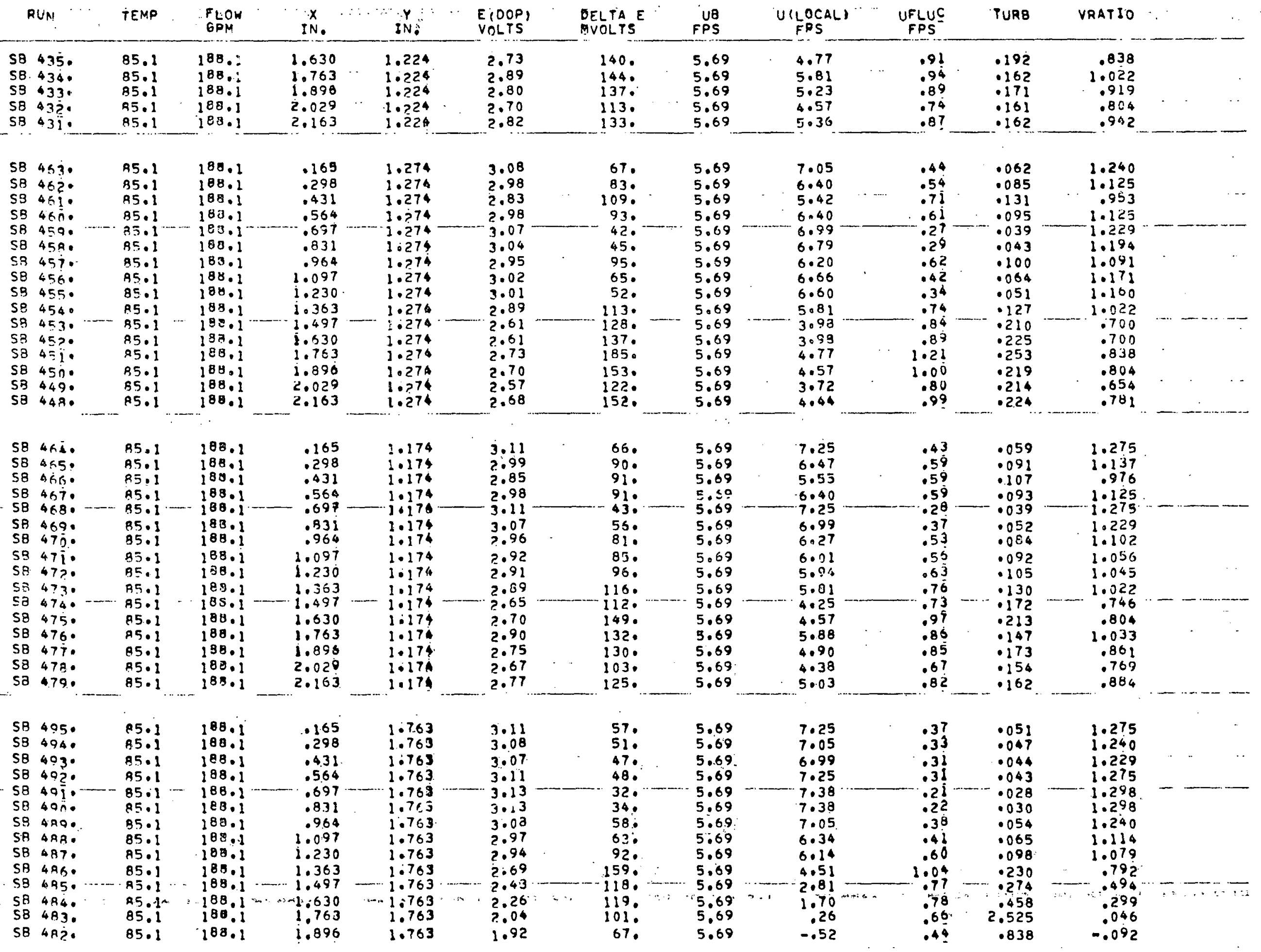




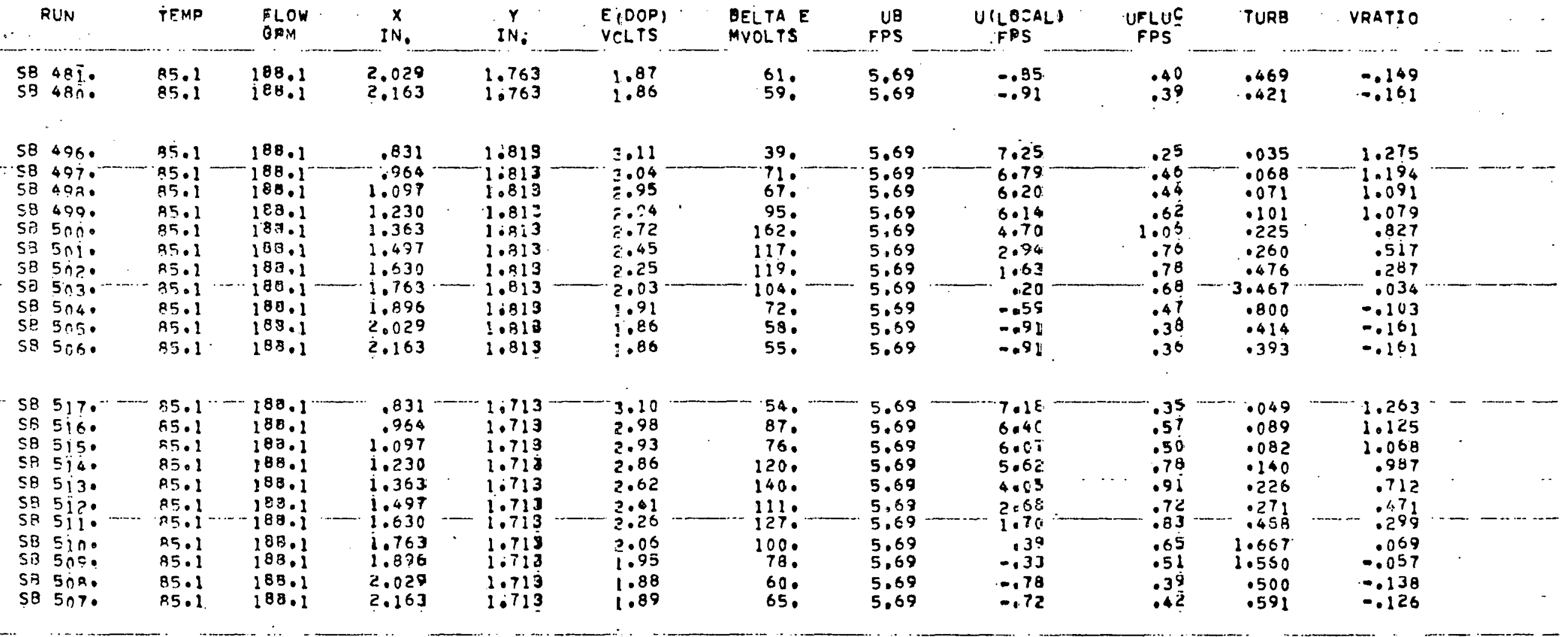




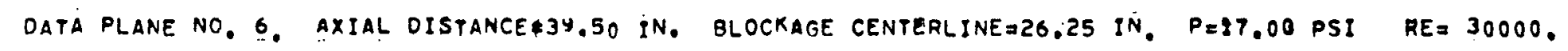

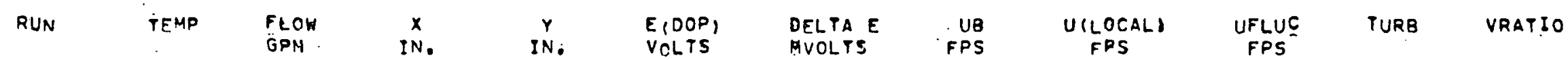

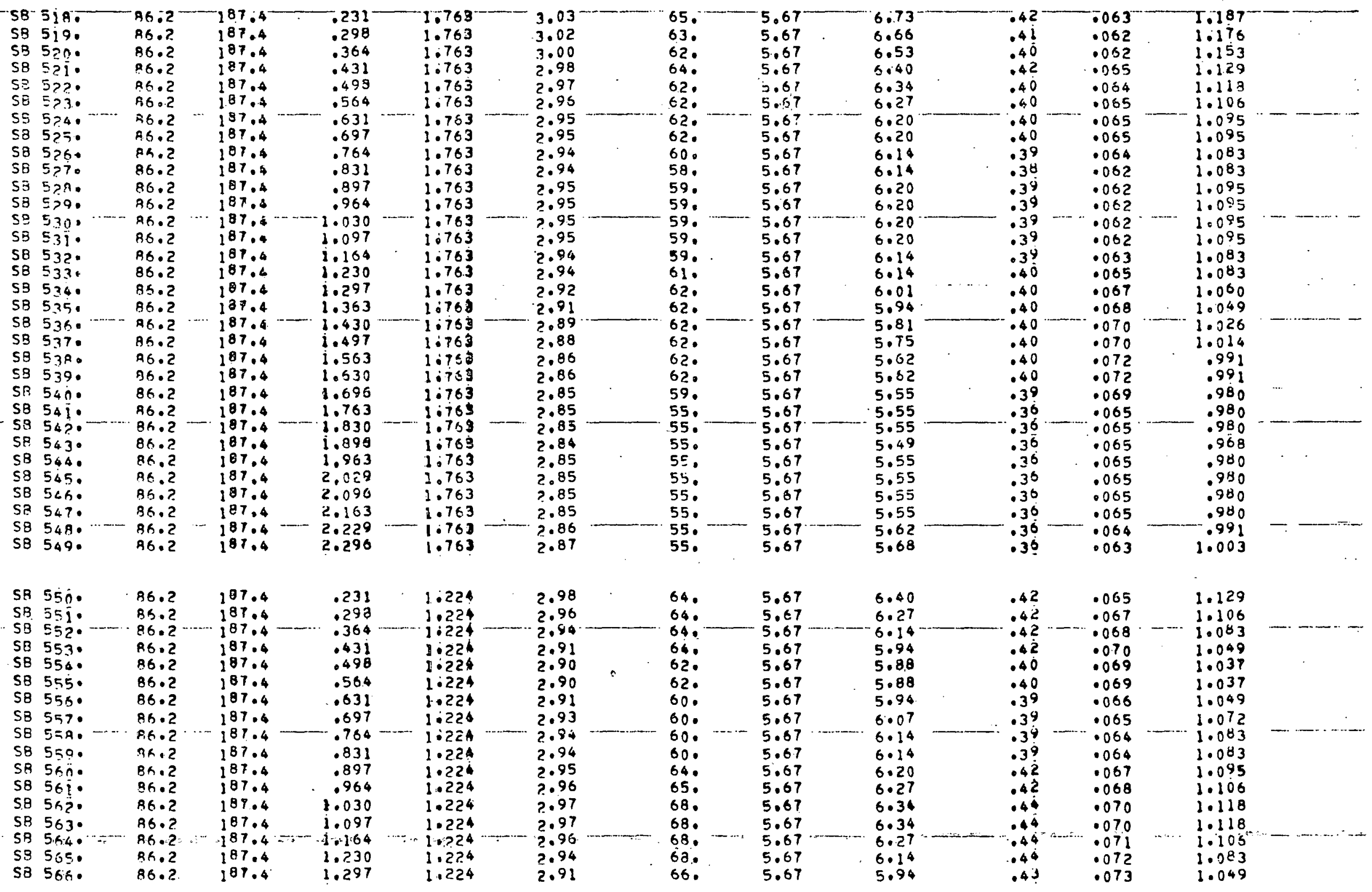




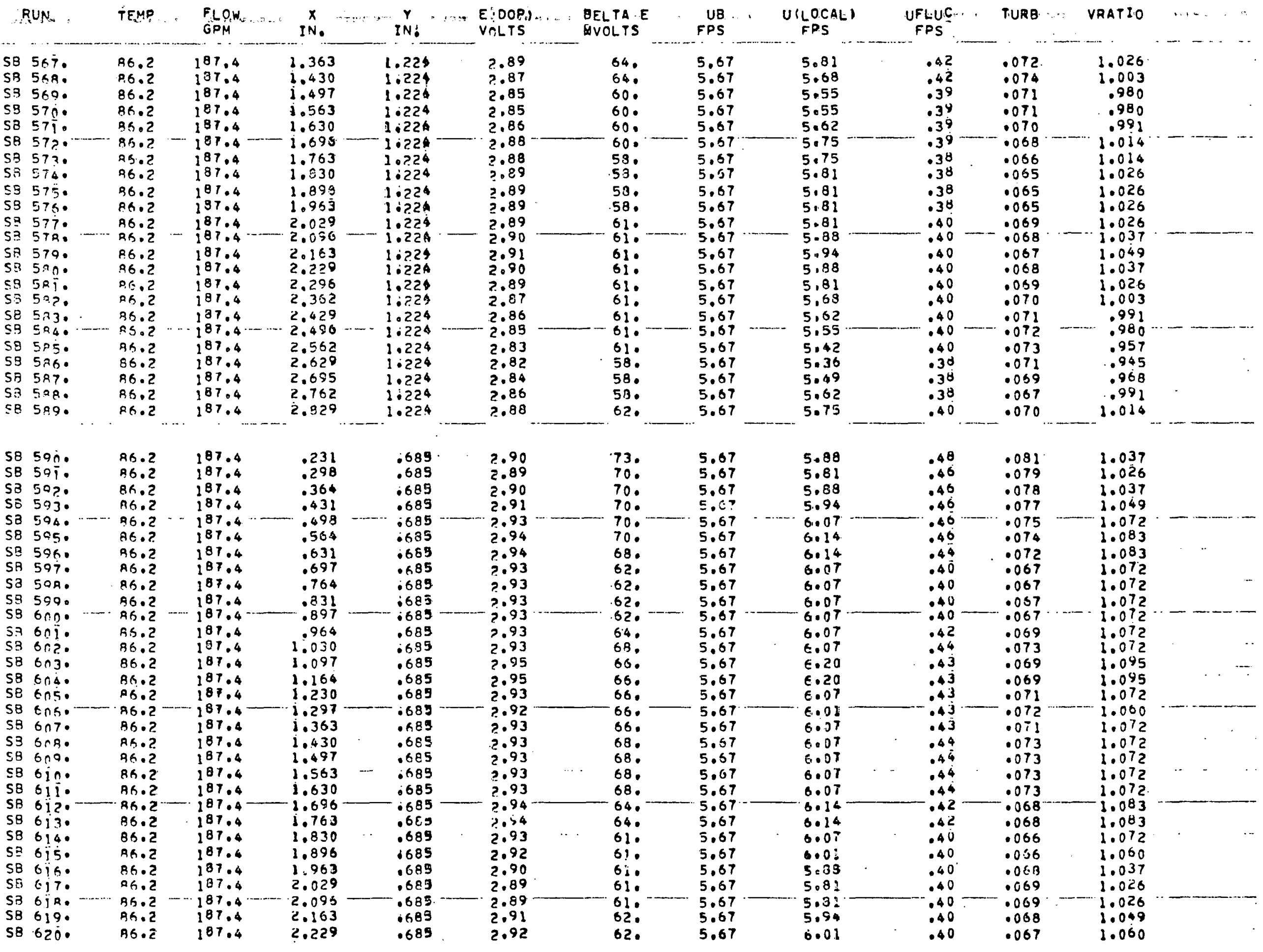




\begin{tabular}{|c|c|c|c|c|c|c|c|c|c|c|c|c|c|}
\hline RUN & TEMP & $\begin{array}{l}\text { FLOW } \\
\text { ODM }\end{array}$ & $\begin{array}{c}x \\
I N .\end{array}$ & $\begin{array}{c}Y \cdot- \\
\text { IN. }\end{array}$ & $\begin{array}{l}\text { E (DOP) } \\
\text { VOLTS }\end{array}$ & $\begin{array}{l}\text { DELTA E } \\
\text { MVOLTS }\end{array}$ & $\begin{array}{l}\text { UB } \\
\text { FPS }\end{array}$ & $\begin{array}{c}\text { U(LOCAL) } \\
\text { FOS }\end{array}$ & $\begin{array}{l}\text { UFLUS } \\
\text { FPS }\end{array}$ & TUAB & VRATIO & & \\
\hline $\begin{array}{ll}58 & 690^{\circ} \\
58 & 691^{\circ} \\
58 & 600^{\circ} \\
58 & 689 .\end{array}$ & $\begin{array}{l}86.2 \\
86.2 \\
86.2 \\
86.2\end{array}$ & $\begin{array}{l}187.4 \\
137.4 \\
187.4 \\
187.4\end{array}$ & $\begin{array}{r}.310 \\
.607 \\
1.229 \\
1.763\end{array}$ & $\begin{array}{l}.110 \\
.110 \\
.110 \\
.110\end{array}$ & $\begin{array}{l}3.05 \\
2.98 \\
3.01 \\
3.00\end{array}$ & $\begin{array}{l}67 . \\
74: \\
68: \\
58 .\end{array}$ & $\begin{array}{l}5.67 \\
5.67 \\
5.67 \\
5.67\end{array}$ & $\begin{array}{l}6.86 \\
6.40 \\
6.60 \\
6.53\end{array}$ & $\begin{array}{l}.44 \\
.48 \\
.44 \\
.38\end{array}$ & $\begin{array}{l}.064 \\
.076 \\
.067 \\
.058\end{array}$ & $\begin{array}{l}1.220 \\
1.129 \\
1.164 \\
1.153\end{array}$ & - & - \\
\hline
\end{tabular}


DATA FLANE NO. 7. AXIAL DISTANCEA51.50 IN. BLOCKRGE CENTERLINE=26.25 IN. P=17.00 PSI RE=30000.

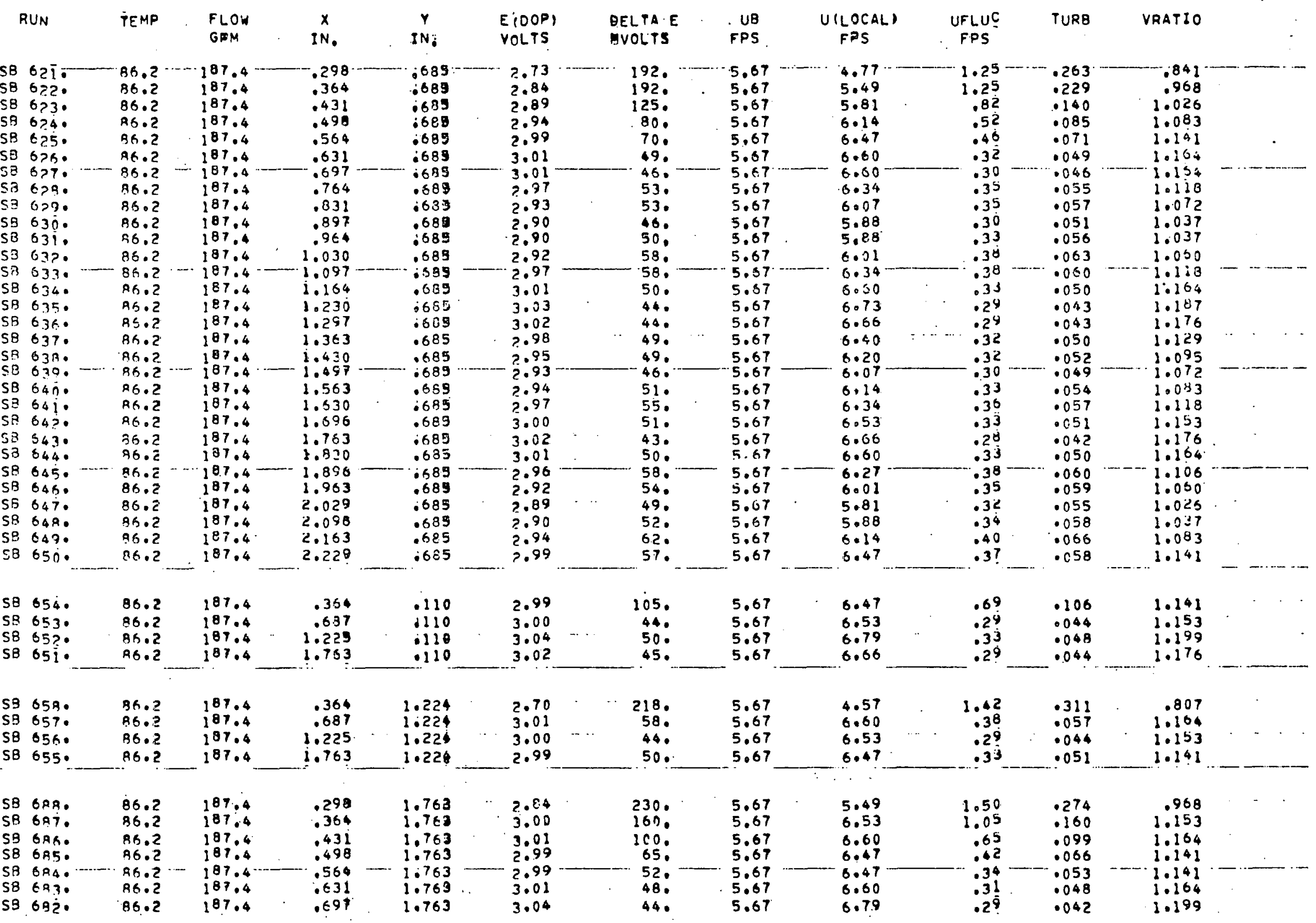




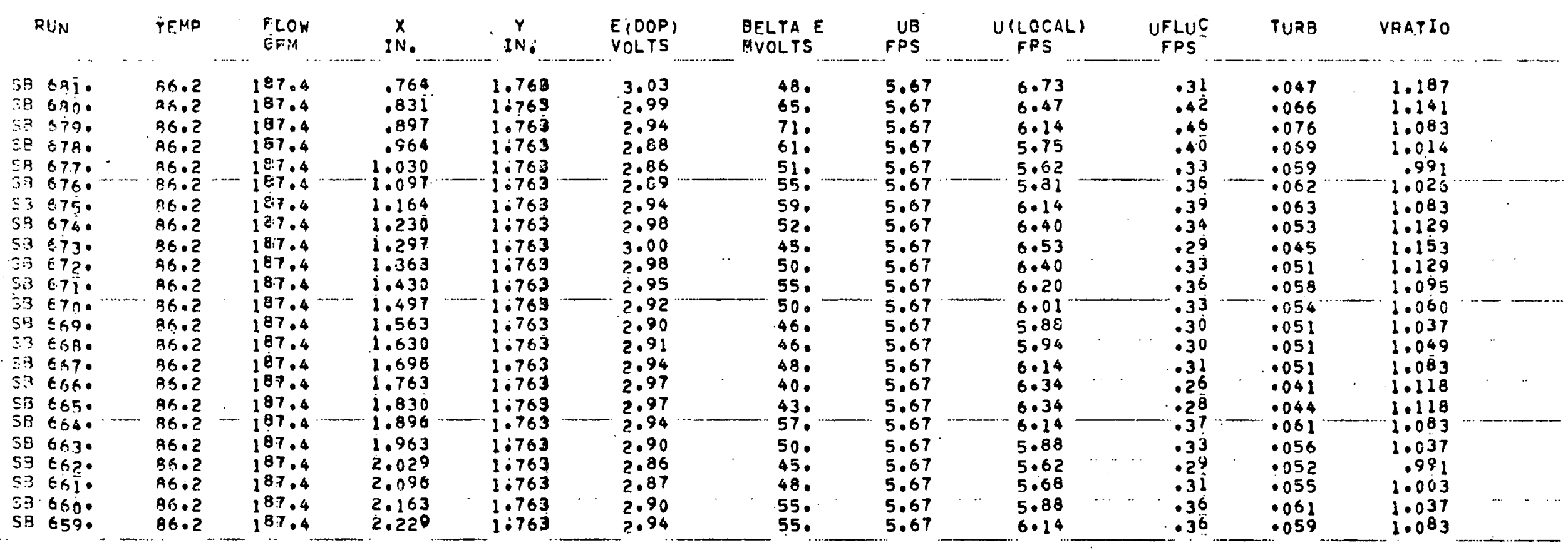




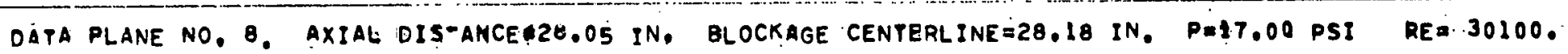

RUN TEMP FLOW $X X$ EIOOPI OELTAE UB UTLOCALI UFLUC TURB VRATIO

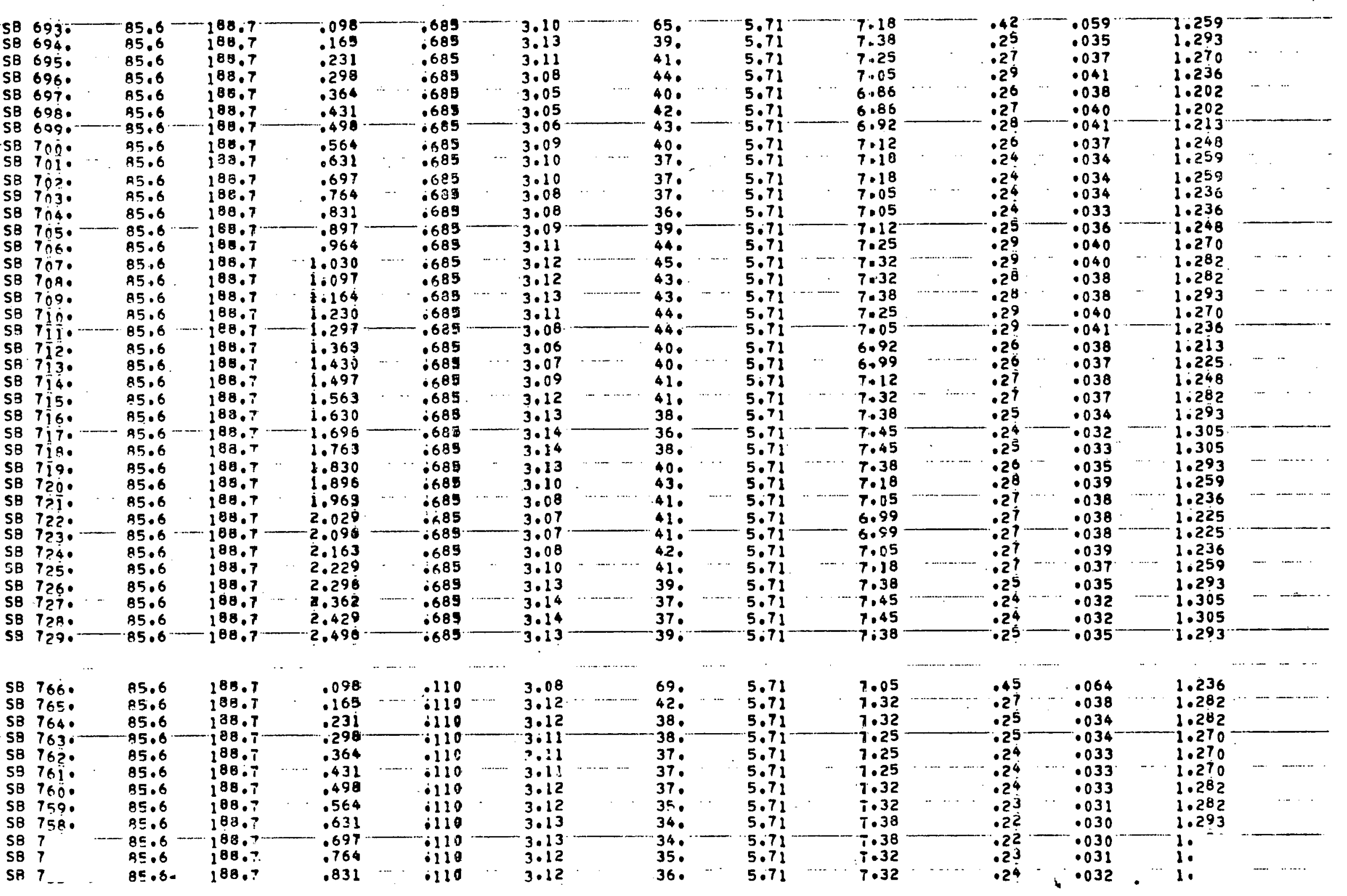




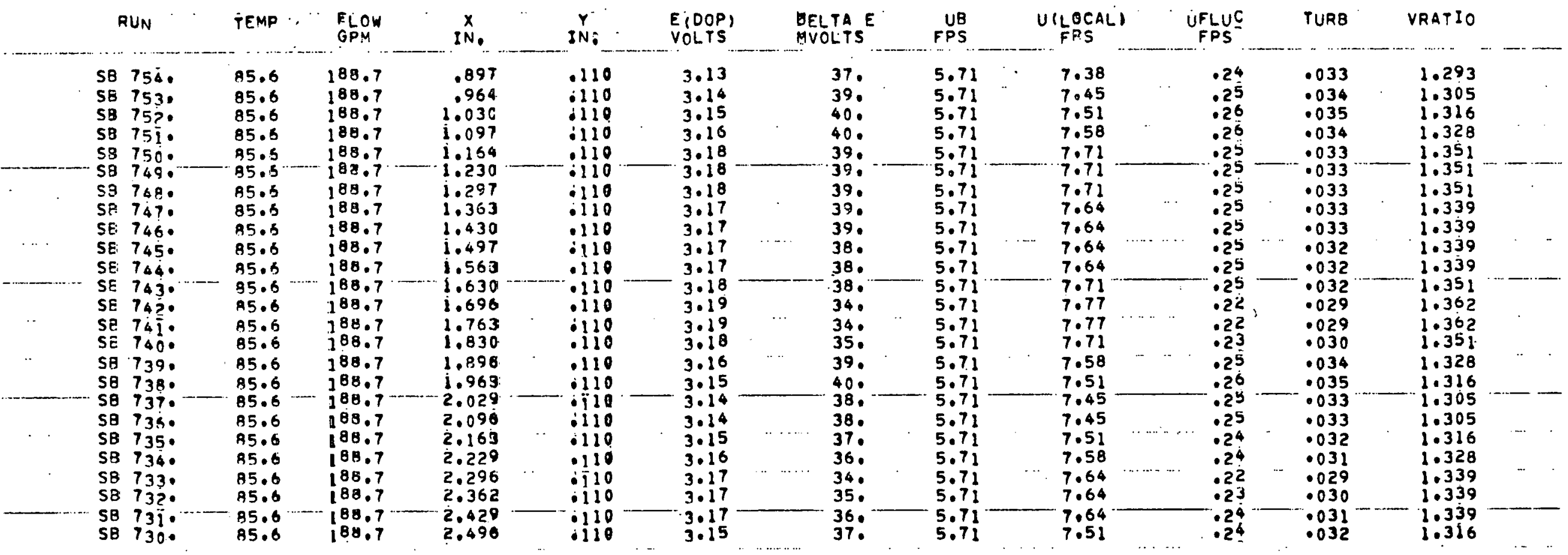


DATA PLANE No, 9. AXIAL DișTANCE:20.95 IN. BLOCKAGE CENTERLINE=28.18 IN. P=17.00 PSI REa:30100.

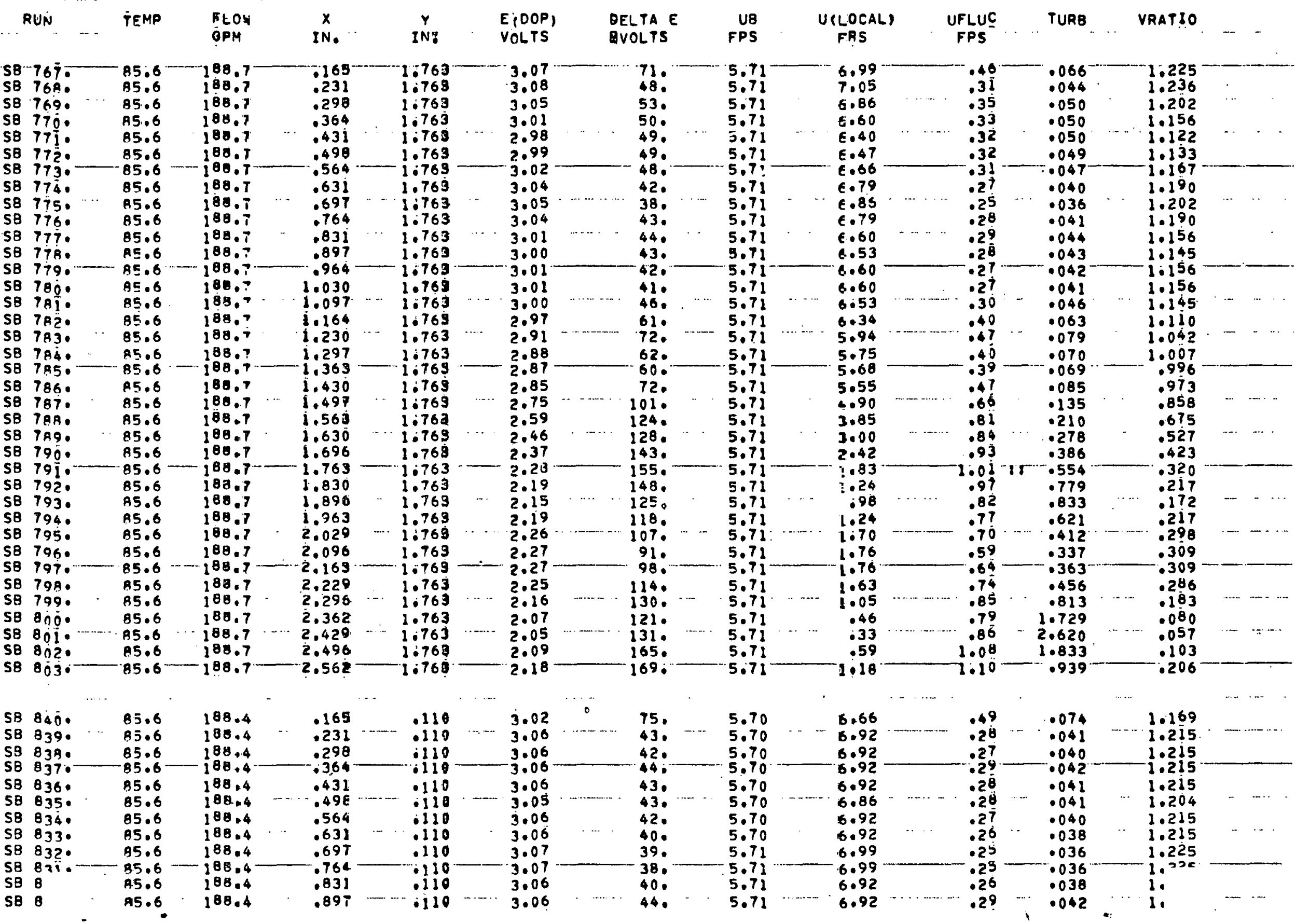




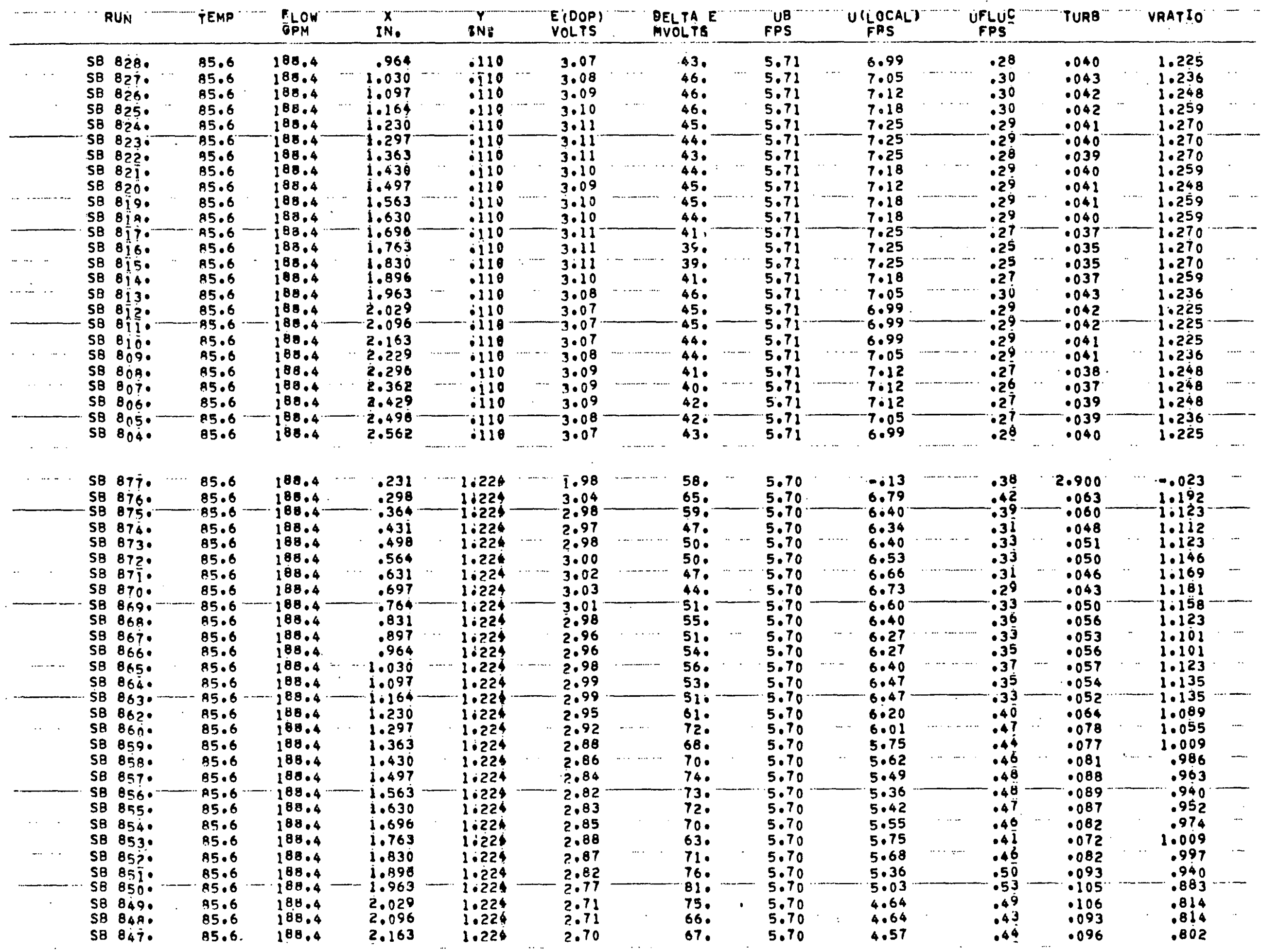




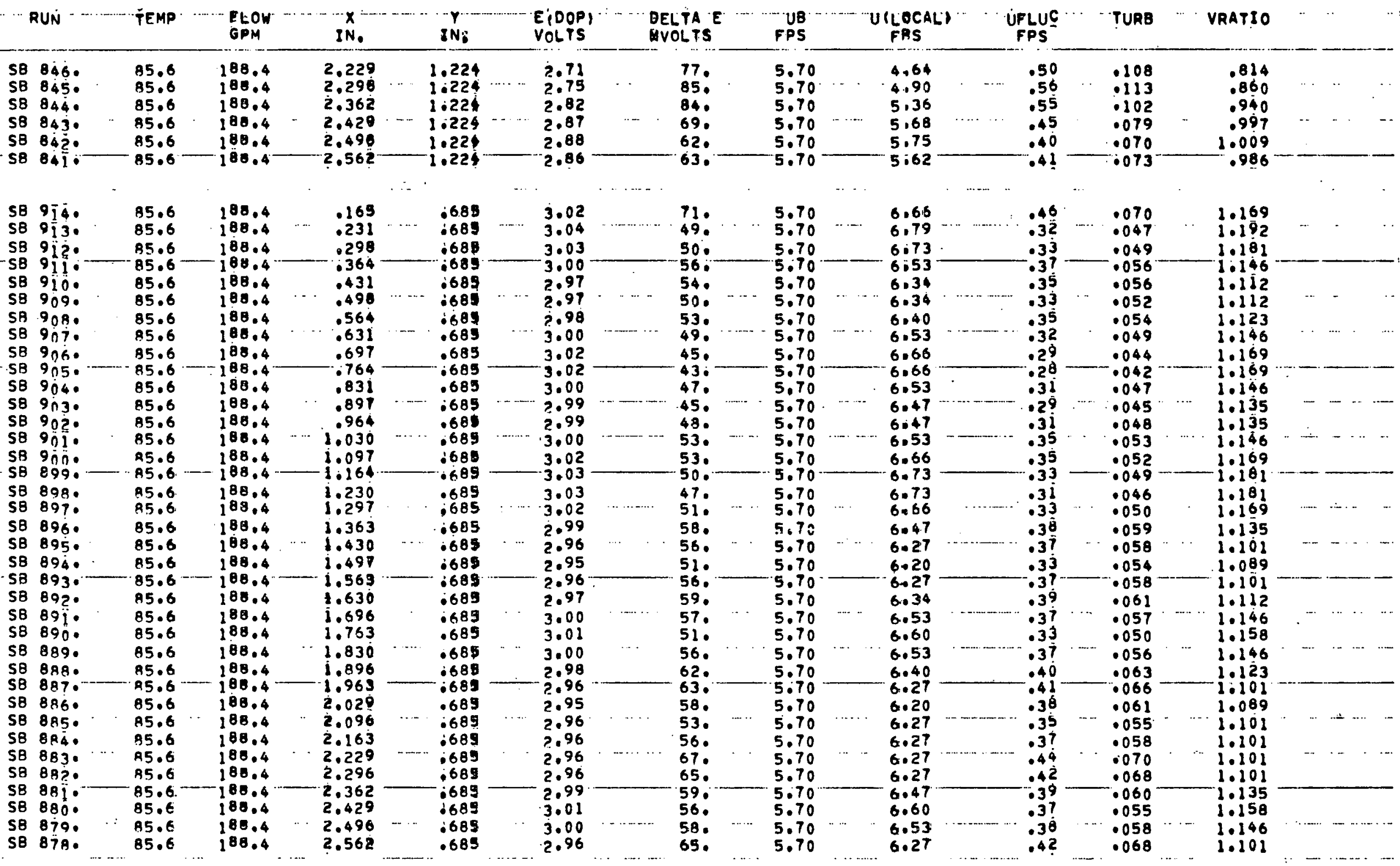


TABLE :CE1. TABULATION OF EXPERIMENTAL LDA OATA

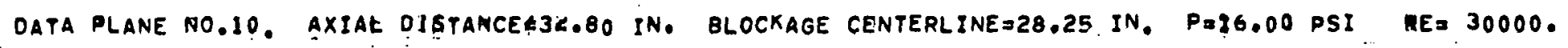

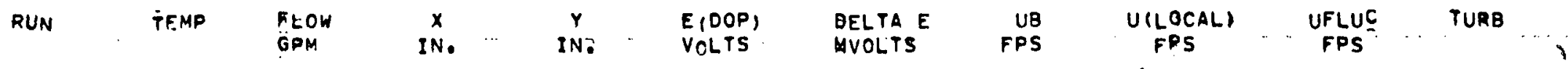

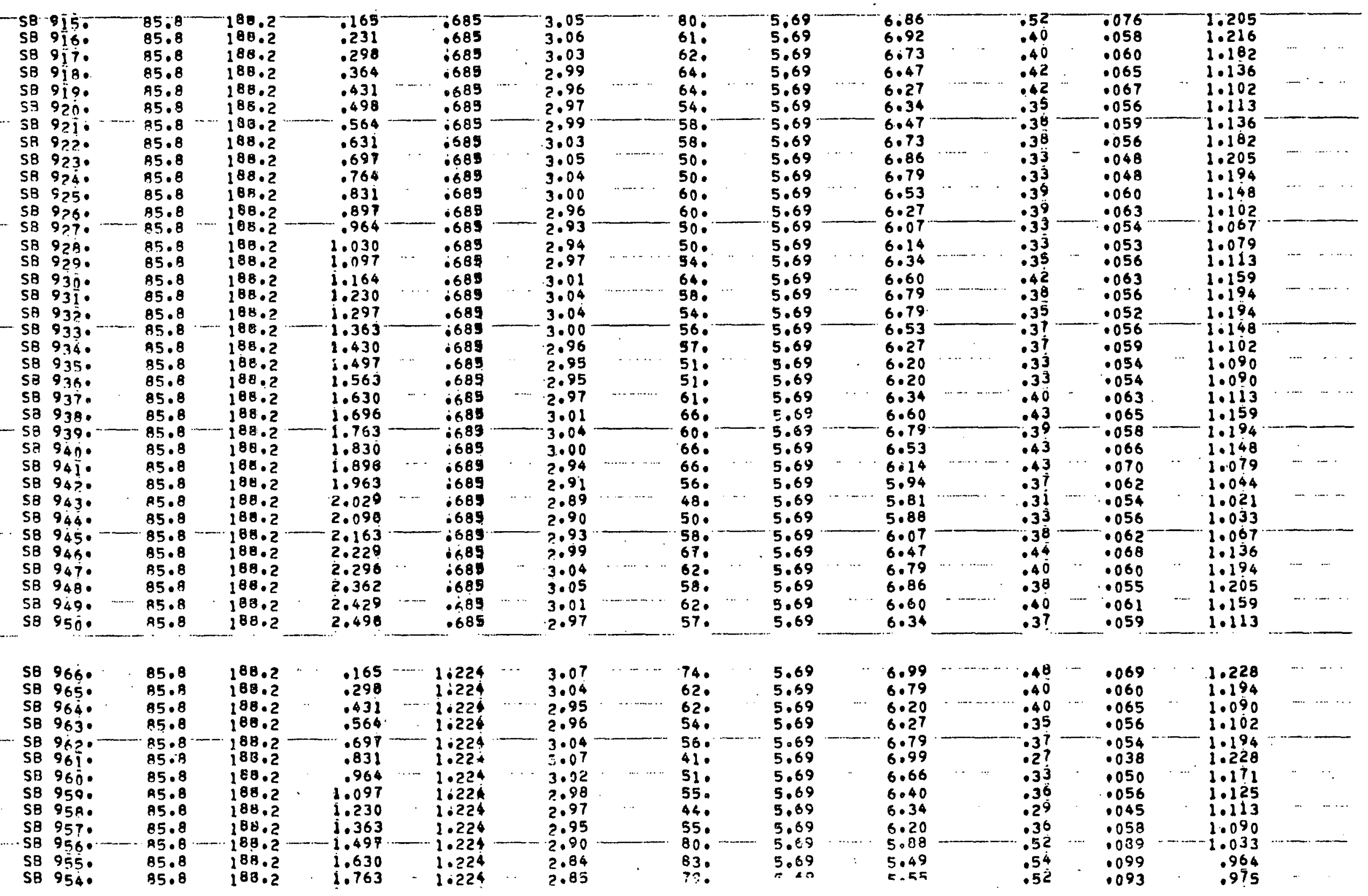




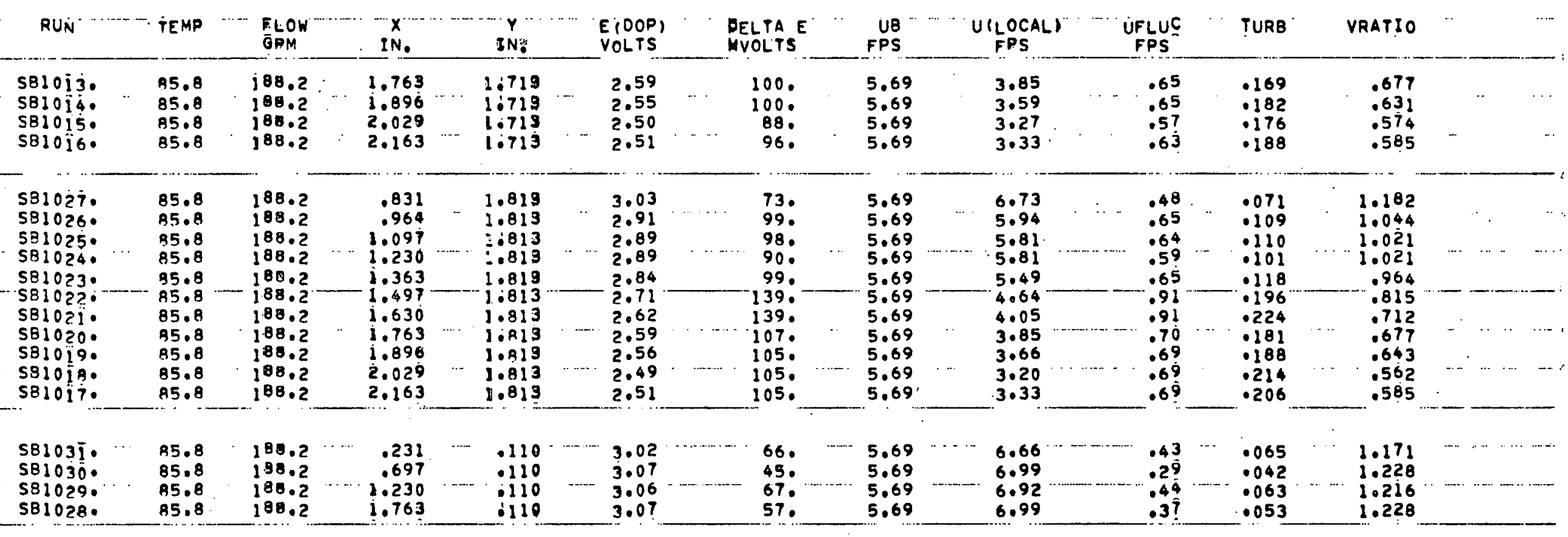


TMBLE CEI. TABULAYION OF EXPERIAENYAL LOA DATA

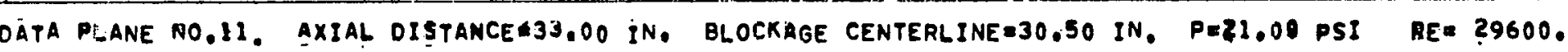

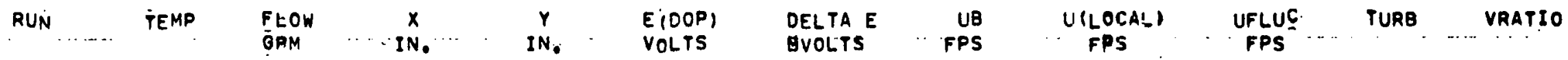

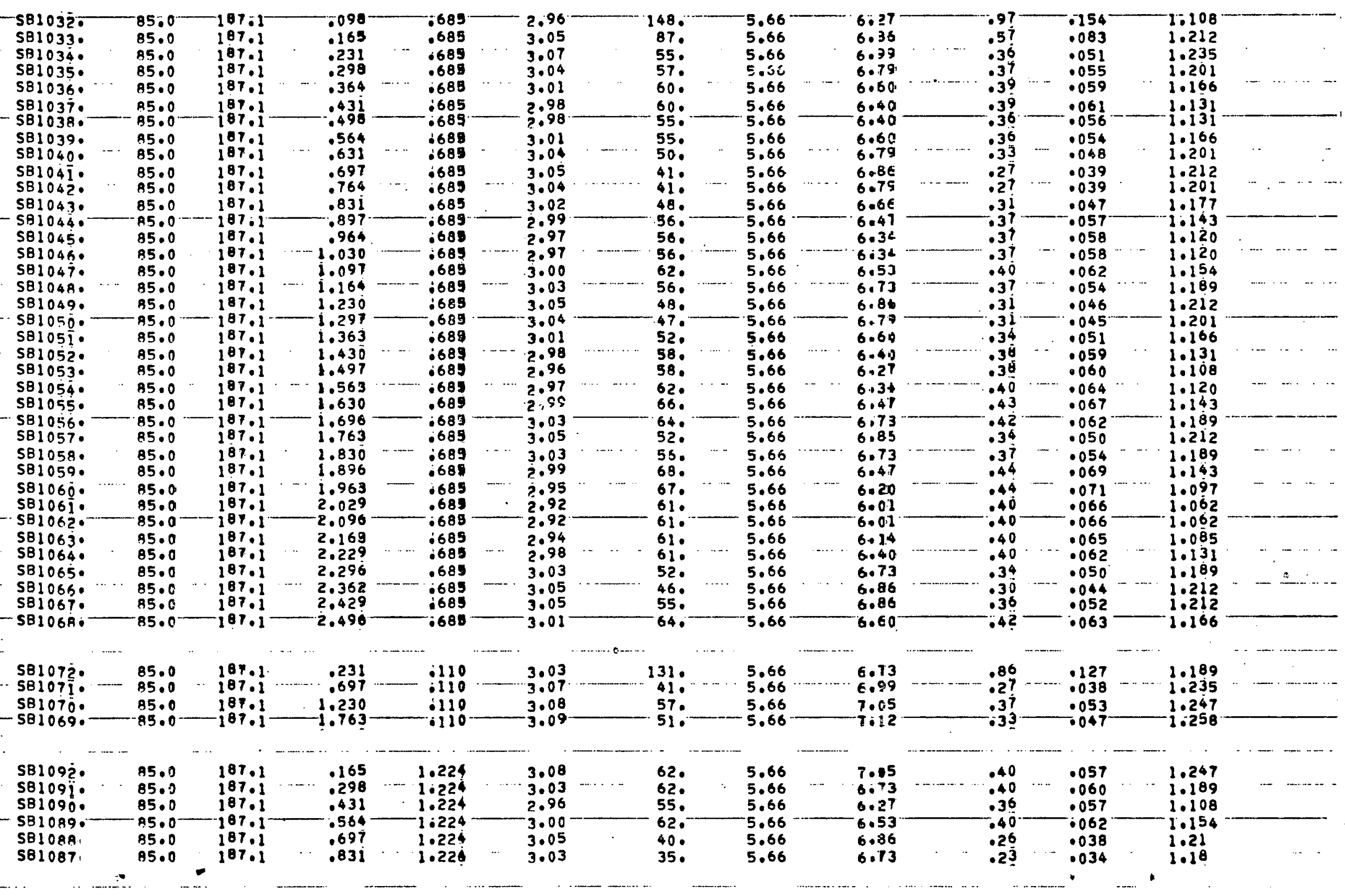




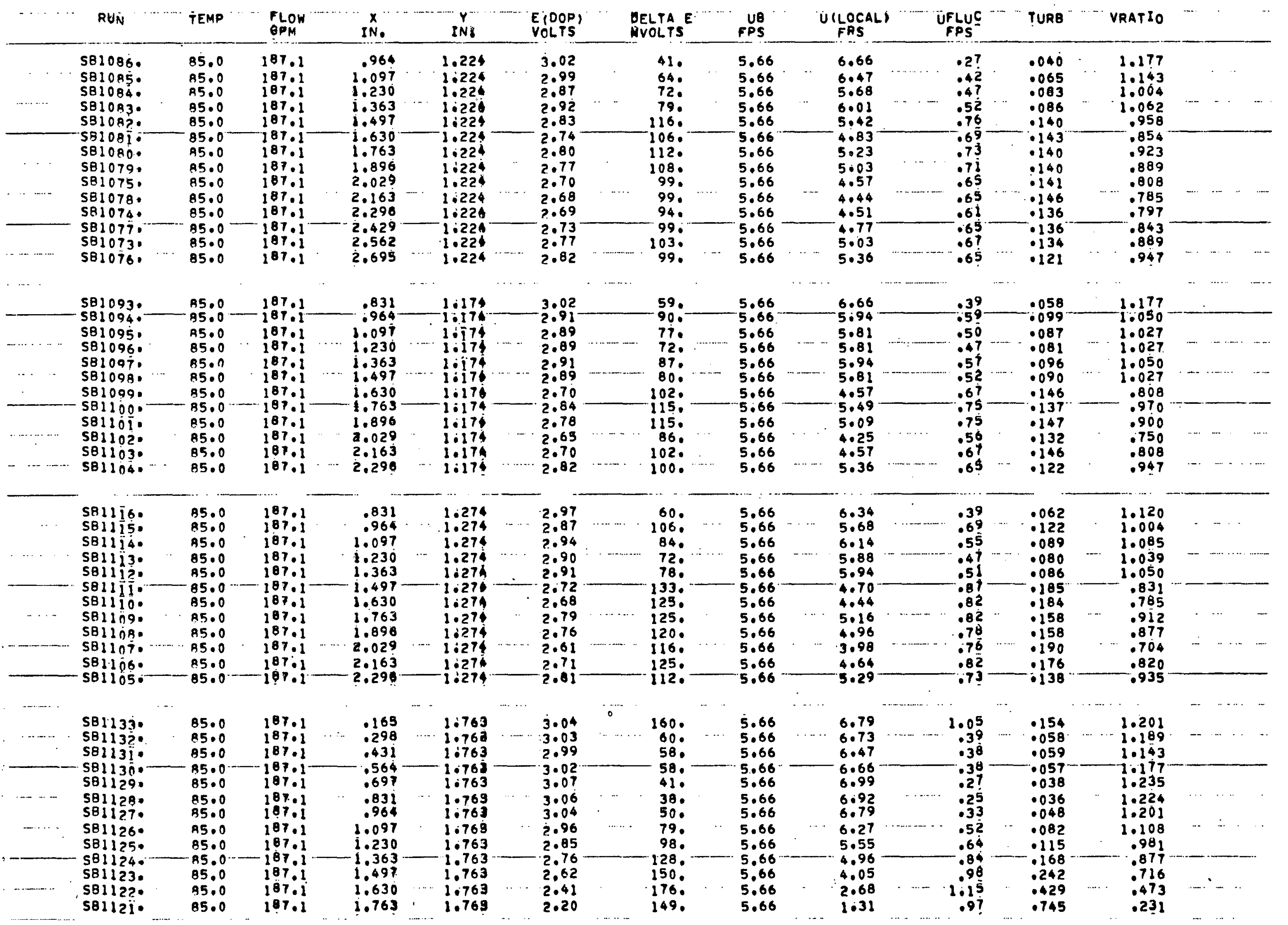




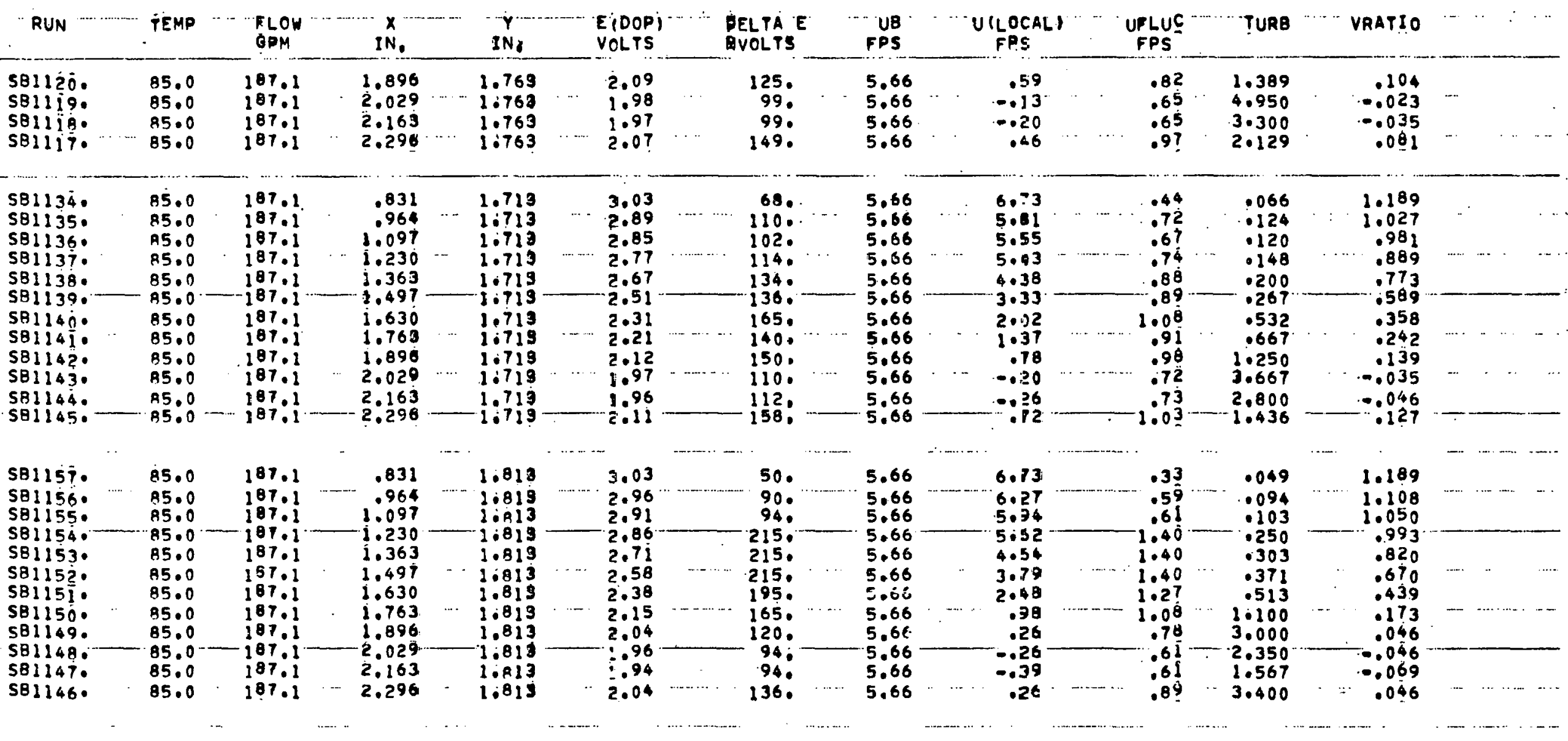




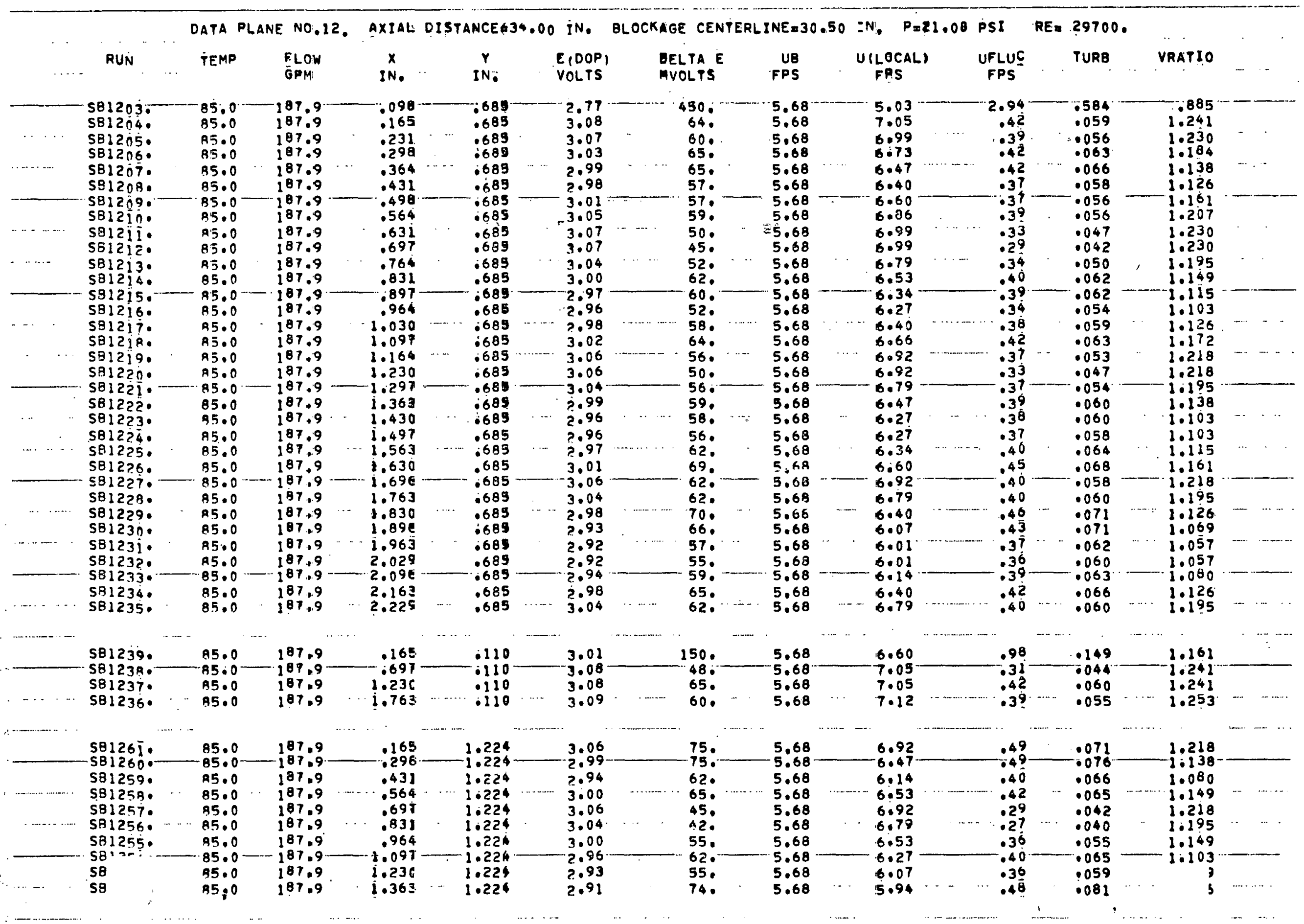




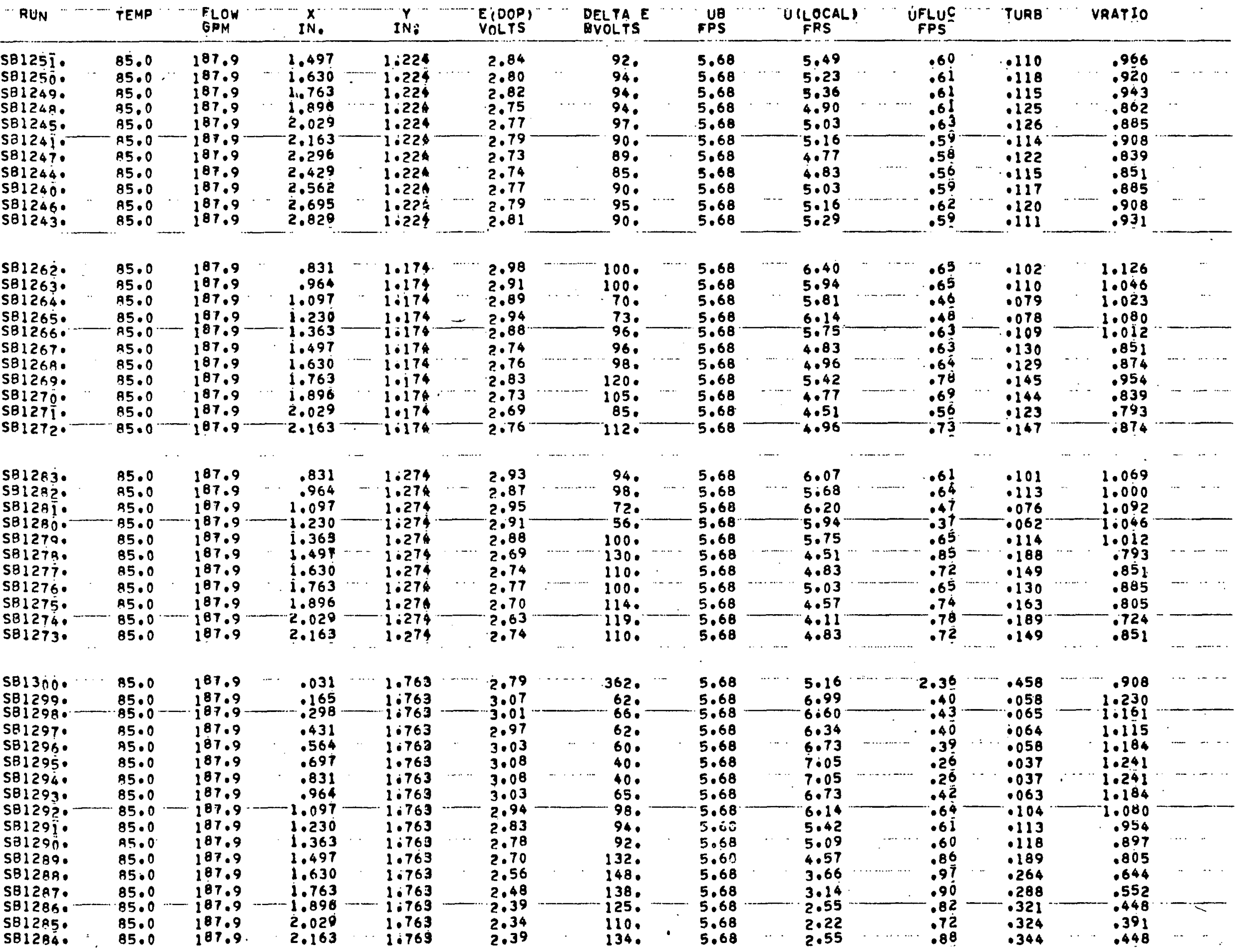




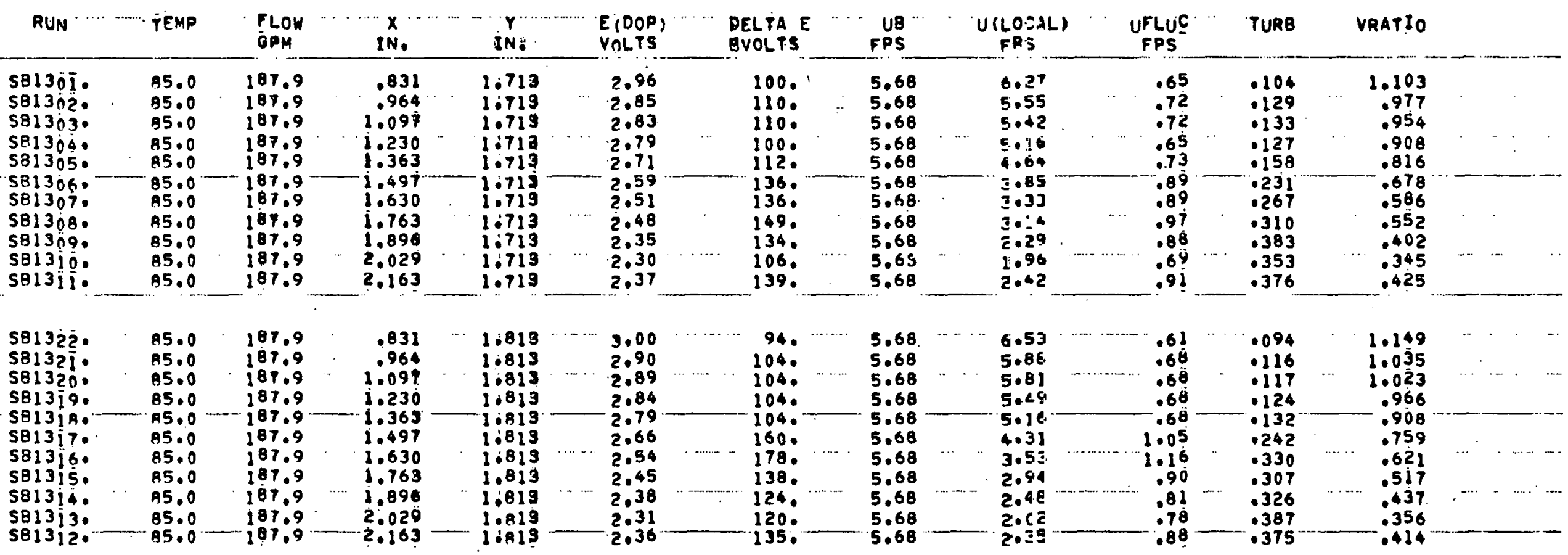


TABLE CAI. TABULATION OF EXRERIMENTAL LDA OATA

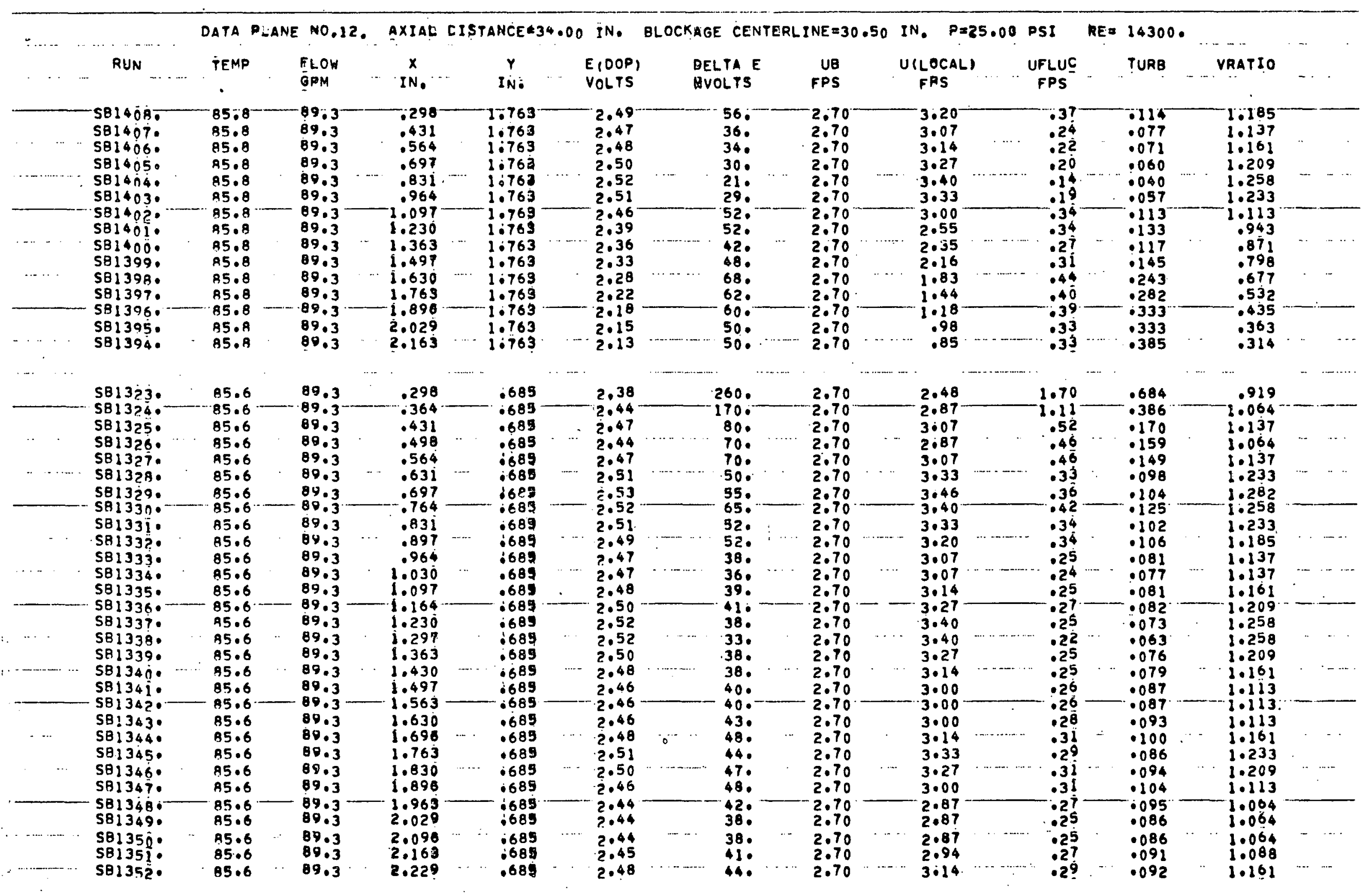




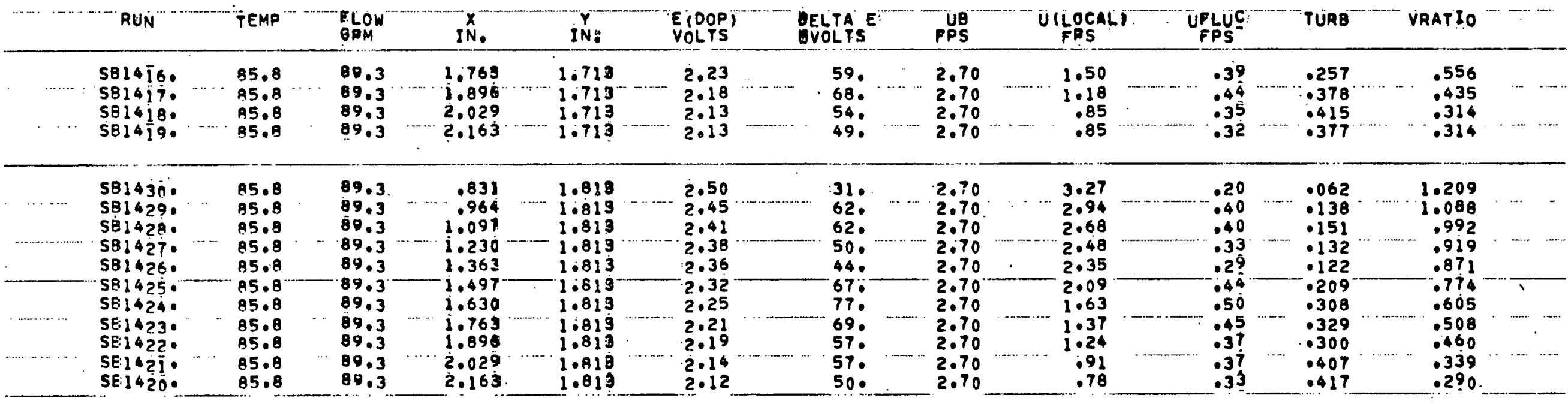




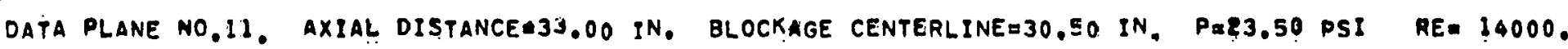

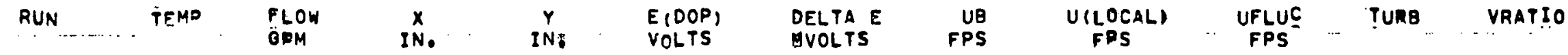

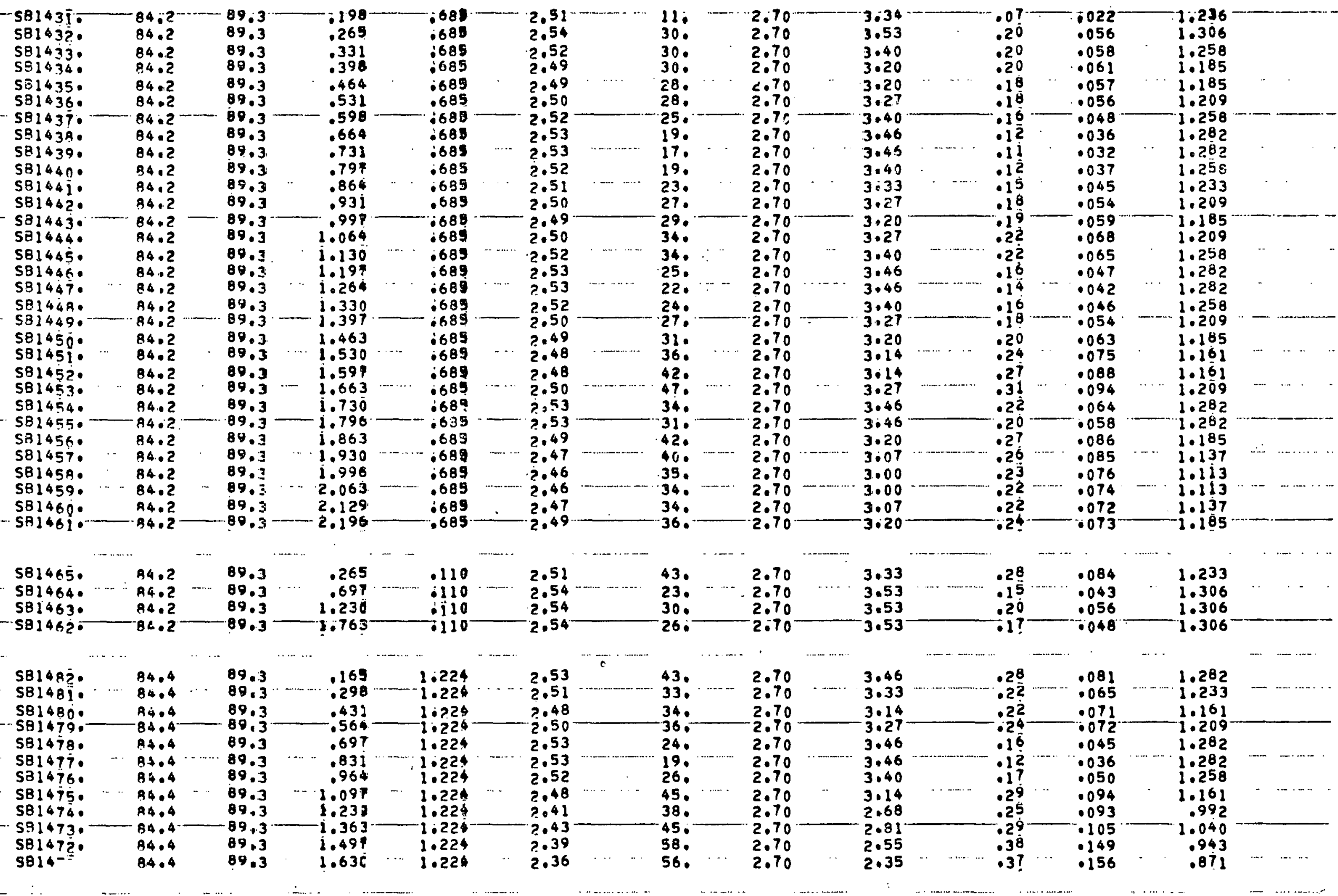




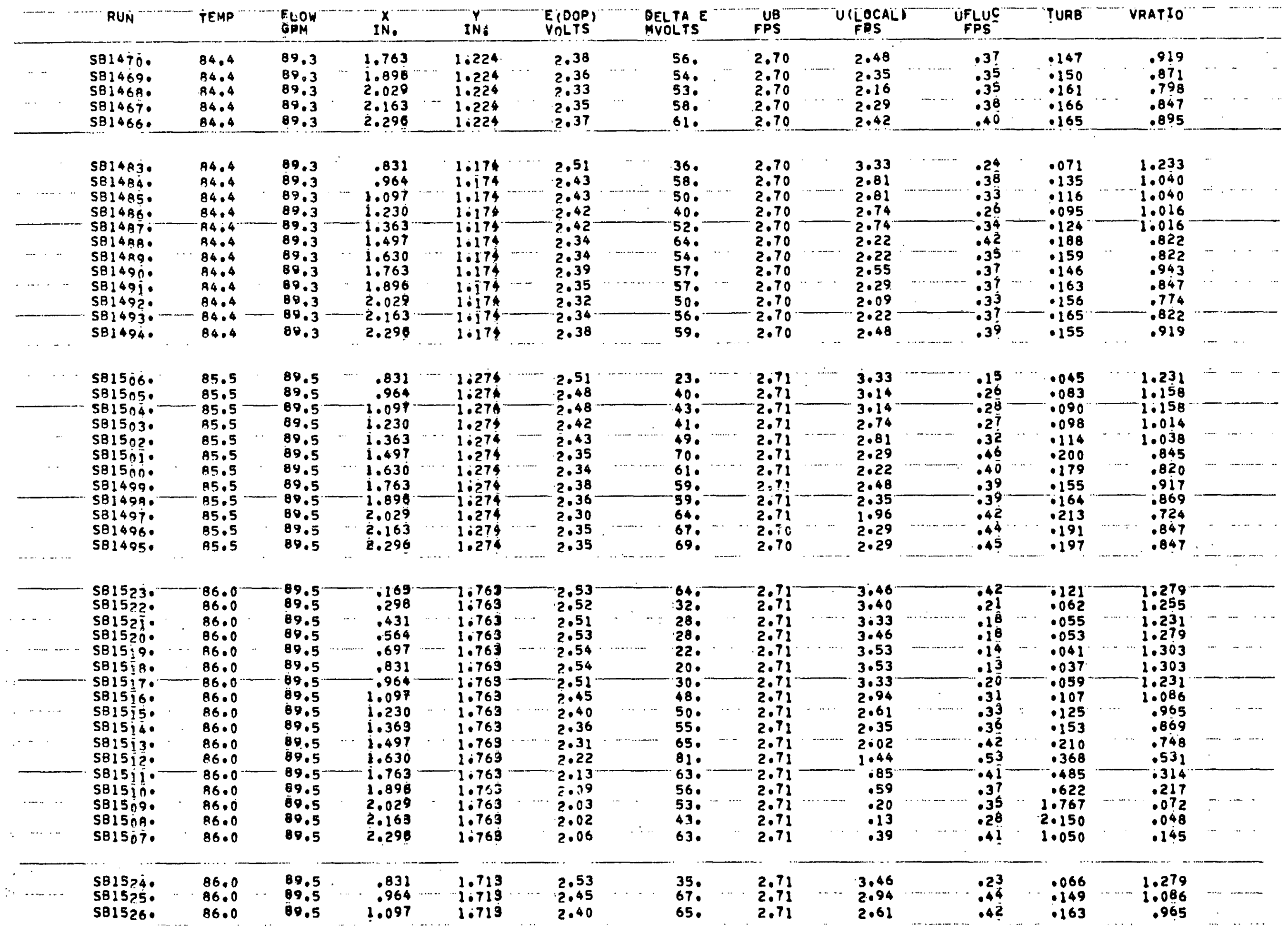




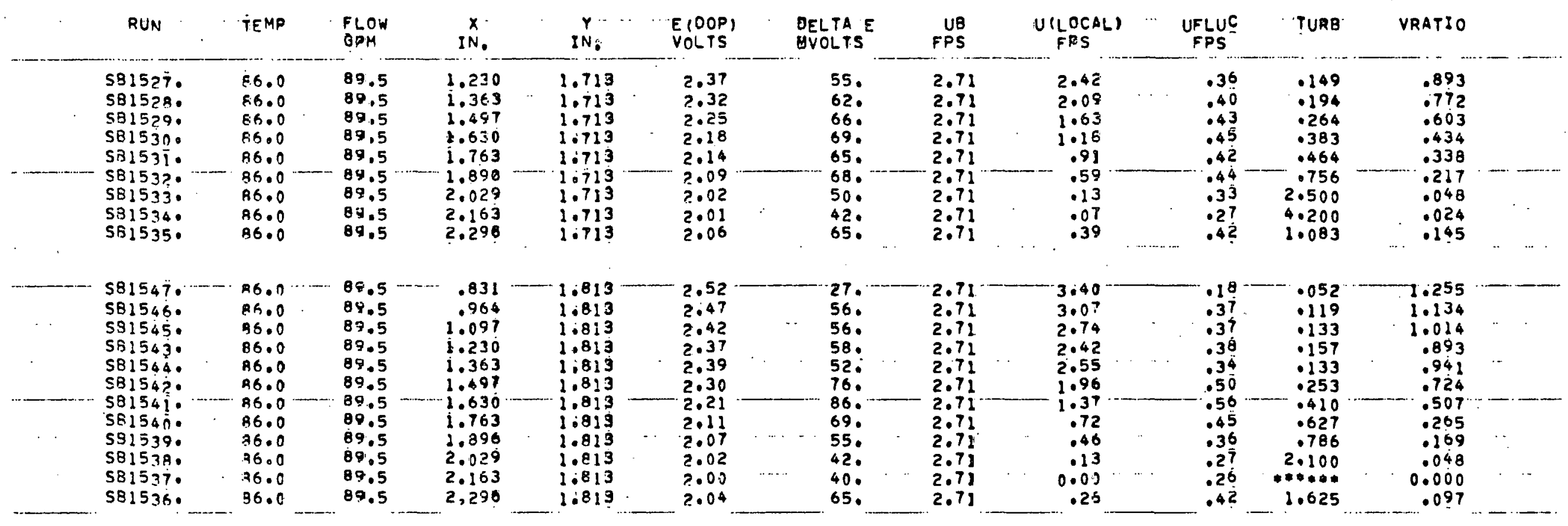


TABLE :CH. TARULATION OF EXPERIMENTAL: LOA CATA

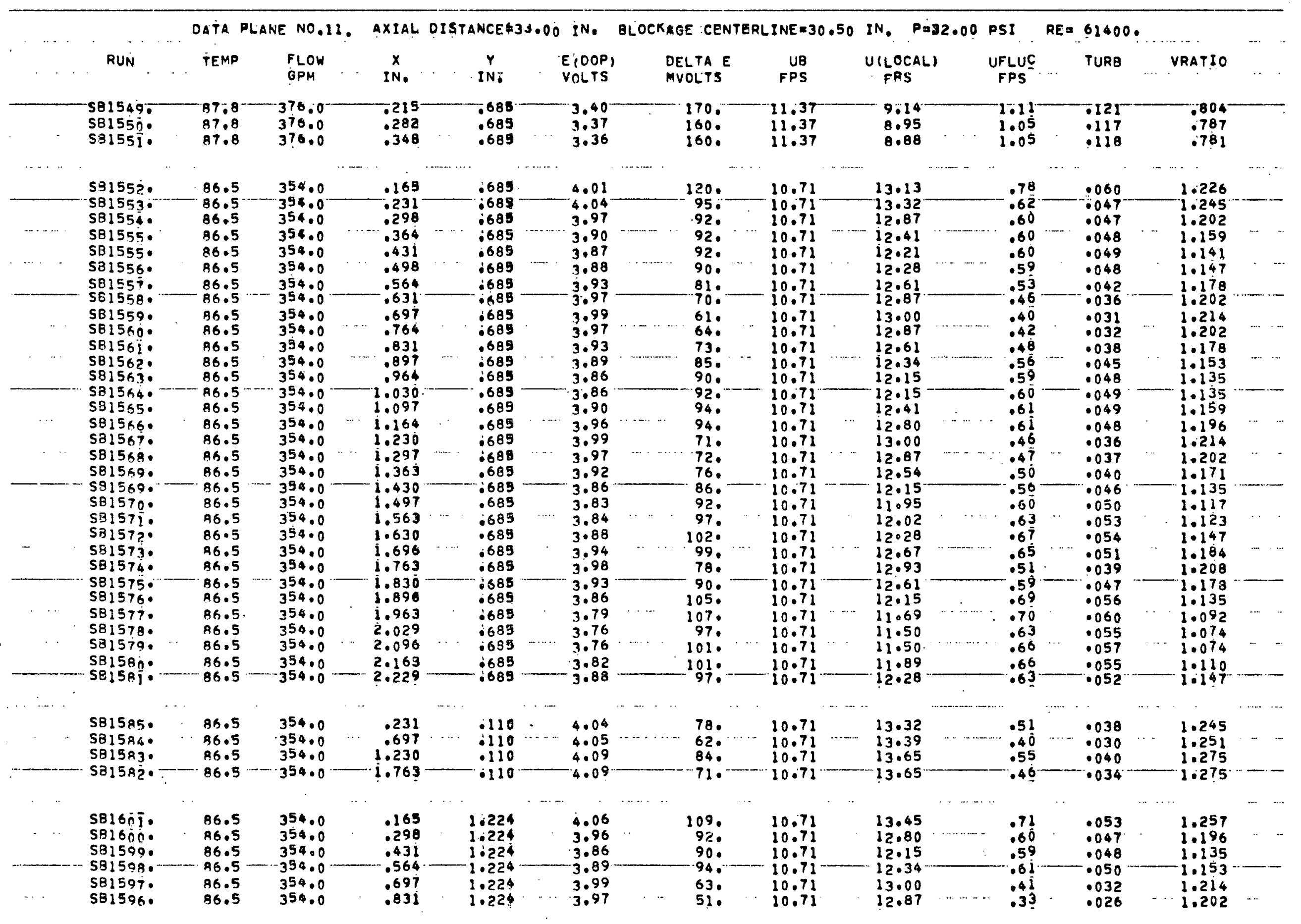




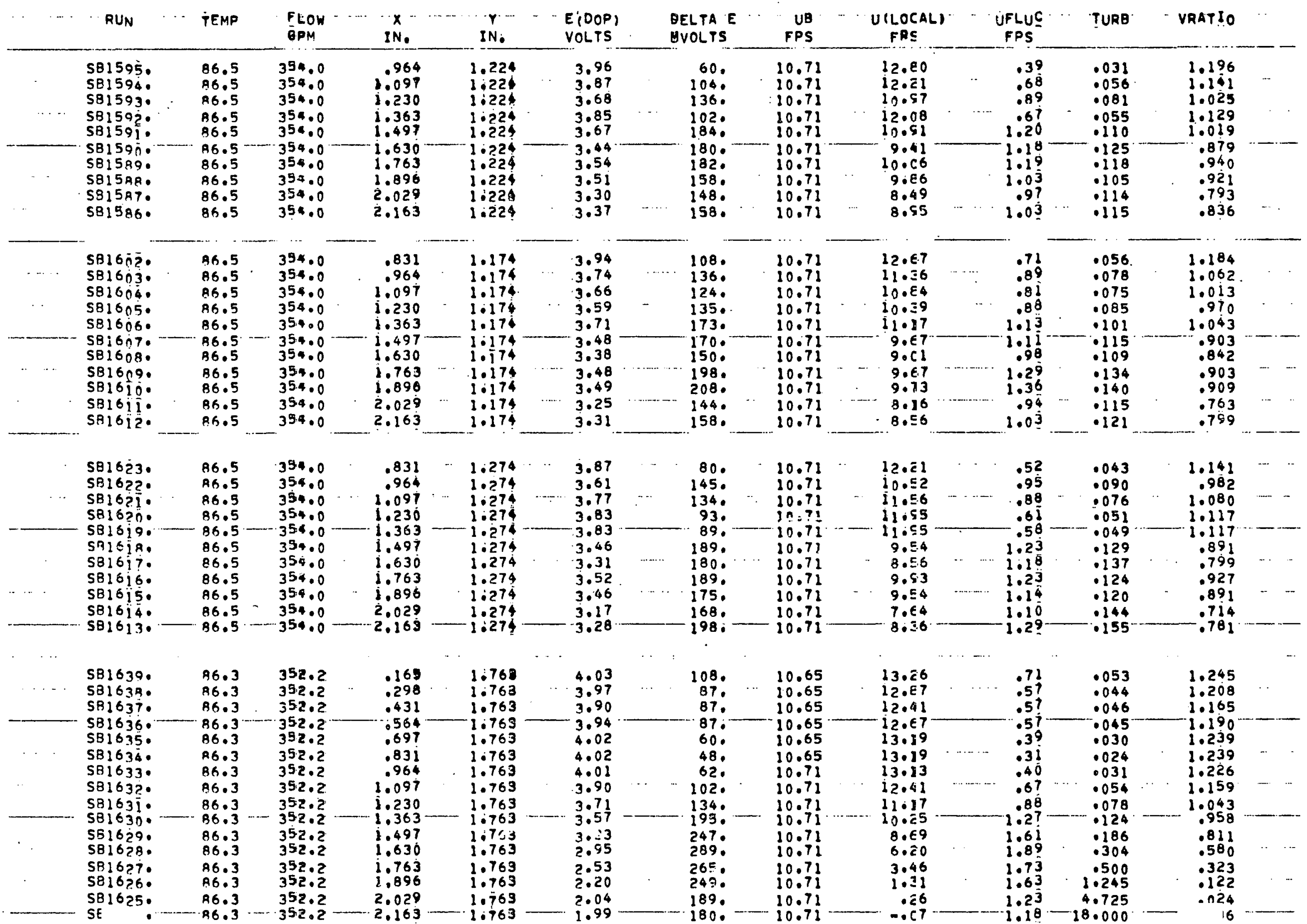




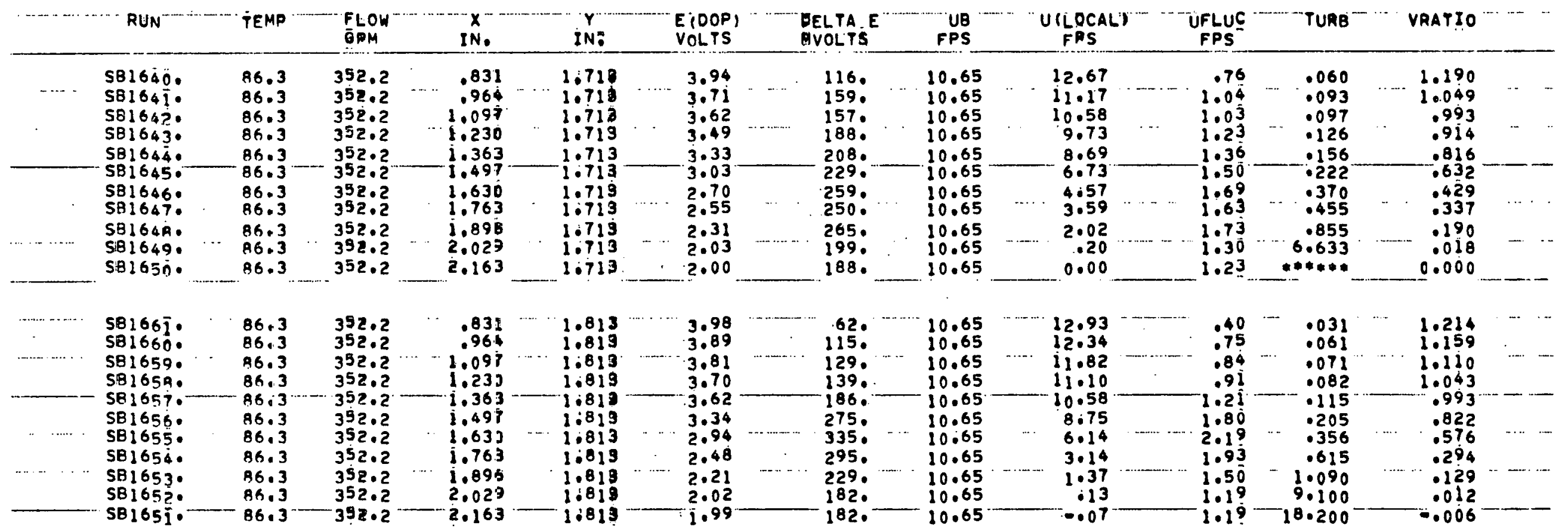




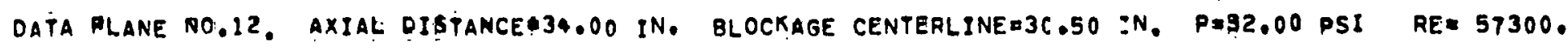

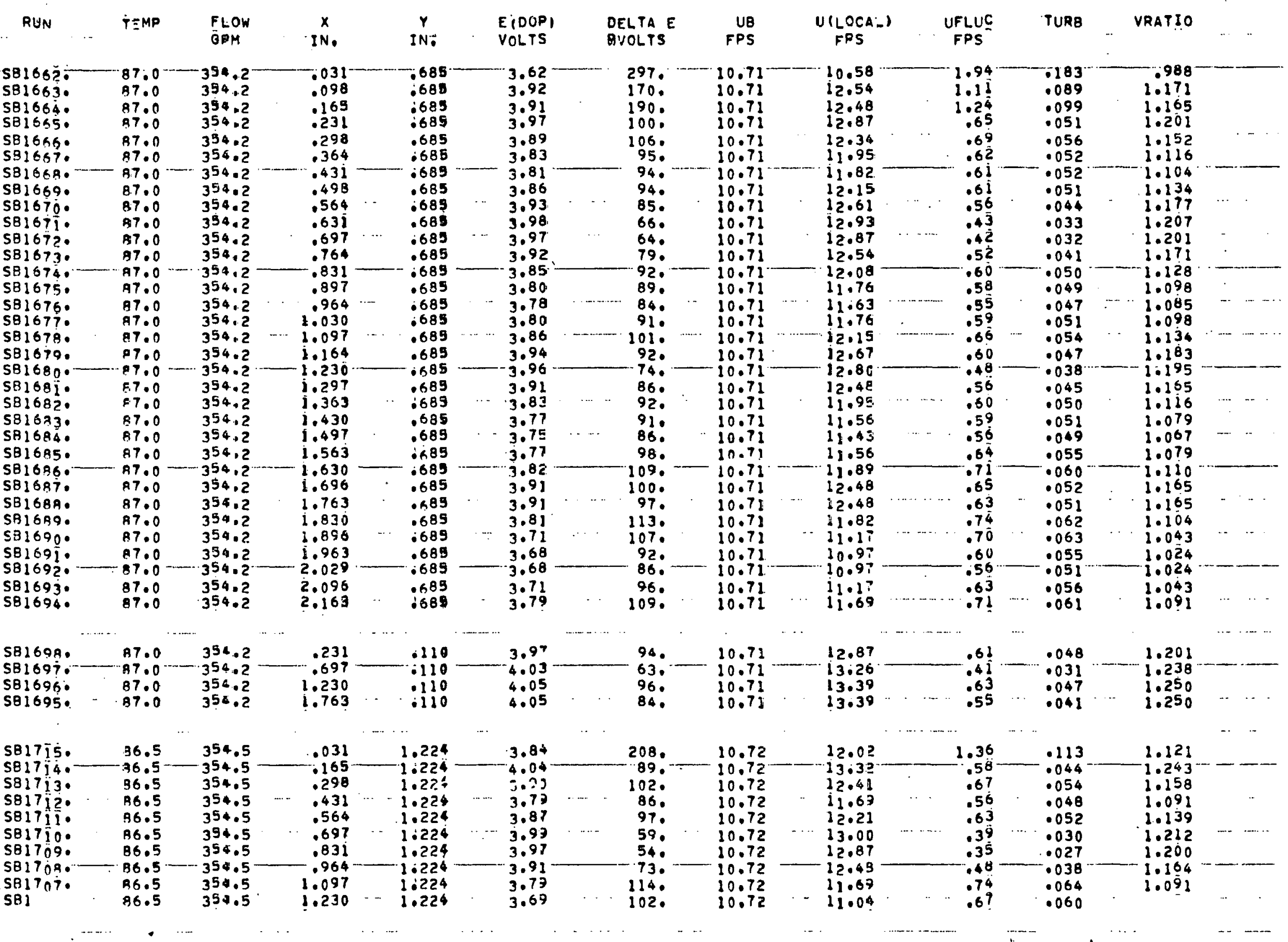




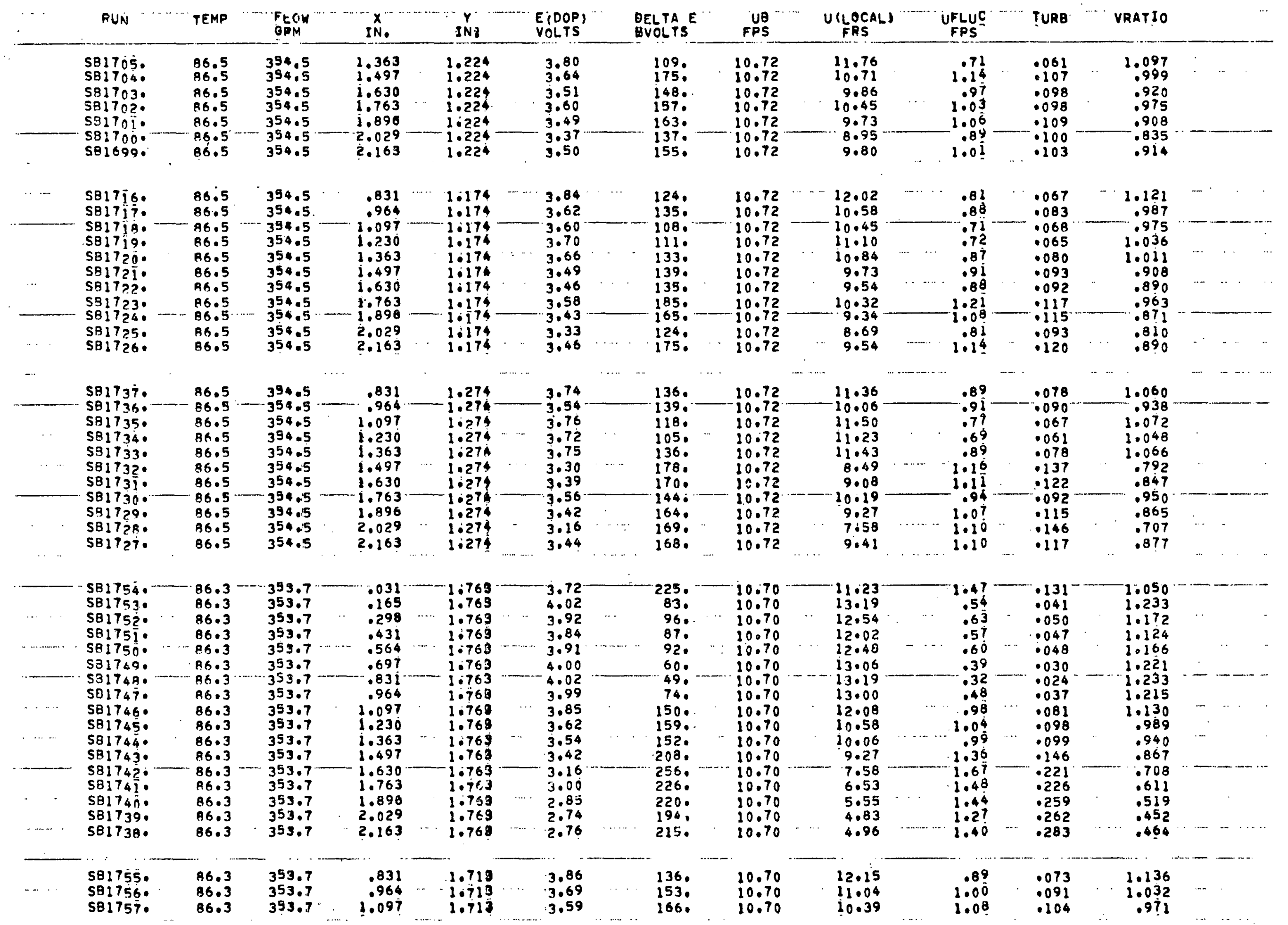




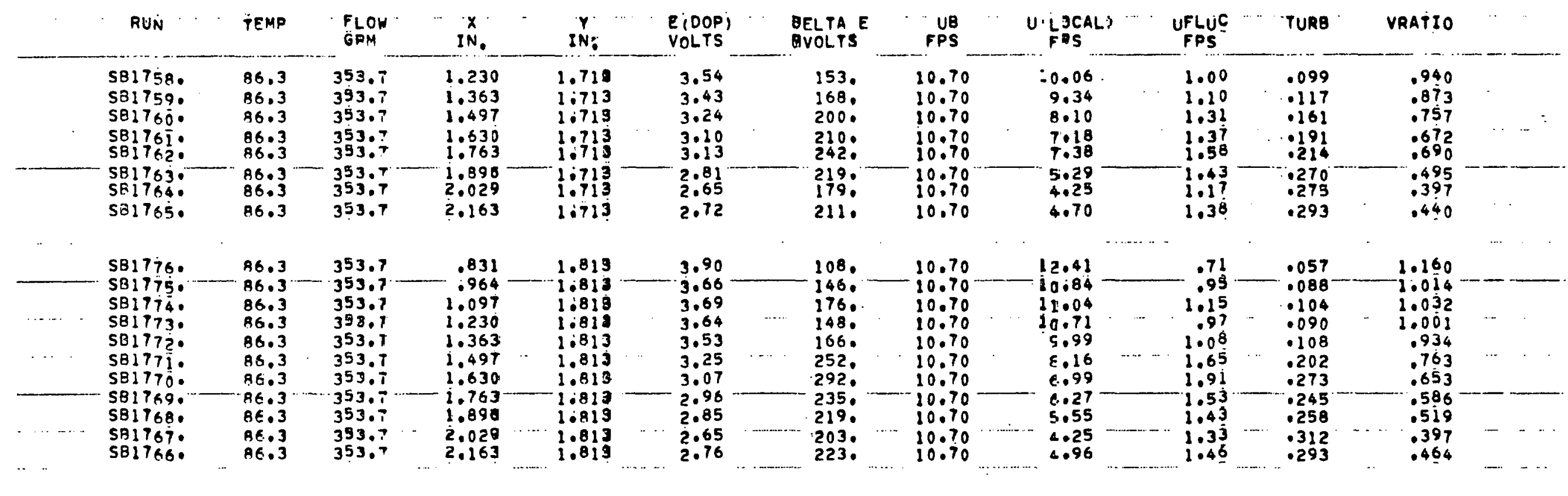


TABLE CII. TABULATION OF EXPERIAENTAL LOA DATA

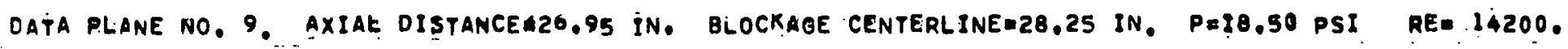

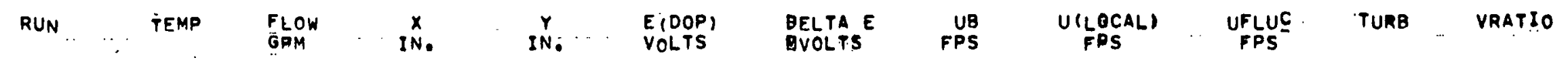

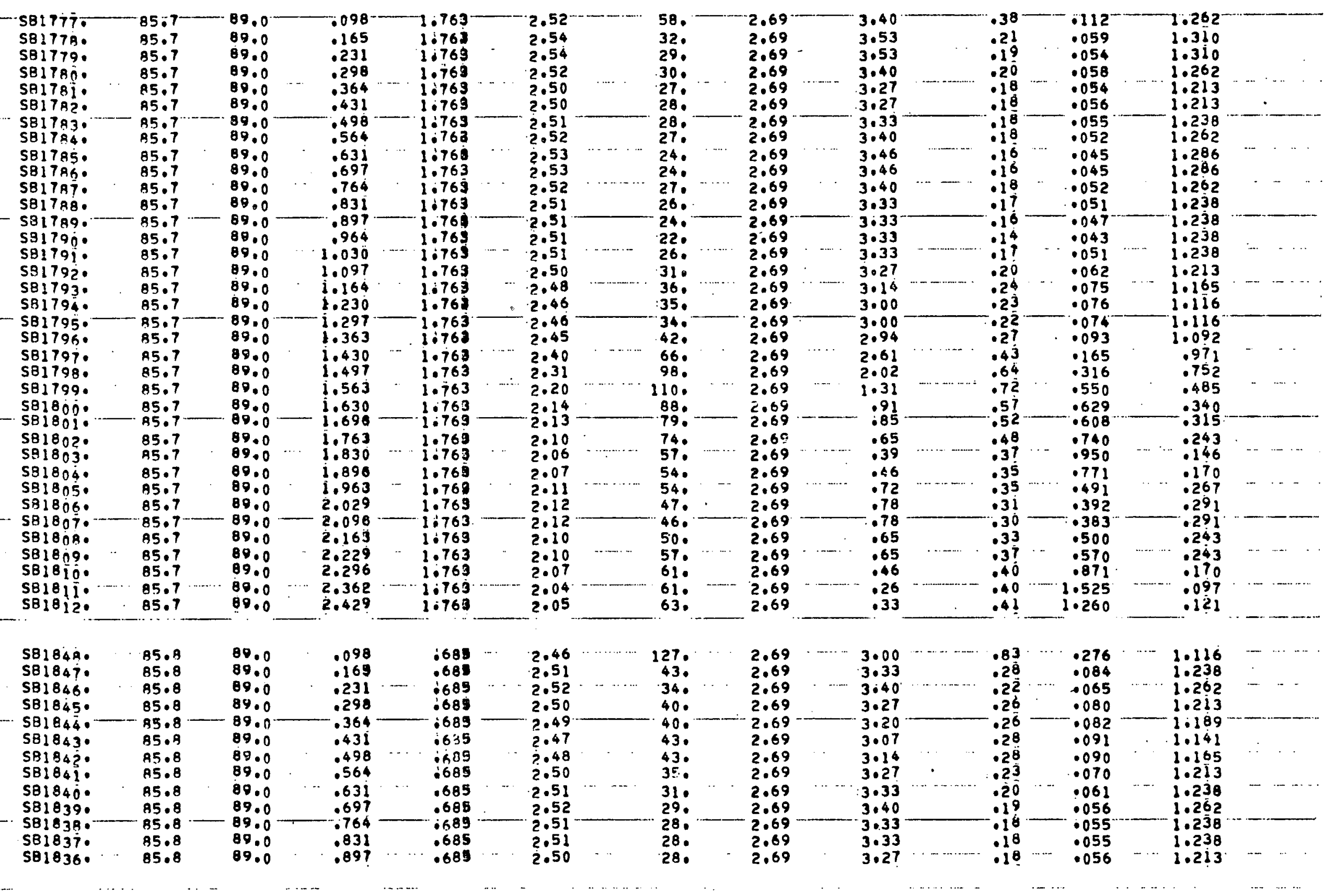




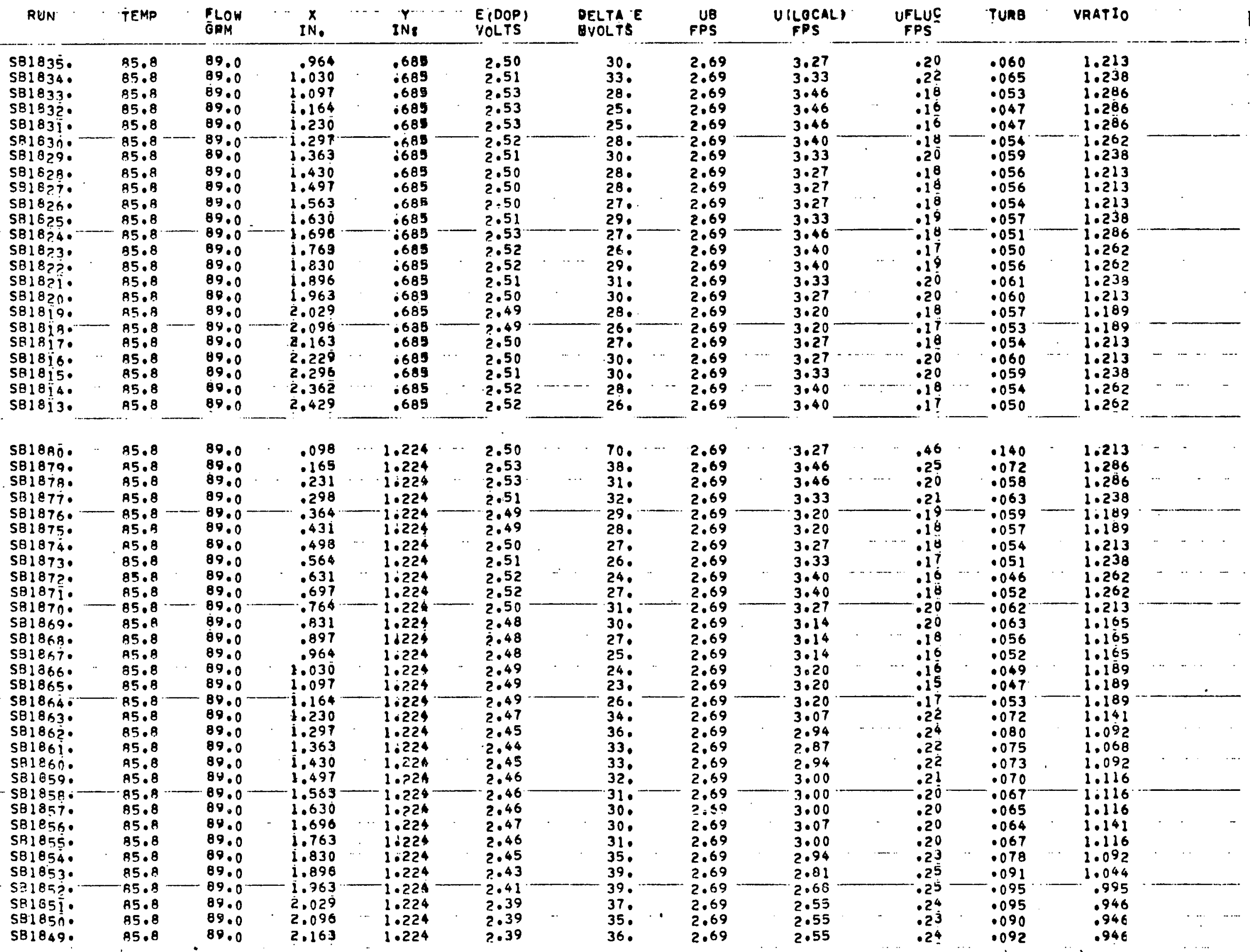




\begin{tabular}{|c|c|c|c|c|c|c|c|c|c|c|c|}
\hline$R U_{N}$ & TEMP & $\begin{array}{l}\text { FLOW } \\
\text { G.PM }\end{array}$ & $\begin{array}{r}X \\
\text { IN. }\end{array}$ & $\begin{array}{c}Y \\
\text { INa }\end{array}$ & $\begin{array}{l}\text { EjoOP } \\
\text { VOLTS }\end{array}$ & $\begin{array}{l}\text { DELTA } \\
\text { HVOLTS }\end{array}$ & $\begin{array}{l}\text { U日 } \\
\text { FPS }\end{array}$ & $\begin{array}{c}U(\mathcal{O C C A L}) \\
\text { FPS }\end{array}$ & $\begin{array}{l}\text { UFLUUE } \\
\text { FPS }\end{array}$ & TURB & VRATIO \\
\hline
\end{tabular}


DATA PLANE NO. 8. AXIAL OISTANCE\$28.05 IN. BLOCKMGE CENTERLINEa28.28 IN. P=25.00 PSI RE* 14000.

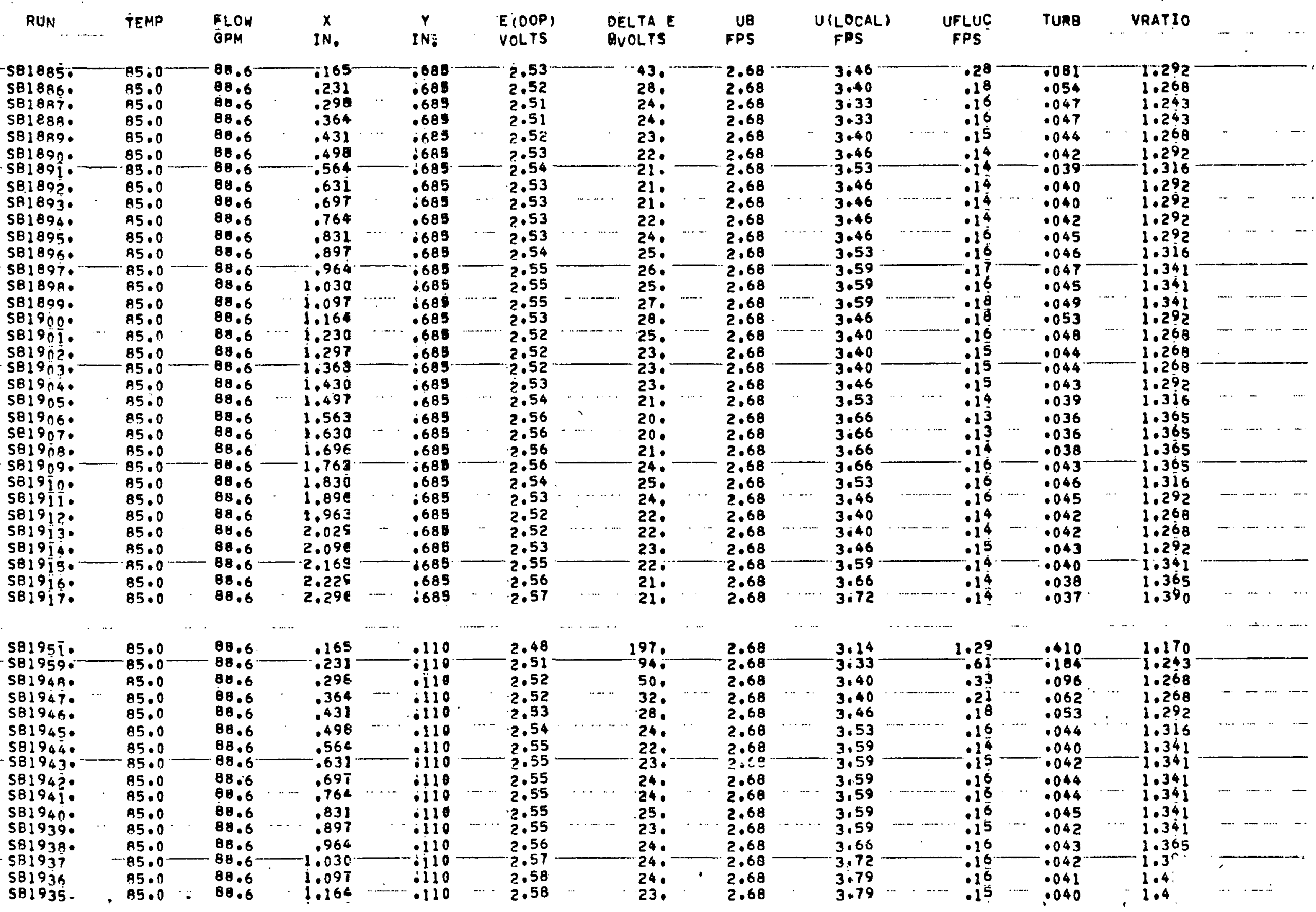




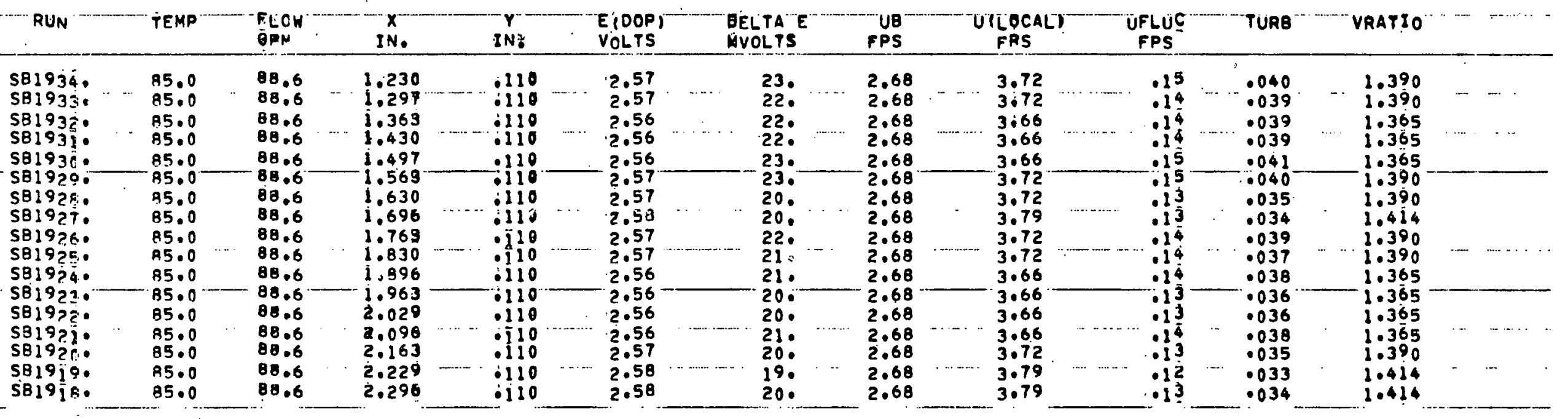




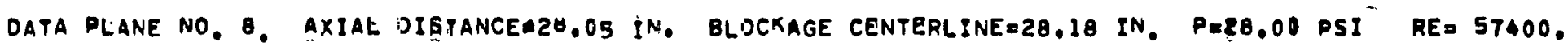

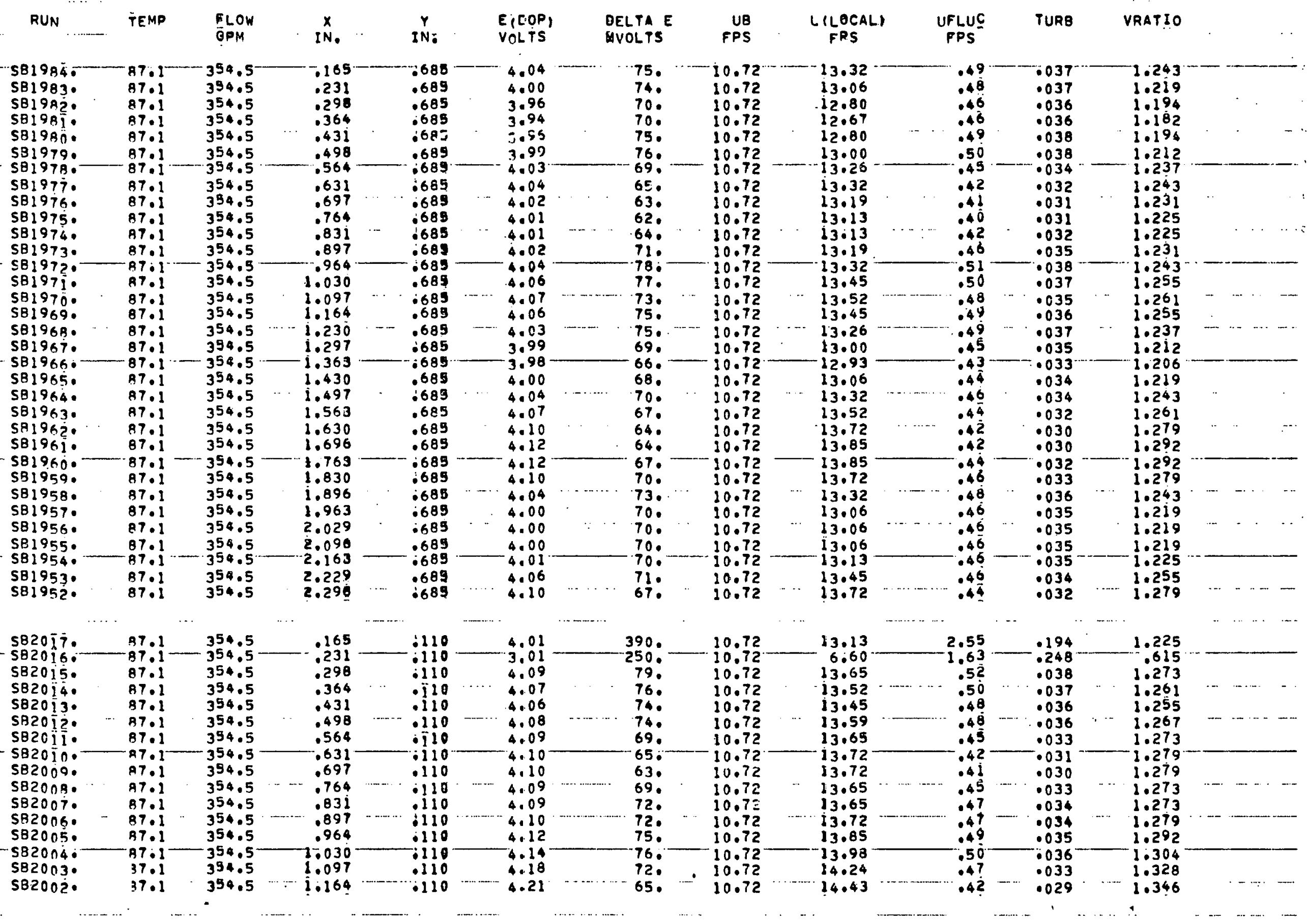




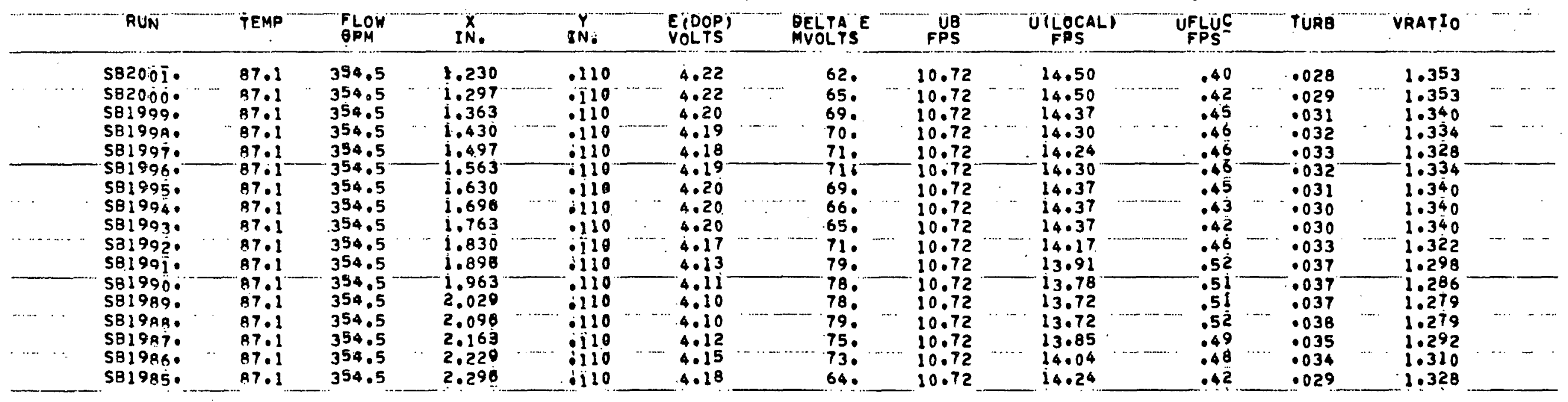


TABLE:Cil. TABULATION OF EXPERIMENTAL LDA DATA

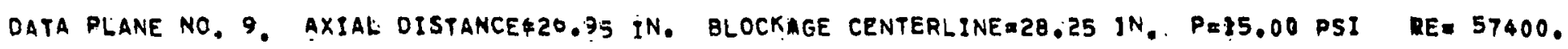

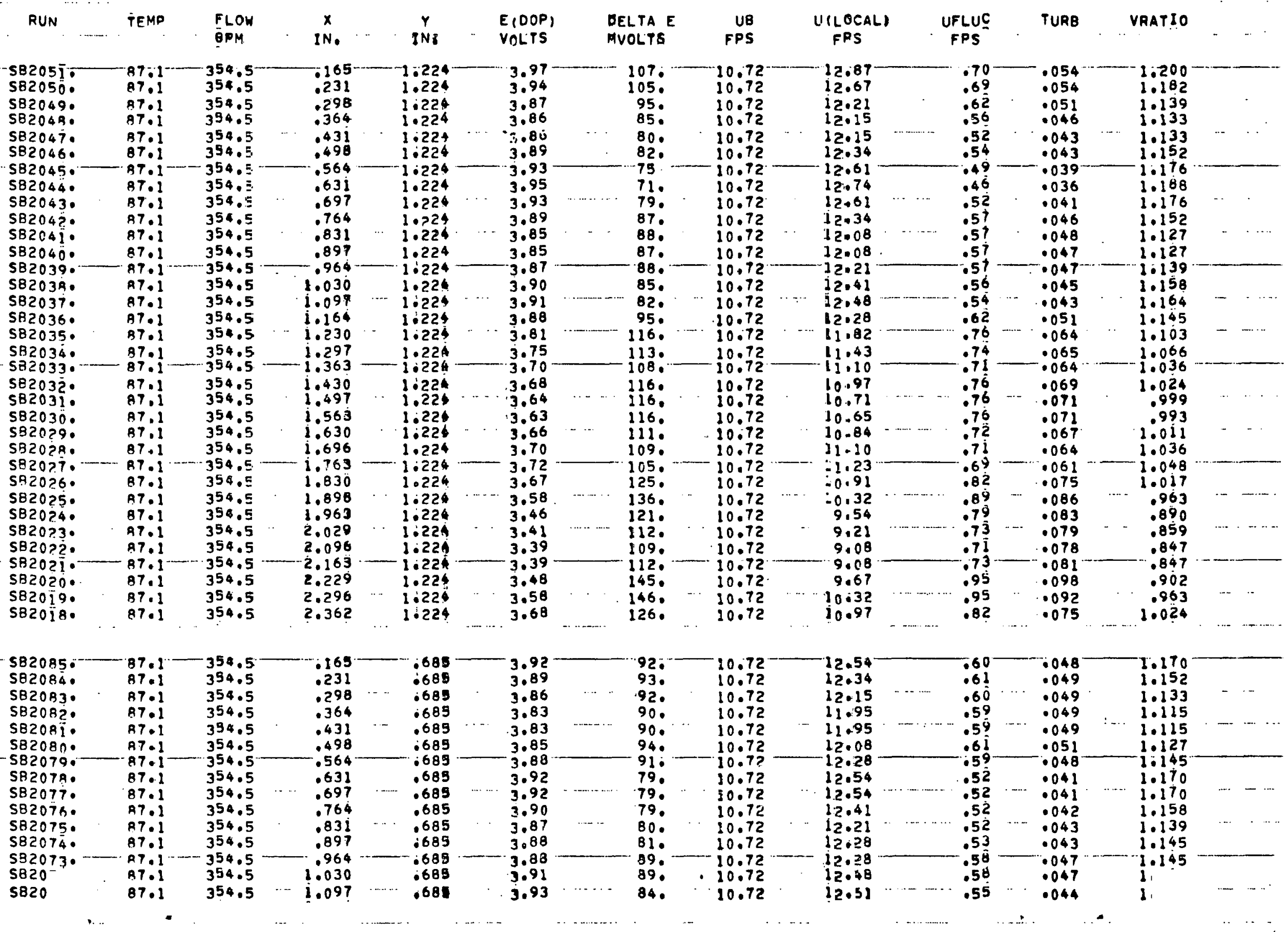




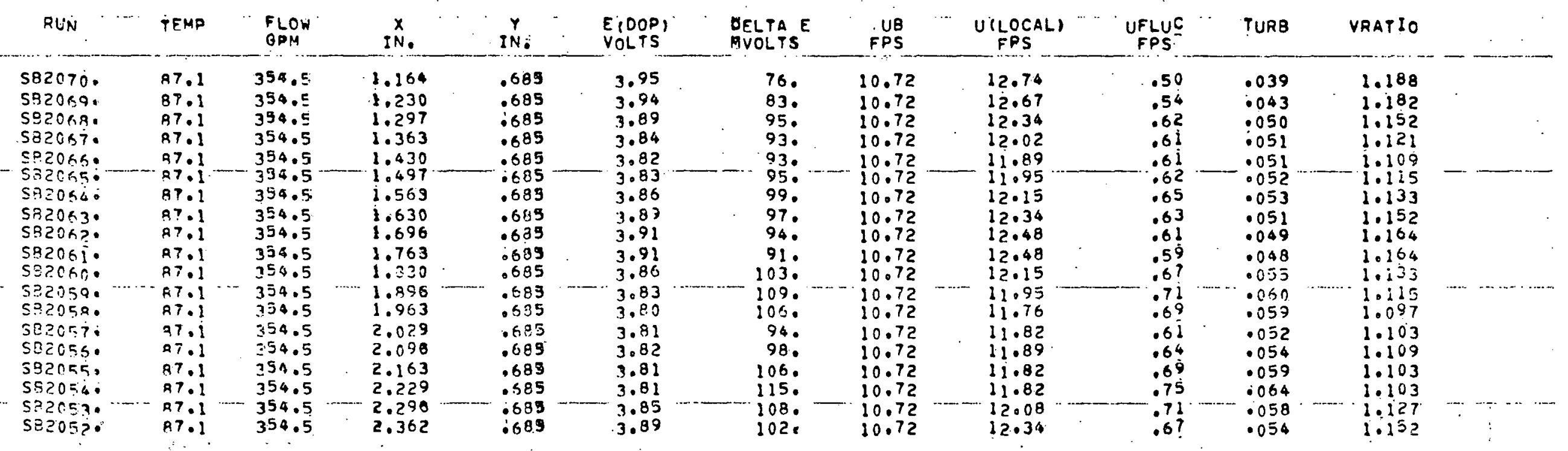




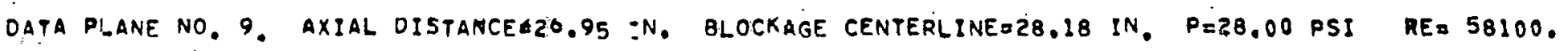

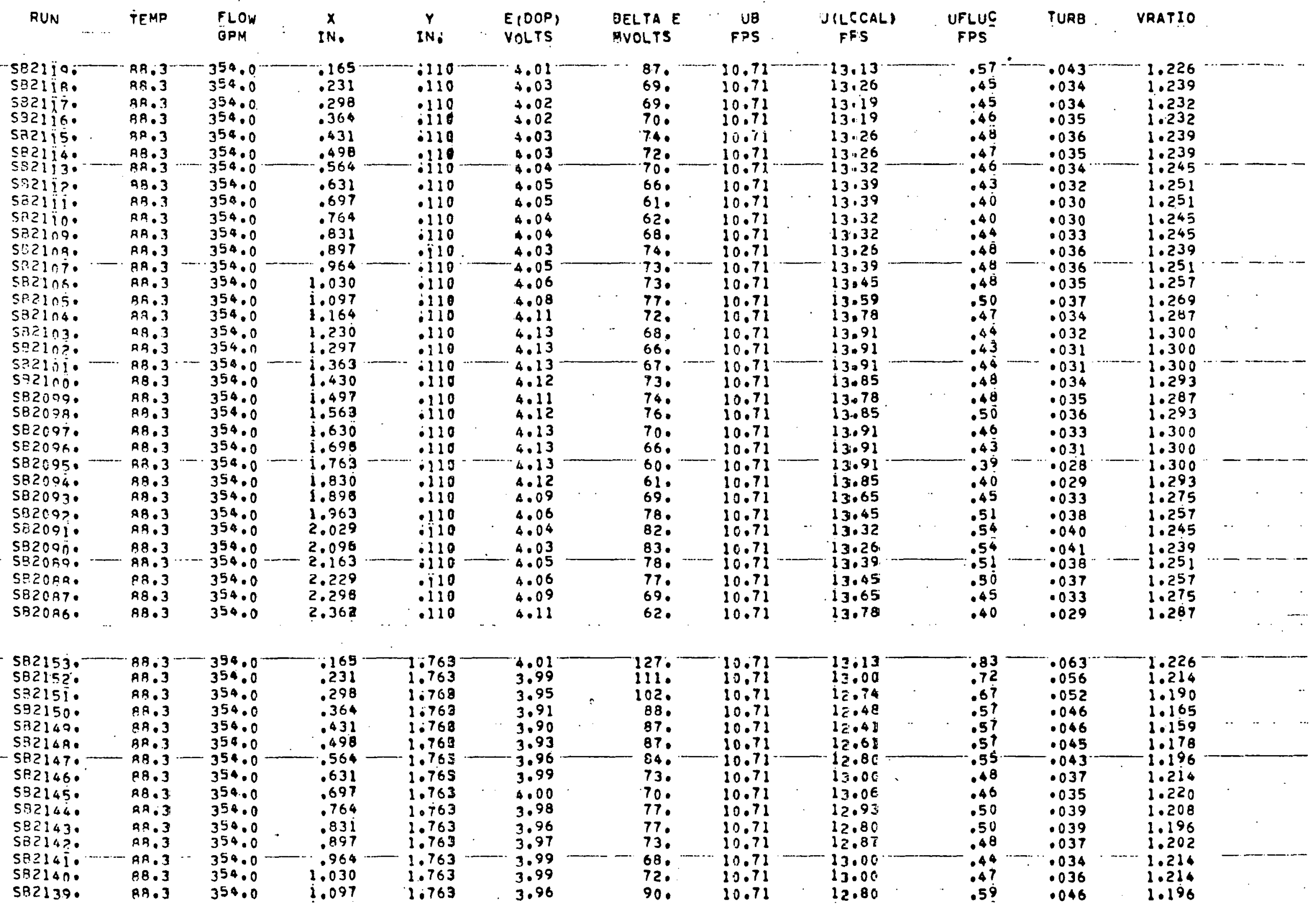




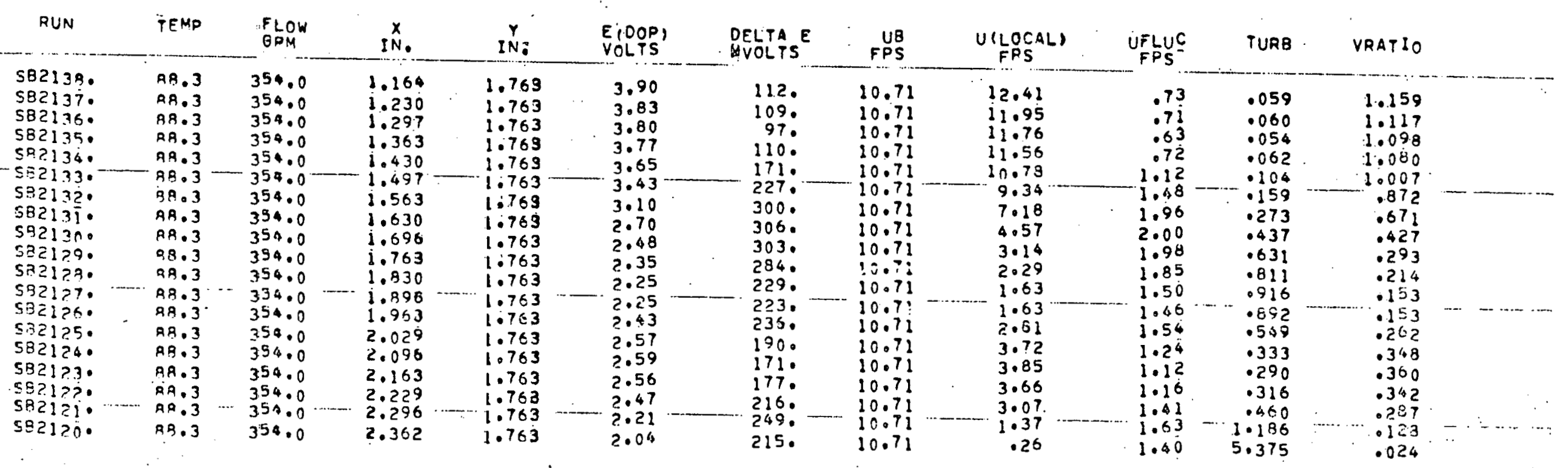


DATA F-ANE NO. 4, AXIAL DISTPAACEA21.50 IN, BLOCKAGE CENTERLINE=26.25 IN, P=23.00 PSI RE=58300.

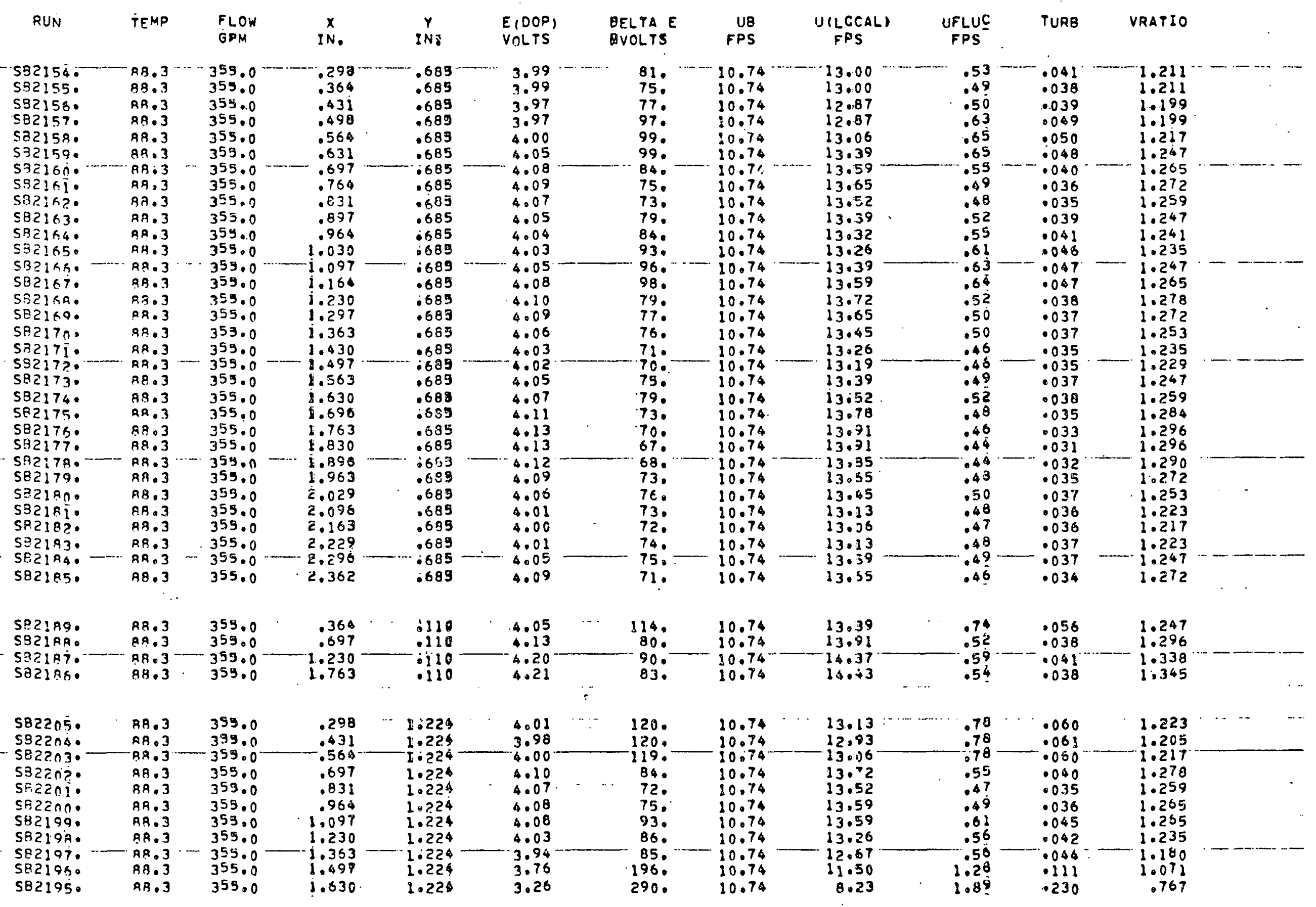




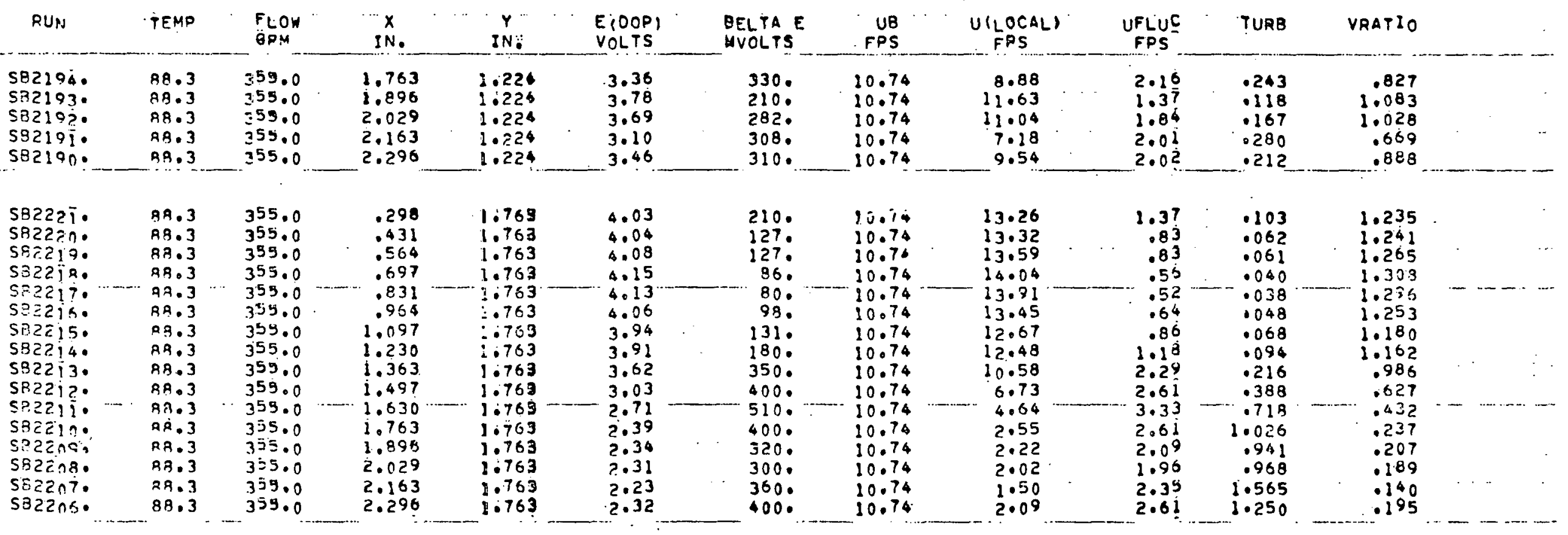


DATA PLANE NO. 5. AXIAL DISTANCE 20.20 IN. BLOCKAGE CENTERLINE=26.25 IN. P=23.08 PSI RE 58200.

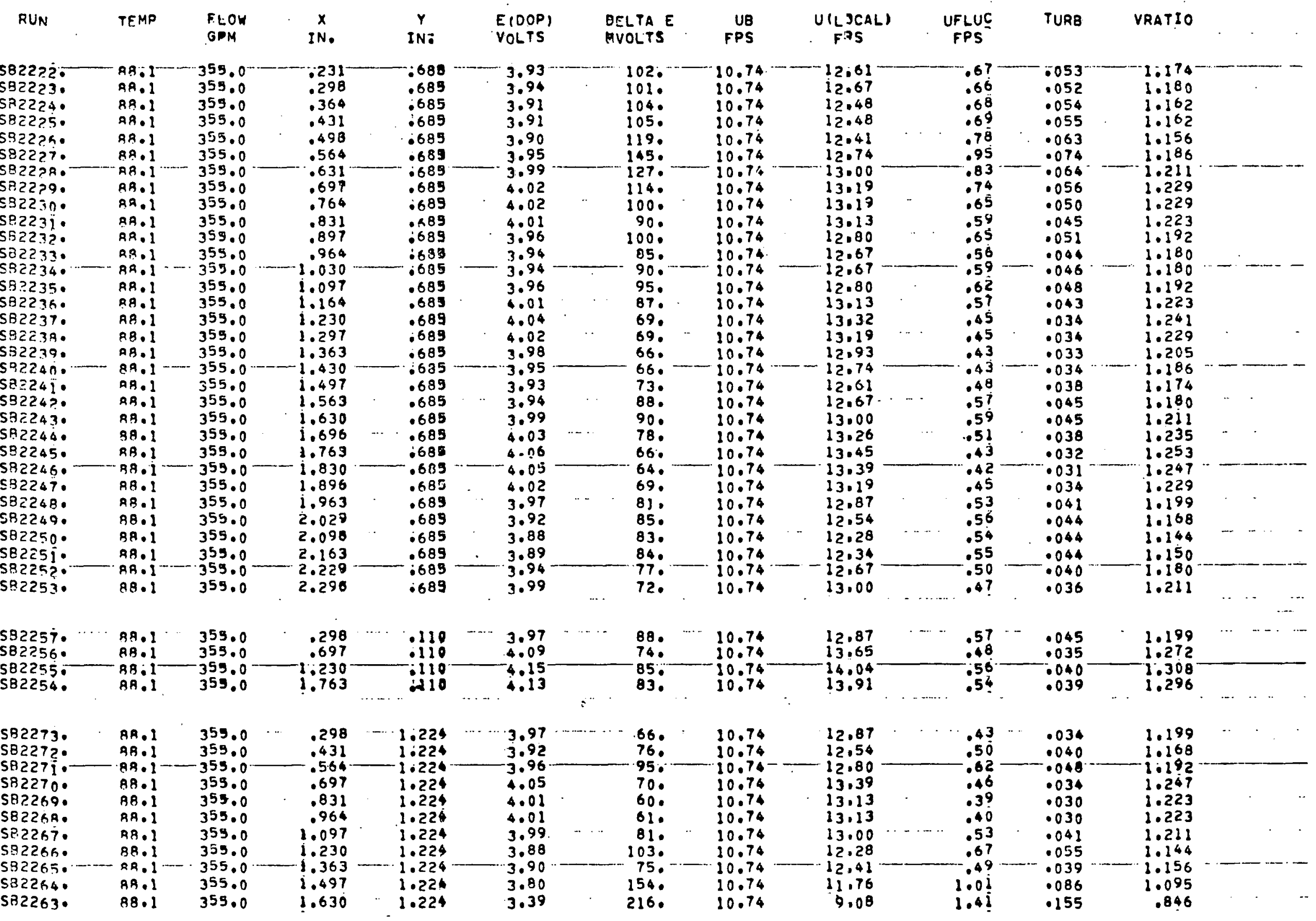




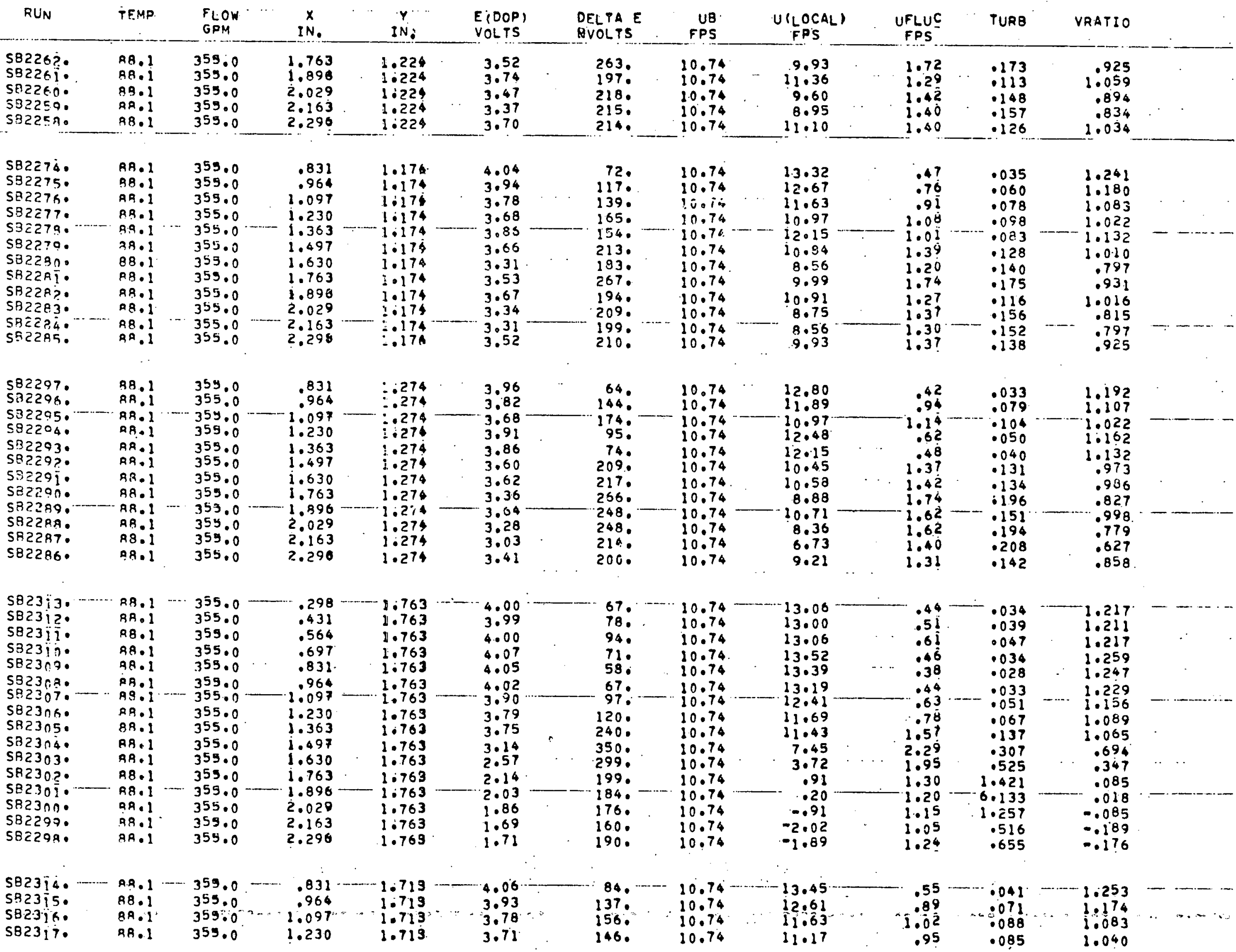




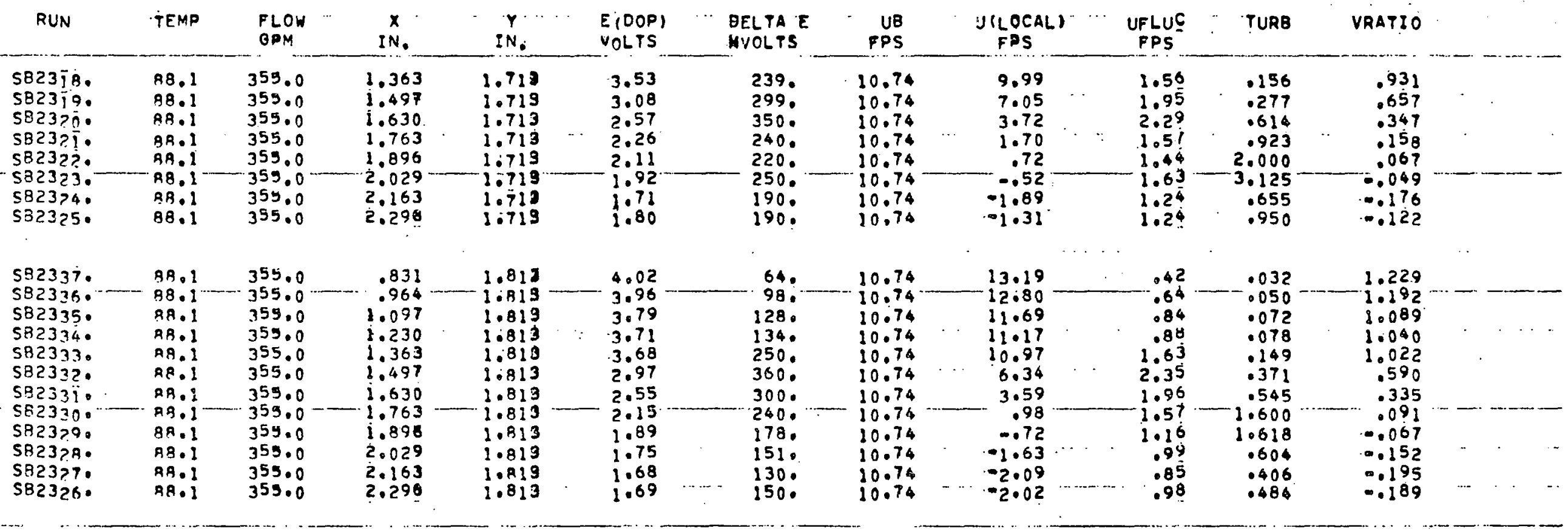




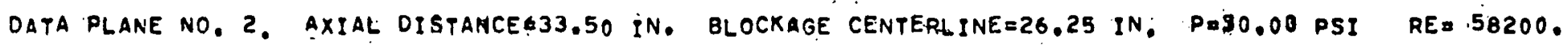

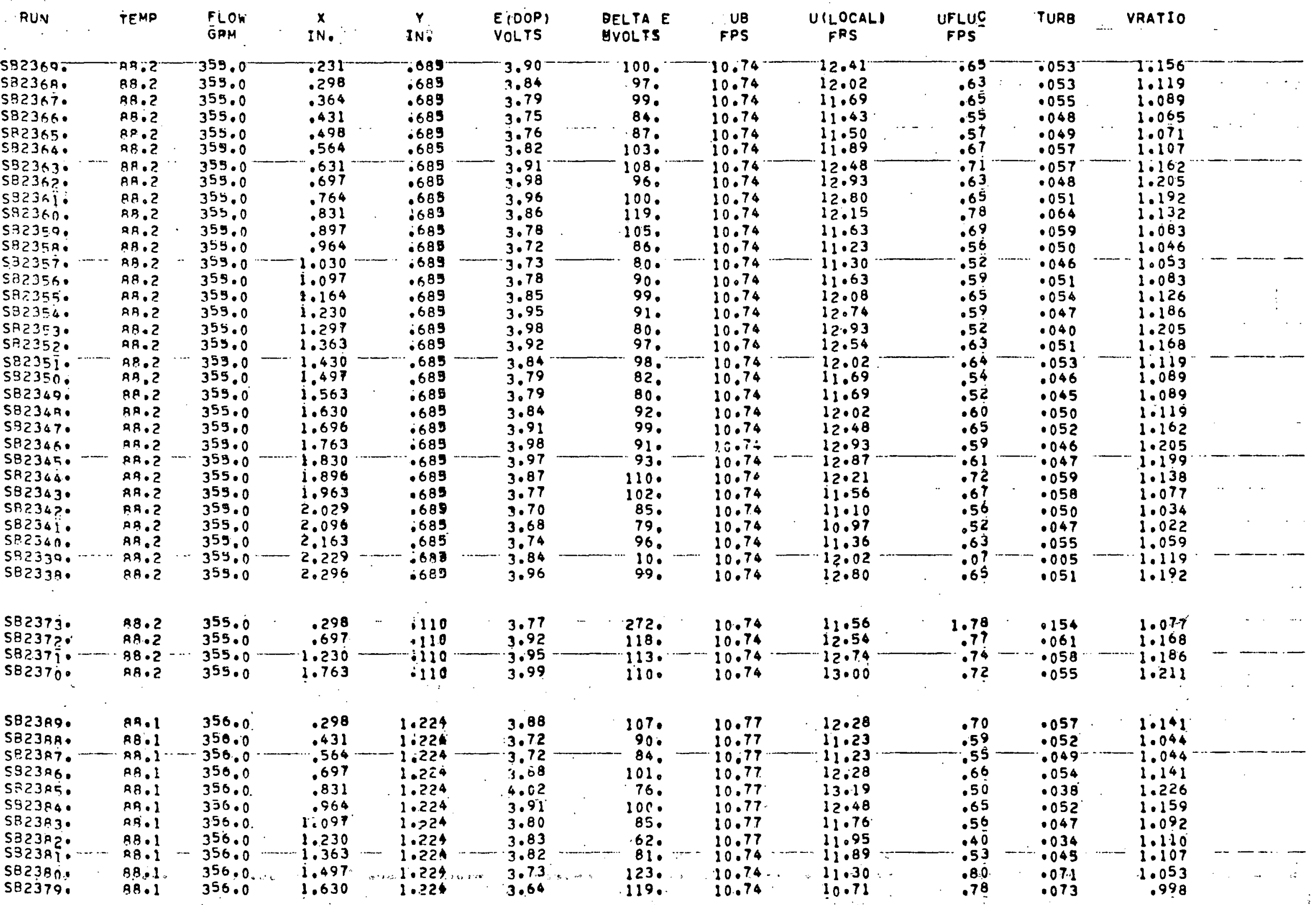




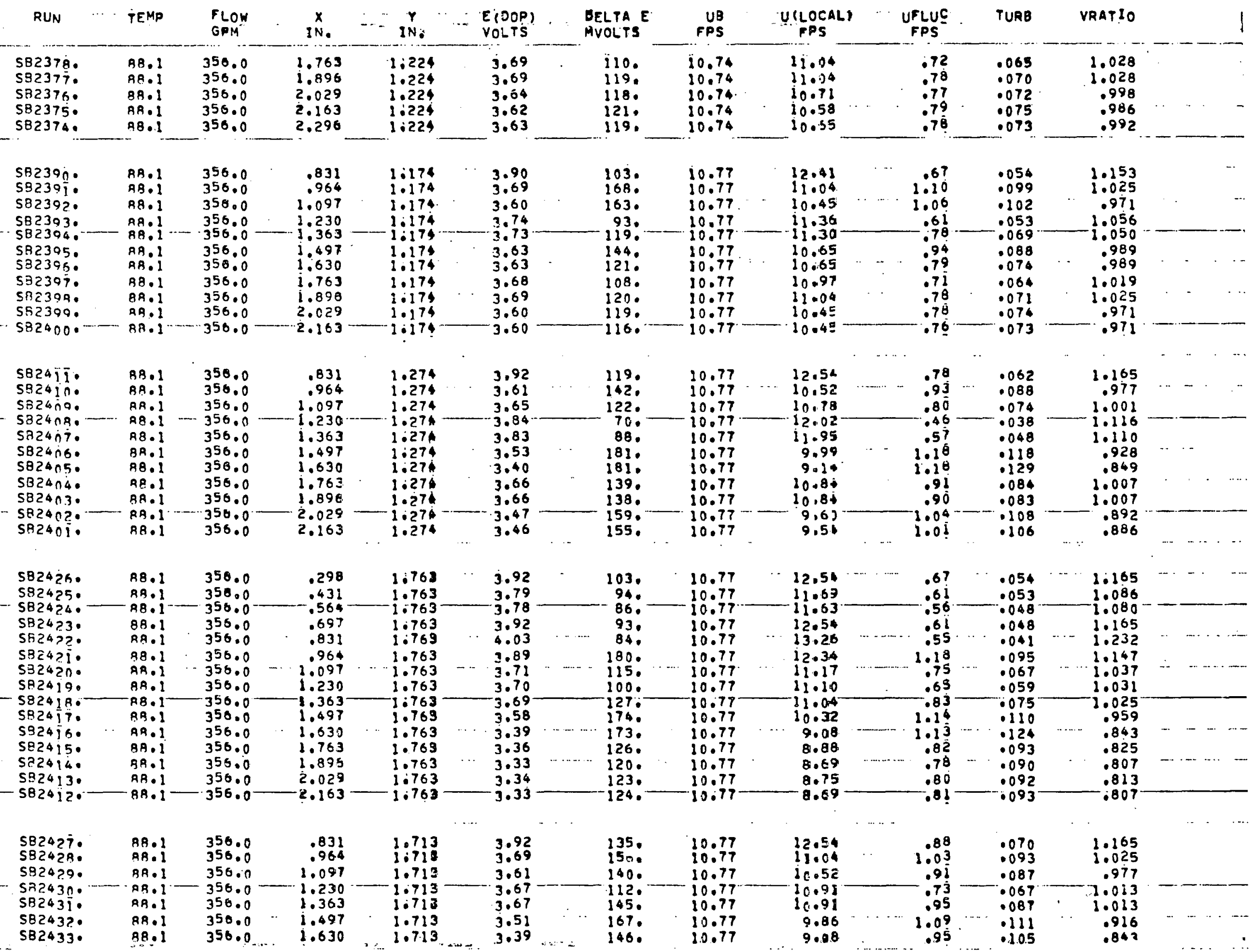




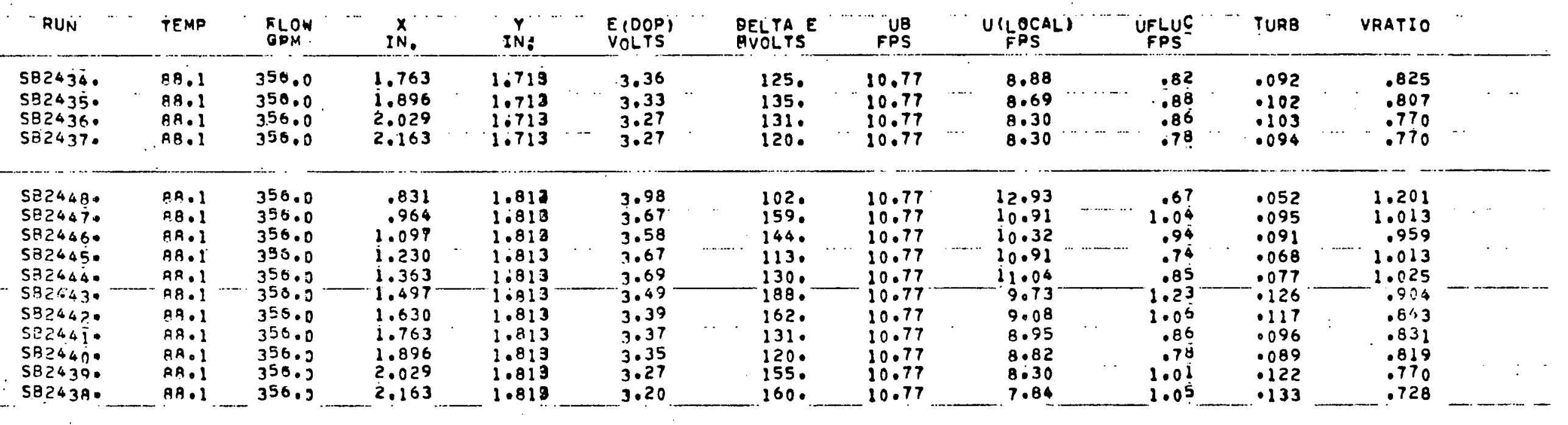


TAB_E C\$2. TABULATION OR EXPERIMENTAL LDA OATA

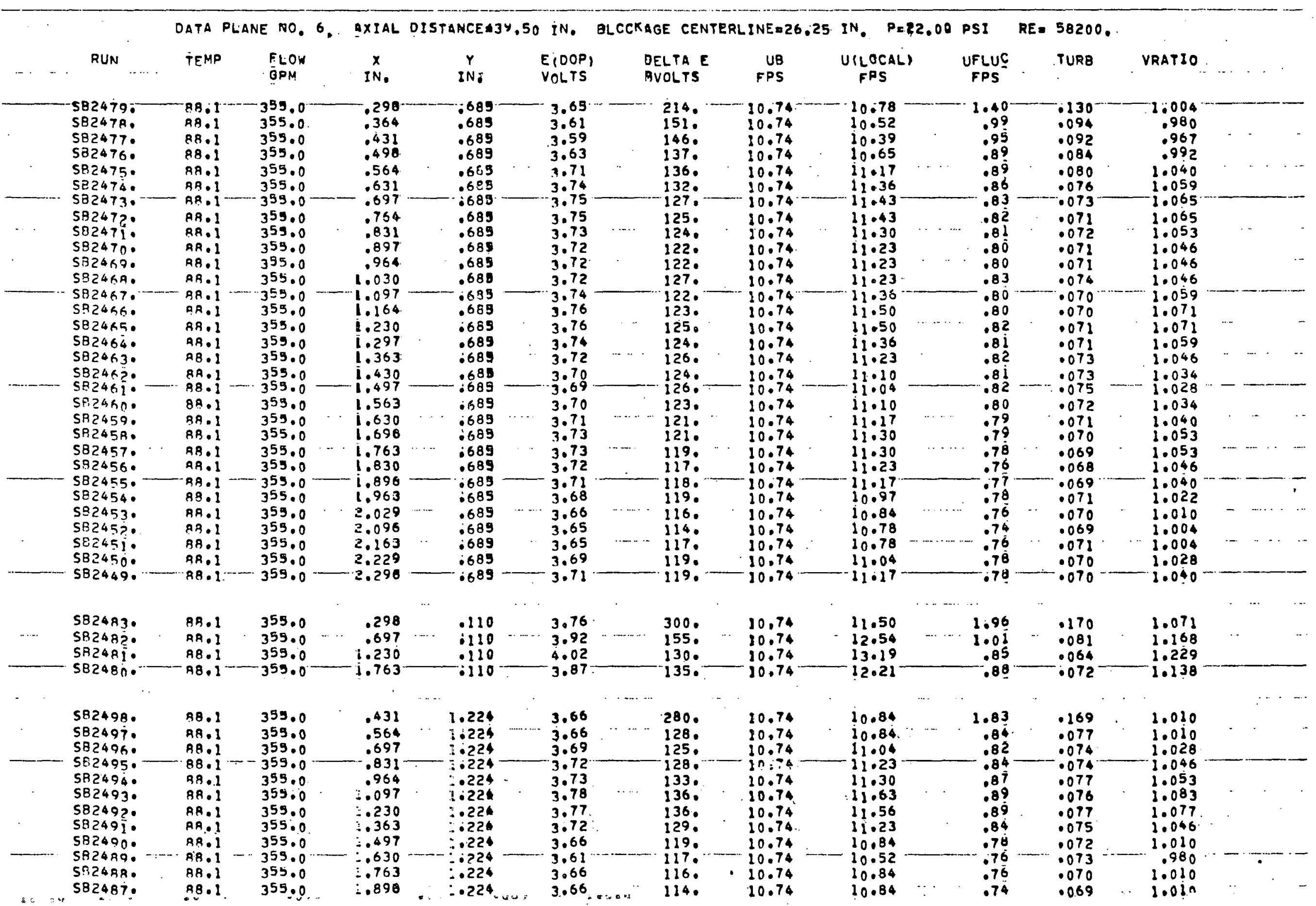




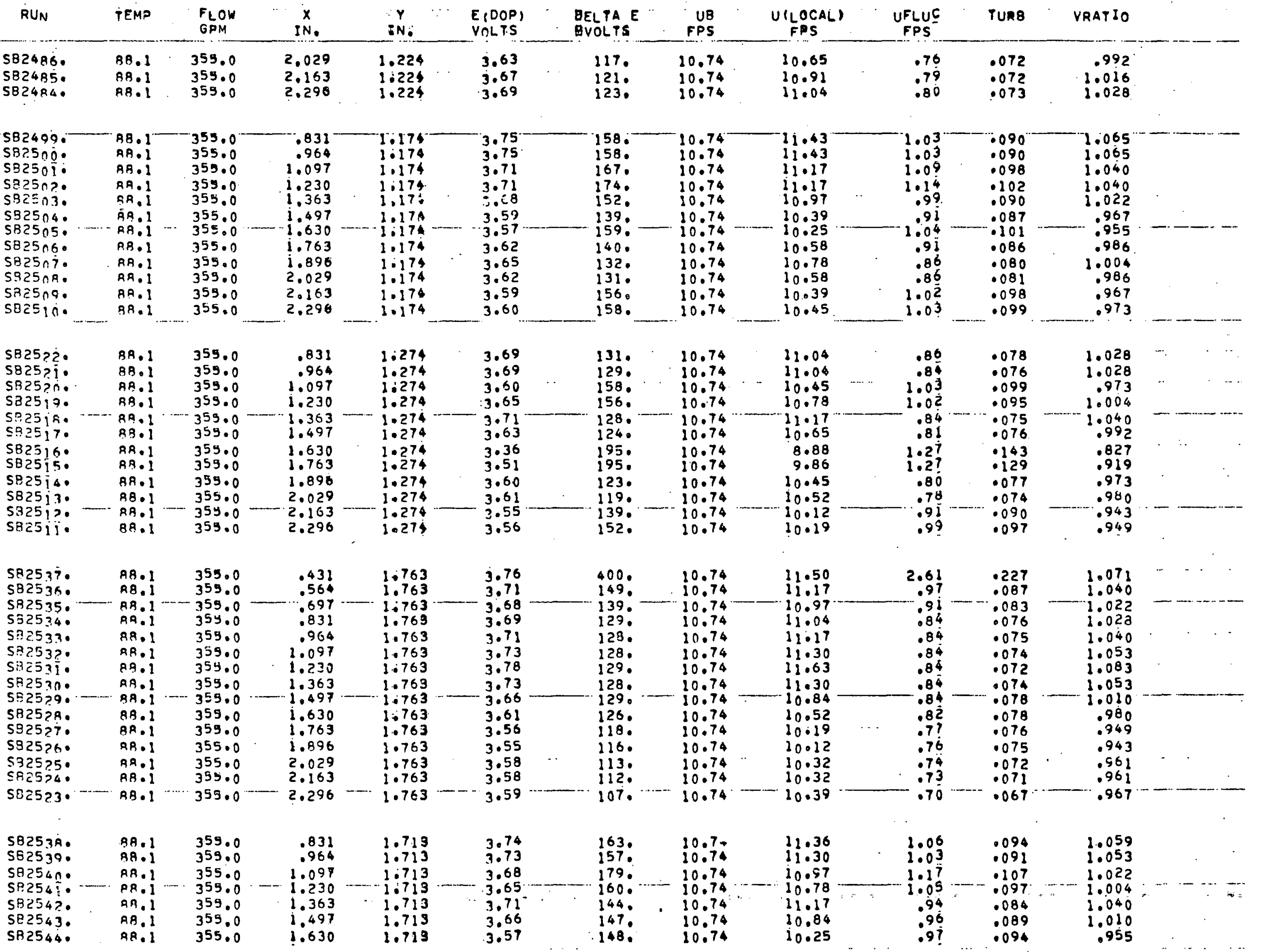




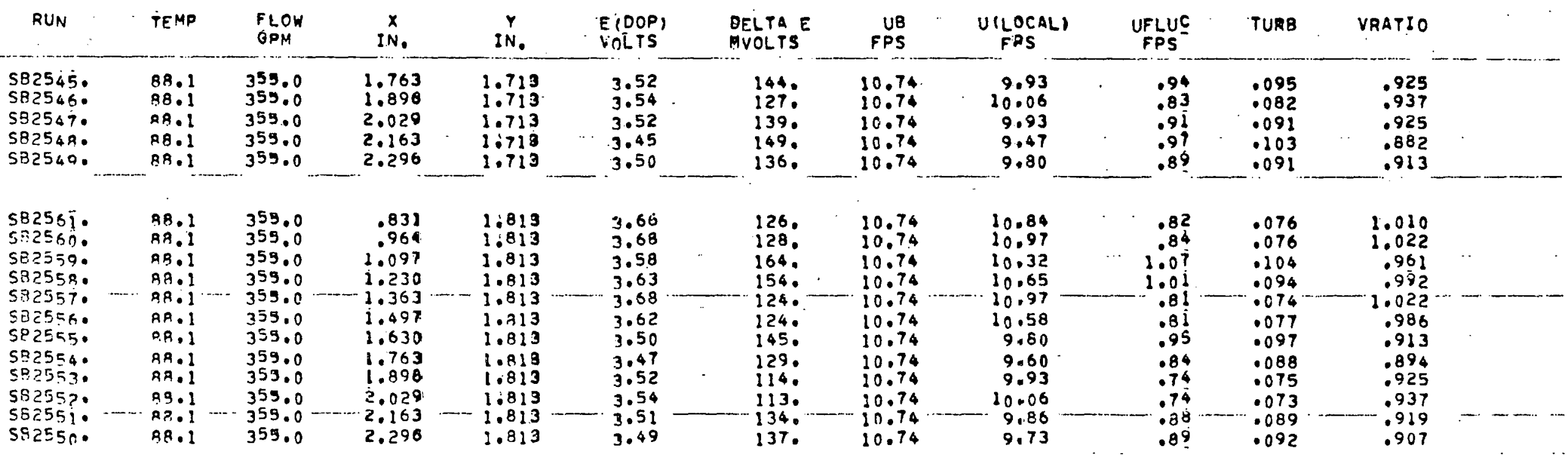


TABLE CII. TABULATION OF EXPERIMENTAL LOA DATA

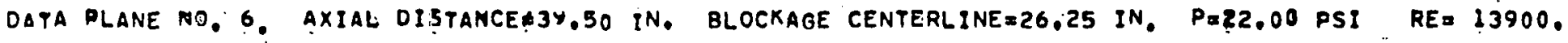

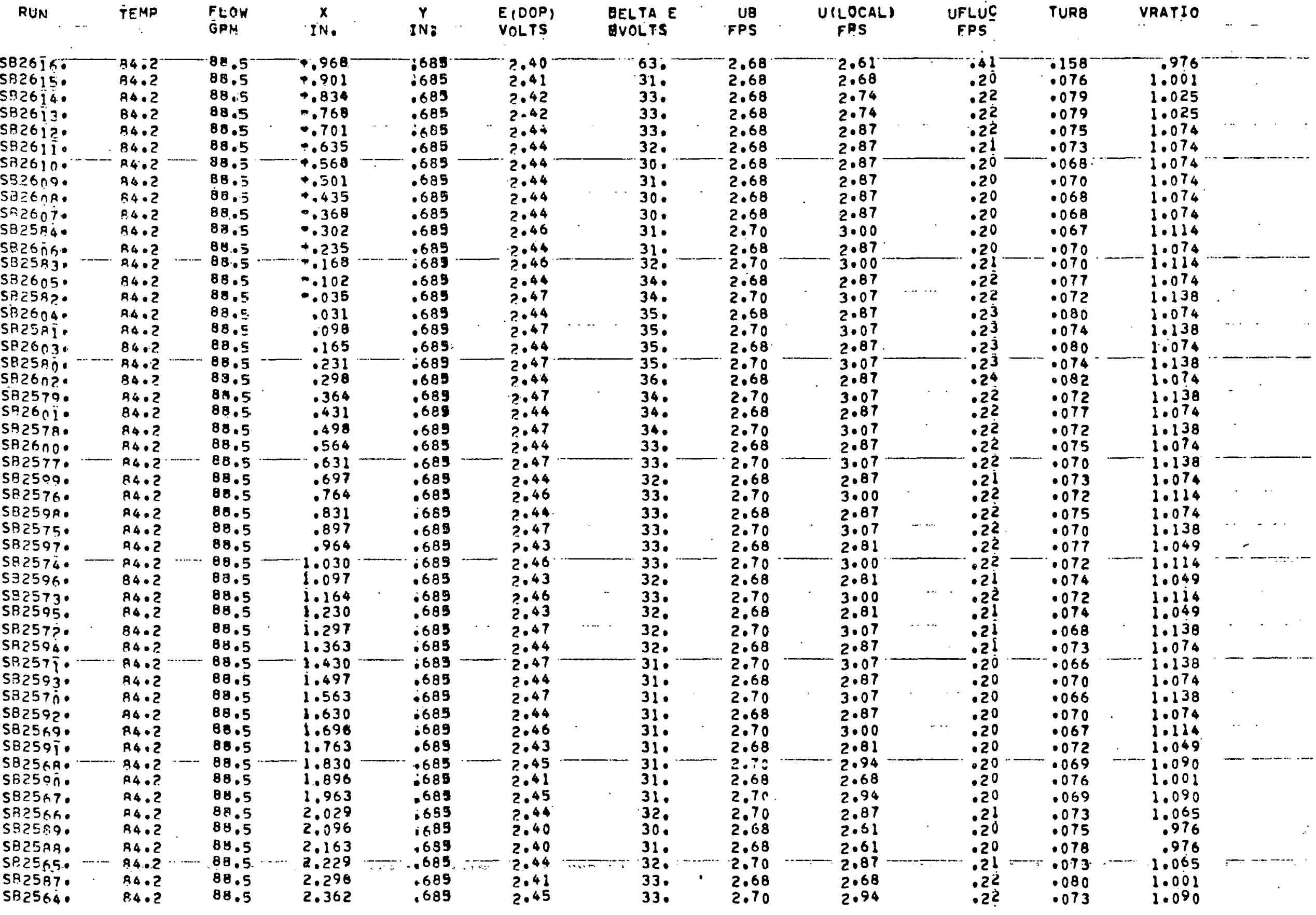


FLOW *...X X

Y... ETODOPI EiDOP
VOLTS

DELTA E $\because$ UB - UPLOCALD - . U UFLUC

TURB

VAATIO

$\begin{array}{lllll}84.2 & 88.5 & 2.420 & .689 & 2.42 \\ 84.2 & 88.5 & 2.498 & .683 & 2.46 \\ 84.2 & 88.5 & 2.562 & .689 & 2.43\end{array}$

SB2586.

SB25R.5.

34.2

$80.5 \quad 2.629$

$.689 \quad \cdots \quad 2.47$

33
33
32
32

SB264R.

- 84.

88.5

$\begin{array}{lll}.098 & 110 & 2.43 \\ .165 & 1110 & 2.47\end{array}$

592646.

582645.

$582643^{\circ}$

$59264 ?$ ?

5e264 1.

$522640^{\circ}$

552638.

SR2636.

SB26 $355^{\circ}$

SE2E34.

582633.
SB253?

S5263i.

S8.25?

SA26?\%.

SE26?7.

Sก 2625.

SR26?3.

SB26??

SB26?:

S826?0.

SQ26)

S?2617.

ค4. 2

84.2

ค4. 2

94.2

88.5

8.5

.231

$94 . ?$

$84.2 \quad 89.5$

A4.2 83.5

ค.4.?

84.2

8.5
88.5

84.2
$24.2-88.5$
84.2

$84.2 \quad 80.5$

$84.2 \quad 88.5$

$94.2 \quad 88.5$

94.2

94. 2

83.5

84.5

84. ?

94.2 88.5

$84.2 \quad 88.5$

94.2

$94.2-86.5$

ค4.?

ค4.?

94.?

$\begin{array}{rr}94.2 & 88.5 \\ 84 . ? & 8.5\end{array}$

$\begin{array}{lll}84.2 & 88.5 & 2.096\end{array}$

$88.5 \quad 2.096$

110

.364

$\because 1: 0$

110

$.431-\cdots$
.490

110
1110

.0641110

$.76+.110$

.110

$\begin{array}{ll}110 & 2.49 \\ 110- & 2.50 \\ 110 & 2.51\end{array}$

.43
.47

2.47

2.47

2.46

$2.46 \quad 39$.

$\begin{array}{ll}2.46 & 34 . \\ 2.47 & 31 .\end{array}$

2. $5 !$

2.51

2.51
2.51

$\begin{array}{ll}2.49 & 33 . \\ 2.47-30 .\end{array}$

$1.230 \ldots .110$

$.110-2.47$

$582680^{\circ}$

$94.2 \quad 88.5$

$582679^{\circ}$

$\begin{array}{rr}84.2 & 88.5 \\ 84.2 & 88.5\end{array}$

2.47
2.47
2.46 .32$.

2.46 37.

j. 430

1. 497

$\because 110$

.110

$\because 112$

$\begin{array}{ll}1110 & 2.48 \\ .110 & 2.47\end{array}$

1.690

1.763

1.830

-110

.110

2.48
$-\quad 2.48$

110

$110-2.51$

$\begin{array}{rr}110 \\ 110 & 2.52 \\ 110 & 2.51\end{array}$

95.
$38:$
31.
320
340
37.
$39 \circ$
37.
34.

$\begin{array}{ll}2.68 & 2.74 \\ 2.70 & 3.00\end{array}$

$\begin{array}{ll}2.68 & 2.81 \\ 2.70 & 3.07\end{array}$

3.07

2.68
2.68

2.68
2.68

2.68

2.68
2.68
2.68

$2.68-3.07$

3.07

2.68
2.58

2.58
2.68

2.68
2.68

2.68
2.68

$29 .-1.68$
$28 . \quad 2.68$
$30 . \quad 2.68$
32

2.68
2.68

2.68

2.68
$? .68$

2.68

2.68
2.68

2.68

34.

31.

31.
29. $\quad 2.68$

2.68

2.68

2.68

31.

$30 . \cdots \quad 2.68$

33 .

2.68
2.68

2.8

2.81

\begin{tabular}{|c|c|c|}
\hline $\begin{array}{l}.22 \\
.22 \\
.21 \\
.21\end{array}$ & $\begin{array}{l}.079 \\
.072 \\
.074 \\
.068\end{array}$ & $\begin{array}{l}1.025 \\
1.114 \\
1.049 \\
1.138\end{array}$ \\
\hline
\end{tabular}

SB2679.

84.280 .5

$.098 \quad 1.224$

$50^{2}-\cdots$

SB2676.

$582675^{\circ}$

$582674^{\circ}$

$592673^{\circ}$

58267 i.

$582670^{\circ}$

$582600^{\circ}$

SE26RR.

532667.

SE2665.

$592665^{\circ}$

84.2

80.5

$.165-1.224$

$.165-1.224$
$.231 \quad 1.224$

$80.5 \quad .298$

80.5

94.280 .5

B4,

88.5

.364
.364

$.431 \quad 1.234$

.498

$94.2 \quad 88.5$

34.2

R4. 2

84.2

88.5

.632

.897

$\begin{array}{ll}1.224 & 2.49 \\ 1.224 & 2.42\end{array}$

1.224
1.224

$1: 224$

1.224

.831

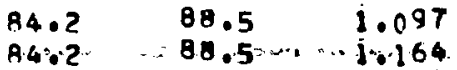

1.224

$1.224 \quad 2.46$

$1.224-2.46$

$1.224 \quad 2.44$

2.44
2.43

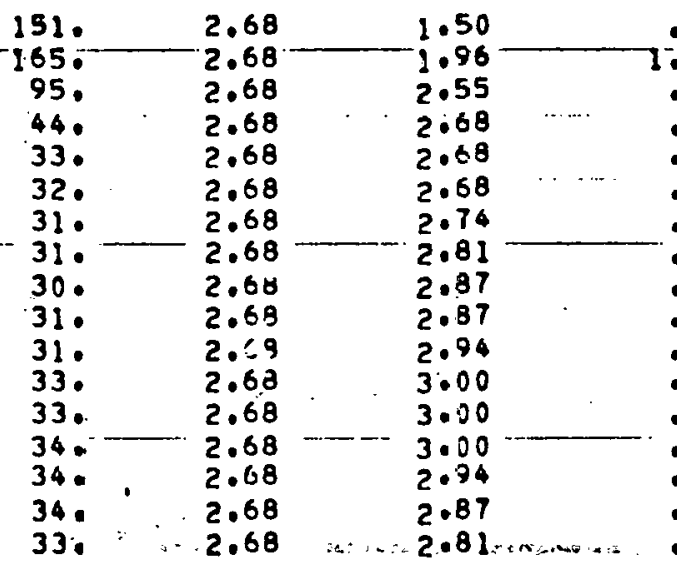

$.99 \quad .657$

.657

$.550 \quad .561$

$\begin{array}{lll}.62 & .244 & .732 \\ .29 & .107 & 1.052\end{array}$

$.22 \quad .080 \quad 1.002$

$.21 \quad .078 . \quad 1.001$

201.002

20.074

$\begin{array}{lll}.20 & .072 & 1.049 \\ .20 & .068 & 1.074\end{array}$

$\begin{array}{lll}.20 & .068 & 1.074 \\ .20 & .070 & 1.074\end{array}$

$\begin{array}{lll}.20 & .069 & 1.098 \\ .22 & .072 & 1.023\end{array}$

$\begin{array}{rrr}.22 & .072 & 1.123 \\ .22 & .072 & 1.123\end{array}$

$22-.074$

$.22 \quad .077$

.077
.077

1.123

1.074 


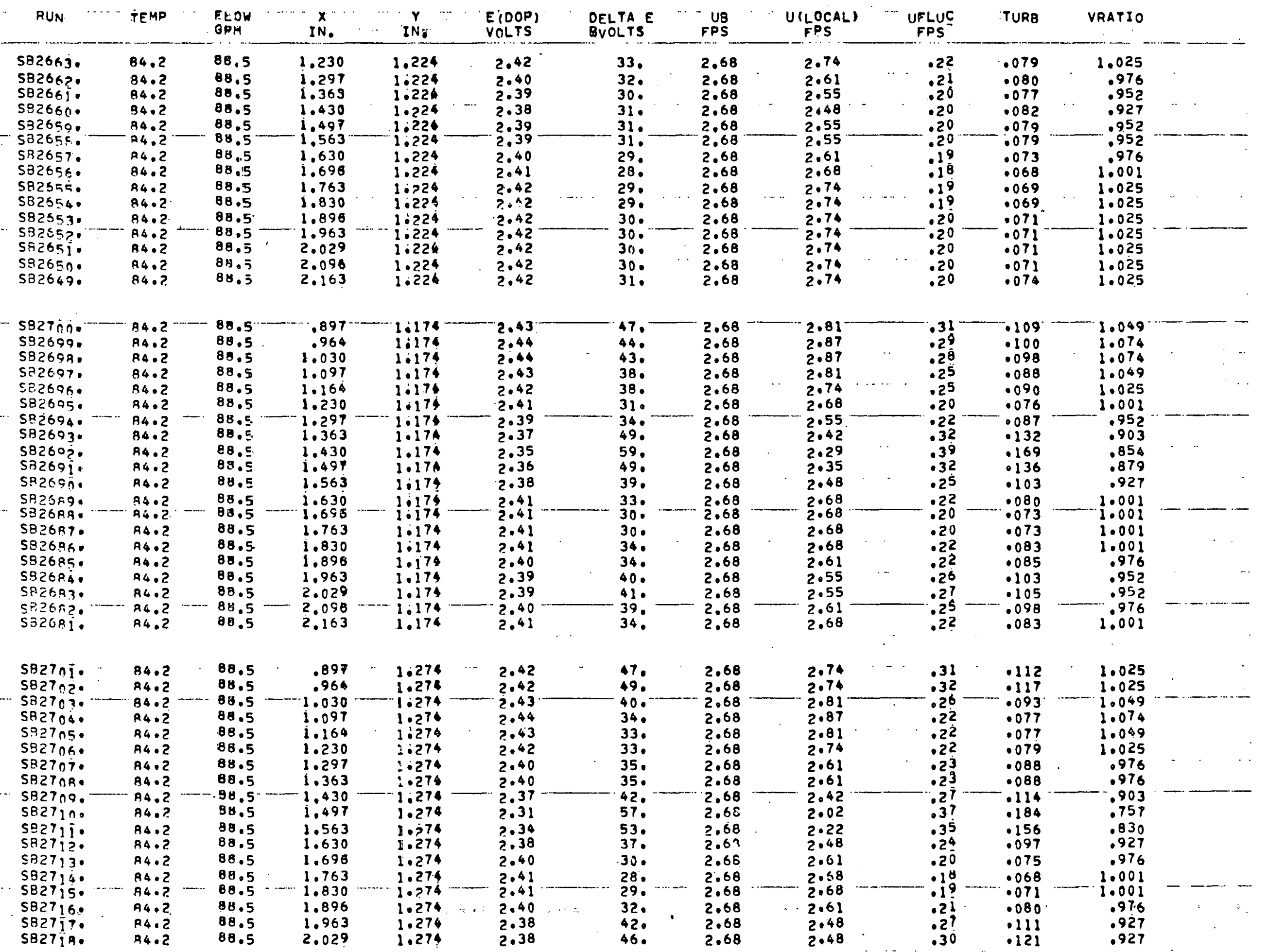




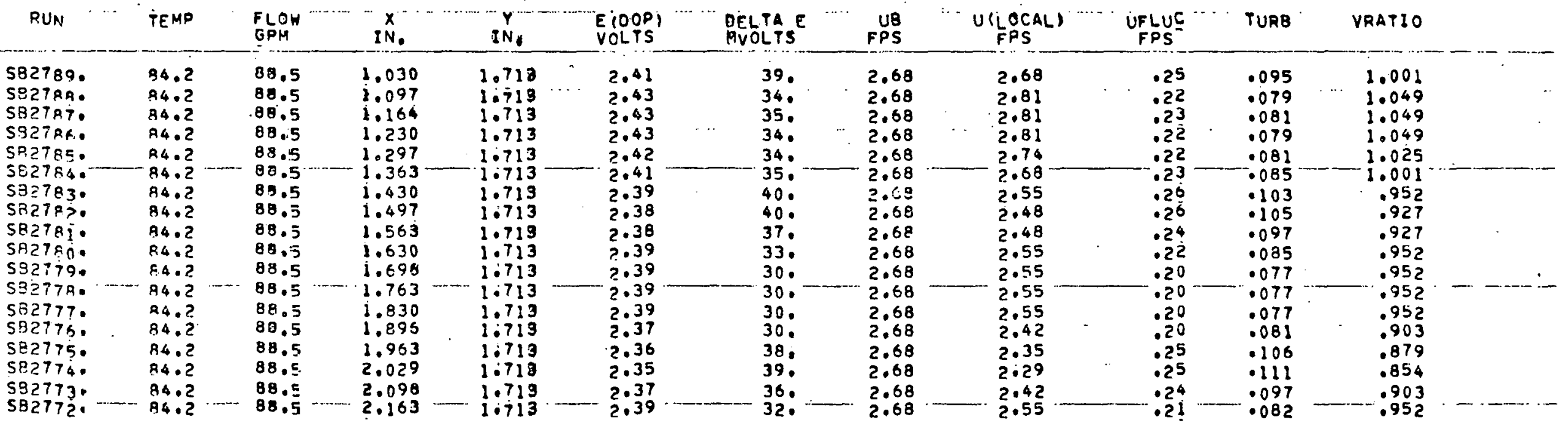


Data Plane No. 2. AXIAL DISTTANCE:33.50:N. BLOCKIGE CENTERLINE=26.25 IN, Pą2.00 PSI RE: 13900 .

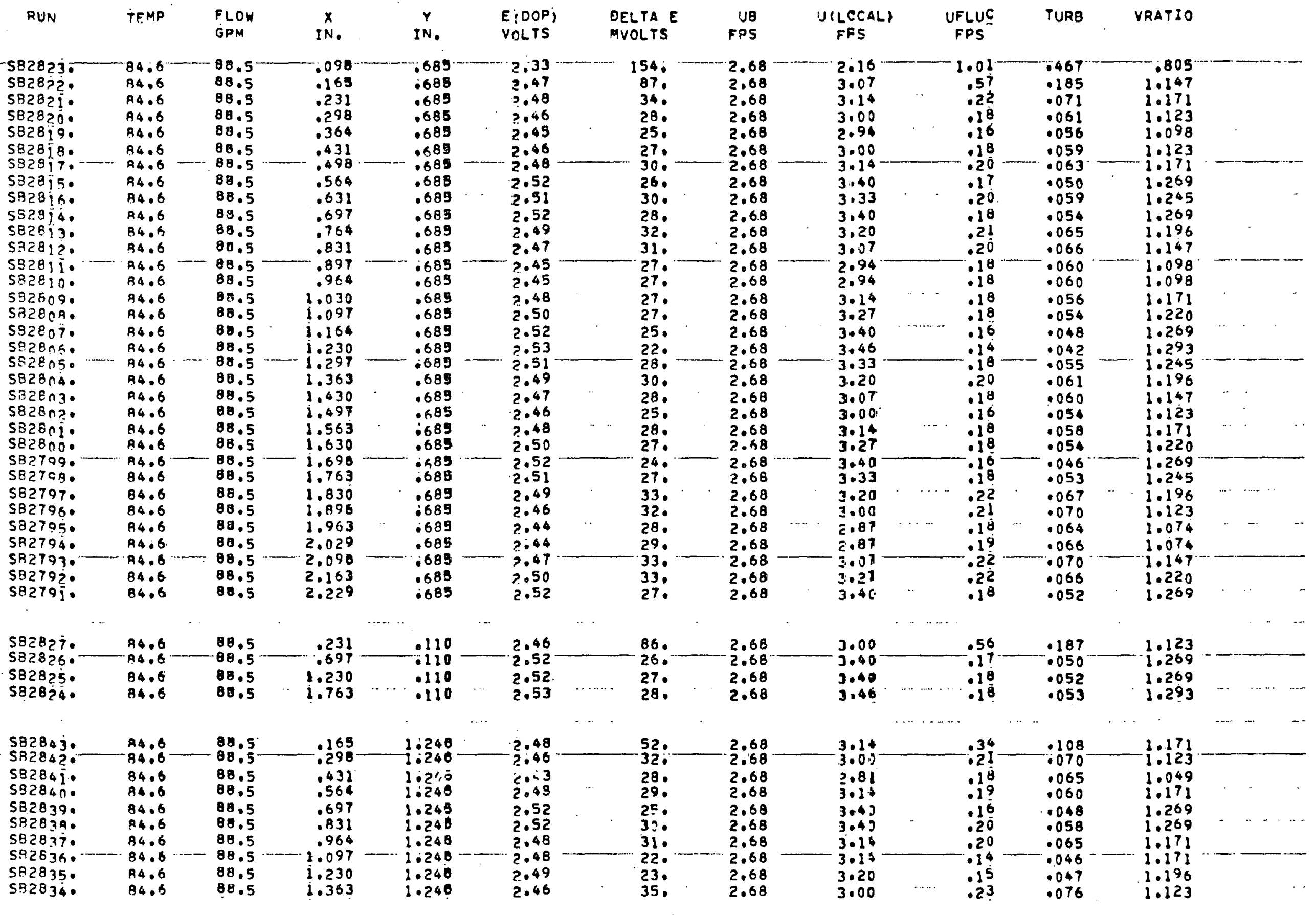




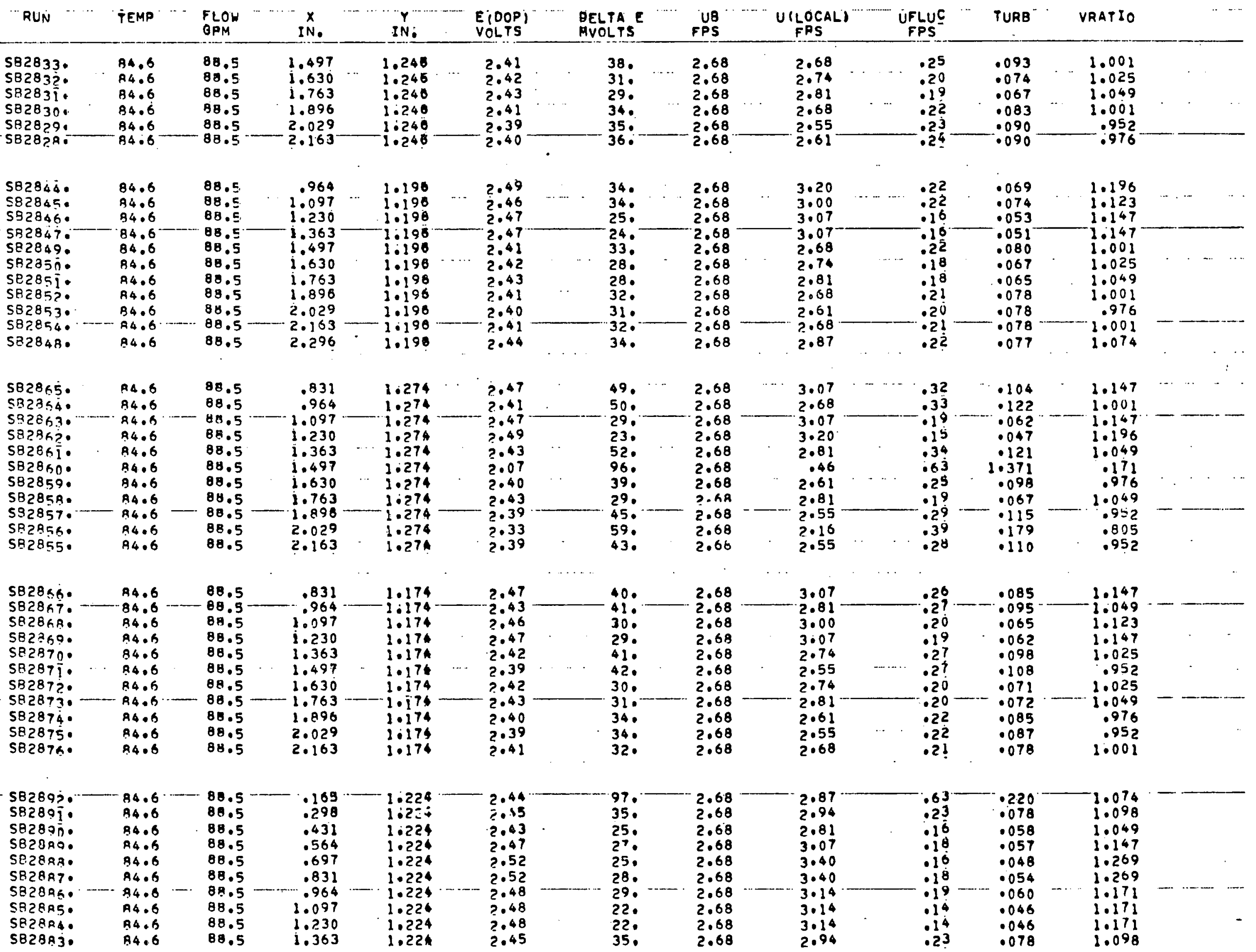




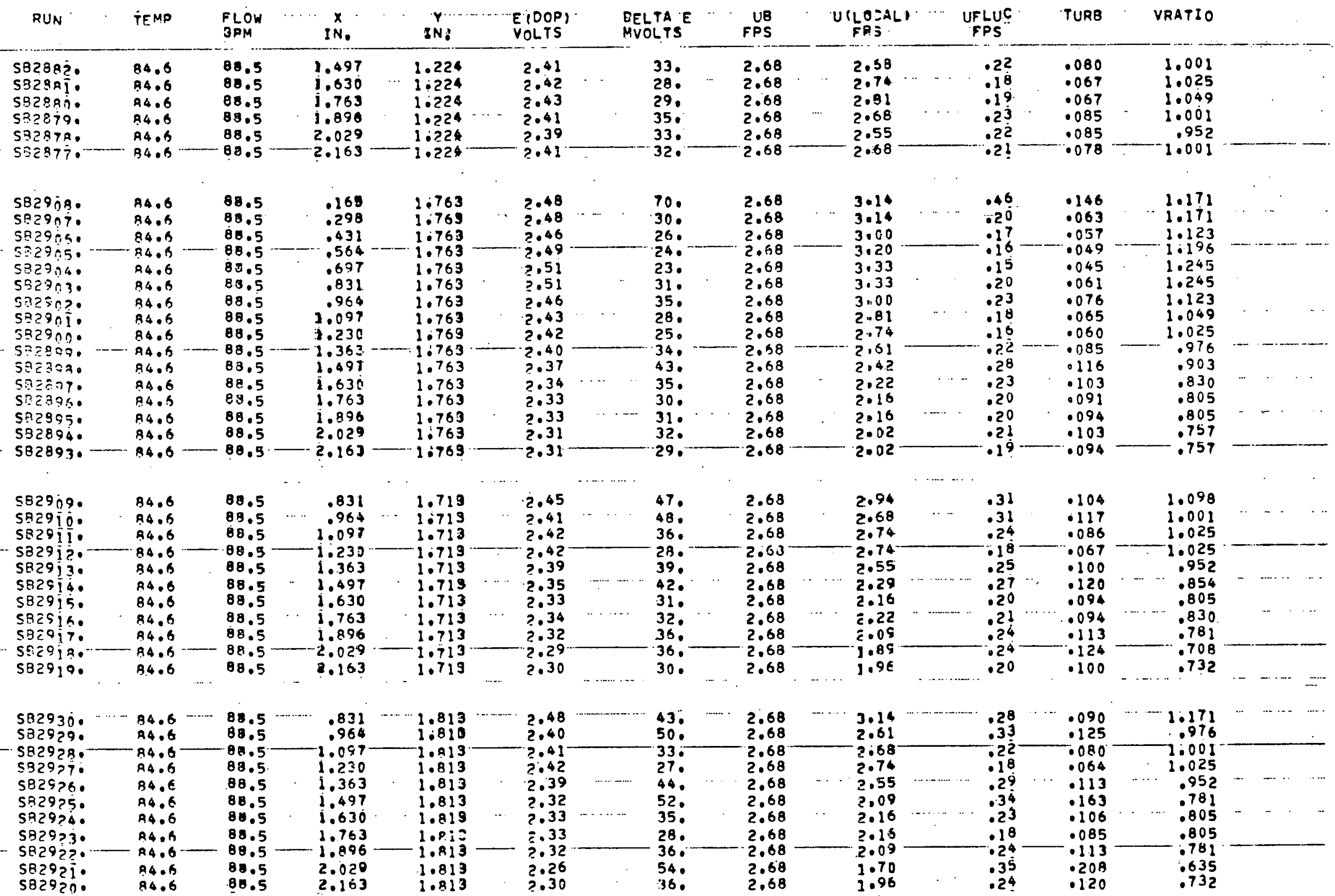


TABLE CII. TABULATION OE EXRERIMENTAL LDA CATA

DATA PLANE NC. 7. AXIAL DISTANCE 651.50 IN. BLOCKAGE CENTERLINE=26.25 IN, P=20.00 PSI RE= 13900.

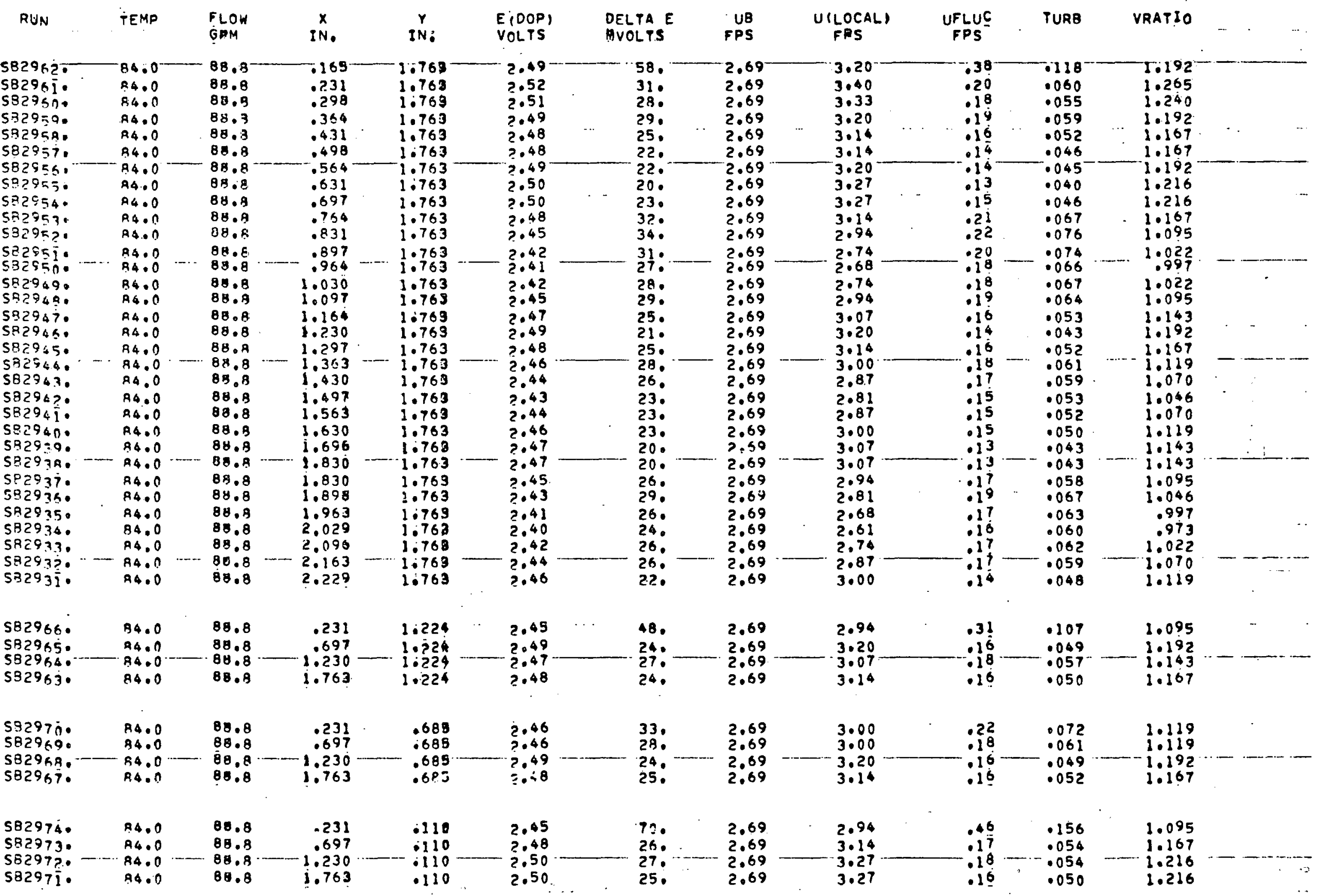




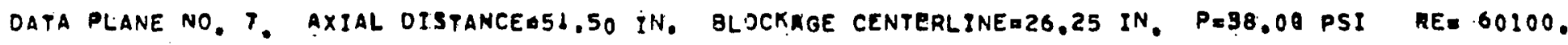

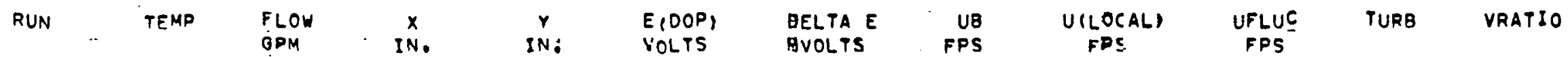

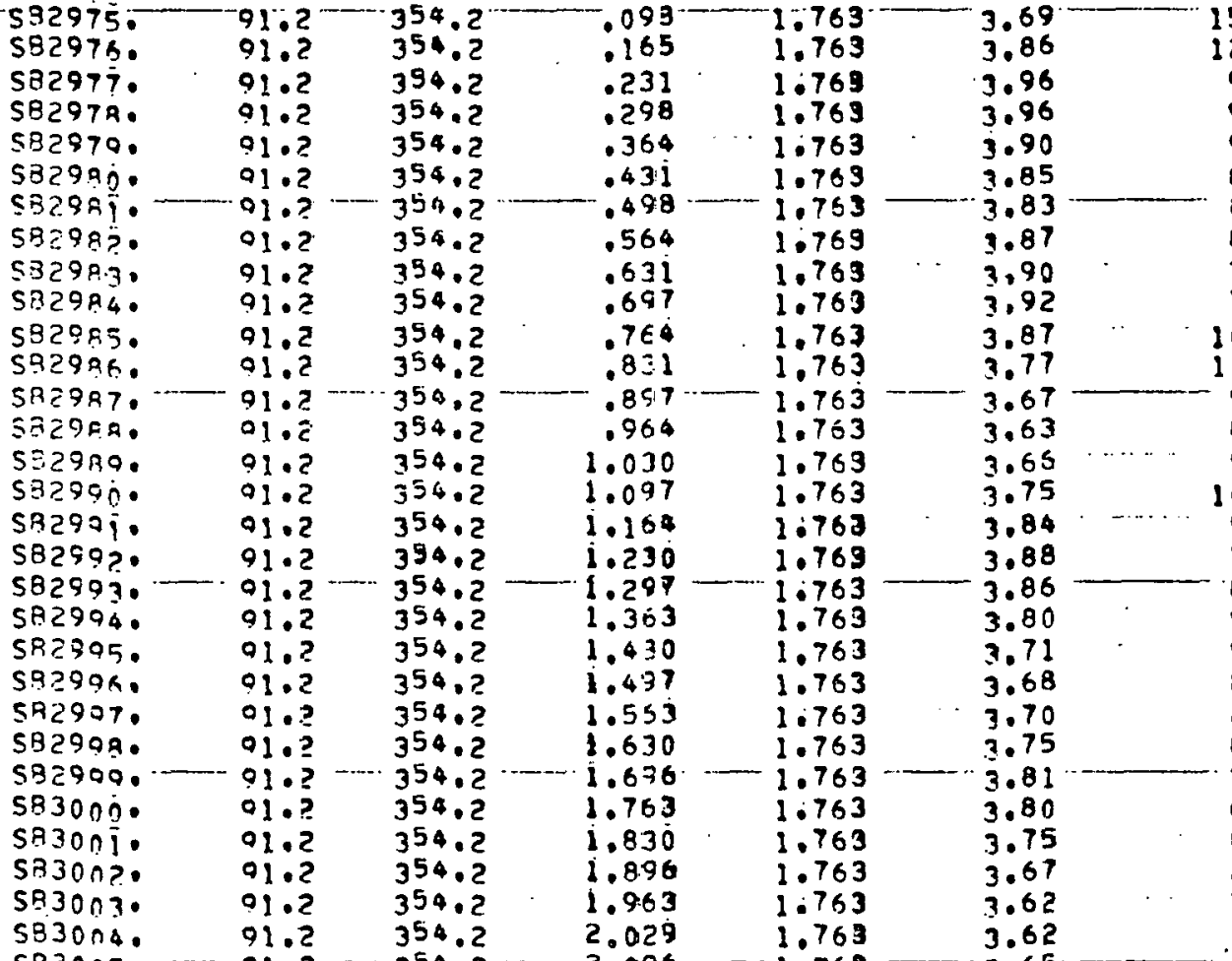

$80 . \quad 10.71$

$91 . \quad 10.71$

99.10 .71

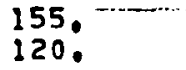

92.

98.

80.

10.71

73.

16.

114 .

98 .

32 .

92. 10.7

$102 . \quad 10.71$

72.

10.7

96.10 .71

85. $\quad 10.71$

86. $\quad 10.71$

B2.

72.

69.

85.

$740^{\circ}$
88. 10.71

10.72

10.71

30.71

30.71

10.71

$1: 763$

3.65
$11 \cdot 0.4$ 12.05
12.80 $1 \mathrm{c} .80$
$1 \mathrm{c} .80$ $1 \bar{c} \cdot 91$ $1=.98$

SB3C05.

$i_{i}^{2.256}$

?. 3.91

i) 0.34

1).34

12.02 12.20

3.15

1.1 .17

2.0 .97

11.10

11.43

1.76

i). 43

16.91

10.58

10.58 31.2
$-91.2-354.2$
1.224
$10 j 25$

1.22

3.85

3.91

3.88

121.

75.

10.71
10.72

10.71

10.71

83.

75,

10.71
10.71
10.71

10.71

83.
85.
97.

\begin{abstract}
10.71
10.71
10.71
\end{abstract}
10.71

i110

3.98
.3 .97

82
$1.03-.092$

.065

$.60 \quad .047 \quad 1.195$

$\begin{array}{lll}.60 & .047 & 1.195 \\ .64 & .052 & 1.159\end{array}$

$.58 \quad .048 \quad 1.129$

$.52-.044-1.116$

$.52 \quad .043 \quad 1.140$

$\begin{array}{llll}12.21 & .52 & .043 & 1.140 \\ 12.41 & .40 & .038 & 1.159 \\ 12.54 & .50 & .040 & 1.171\end{array}$

$\begin{array}{llll}12.21 & .50 & .040 & 1.171\end{array}$

.7

$.064 \quad .059$

.040 .050

.60

$\begin{array}{rrr}.67 & .59 & .058 \\ .047 & .049\end{array}$

$\begin{array}{rr}.59 & .049 \\ .47 & .038\end{array}$

$.47 \quad .038$

$.65 \quad .055$

$.63 \quad .056$

$.56 \quad .051$

$.56 \quad .051$ $.54 \quad .047$

$\begin{array}{ll}.47 & .040 \\ .45 & .038\end{array}$

$.54 \quad .047$

$.56 \quad .051$

$.44 \quad .046$ $.52 \quad .049$

1.079

1.018

0.594

1.012

1.122

1.146

1.134

1.043

1.024

1.037 1.067

1.104

1.007

1.018

988

$053-10006$

S83015.

$91.2 \quad 354.2$

i. .763

1.128

$\begin{array}{ll}.039 & 1.165 \\ .039 & 1.146\end{array}$

2.48

$.79 \quad .065$

$.48+.040$

1.134

$\begin{array}{lll}.54 & .044 & 1.159 \\ .54 & .046 & 1.110 \\ .49 & .039 & 1.165 \\ .53 & .043 & 1.152\end{array}$

$3=.34$

$\begin{array}{lll}.54 & .044 & 1.159 \\ .56 & .045 & 1.165 \\ .63 & .049 & 1.207\end{array}$

1.207

.54 
TABLE CII. TABULATION OP, EXPERIMENTAL LOA DATA

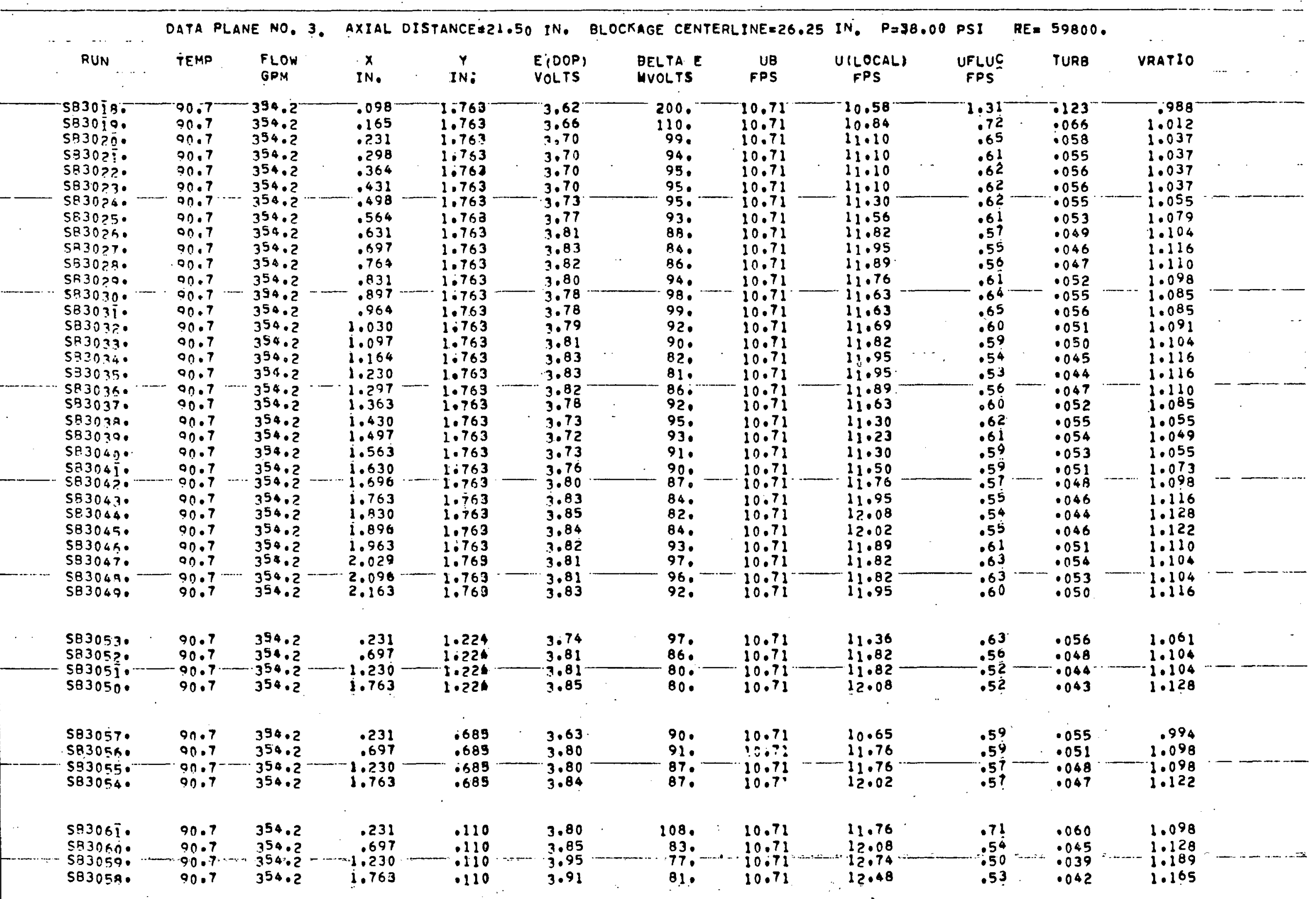




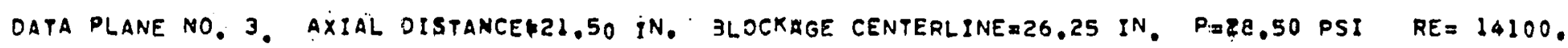

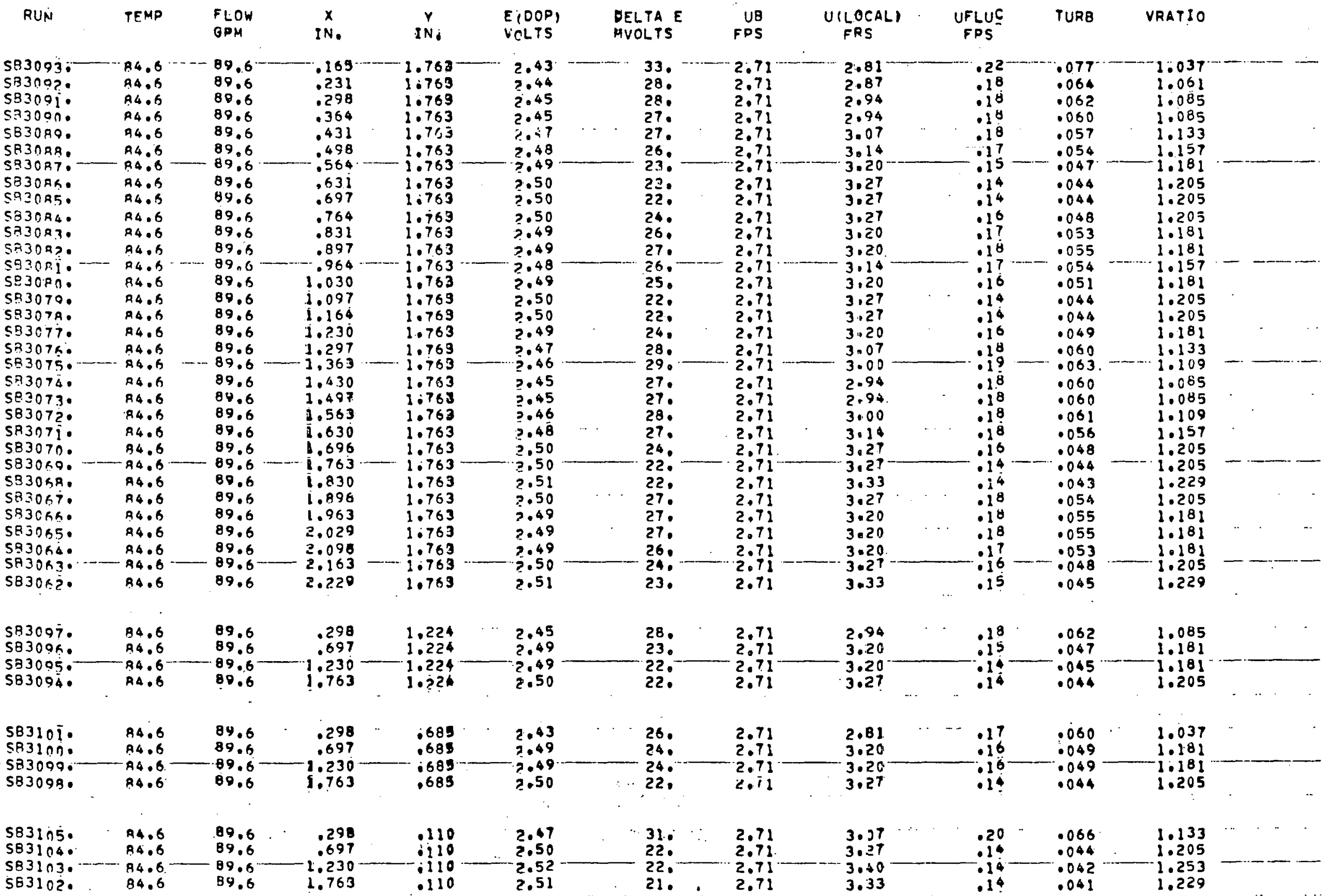


DATA PLANE NO. 5. AXIAL DISTANCEस26.20 IN. BLOCKMGE CENTERLINE=26.25 IN. P=28.50 PSI RE= 14300 .

\begin{tabular}{|c|c|c|c|c|}
\hline RUN & TEMP & $\begin{array}{l}\text { FLOW } \\
\text { GPM }\end{array}$ & & \\
\hline
\end{tabular}

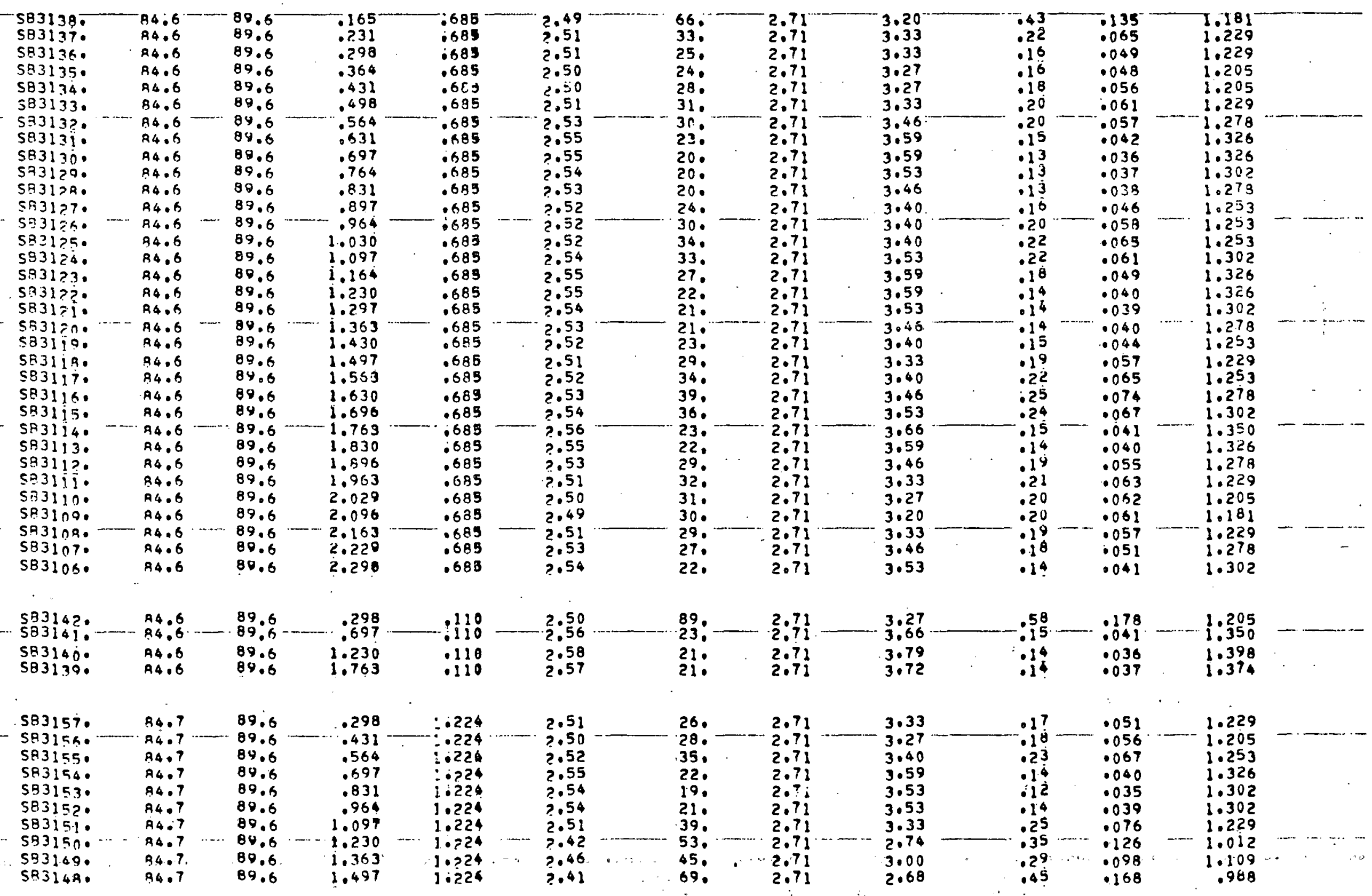




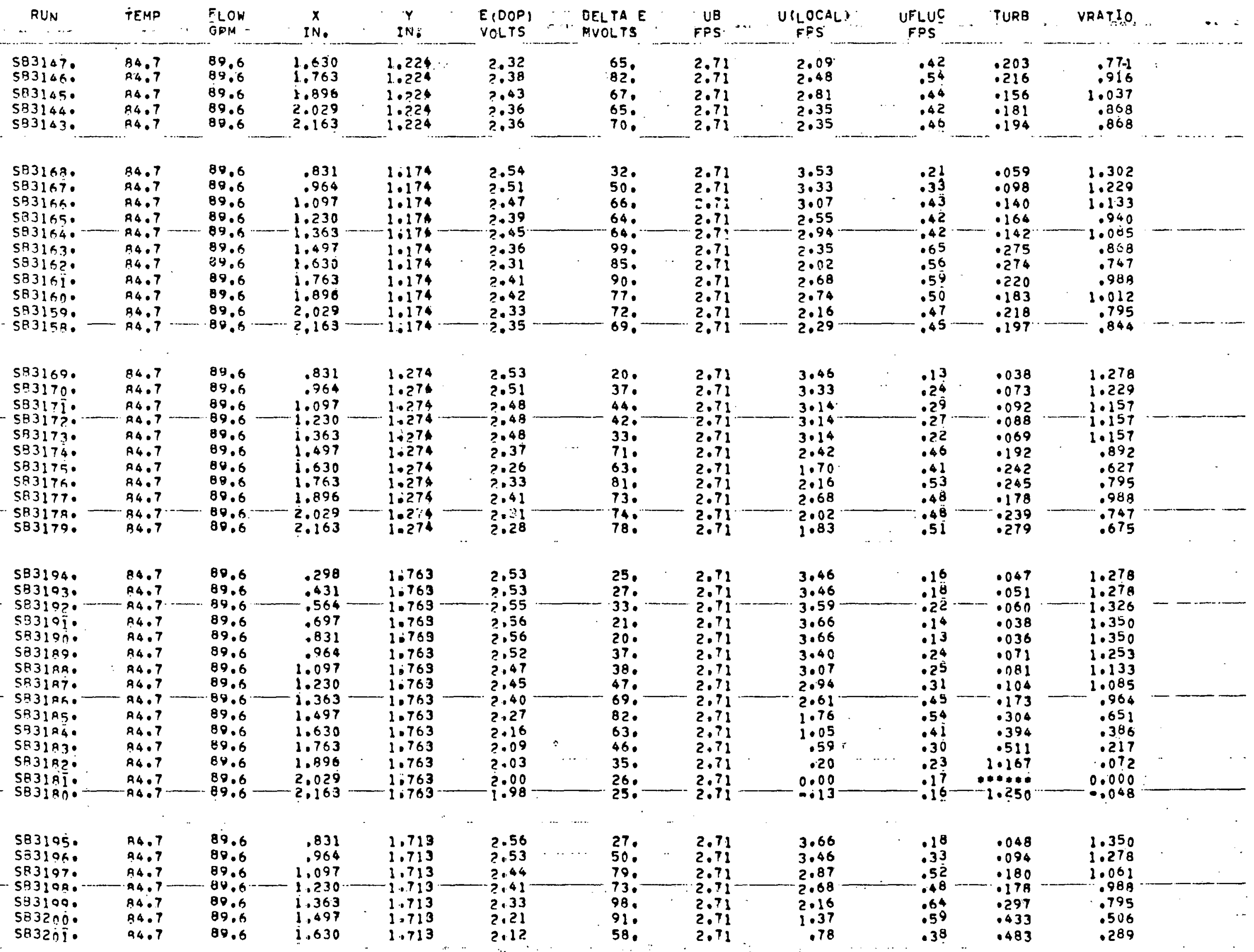




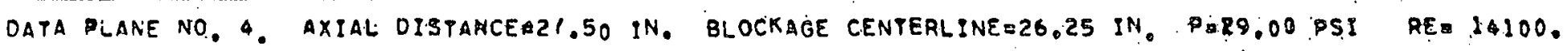

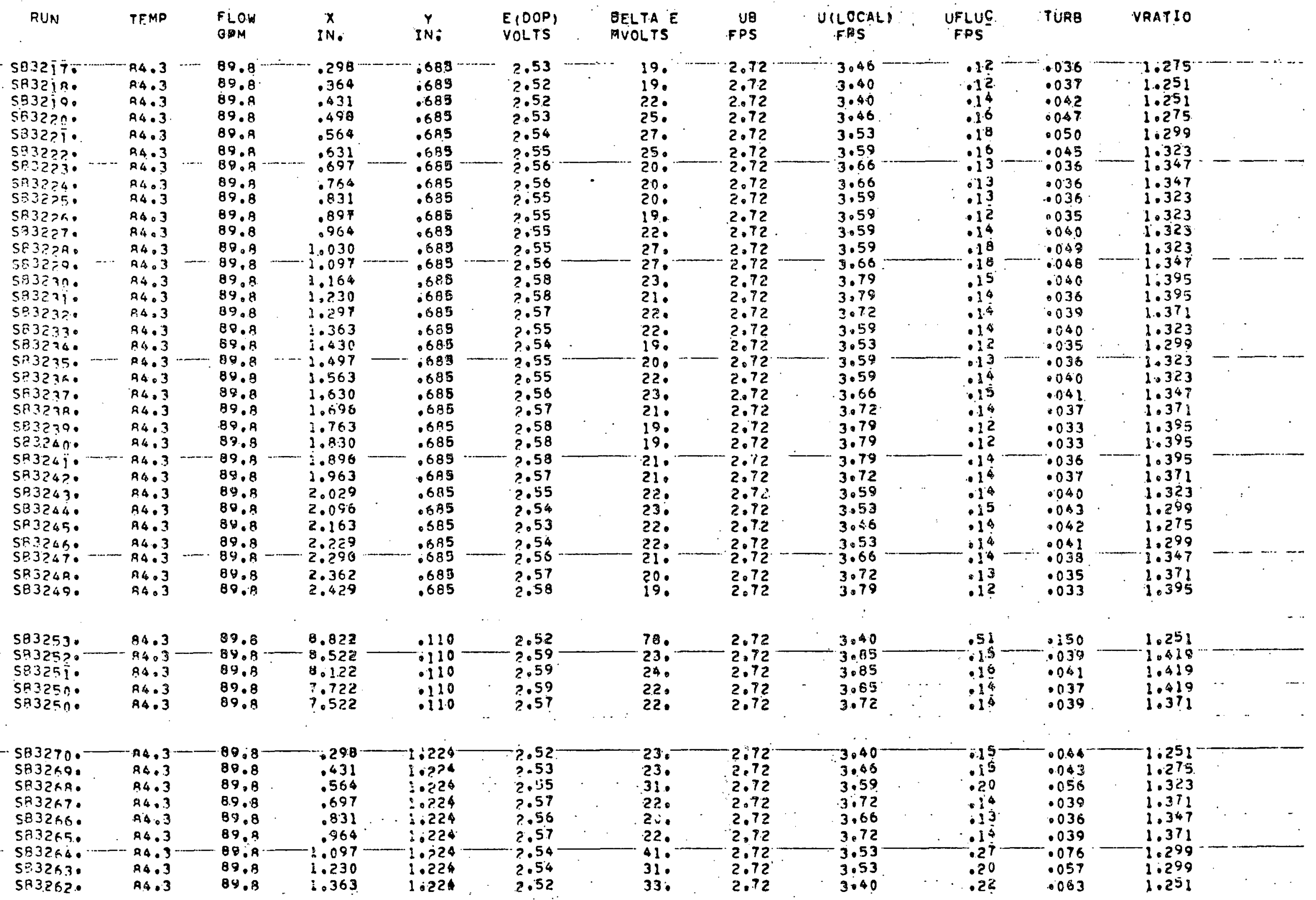




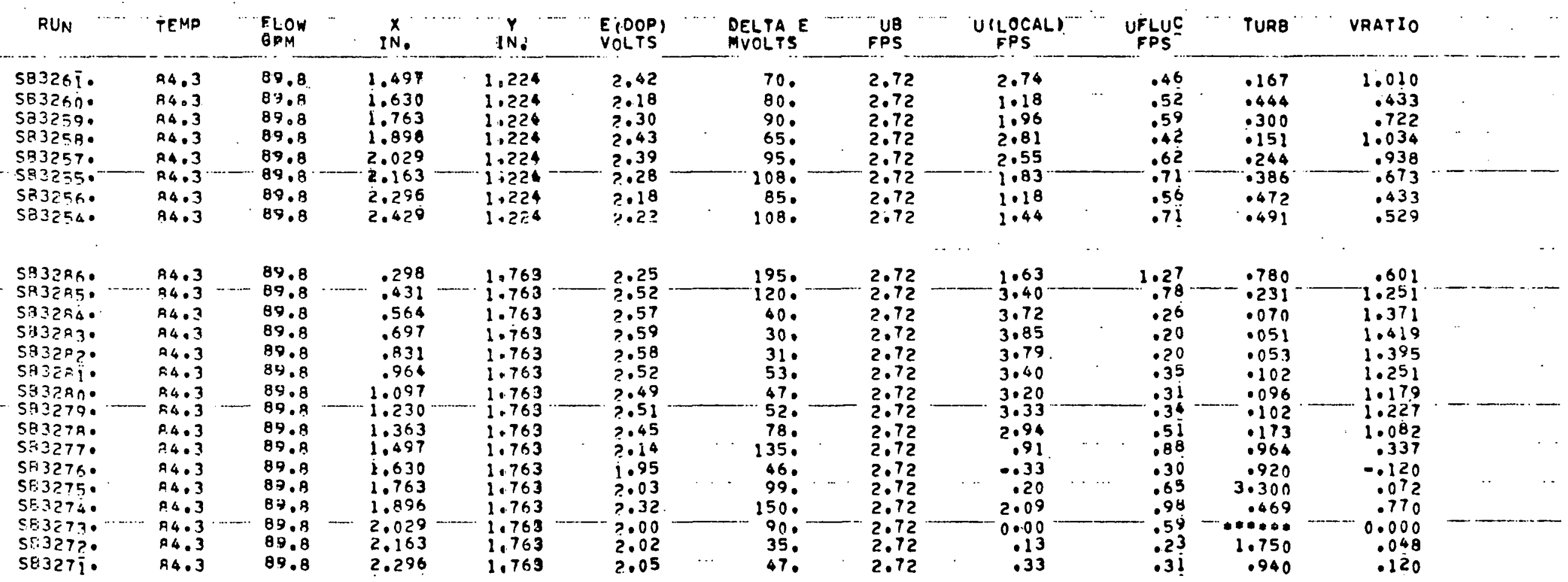




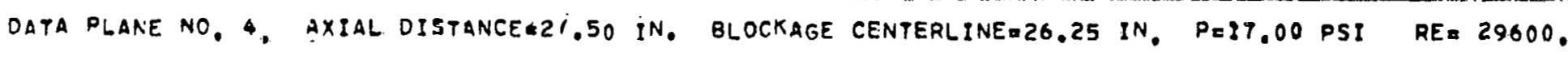

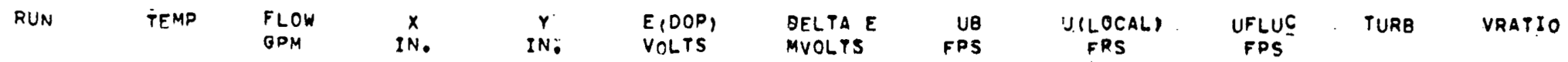

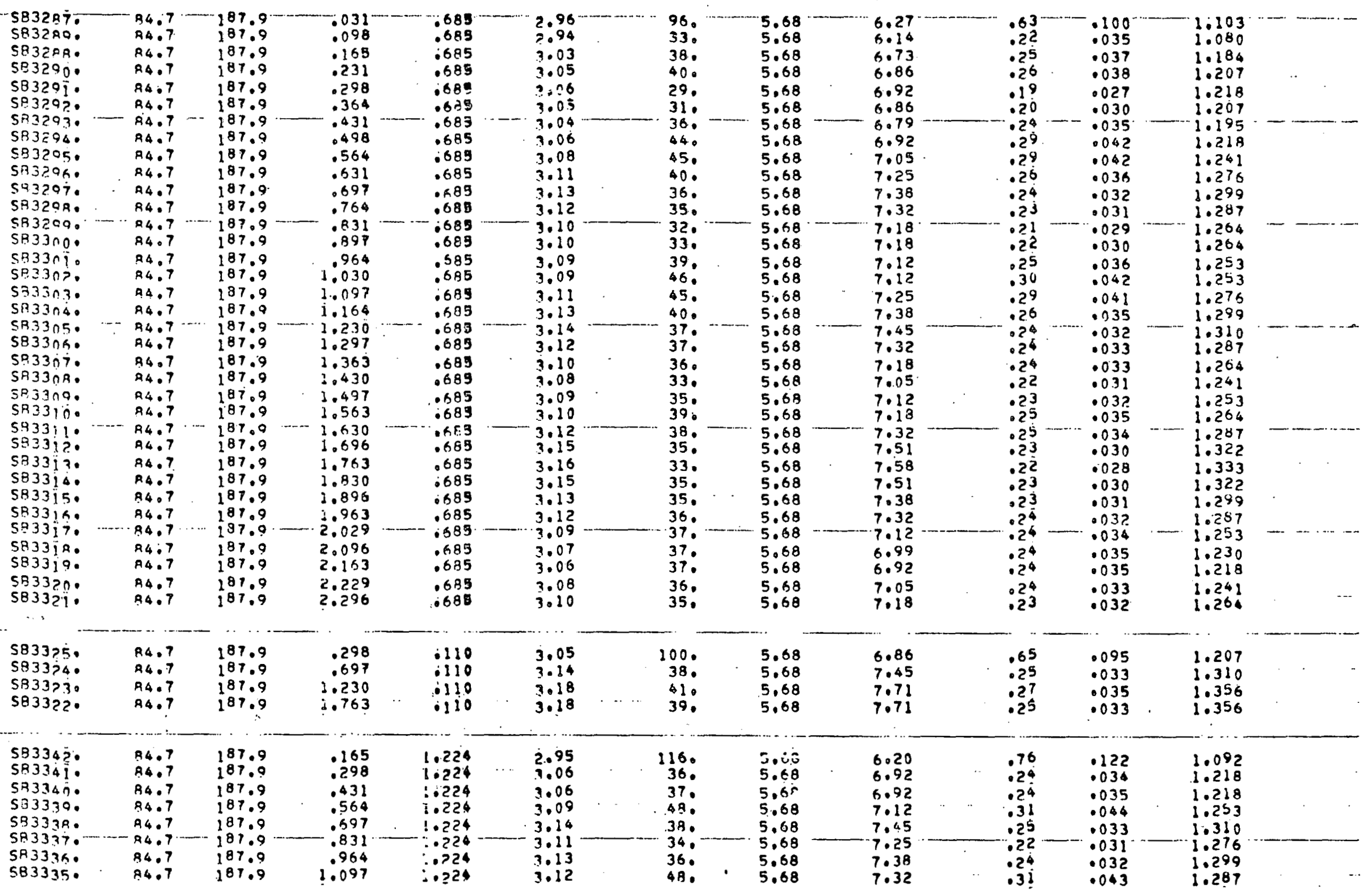




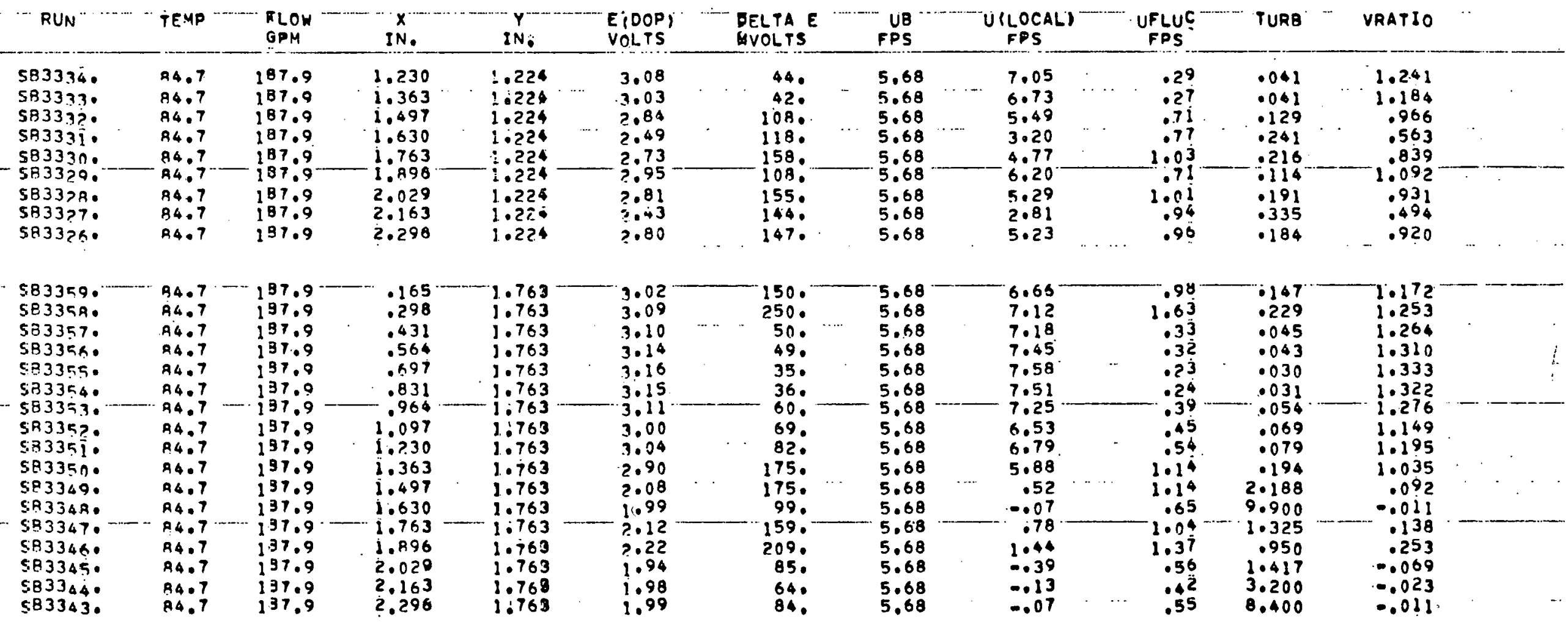




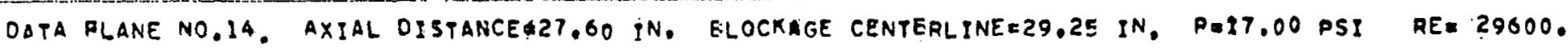

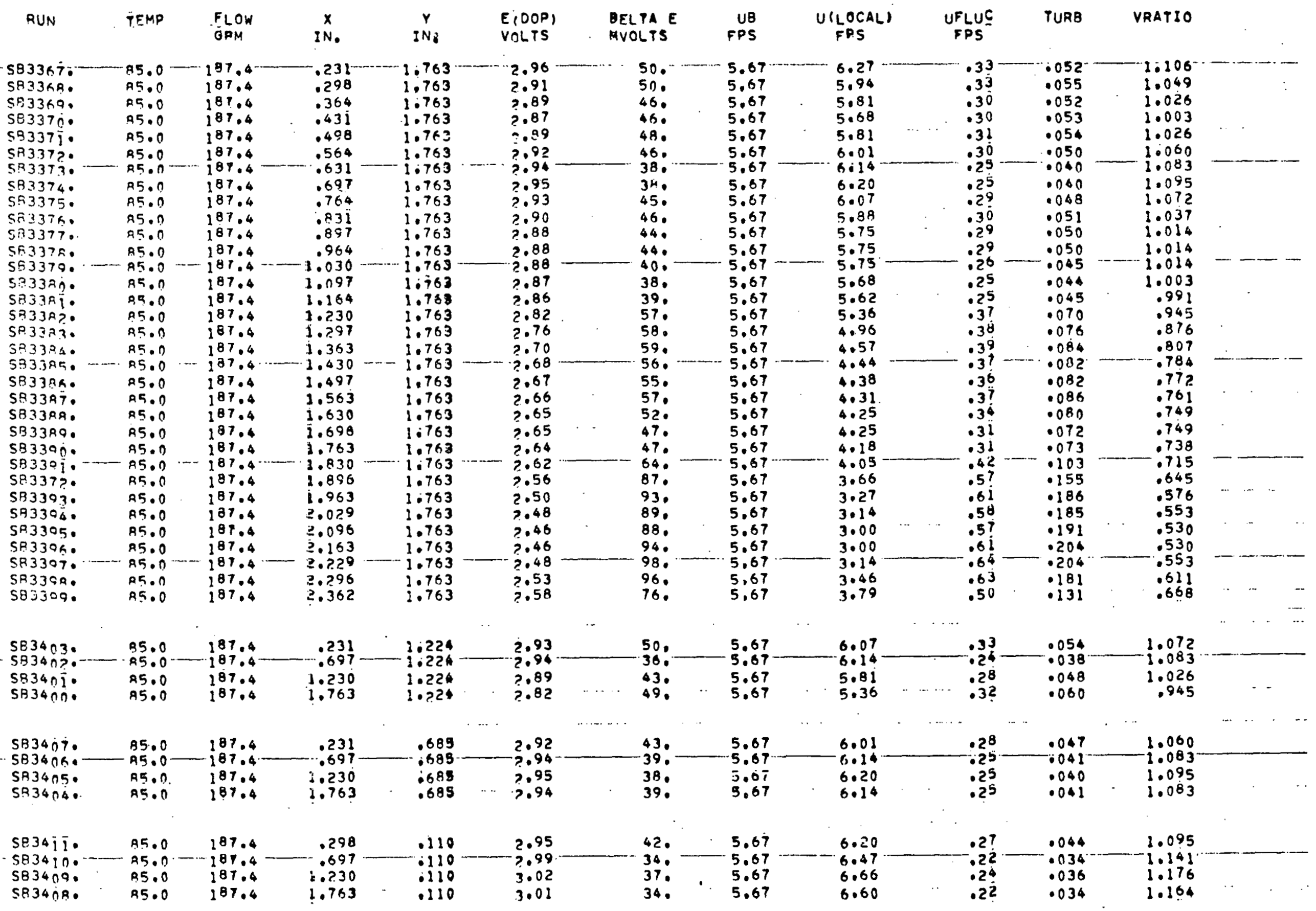


TABLE CII. TABULATION OS EXRERIMENTAL LOA DATA

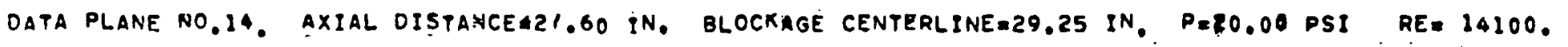

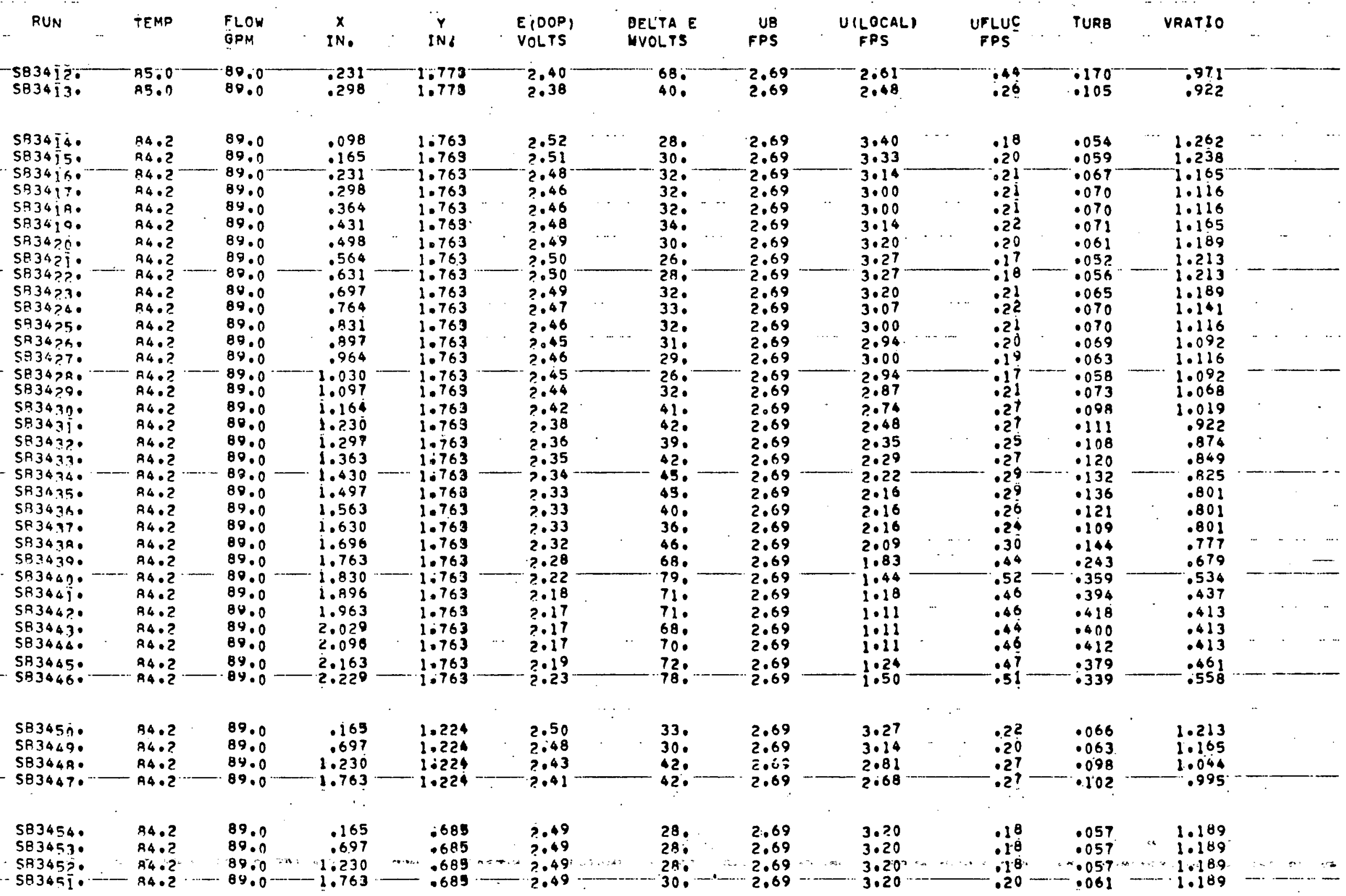




\begin{tabular}{|c|c|c|c|c|c|c|c|c|c|c|c|c|}
\hline RUN. & TEMP & $\begin{array}{l}\text { PLOW } \\
\text { GPM }\end{array}$ & $\stackrel{x}{x}$ & IN: & $\begin{array}{l}E: O(P) \\
V O L T S\end{array}$ & $\begin{array}{l}\text { BELTA E } \\
\text { MVOLTS }\end{array}$ & $\begin{array}{r}\text { UB } \\
\text { FPS }\end{array}$ & $\begin{array}{c}\text { U(LOCAL) } \\
\text { FPS }\end{array}$ & $\begin{array}{l}\text { UFLUS } \\
\text { FPS }\end{array}$ & TURB & $\because$ VRATIO & . \\
\hline $\begin{array}{l}583458 \\
583450^{\circ} \\
5834550^{\circ} \\
5534550^{\circ}\end{array}$ & $\begin{array}{l}84.2 \\
84.2 \\
84.2 \\
84.2\end{array}$ & $\begin{array}{l}89.0 \\
89.0 \\
89.0 \\
89.0\end{array}$ & $\begin{array}{r}.169 \\
.697 \\
1.230 \\
i .763\end{array}$ & $\begin{array}{l}.110 \\
.110 \\
.110 \\
.110\end{array}$ & $\begin{array}{l}2.49 \\
2.52 \\
2.53 \\
2.53\end{array}$ & $\begin{array}{l}46 . \\
22 . \\
24 . \\
24 .\end{array}$ & $\begin{array}{l}2.69 \\
2.69 \\
2.69 \\
2.69\end{array}$ & $\begin{array}{l}3.20 \\
3.46 \\
3.46 \\
3.46\end{array}$ & $\begin{array}{l}.30 \\
.14 \\
.16 \\
.16\end{array}$ & $\begin{array}{l}.094 \\
.042 \\
.045 \\
.045\end{array}$ & $\begin{array}{l}1.289 \\
1.262 \\
1.286 \\
1.226\end{array}$ & $\begin{array}{ll}\cdots & n .\end{array}$ \\
\hline
\end{tabular}




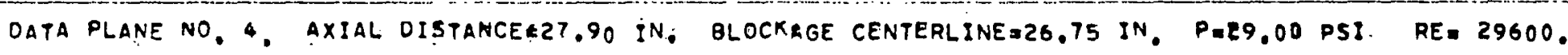

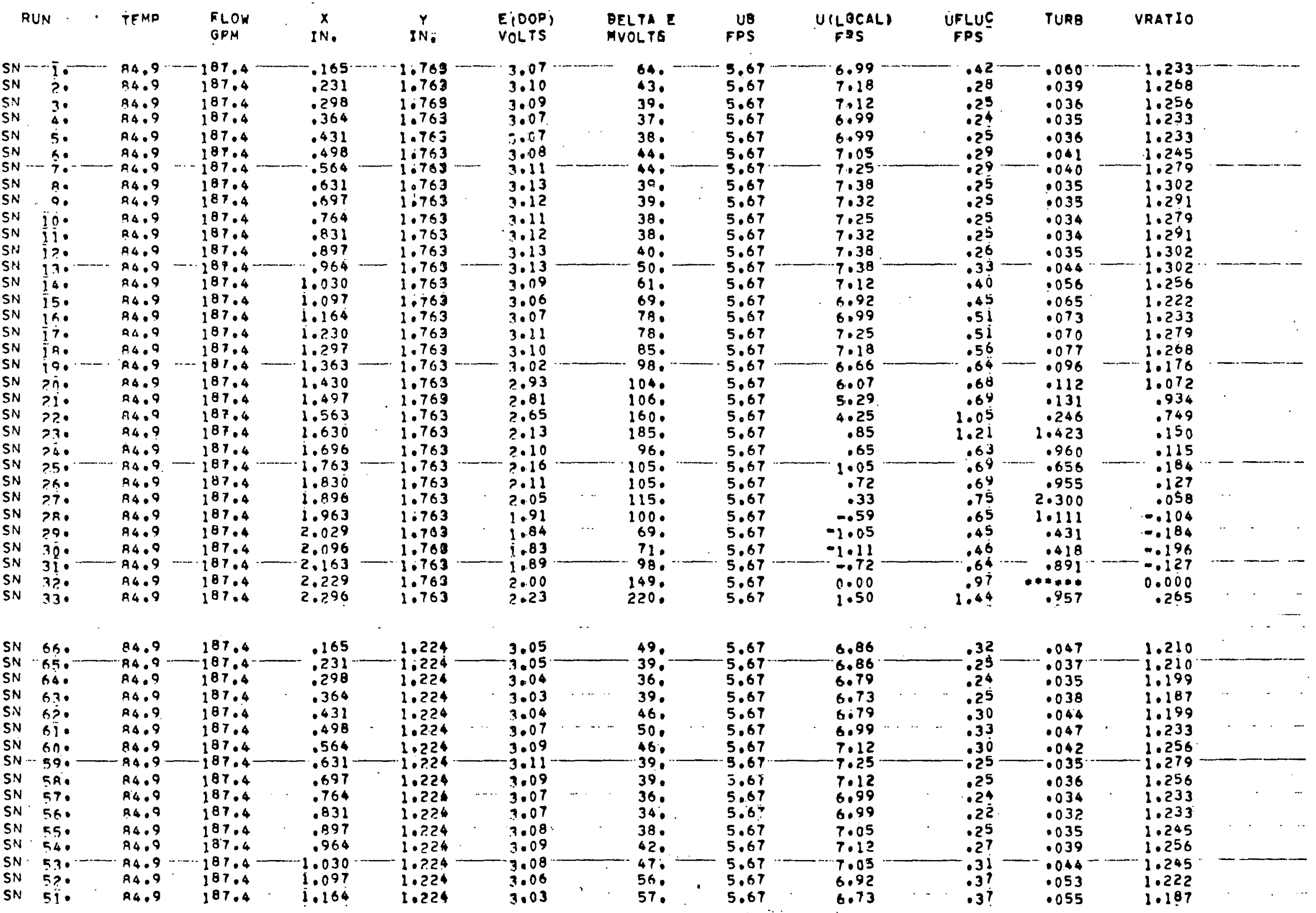




\begin{tabular}{|c|c|c|c|c|c|c|c|c|c|c|c|}
\hline RUN & TEMP & $\begin{array}{l}\text { FLOH } \\
\text { GPM }\end{array}$ & $\begin{array}{c}x \\
I N .\end{array}$ & $\stackrel{Y}{Z}$ & $\begin{array}{l}\text { E(DOP) } \\
\text { VOLTS }\end{array}$ & $\begin{array}{l}\text { BELTA E } \\
\text { BVOLTS }\end{array}$ & $\begin{array}{r}\text { UB } \\
\text { FPS }\end{array}$ & $\begin{array}{c}\text { U(LJCAL) } \\
\text { FOS }\end{array}$ & $\begin{array}{l}\text { UFLUUC } \\
\text { FPS }\end{array}$ & TURB & VRATIO \\
\hline SN 100. & 84.7 & 187.7 & 3.763 & .120 & 3.28 & 41. & 5.68 & 7.71 & .27 & .035 & 1.358 \\
\hline
\end{tabular}


TABLE CII. TABULATION OF EXPERIMENTAL LOA DATA

DATA PLANE No.8. AXIAL DISTANCE:26.80 IN. BLOCKRgE CENTERLINE=26.75 IN. Pa?9.00 PSI RE= 29700.

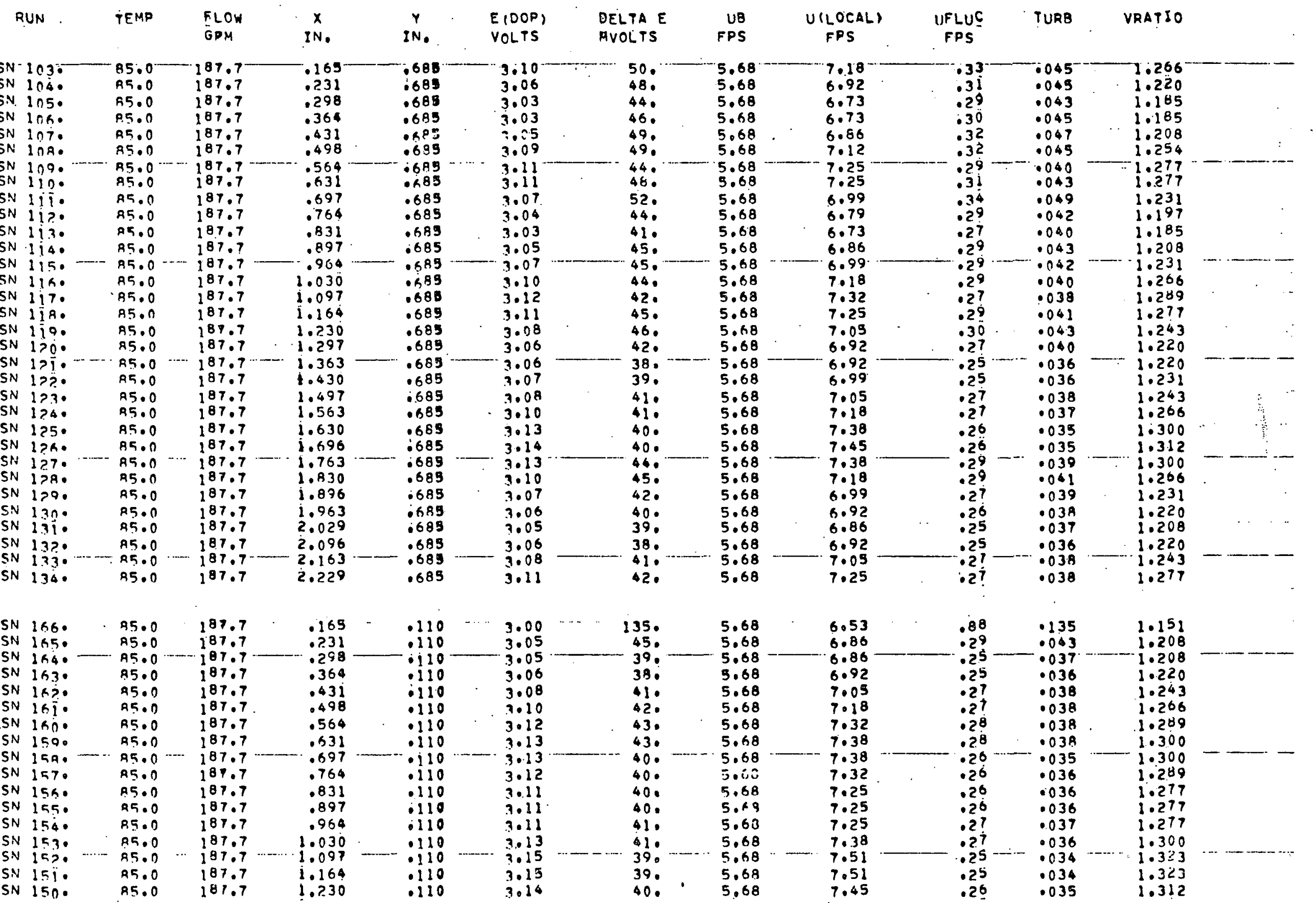




\begin{tabular}{|c|c|c|c|c|c|c|c|c|c|c|c|c|c|}
\hline & $R U_{N}$ & TEMP & $\begin{array}{l}\text { FLOW } \\
\text { GDM }\end{array}$ & $\stackrel{x}{x}$. & $\underset{I N:}{Y}$ & $\begin{array}{l}\text { E(ECP) } \\
\text { rOLTS }\end{array}$ & $\begin{array}{l}\text { DELTA E } \\
\text { BVOLTS }\end{array}$ & $\begin{array}{r}\text { U8 } \\
\text { FPS }\end{array}$ & $\begin{array}{c}U(L O C A L) \\
\text { FPS }\end{array}$ & UFLUE & TURB & VRATIOO & $\therefore$ \\
\hline SN & 149. & 85.0 & 187.7 & 1.297 & .110 & 3.12 & 39. & 5.68 & 7.32 & .25 & .035 & 1.289 & \\
\hline SN & 149. & 25.0 & 187.7 & 1.363 & .110 & 3.11 & 38. & 5.68 & 7.25 & .25 & .034. & 1.277 & \\
\hline SN & 147. & A5. 0 & 187.7 & 2.430 & .110 & 3.11 & 39. & 5.68 & 7.25 & .25 & .035 & 1.277 & \\
\hline SN & $14 \mathrm{k}$. & 95.0 & 187.7 & 1.497 & .110 & 3.12 & 42. & 5.68 & 7.32 & .27 & .038 & 1.289 & \\
\hline $5 \mathrm{~N}$ & 145. & 85.0 & 187,7 & 1.563 & .110 & 3.13 & 44. & 5.68 & 7.33 & .29 & .039 & 1.300 & \\
\hline Sis & 144. & 0.5 .0 & 187.7 & 1.630 & .110 & 3.16 & 44. & 5.68 & 7.53 & $.2^{9}$ & .038 & 1.335 & \\
\hline SN & 1430 & $=5.0$ & 187.7 & 1.696 & .110 & 3.18 & 40. & 5.68 & 9.71 & .26 & .034 & 1.358 & \\
\hline SN & 1420 & 25.0 & 187.7 & 1.763 & .110 & 3.18 & 41. & 5.88 & $7.7 i$ & .27 & .035 & 1.358 & \\
\hline SN & $1 \Delta I_{0}^{\circ}$ & 0.5 .0 & 287.7 & 1.830 & .110 & 3.17 & 43. & 5.68 & 7.64 & .28 & .037 & 1.346 & \\
\hline SN & $140^{\circ}$ & 8.5 .0 & 187.7 & 1.896 & .110 & 3.15 & 43. & 5.68 & 7.51 & $.2^{8}$ & .037 & 1.323 & \\
\hline SN & 139. & 85.0 & 187.7 & 1.963 & .110 & 3.14 & 39. & 5.68 & 7.45 & .25 & .034 & 1.312 & \\
\hline SiN & 1.72. & R5. 0 & 187.7 & 2.029 & .110 & 3.14 & 38. & 5.68 & 7.45 & .25 & .033 & 1.312 & \\
\hline SN & 1370 & 8.5 .0 & 187.7 & 2.096 & .110 & 3.14 & 40. & 5.68 & 7.45 & .26 & .035 & 1.312 & \\
\hline $\begin{array}{l}\text { SN } \\
\text { SN }\end{array}$ & 1350 & 85.0 & 187.7 & 2.163 & .110 & 3.15 & 40. & $5.6 B$ & $7 \cdot 58$ & .26 & .034 & 1.335 & \\
\hline SN & 135. & 85.0 & $1^{87.7}$ & 2.229 & .110 & 3.17 & 40. & & 7.64 & .26 & .034 & 1.346 & \\
\hline
\end{tabular}


TABLE:CEL. TABULATION OF EXPERIMENTAL LOA DATA

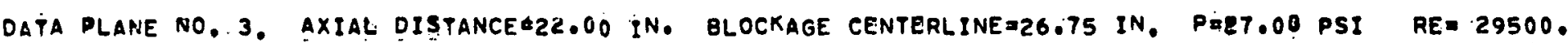

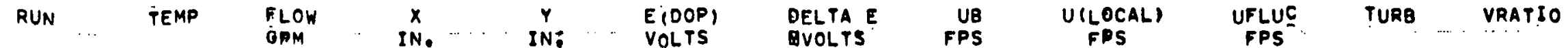

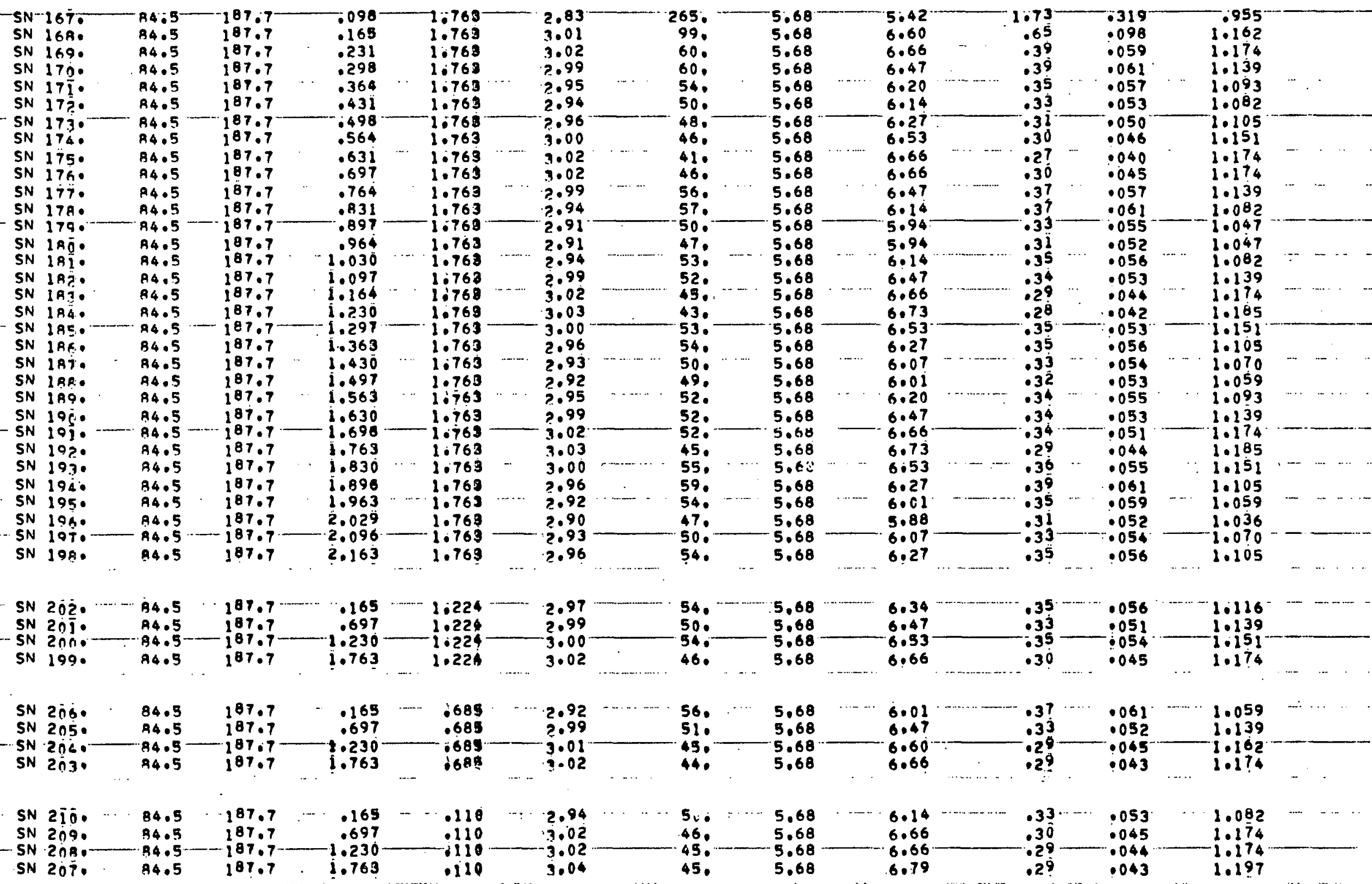


TABLE Cị. TTABULATION OF EXPERIMENTAL LDA DATA

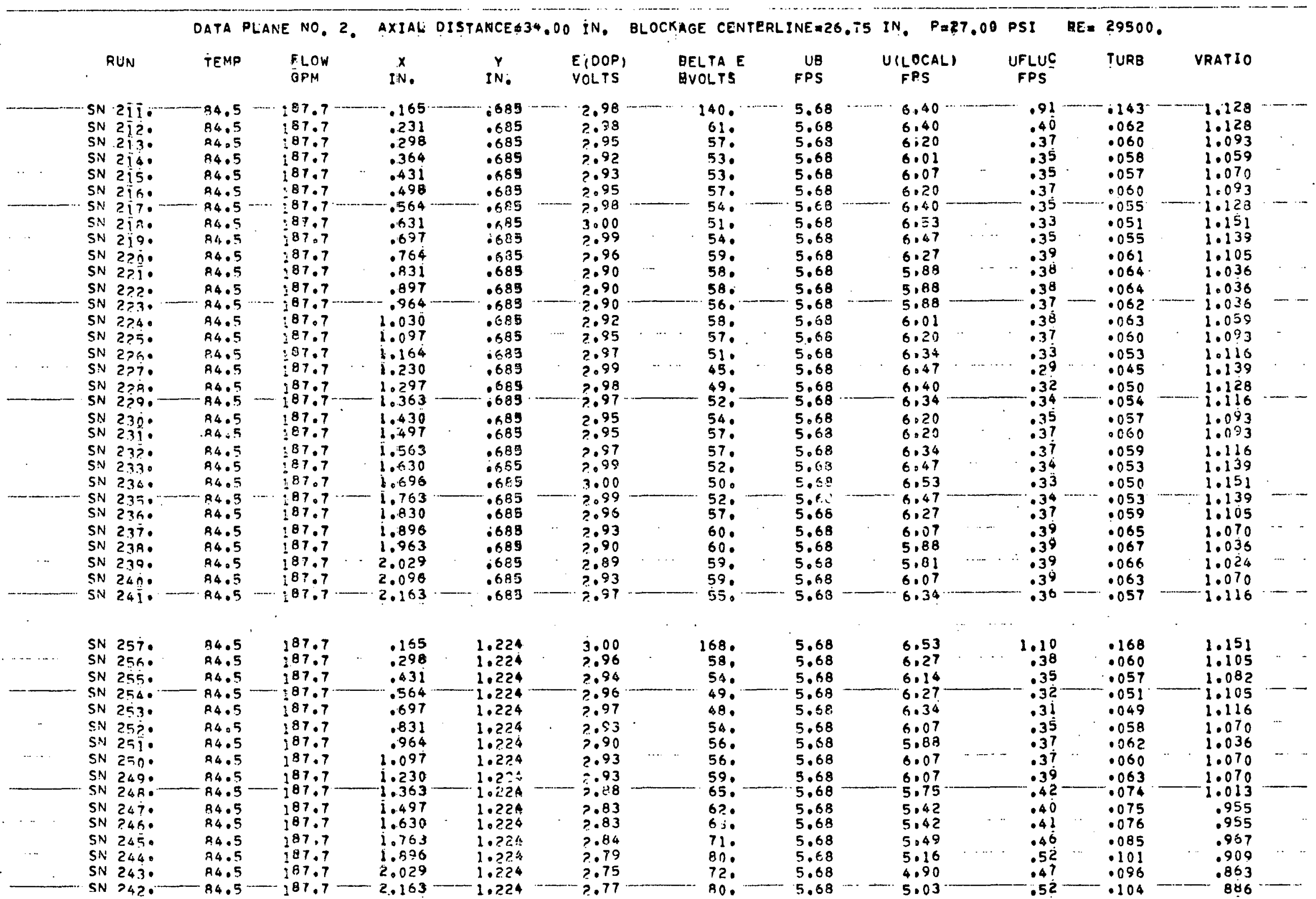




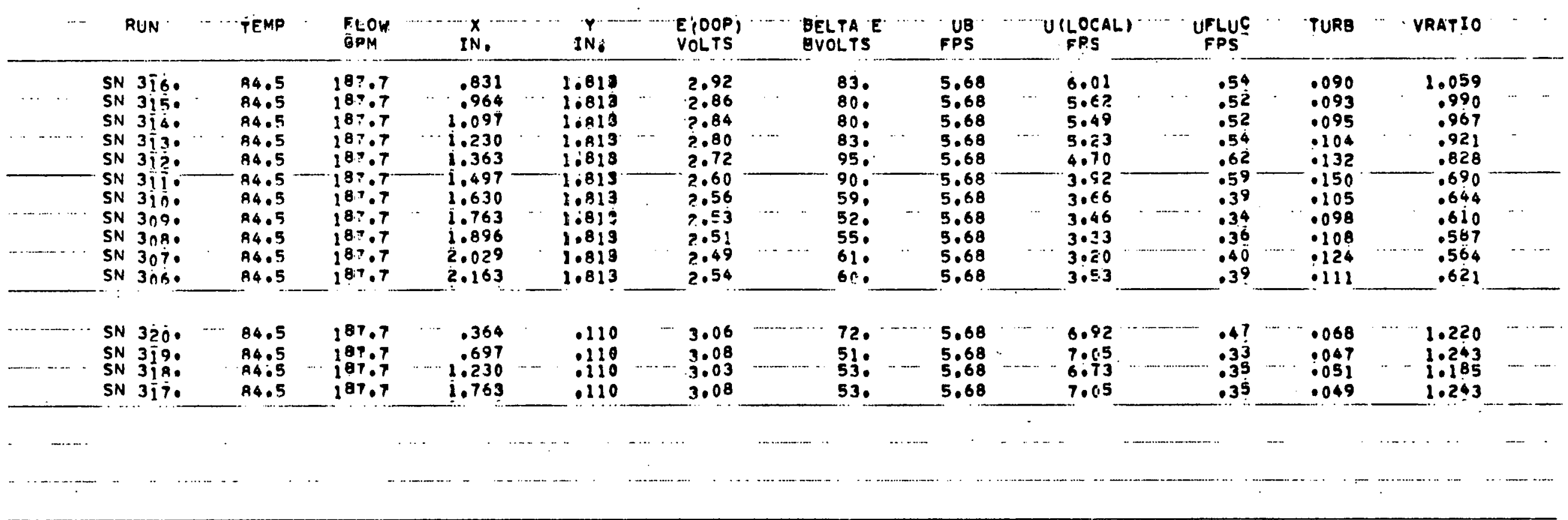

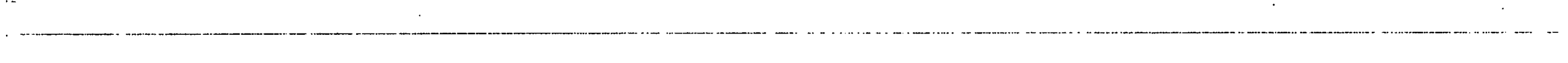


TABLE COS. TABULATION OF EXPERZMENTAL LOA DATA

data Plane No. ?. AXIAL OI\$TANCEN52.00 IN. BLOCK

RUN

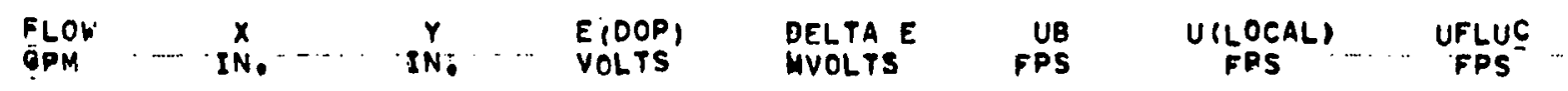

TURB

VRATIO

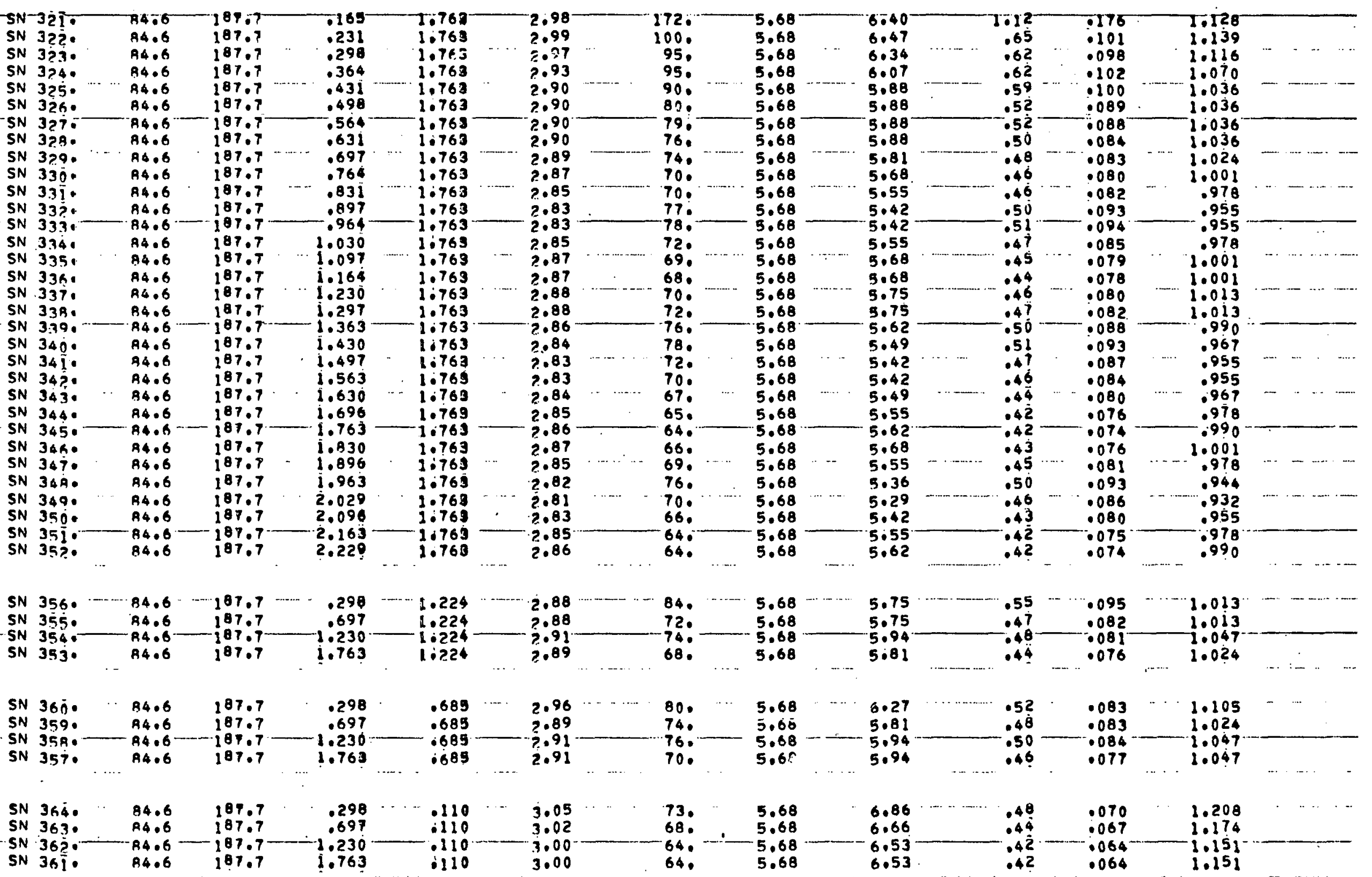




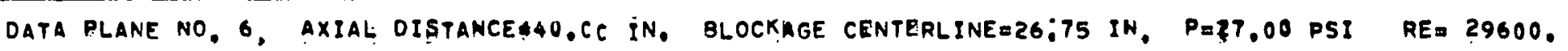

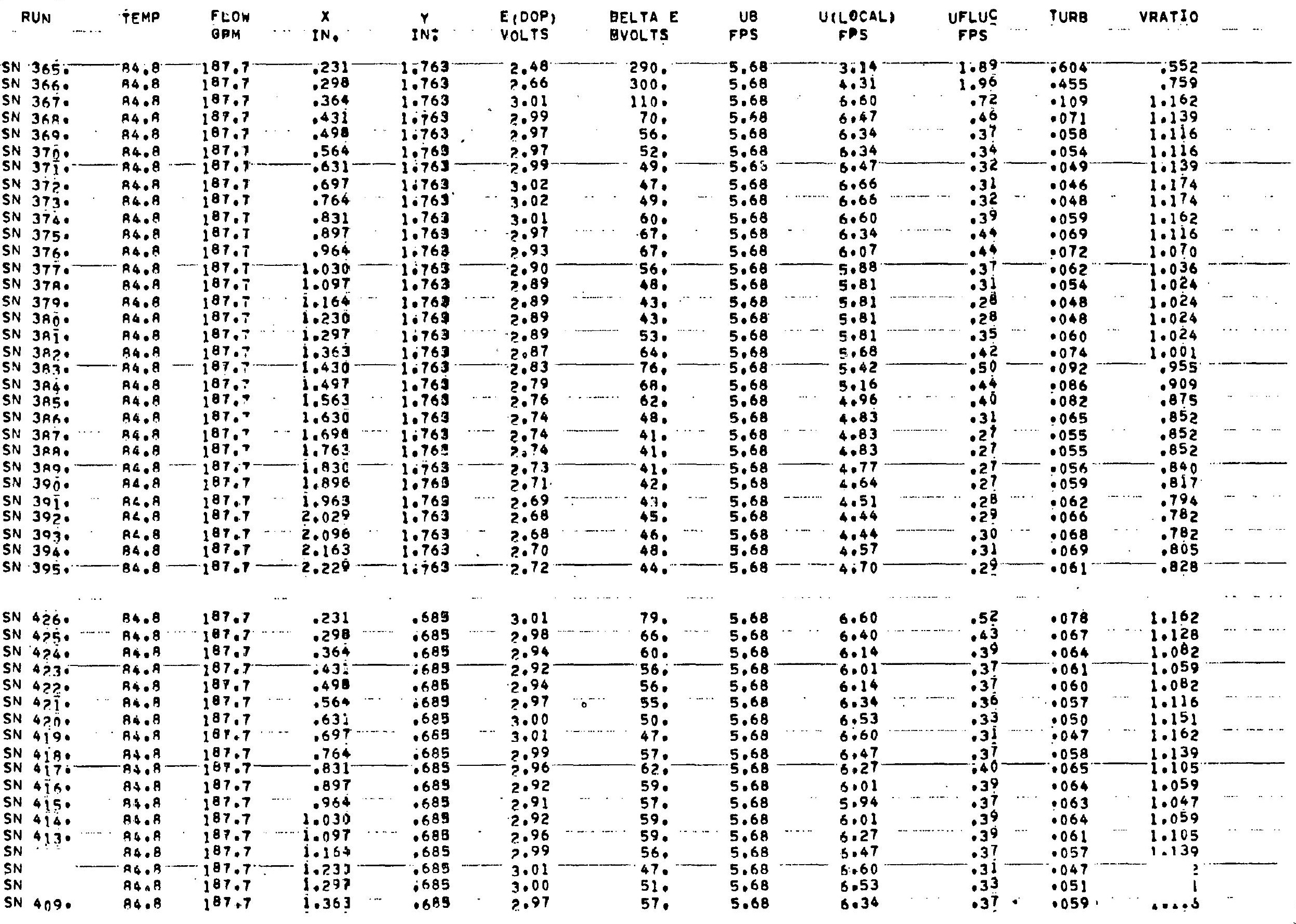




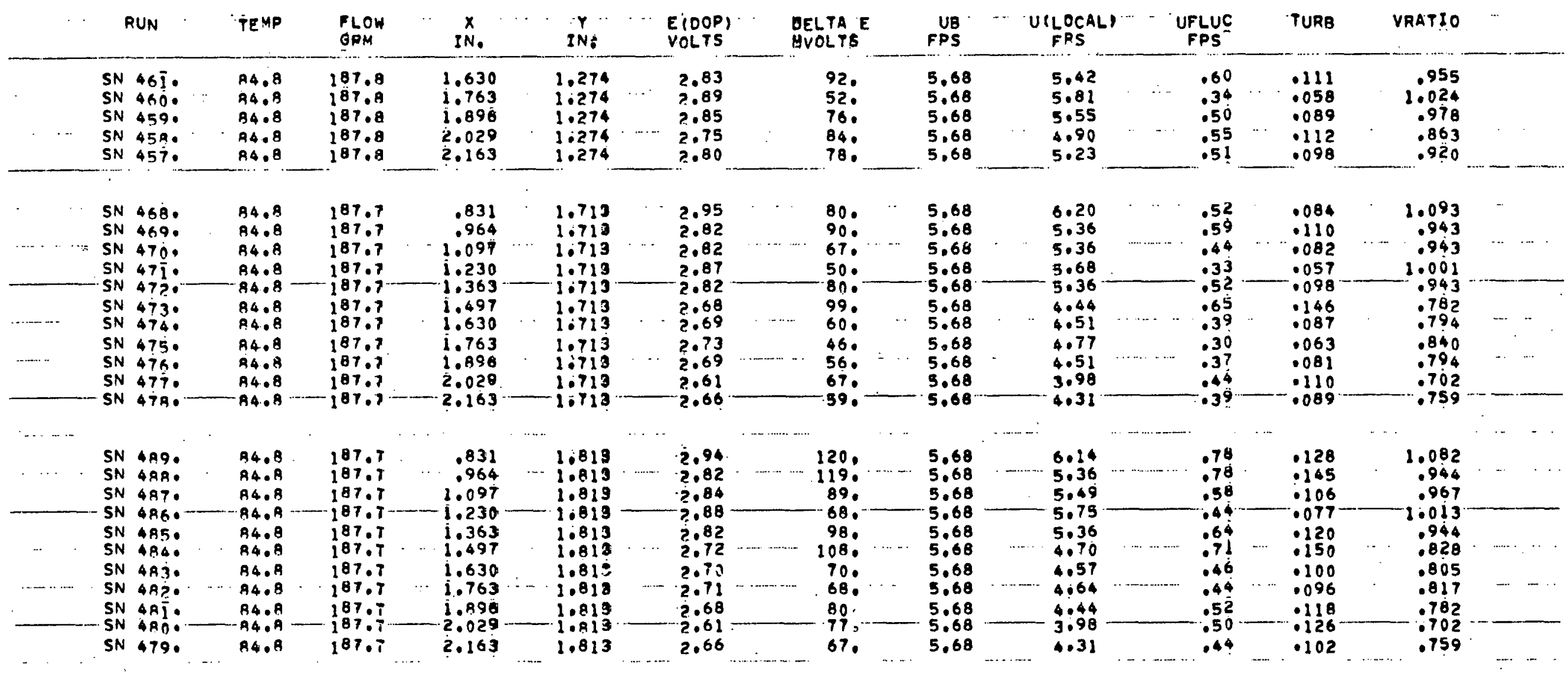


TABLE CAI. TABULATION OT EXPERIMENTAL LDA DATA

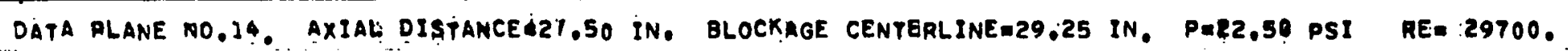

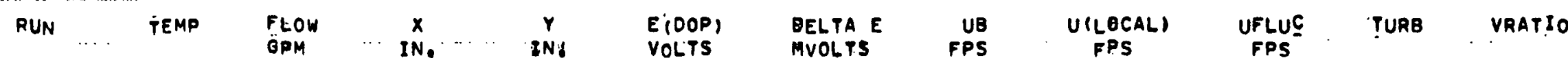

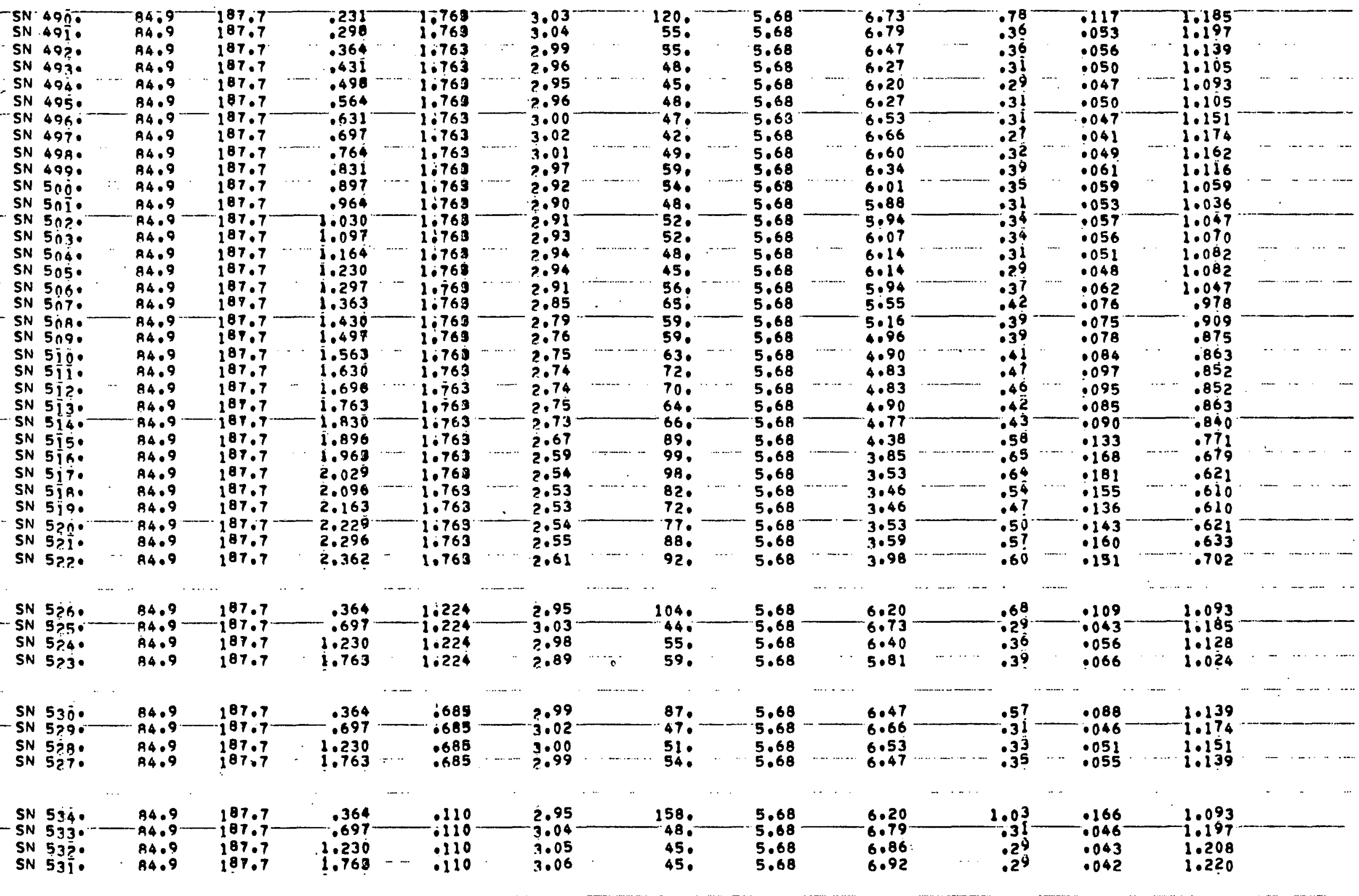


TABLE CiI. TABULATION OF EXPERIMENTAL LDA DATA

data plane no. C. axial distancea27.53 in, blockroe centerlinea29.25 JN. Pal3.00 psi mea 29800.

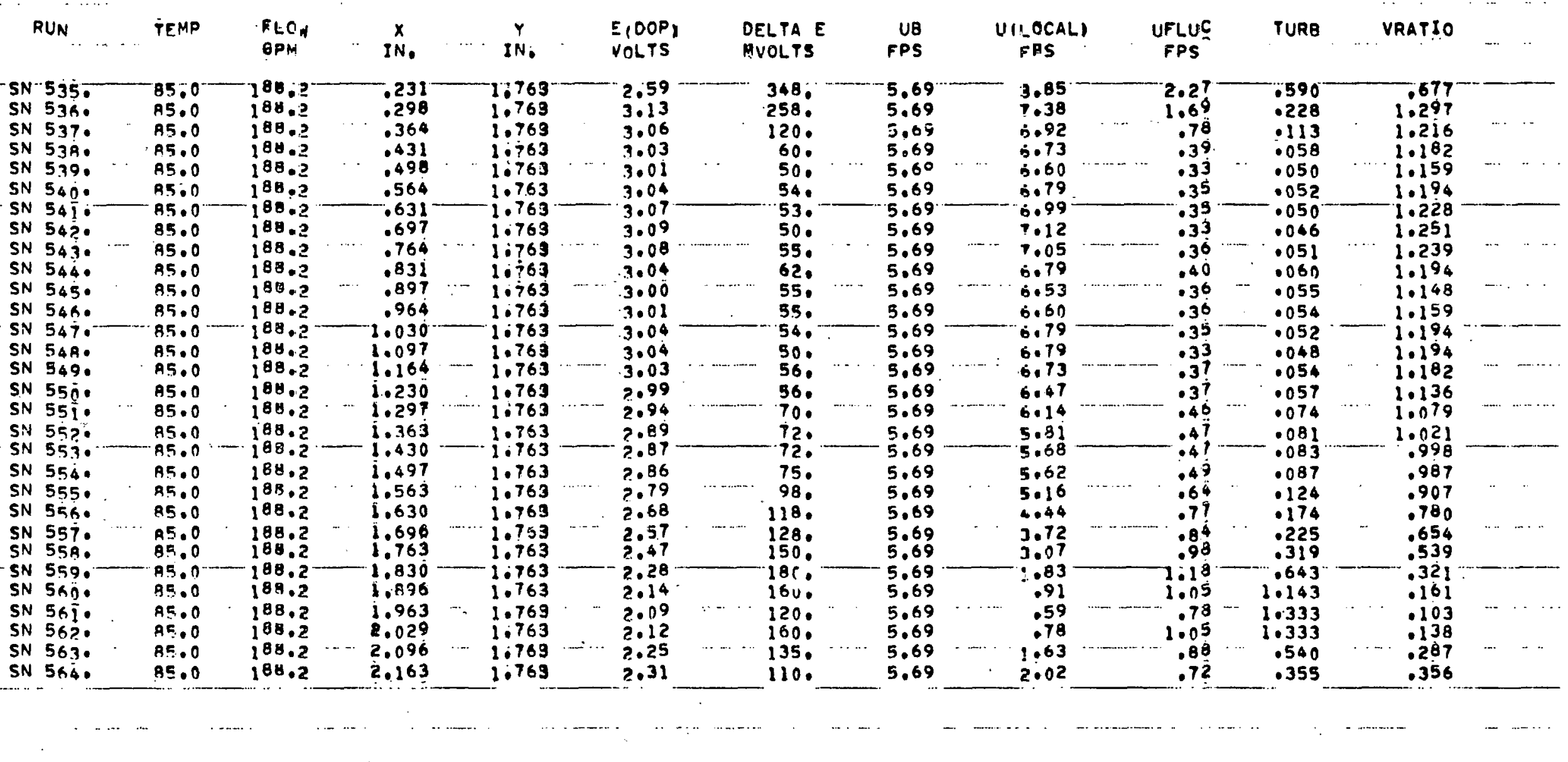


TABLE CEI. TABULATION OF, EXPERIMENTAL LDA DATA

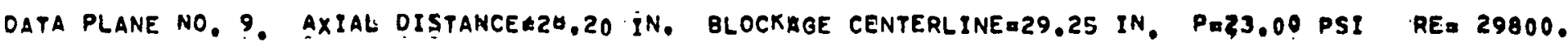

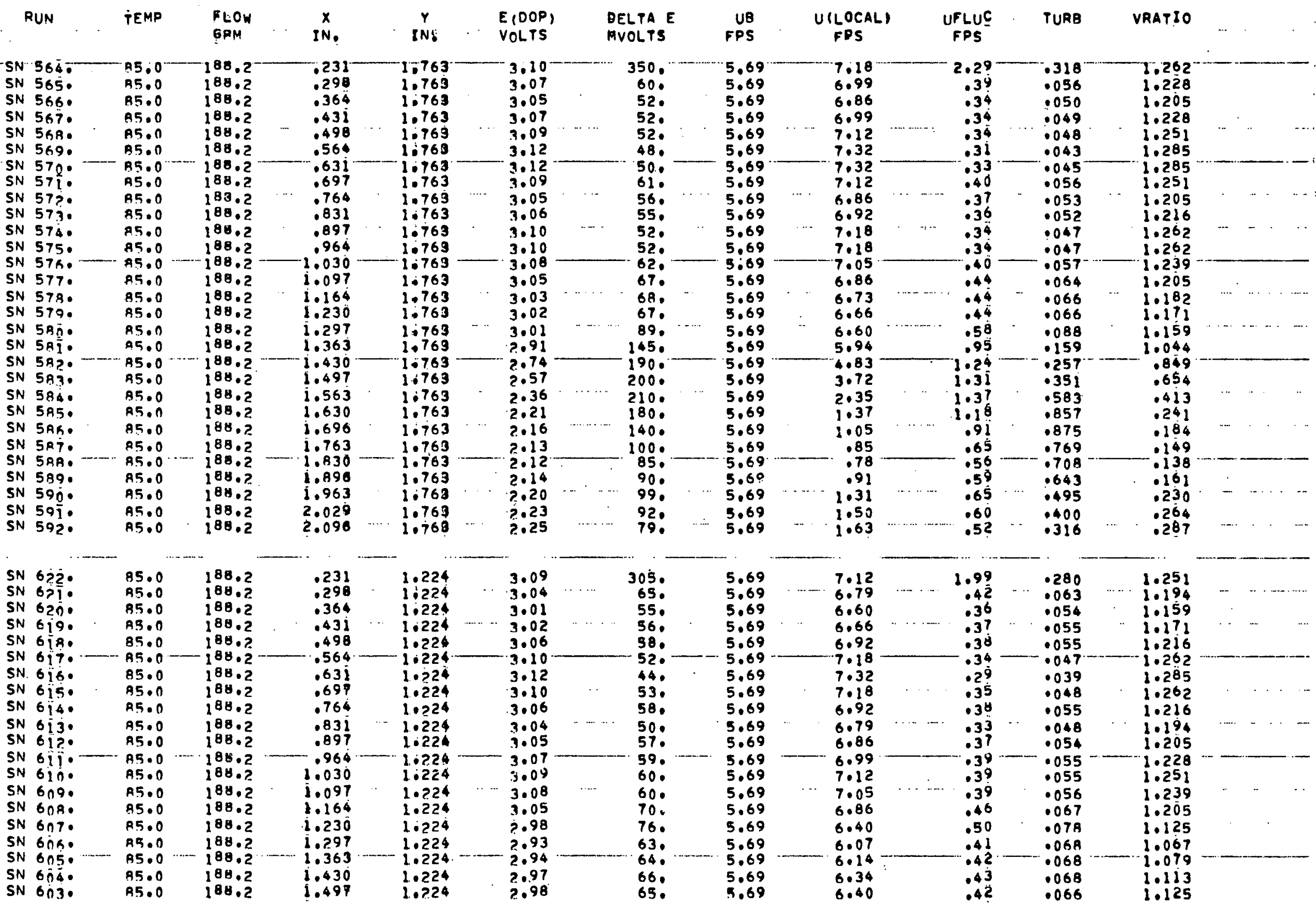




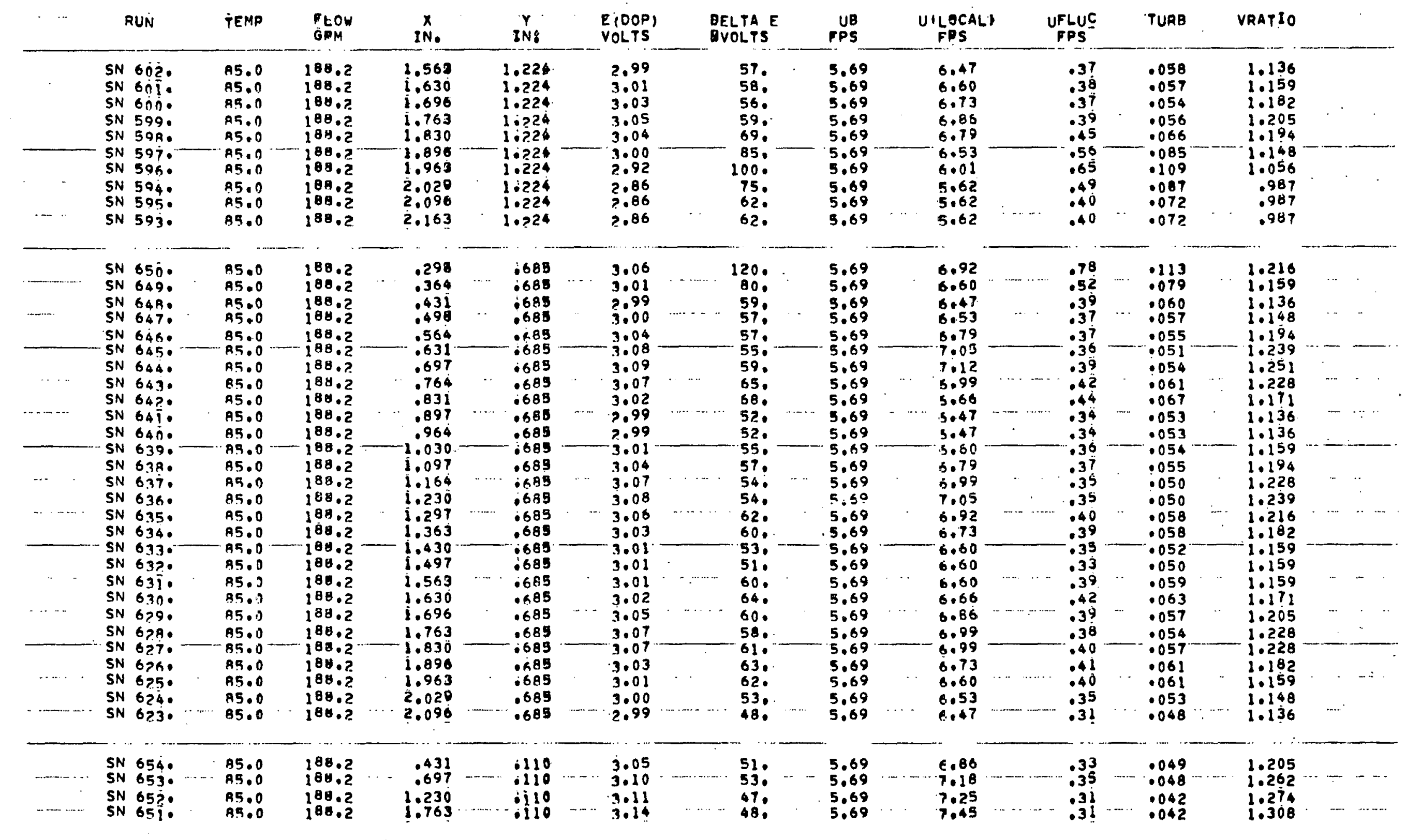




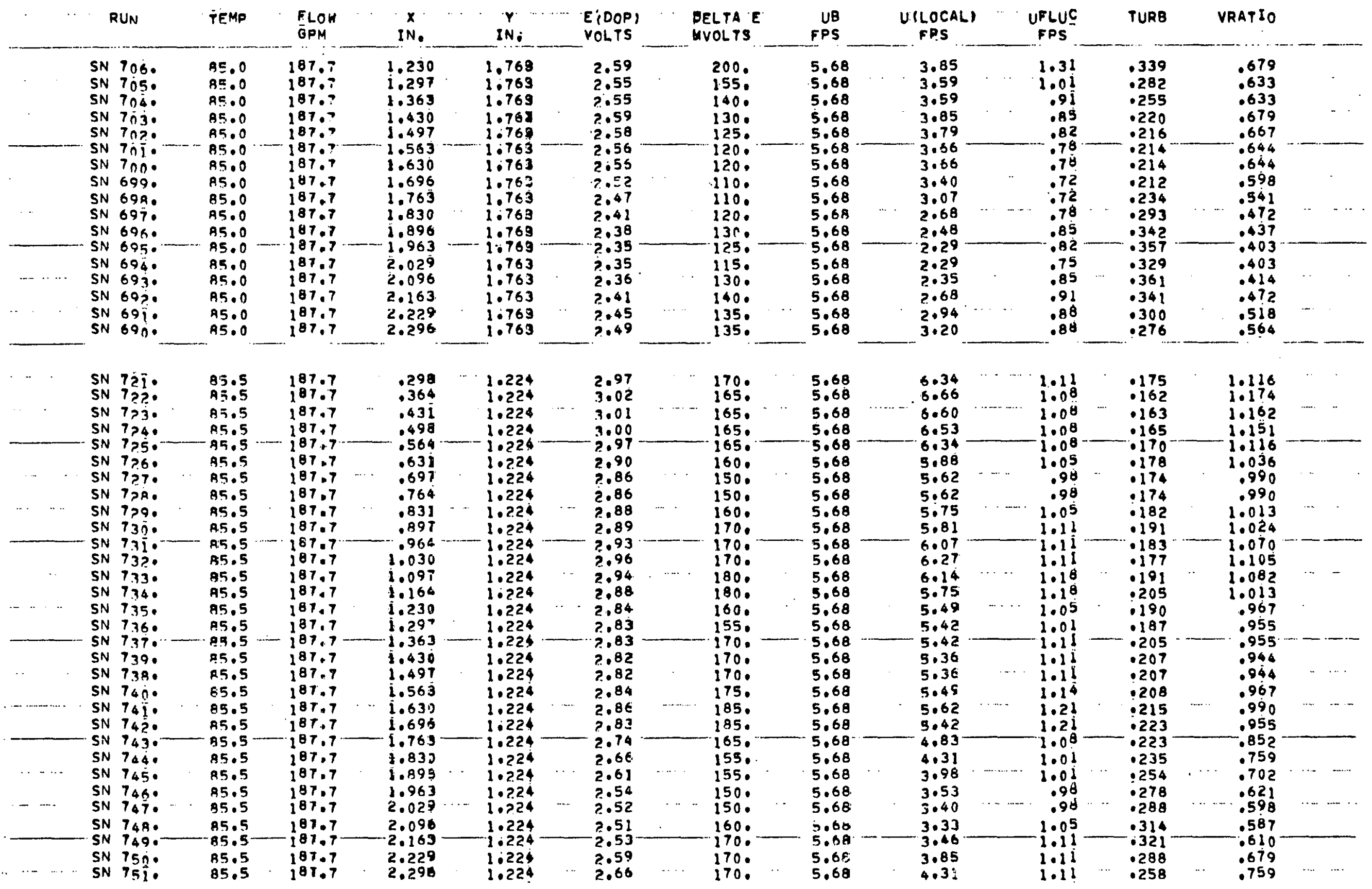


TABLE COL. TABULATION OF EXRERIMENTAL LOA DATA

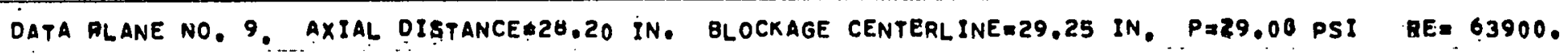

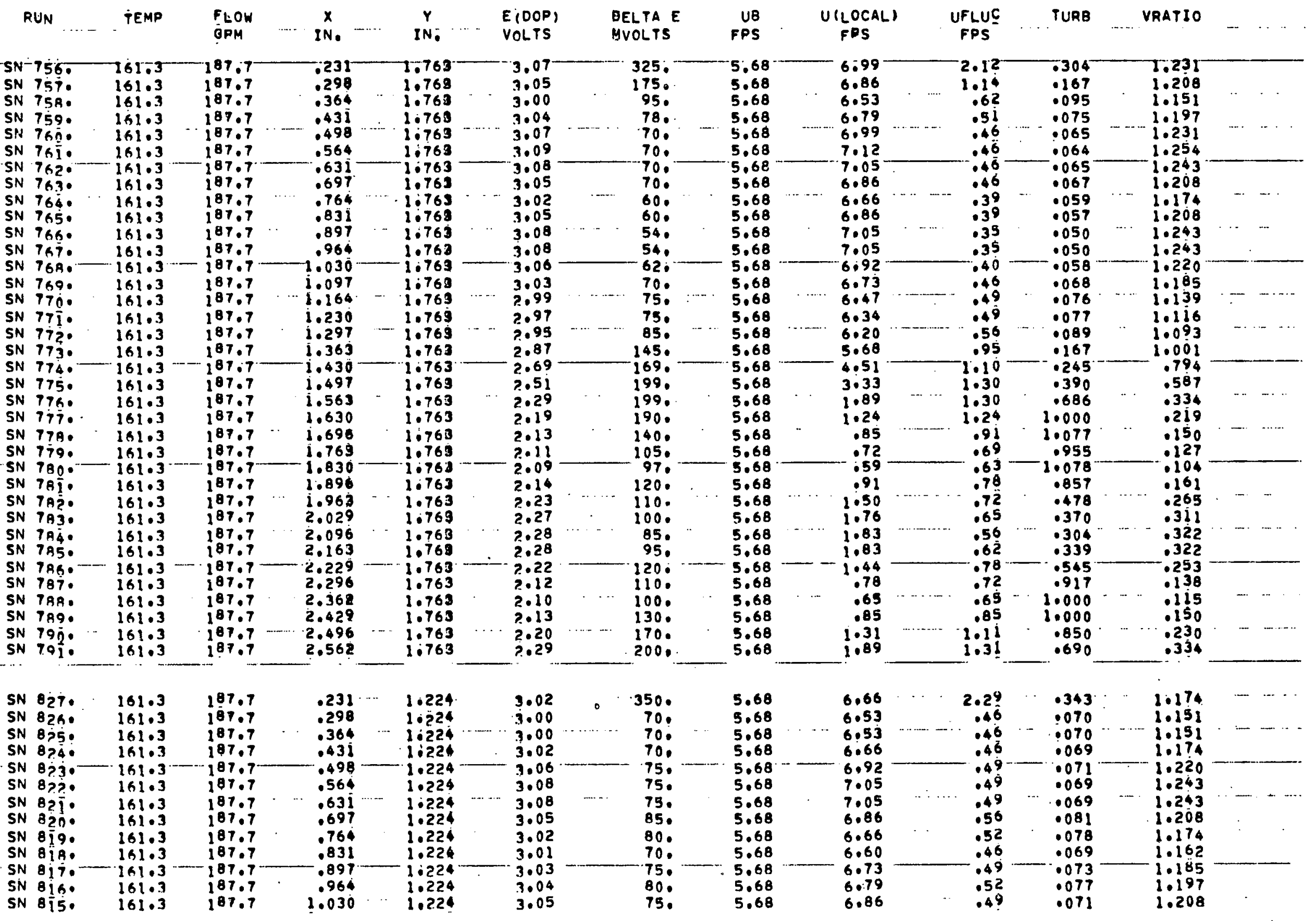




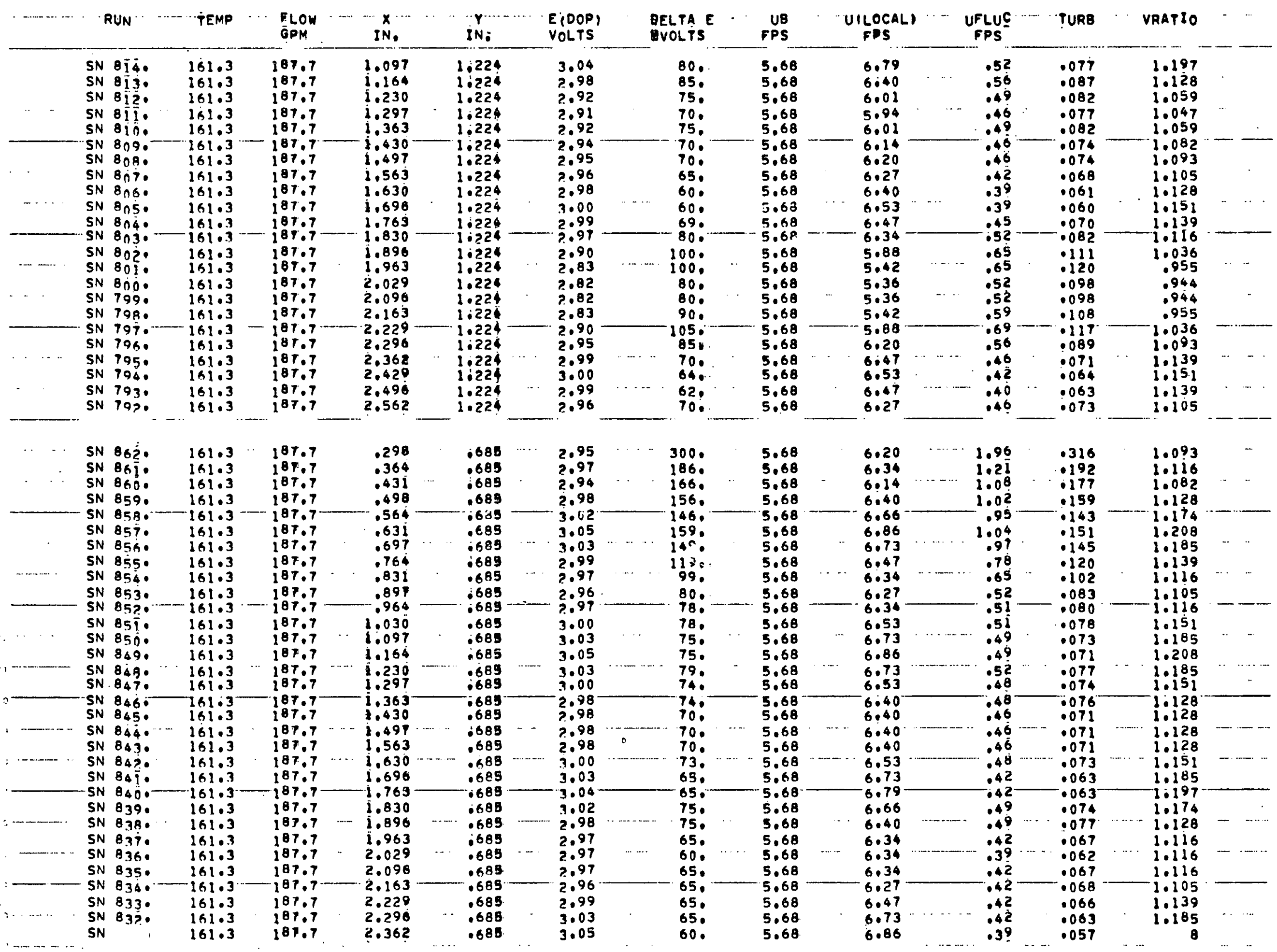




\begin{tabular}{|c|c|c|c|c|c|c|c|c|c|c|c|c|}
\hline RUN & TEMP & $\begin{array}{l}\text { FLOW" } \\
\text { GAM }\end{array}$ & $\begin{array}{l}X \\
I N .\end{array}$ & $\begin{array}{l}Y \\
I N:\end{array}$ & $\begin{array}{l}\text { E COOP 1 } \\
\text { VoLTS }\end{array}$ & $\begin{array}{l}\text { BELTA E } \\
\text { GVOLIS }\end{array}$ & $\begin{array}{c}\text { UB } \\
\text { FPS }\end{array}$ & $\begin{array}{c}\text { UICOCALI } \\
\text { FRS }\end{array}$ & $\begin{array}{l}\text { UFLüS } \\
\text { FPS }\end{array}$ & TURB & VRATIO & $\cdots$ \\
\hline $\begin{array}{l}\text { SN } 830 . \\
\text { SN } 829 . \\
\text { SN } 829 .\end{array}$ & $\begin{array}{l}161.3 \\
161.3 \\
151.3\end{array}$ & $\begin{array}{r}187.7 \\
187.7 \\
187.7\end{array}$ & $\begin{array}{r}2.420 \\
2.496 \\
2.562\end{array}$ & $\begin{array}{l}.683 \\
i 685 \\
.685\end{array}$ & $\begin{array}{l}3.03 \\
3.00 \\
2.99\end{array}$ & $\begin{array}{l}69 . \\
70 . \\
79 .\end{array}$ & $\begin{array}{l}5.68 \\
5.68 \\
5.68\end{array}$ & $\begin{array}{l}6.73 \\
6.53 \\
6.47\end{array}$ & $\begin{array}{l}.45 \\
.46 \\
.49\end{array}$ & $\begin{array}{l}.067 \\
.070 \\
.076\end{array}$ & $\begin{array}{l}1.185 \\
1.151 \\
1.139\end{array}$ & ......... \\
\hline $\begin{array}{l}S N-865^{\circ} \\
S N 865^{\circ} \\
S N 864^{\circ} \\
S N 863\end{array}$ & $\begin{array}{l}161.3 \\
161.3 \\
161.3 \\
161.3\end{array}$ & $\begin{array}{l}187.7 \\
189.7 \\
189.7 \\
187.7\end{array}$ & $\begin{array}{r}.465 \\
.697 \\
1.230 \\
1.963 \\
. .76\end{array}$ & $\begin{array}{l}.110 \\
1110 \\
1110 \\
1110\end{array}$ & $\begin{array}{l}3.07 \\
3.10 \\
3.11 \\
3.14\end{array}$ & $\begin{array}{l}790^{\circ} \\
700^{\circ} \\
480^{\circ} \\
48 .\end{array}$ & $\begin{array}{l}5.68 \\
5.68 \\
5.66 \\
5.68\end{array}$ & $\begin{array}{l}6.99- \\
7.18 \\
7.25 \\
7.45\end{array}$ & $\begin{array}{l}49 \\
446 \\
431 \\
.31\end{array}$ & $\begin{array}{l}.070 \\
.064 \\
.043 \\
.042\end{array}$ & $\begin{array}{l}1.231 \\
1.266 \\
1.277 \\
1.312 .\end{array}$ & - \\
\hline $\begin{array}{l}\text { SN } 066: \\
\text { SN } 86.7 .\end{array}$ & $\begin{array}{l}761.3 \\
161.3\end{array}$ & $\begin{array}{l}187.7 \\
187.7\end{array}$ & $\begin{array}{l}1,856 \\
1.896\end{array}$ & $\begin{array}{l}1.835 \\
l .835\end{array}$ & $\begin{array}{l}2.05- \\
2.13\end{array}$ & $\begin{array}{l}125 . \\
165 .\end{array}$ & $\begin{array}{r}5,68 \\
5.68\end{array}$ & $\begin{array}{r}.633 \\
.85\end{array}$ & $\begin{array}{l}.82 \\
1.08\end{array}$ & $\begin{array}{l}2.500 \\
1.269\end{array}$ & $\begin{array}{l}.058 \\
.150\end{array}$ & \\
\hline
\end{tabular}


TABLE CAI. TABULATION OR EXPERIMENTAL LOA DATA

data plane no. 9. aXIAL DISTANCE\&24.20 iN. BLOCKAgE CENTERLINE=29.25 IN, P=88.00 PSI RE= 60600.

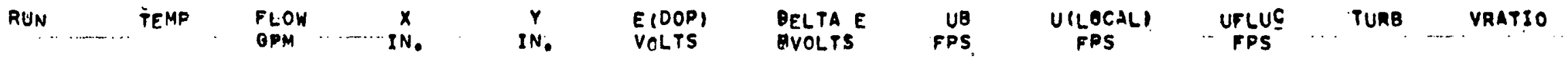

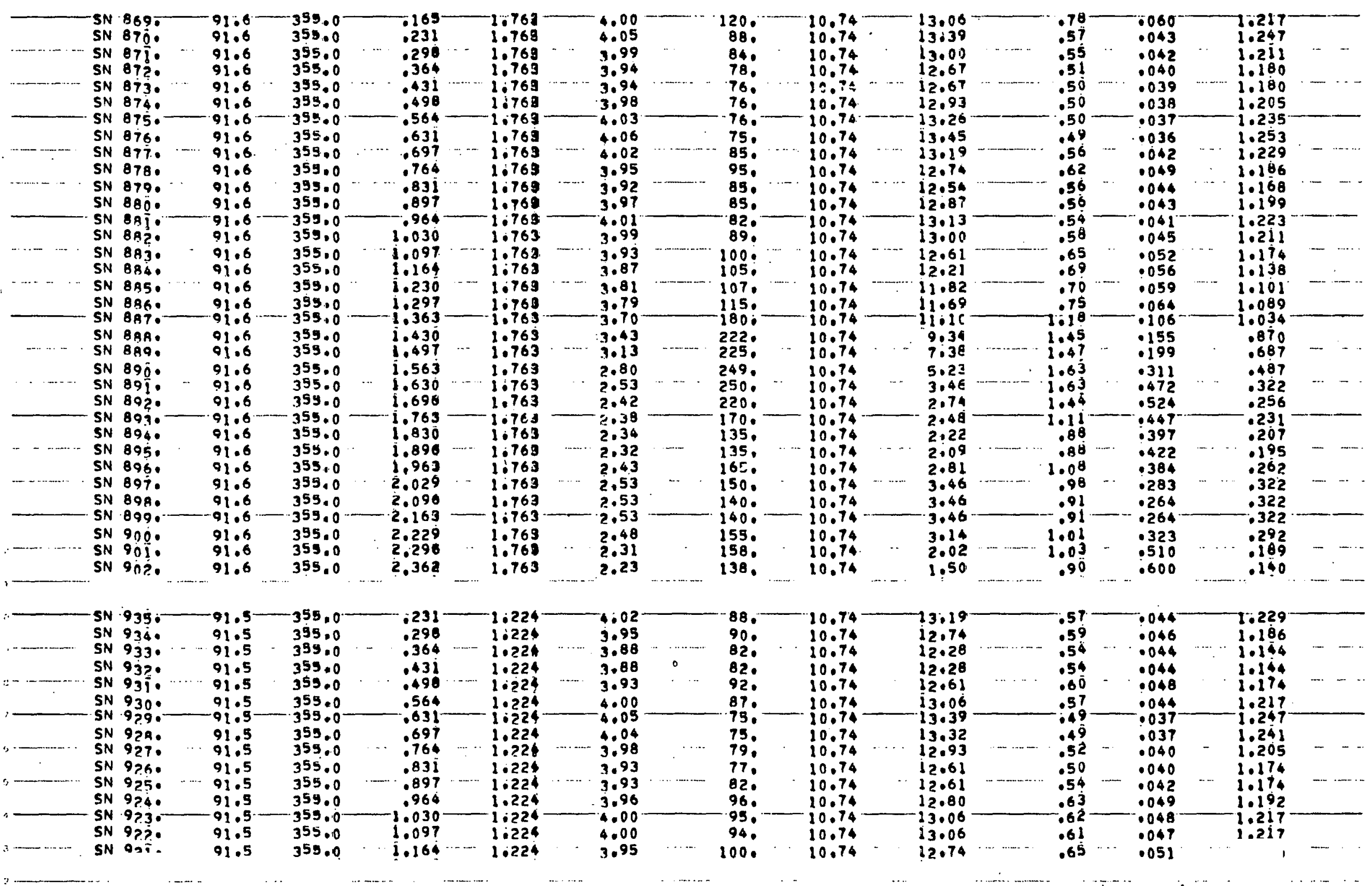




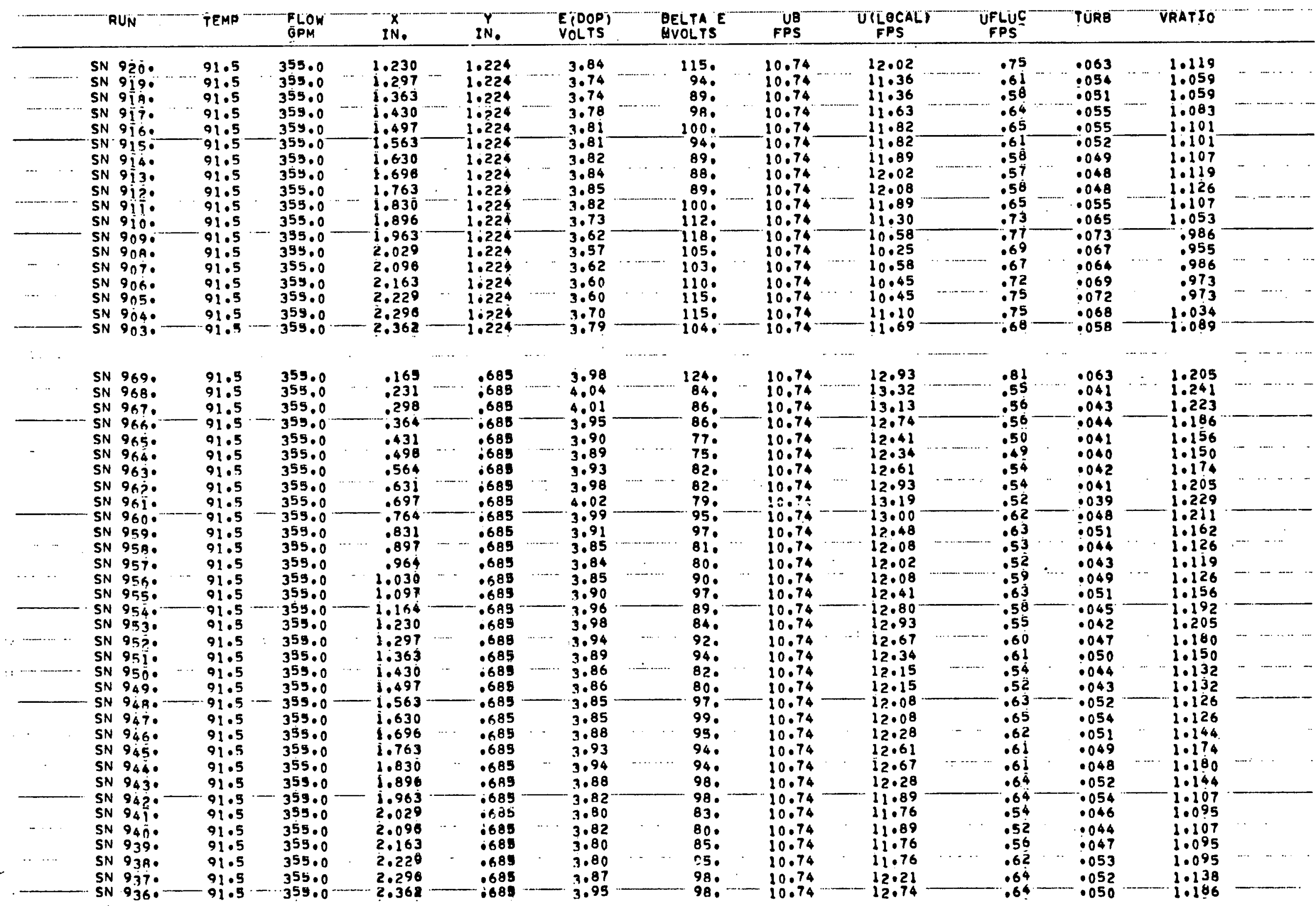




\begin{tabular}{|c|c|c|c|c|c|c|c|c|c|c|c|}
\hline RUN $\cdots \cdot$ & TEMP & $\begin{array}{l}\text { FLOW } \\
\text { ORM }\end{array}$ & $\begin{array}{l}\cdots \\
I N .\end{array}$ & IN: & $\begin{array}{l}\text { EYOOP) } \\
\text { VOLTS }\end{array}$ & $\begin{array}{l}\text { MELTA E } \\
\text { MVOLTS }\end{array}$ & $\begin{array}{r}\quad \text { U日 } \\
\quad \text { FPS }\end{array}$ & 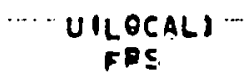 & $\operatorname{FFLUC~}_{\text {FPS }}^{\text {UFL }}$ & .. TURB & VRATIO \\
\hline $\begin{array}{l}\text { SN } 9730 \\
\text { SN } 970^{\circ} \\
\text { SN } 971: \\
\text { SN } 970^{\circ}\end{array}$ & $\begin{array}{l}91.5 \\
91.5 \\
91.5 \\
91.5\end{array}$ & $\begin{array}{l}355.0 \\
355.0 \\
359.0 \\
359.0\end{array}$ & $\begin{array}{r}.231 \\
.697 \\
1.230 \\
i .763\end{array}$ & $\begin{array}{l}0110 \\
0110 \\
\text { illo } \\
0110\end{array}$ & $\begin{array}{r}3.93 \\
4.11 \\
4.11 \\
4.12\end{array}$ & $\begin{array}{l}300 . \\
710 \\
710 \\
770\end{array}$ & $\begin{array}{l}10.74 \\
10.74 \\
10.74 \\
10.74\end{array}$ & $\begin{array}{l}12,61 \\
13,78 \\
13,78 \\
13,85\end{array}$ & $\begin{array}{l}.65 \\
.46 \\
.46 \\
.50\end{array}$ & $\begin{array}{r}.052 \\
.034 \\
.034 \\
.036\end{array}$ & $\begin{array}{l}1.174 \\
1.284 \\
1.284 \\
1.290\end{array}$ \\
\hline $\begin{array}{l}\text { SN } 974^{\circ} \\
\text { SN } 975^{\circ}\end{array}$ & $\begin{array}{l}91.5 \\
91.5\end{array}$ & $\begin{array}{l}355.0 \\
355.0\end{array}$ & $\begin{array}{r}1.923 \\
i .968\end{array}$ & $\begin{array}{l}1.800 \\
1.800\end{array}$ & $\begin{array}{l}2.22 \\
2.43\end{array}$ & $\begin{array}{l}170 . \\
252:\end{array}$ & $\begin{array}{l}10.74 \\
10.74\end{array}$ & $\begin{array}{l}1,44 \\
3,14\end{array}$ & $\begin{array}{l}1.11 \\
1.65\end{array}$ & $\begin{array}{l}.773 \\
.525\end{array}$ & $\begin{array}{l}.134 \\
.292\end{array}$ \\
\hline
\end{tabular}


TABLE :C\$1... FABULATION OF EXPERIMENTAL LOA DATA

DATA LLANE NO. 6. AXIAE OISTANCE\$3Y.50 iN, BLOCKMGE CENTERLINE=26.25 IN, P=\$7.00 PSI RE= 29400.

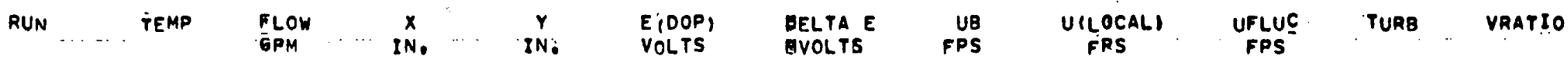

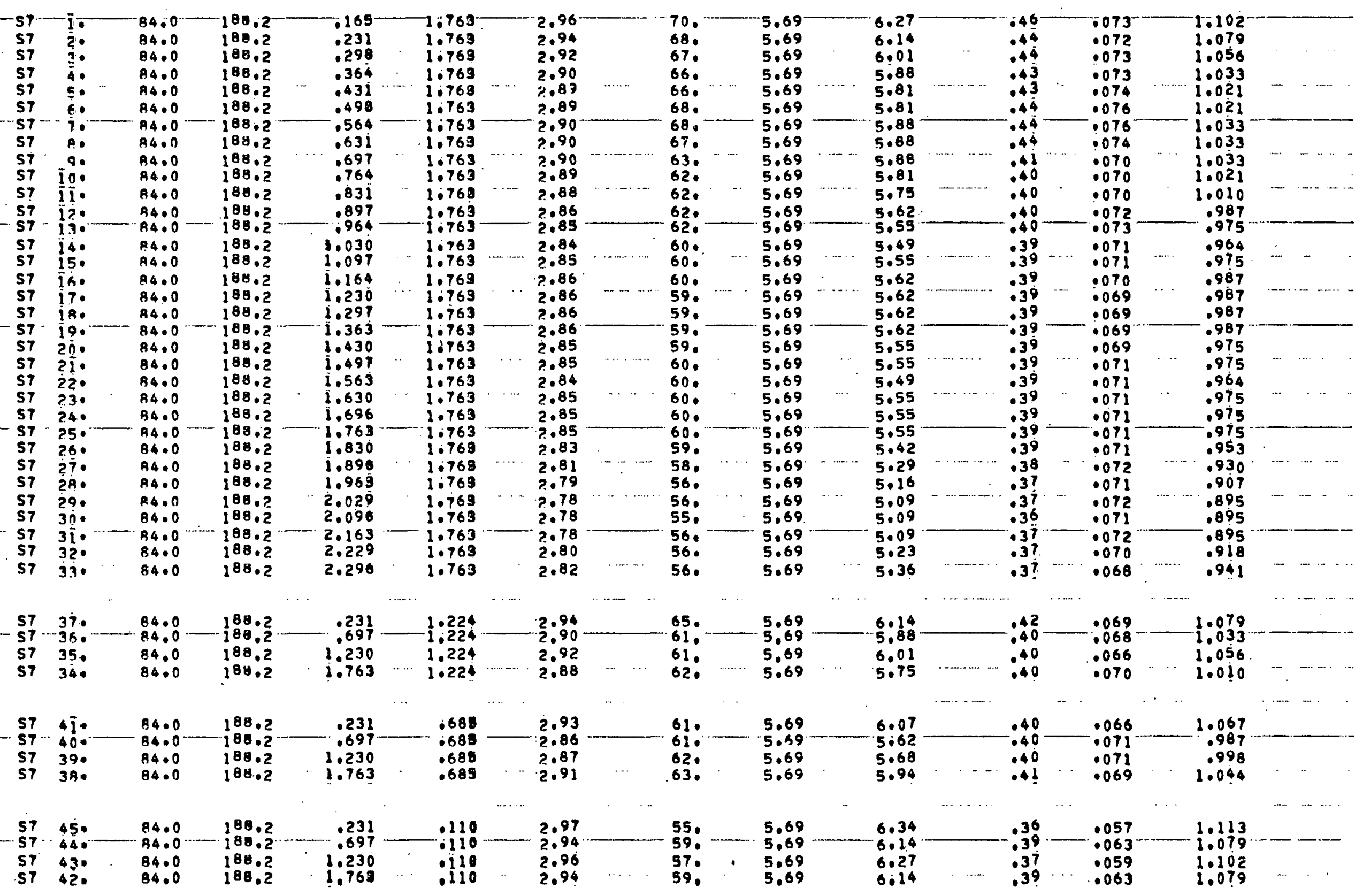


TABLE CII. TABULATION OF. EXPERIMENTAL LDA DATA

data pliave no. 3. axiali distanceezd.50 in. blocknge centerline-26.25 IN. Pa\$6.00 psi RE= 29500.

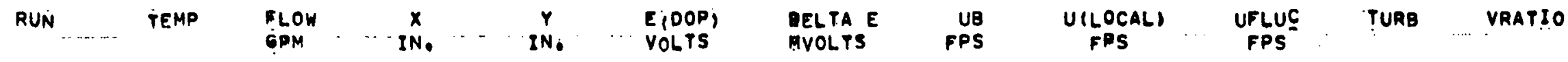

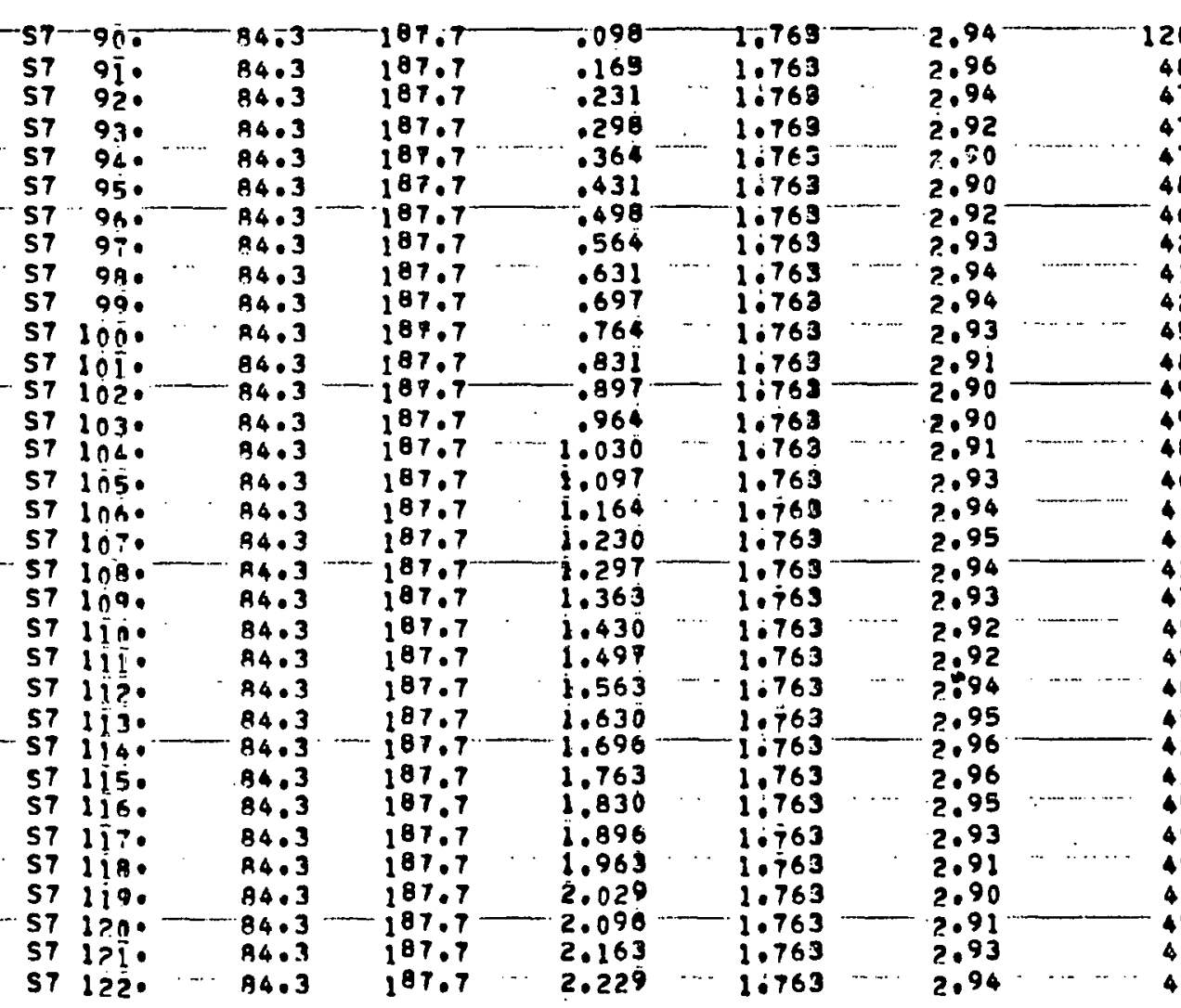

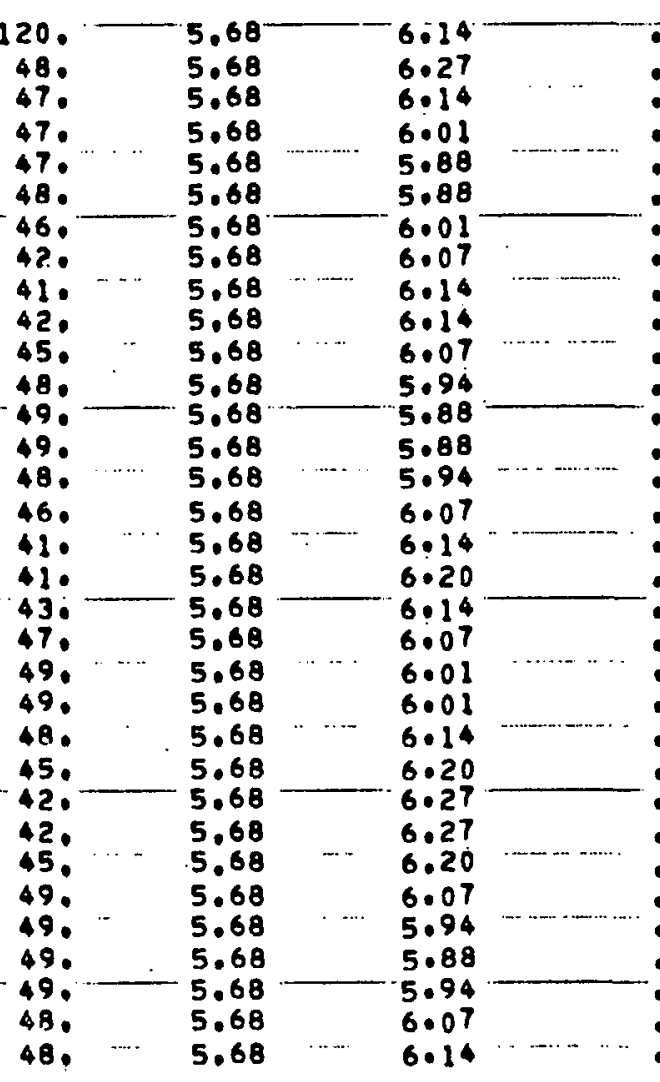

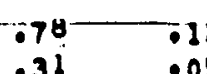

0.050

$.050 \quad 1.082$

$.31 \quad .051 \quad 1.059$

.052 …1.036

$.31+.053 \quad 1.036$

$\begin{array}{lll}30 & .050 & \\ 27 & .045 & 1.059 \\ 27 & 1.070\end{array}$

$\begin{array}{lll}1 & .044 & 1.082 \\ 27 & .045 & 1.082\end{array}$

$29 \quad .048 \cdots 1.070$

3j $\quad .053 \quad 1.047$

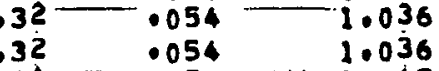

$.31 \cdots \quad .053 \quad \cdots \quad 1.047$

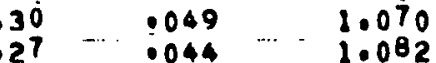

$.27 \quad 043 \quad 1.093$

$28-.046 \cdots 1.082$

31 $\quad .051 \quad 1.070$

$\begin{array}{lll}0.053 & 1.059\end{array}$

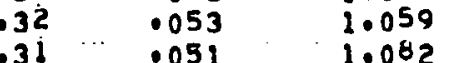

$.29+.047$

$27 \quad 2.105$

$.29 \quad 0.047 \quad \cdots \cdots \quad 1.1093$

$\begin{array}{llll}.32 & .053 & \ldots & 1.070\end{array}$

$\begin{array}{llll}.32 & .054 & \cdots & 1.047 \\ 32 & .054 & 1.036\end{array}$

$.32-.054-1.036$

31 ....... $.051 \ldots 1.070$

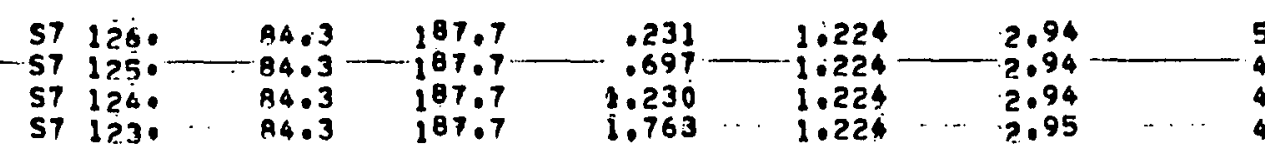

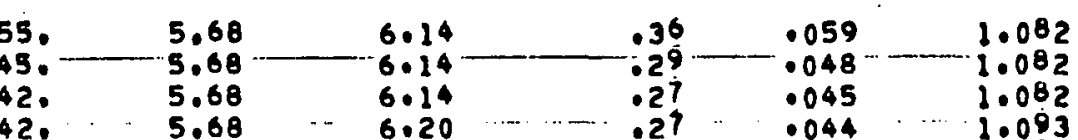

$57130^{\circ}$

$84.3 \quad 187.7$
84.3

S7 128.

$\begin{array}{lll}84.3 & 187.7-0697 \\ 84.3 & 187.7 & 1.69\end{array}$

$5713.7 \cdot$

$84.3 \quad 187.7$

1.230
1.763

688
689
688
689

$2 \cdot 93$

2.93
2.94
$? .93$

67.

689
$\quad 7.93$

45.

$5.68 \quad 6.07$

$\begin{array}{lll}5000 & & 6.14 \\ 5.68 & \ldots & 6.07\end{array}$

47

2.94
2.96

$57234 \circ$

$84.3 \quad 187.7$

.231

1110

57 132 .

$\begin{array}{ll}84.3 & 187.7 \\ 84.3 & 187.7\end{array}$

1.230
1.763

$\begin{array}{ll}.110 & 2.95 \\ .110 & 2.97\end{array}$

$40 . \quad 5.68$
$40 . \quad 5.68$

6.14
6.27

6.27
6.20

6.34

$\cdots+\cdots+\cdots$


TABLE CEl. TABULA-ION OÁ EXRERIMENTAL LDA DA-A

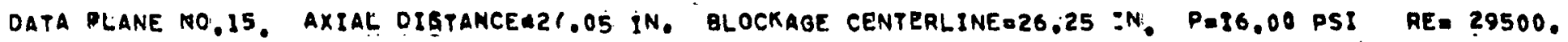

RUN

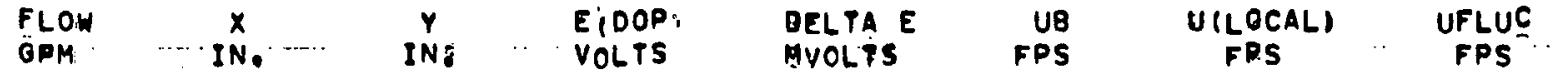
TURB

VRATIO

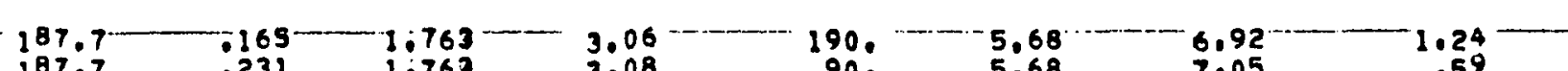

$\begin{array}{lllllll}571350 & 84.3 & 187.7 & .169 & 1.763 & 3.06 & 190 \\ 571360 & 84.3 & 187.7 & .231 & 1.767 & 3.08 & 90 . \\ 57137 . & 84.3 & 187.7 & .298 & 1.763 & 3.04 & 650 \\ 57138 . & 84.3 & 187.7 & .364 & 1.763 & 3.02 & 60 .\end{array}$
S7 138 57140. 57141. 571420 $571430^{\circ}$ 571460 57147 57 149. 571500 S7 $151^{\circ}$ S7 152. S7 $153^{\circ}$ S7 1540 57156. 57157. 57 158. 57.159 5716 ก. $57160^{\circ}$ 57162. $5716 \dot{4}^{\circ}$ S7 $165^{\circ}$ $57166^{\circ}$ ST $167^{\circ}$ $\begin{array}{ll}84.3 & 187.7 \\ 84.3 & 187.7\end{array}$

84.3 84.3187 .7 $84.3 \quad 187.7$ $04.3 \quad 189.7$ $84.3-109.7$ $84.3 \quad 187.7$ $84.3 \quad 187.7$ $84.3 \quad 187.7$ $84.3 \quad 187.7$ $86.3-187.7$ A. 4.3 $84.3 \quad 187.7$ $84.3 \quad 107.7$ $94.3 \quad 187.7$ 84.3 $94.3-187.7$ 84.3 $84.3 \quad 187.7$ A4.3 187.7 $84.3 \quad 187.7$ 84.3 $94.3 \quad 187.7$ $84.3 \quad 107.7$ $\begin{array}{ll}.43 i & 1.763 \\ . & 3.02\end{array}$

.498
-.564
.631
1.763 3.05 $.564-1.763-3.07$

$\begin{array}{llr}.631 & 1.763 & 3.09\end{array}$

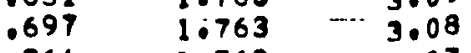
$\begin{array}{rrr}1.763 & & 3007 \\ .831 & 1.763 & 3.08\end{array}$ $\begin{array}{rrr}.897-16763 & 3.11\end{array}$ $\begin{array}{lll}0.964-030 & 1.763-3.12 \\ 1.0303 & 1.763\end{array}$ $\begin{array}{llll}1.030 & 1.763 \\ 1.097 & 1.763 & -. & 3.13 \\ 1.164 & 1.763 & 3.11\end{array}$

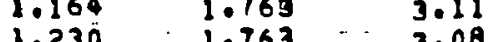
1.763 $1.363-1.763-2.96$ i. $430 \quad 1.763$ i. 563 $1.696 \quad 1.763$ 1.763 $1.830 \quad 1.763$ 1.896 1.963 $\begin{array}{rrr}1.769 & 3.14 \\ 1.763 \quad \cdots \quad & 2.15\end{array}$ 2.096

$60.5,68$

54. 55 $50 \%$ - 5.68 $46 . \quad 5.68$ 45.
45. $45 . \quad 5.68$
$45 . \quad 5.68$ 43. $42 .-5.68$ 5.68
$48 . \cdots \quad 5.68$
5.6 .68 $48, \cdots \quad 5.68$ $5.68 \quad 7.38$ 80. $\ldots . .68 \ldots \ldots .7 .05$ 150. 5.68 $170 .-5.68$ 2.75

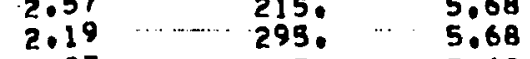
1.97215. $2.16 \cdots \cdots+215$.

5. ... 5.68 2150
$170, \quad 5.68$
$-58,50$ 3.15 $3.15 \quad 88$, 3.09 $.14 \ldots \ldots .48$, 58. - 5.68 198. 278. 118.

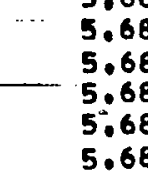

$\begin{array}{ll}6.92 & 1.24 \\ 7.05 & .59 \\ 6.79 & .42 \\ 6.66 & .39\end{array}$

.179
.083
.063
$1.220--$

st 200. 57199

$84.3 \quad 187.7$ $\begin{array}{lll}.165 \quad 1.224 & 3.09\end{array}$ 194

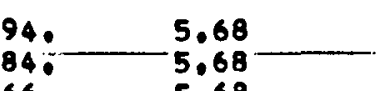
57197. $84.3-187.7$ 1807.7 $04.3 \quad 187.7$ S7 195. $84.3 \cdots 187.7$ $.298 \quad 1.224 \quad 3.02$ $.364 \ldots 1.224 \ldots-3,00$ $57194^{\circ}$ 84.3 107....... 1.224 $571930^{\circ}$ 571920 $\begin{array}{rr}84.3-187.7 \\ 84.3 & 187.7\end{array}$ 187.7 301 57191. $56010 ? 24$ $1.224 \quad 3.03$ $57190^{\circ}$ 57 Iค9. S? 1 A.

187.7 $.631-1.224$ $7 \quad \cdots .764 \cdots \cdots 1.220$

187.7 $84.3 \quad 187.7$ $84.3-107.7$ S7 18R. $\begin{array}{ll}84.3 & 187.7 \\ 84.3 & 187.7\end{array}$ .897 $.964 \quad 1.224$ $\begin{array}{lll}1.0224 & 3.05 \\ 1.097 & 1.224 & 3.07\end{array}$ i.164. $1.224 \quad 3.06$

84
66
59
58
65
50
50
50
50
47
49
53
57
55
56

$66:$
$59:$
$58:$
$65:$
$50:$
$50:$
$50:$
$50: \cdots$
$7 \%:$
$53:$
$57:-$
$55:$
56.

5.68

5.68 $5.68 \cdots$
5.68 5.68. $5.68 \cdot$ 5.68
5.68
5.68 $5.68 \cdots .6 .66$ $\begin{array}{ll}5.68 & 6.66 \\ 5 & 6.79\end{array}$ $5.68-6.86$ $\begin{array}{lll}5.68 & 6.99 \\ 5.68 & 6.92\end{array}$

7.12
6.92
6.66
6.53
6.60
6.73
6.86
6.99
6.92
6.73
6.66
6.66
6.79
6.86
6.99
6.92
.42 .35
.35
.36 .33 $.30 \quad .047$ $.29 \cdots, 0042$ .129
.29
.29 .29
.27
.29
03 .29
.31
.36
.52 .36
.52
.98 $.9 \dot{8}$ 1.11 1.40
1.93 1.40 1.40 .167

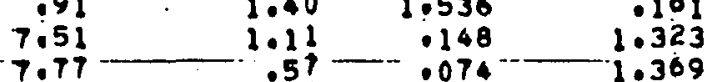
$\begin{array}{rrrr}.91 & 1.40 & 1.536 & 1161 \\ 7.51 & 1.11 & 148 & 1.323 \\ 7.79 & .57 & .074 & 1.369\end{array}$ $\begin{array}{llll}7.77 & .57 & .074 & 1.369 \\ 7.51 & .57 & .077 & 1.323\end{array}$ .98 $\cdot 1.05$ 9.12 $1.03 \cdots \cdots . .145$ $2.93 \quad .393 \quad 1.254$ $\begin{array}{llll}2.19 & 2.187 & \cdots & 1.173\end{array}$ $1.29-1.238-1.800-0.184$
$1.88-.184$ $\begin{array}{llll}1.82 & .255 & \ldots & 1.254\end{array}$ . ...........................

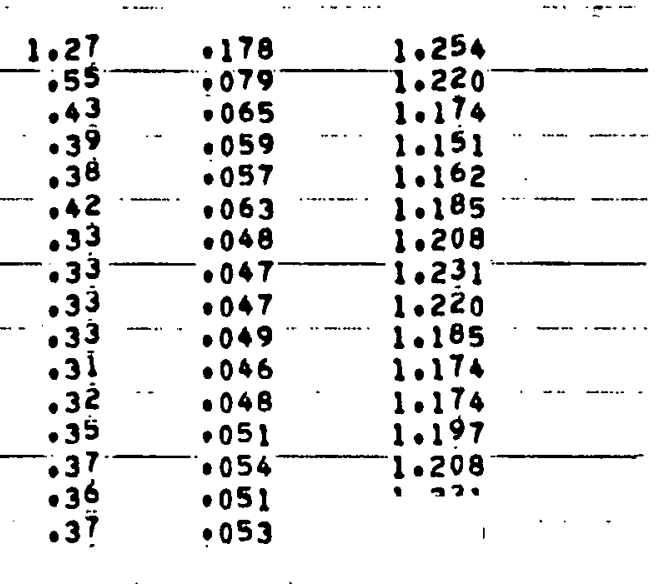




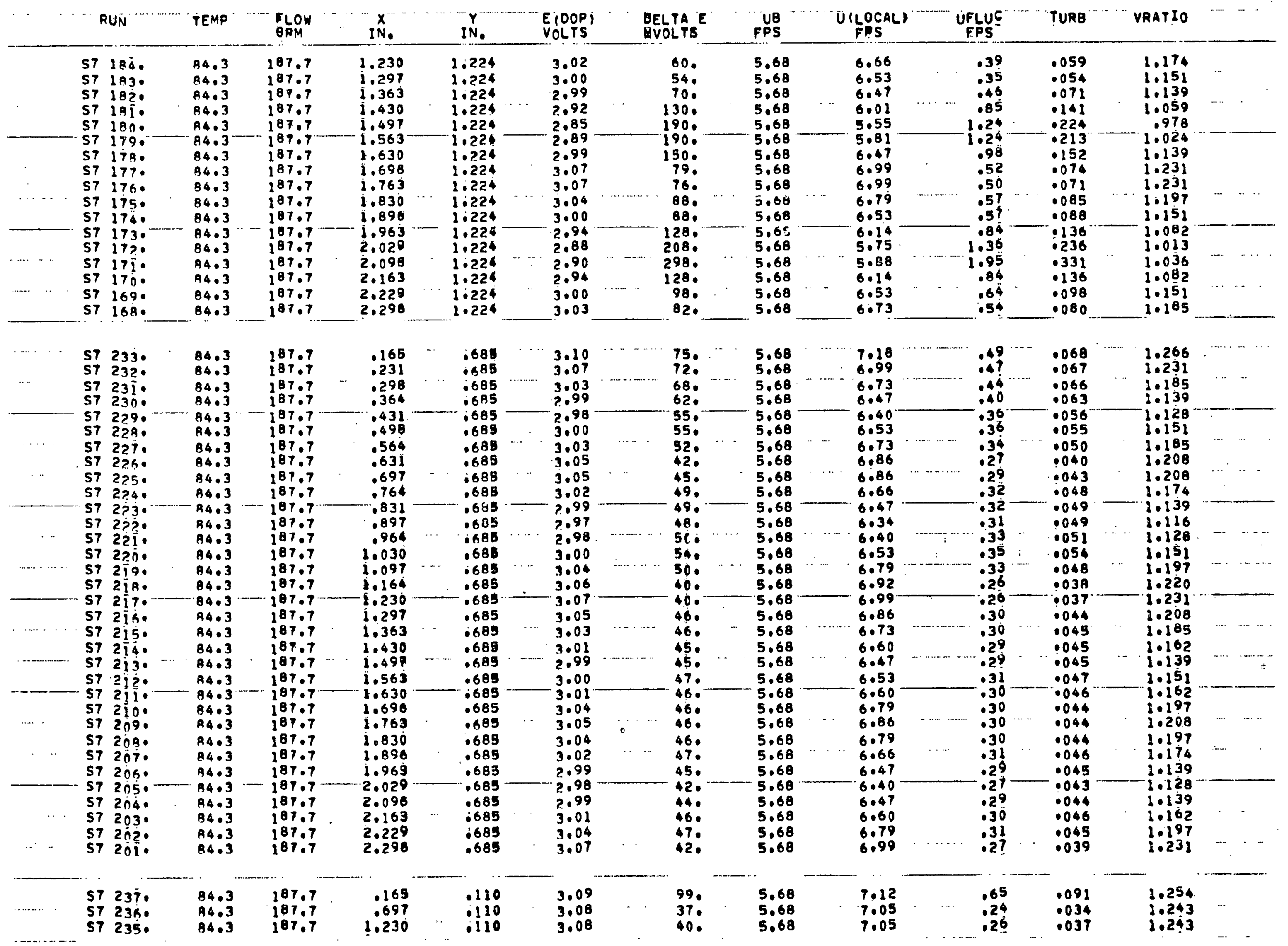




\begin{tabular}{|c|c|c|c|c|c|c|c|c|c|c|c|c|}
\hline RUN & TEMP & FLOW & $\begin{array}{l}x^{\prime} \\
\text { IN. }\end{array}$ & $\cdots$ & $\begin{array}{l}\cdot Y \\
\text { IN. }\end{array}$ & $\begin{array}{l}\text { E (OOP) } \\
\text { VOLTS }\end{array}$ & $\begin{array}{l}\text { DELTA E } \\
\text { MVOLTS }\end{array}$ & $\begin{array}{l}\text { UB } \\
\text { FPS }\end{array}$ & $\begin{array}{c}\text { U(LOCAL) } \\
\text { FOS }\end{array}$ & $\begin{array}{l}\text { UFLUC } \\
\text { FPS }\end{array}$ & TURB & VRATIOO \\
\hline ST $23 \ddot{4}$. & 84.3 & 287.7 & 1.763 & & .110 & 3.09 & 38. & 5.68 & $7: 12$ & .29 & .035 & 1.254 \\
\hline
\end{tabular}


DATA PLANE NO. 5. AXIAL OISTANCE

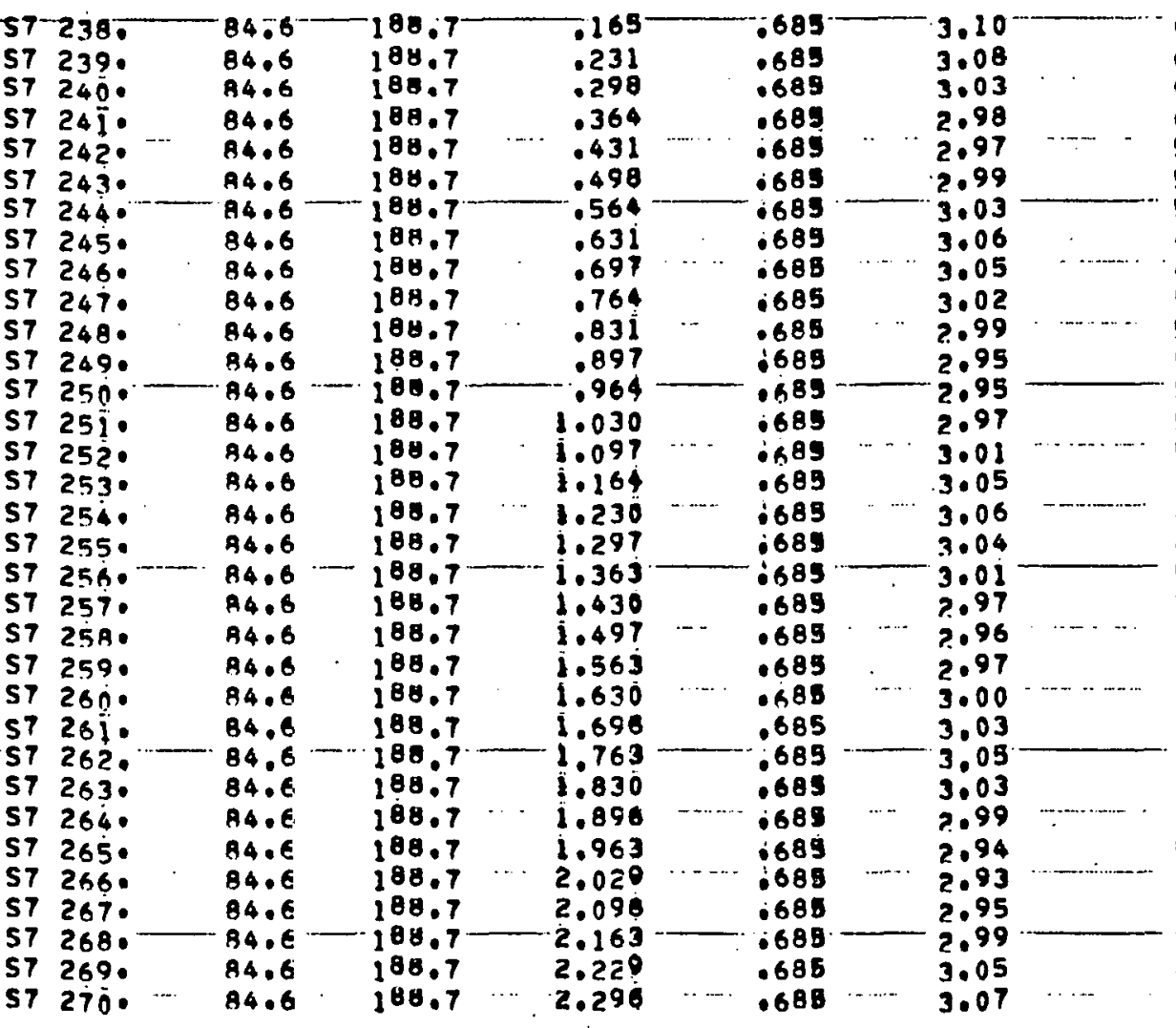

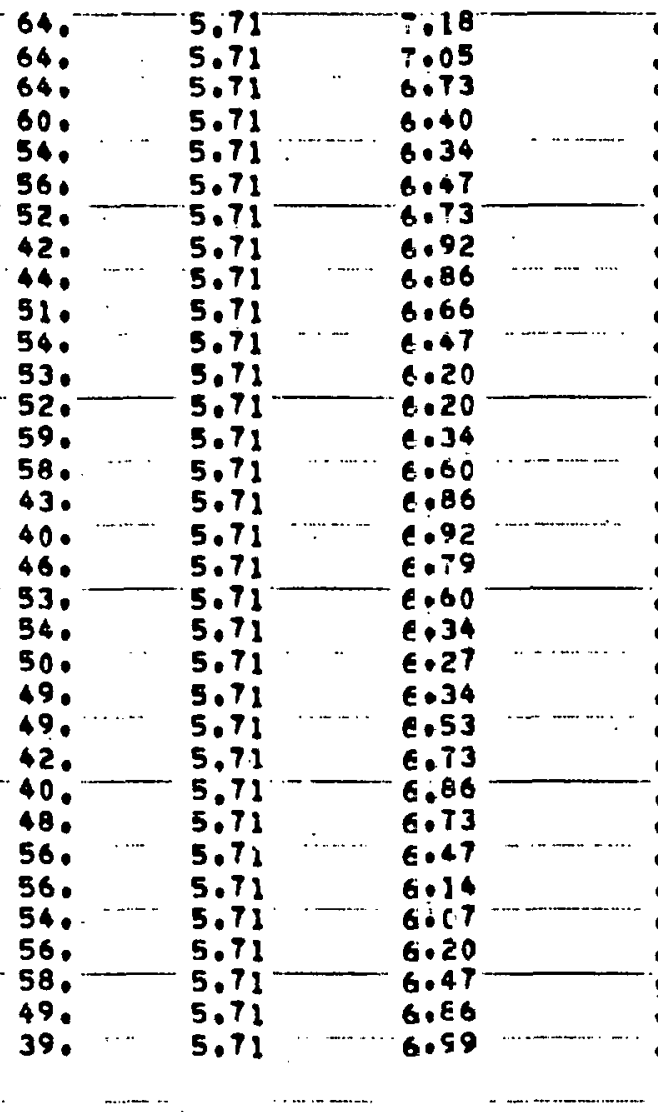

.42
.42
.42
.39
.35
.37
.34
.27
.29

$\begin{array}{ll}.058 & 1.259 \\ .059 & 1.236 \\ .062 & 1.179 \\ .061 & 1.122 \\ .056 & 1.110 \\ .057 & 1.133 \\ .050 & 1.179 \\ .050 & 1.179 \\ .040 & 1.213\end{array}$

57274.

$84.6 \quad 188.7$ .231
-.697

S7 2720

$-188.7$

..........

$$
\text { ing }
$$

S7 27 i.

$\begin{array}{ll}84.6 & 188.7 \\ 94.6 & 188.7\end{array}$

$-\frac{1.69}{1.230}$

110
$.110-3.09$

$\begin{array}{rrr}110 & 3.09 & 36 . \\ 110 & 3.08 & 39 .\end{array}$

$\begin{array}{rr}5.71 & 7.12 \\ 5.71 & 7.22 \\ 5.71 & 7.05\end{array}$

$\begin{array}{ll}12 & .3 \\ 12 & .2 \\ 05 & .2 \\ 05 & .2\end{array}$

$29 \cdots .042 \cdots . \quad 1.202$

$.33 \ldots$

$.35 \cdots .055$

$.35 \quad .056$

39.055

$\begin{array}{rrr}.39 & .061 \\ .38 & \cdots & .057\end{array}$

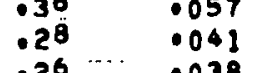

$\begin{array}{ll}.26 \cdots & .038 \\ .30 & .044 \\ .35 & .045\end{array}$

$.35-.052$

$.33 \quad .056$

$.32 \quad .052$

$32 \cdots .049$

$\begin{array}{ll}.27 & .041 \\ 26 & 038\end{array}$

$.31 \quad .047$

$\begin{array}{rr}.37 & .057 \\ .37 & .060 \\ .35 & \cdots\end{array}$

.35
.37
.058

$.38-.059$

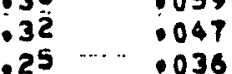

1.167

i. 133

1.087

1.110
1.156

$57290^{\circ}$

$94.6 \quad 188.7$

.265

0.000

57.289

04.6

.298

1.224

3.08

$94.6 \quad 188.7 \quad .43$

ST $2 A$.

S7 $28 \%$.

572840

-57 $2830^{\circ}$

月4.6 188.7

$\begin{array}{lll}04.6 & 188.7 & .697\end{array}$

$94.6 \quad 188.7$

$84.6 \quad 188.7$

.831

ST. $2 A^{2}$

84.6

$188.7-1.097$
$188.7 \quad 1.230$

186.7

1.230
1.363

$\begin{array}{ll}1.224 & 3.01 \\ 1.224 & \\ 1.226 & 3.08 \\ 1.224 & 3.05 \\ 1.224 & 3.05 \\ 1.224 & 3.00 \\ 1.224 & 2.97 \\ 1.224 & \\ 1.224 & 3.99 \\ 1.224 & 3.00\end{array}$

64.

58.

46.

4.?

42.

56.

46.

5.71

$7 \cdot 05$

5.71

5.71

5.71
5.71

5.71

5.71

5.71

5.71

6.060
6.40
6.86
6.86
6.53
6.396
6.47
6.55
6.27

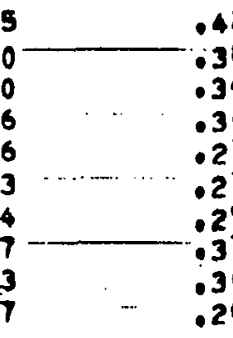

.42
.3
.3
.3
.2
.2
.2
.13
.3
.2

.059

.057

.053
.044

.044

.042

.046
.057

.057

.046
.042

1.202

1.213

1.156

1.090

1.110

1.145

1.179

i.j?

1.133

1.076 1.064 1.087

1.202 


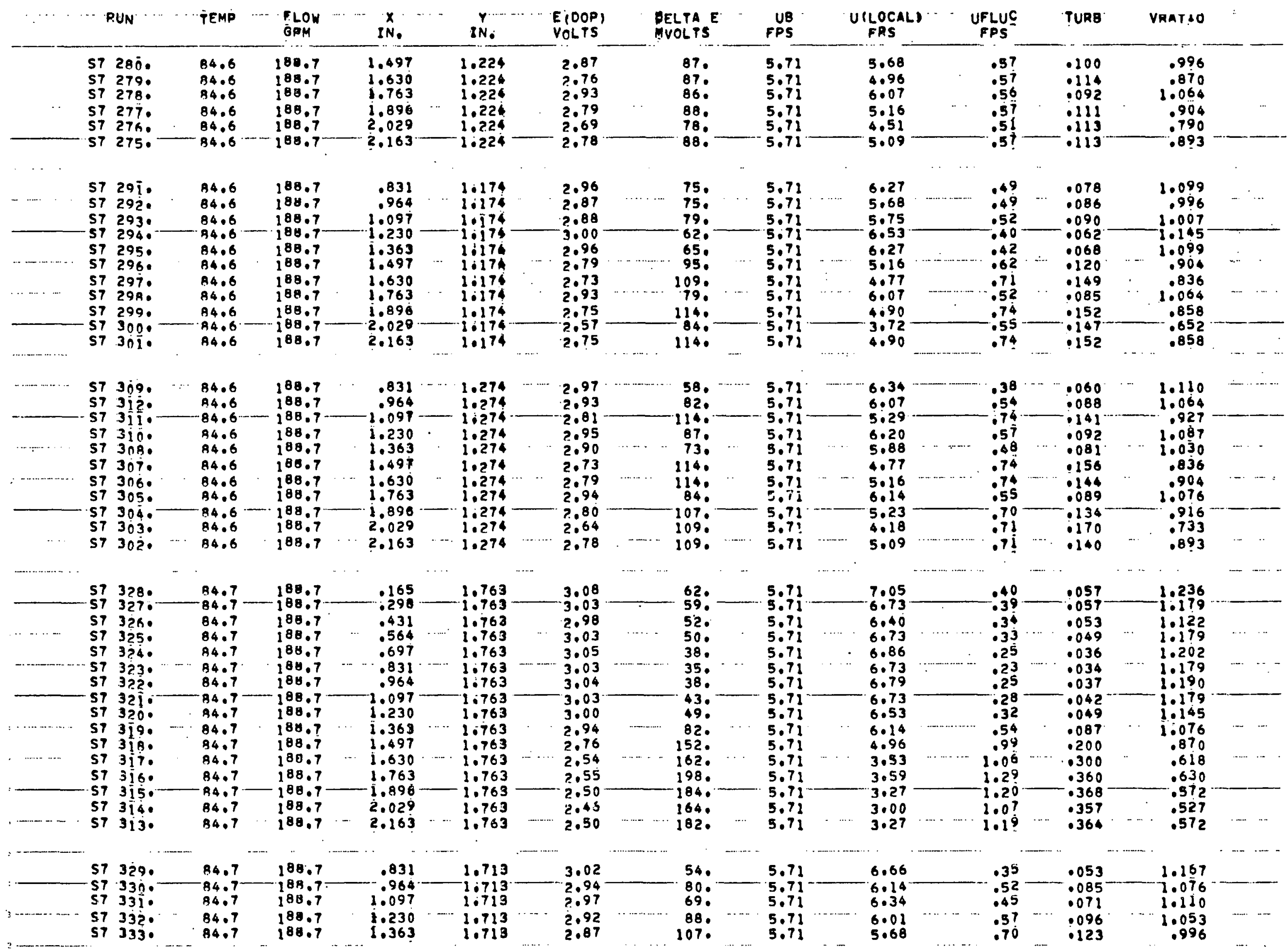




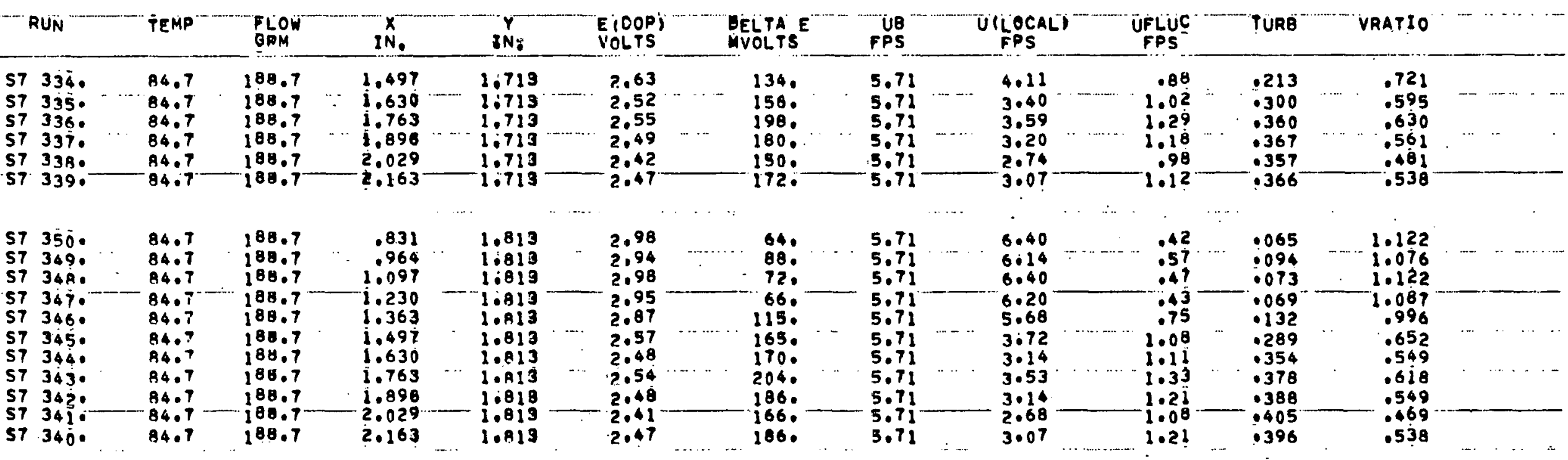


TABLE CAI. TABULATION OP. EXPERIMENTAL LOA DATA

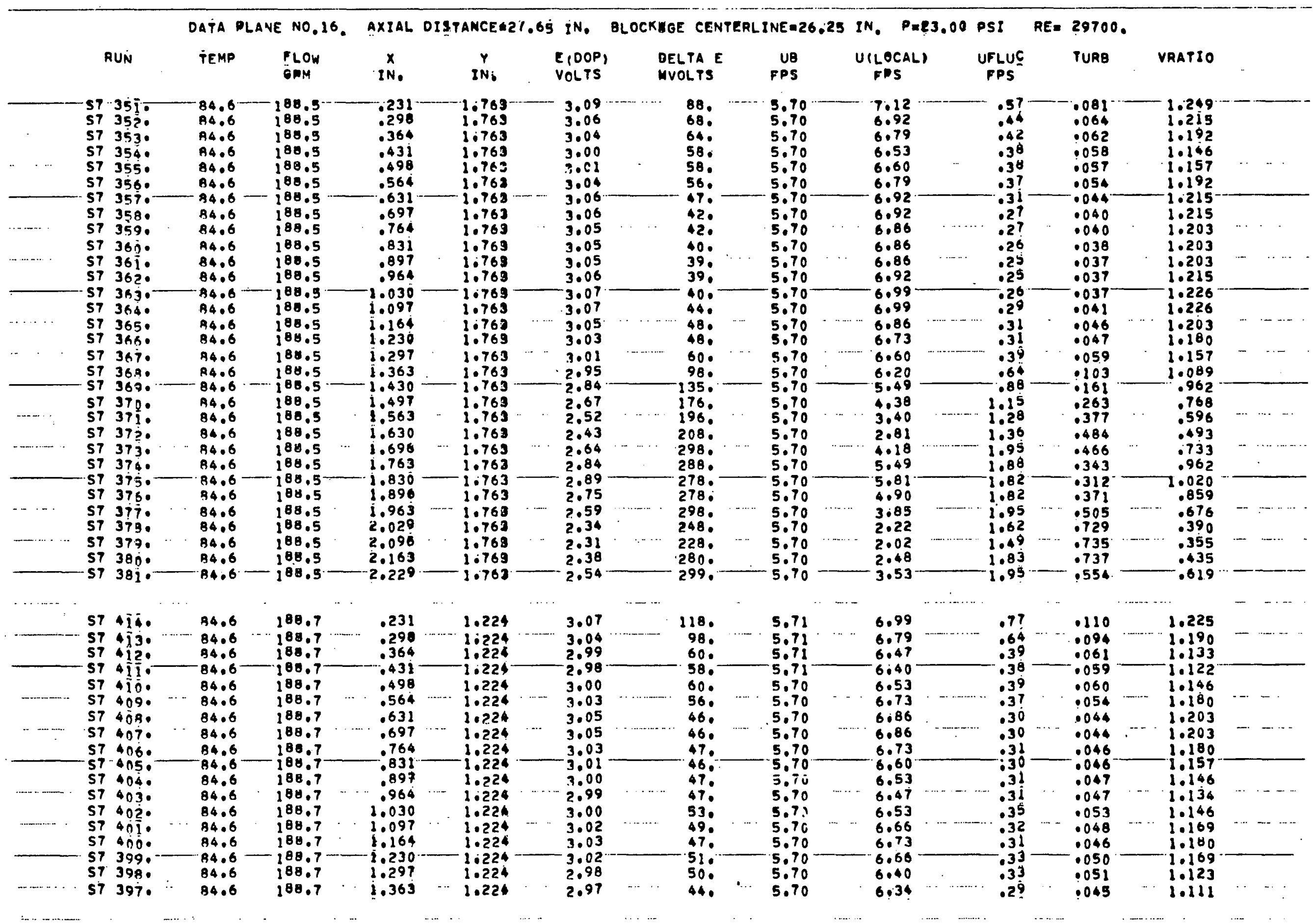




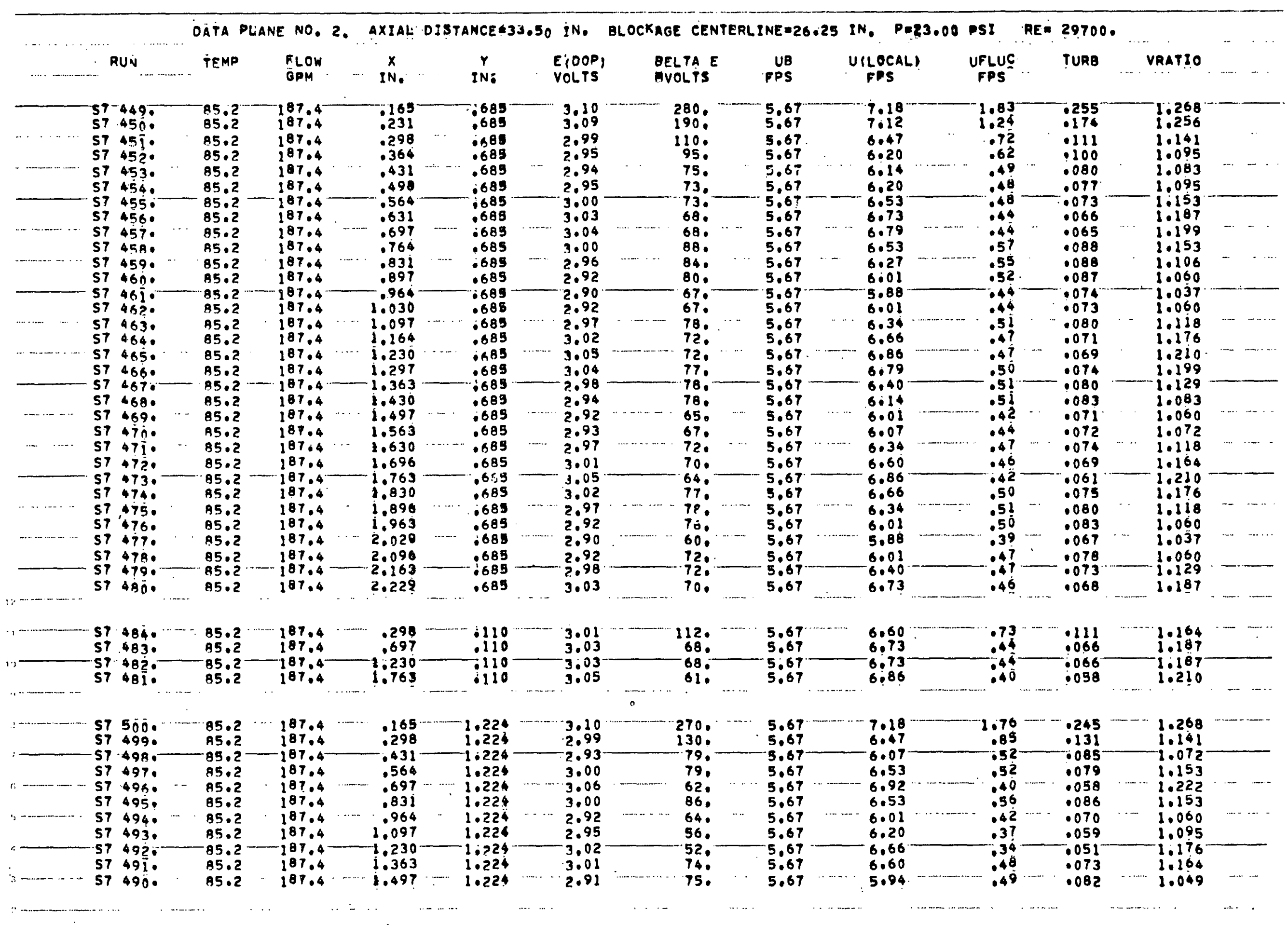




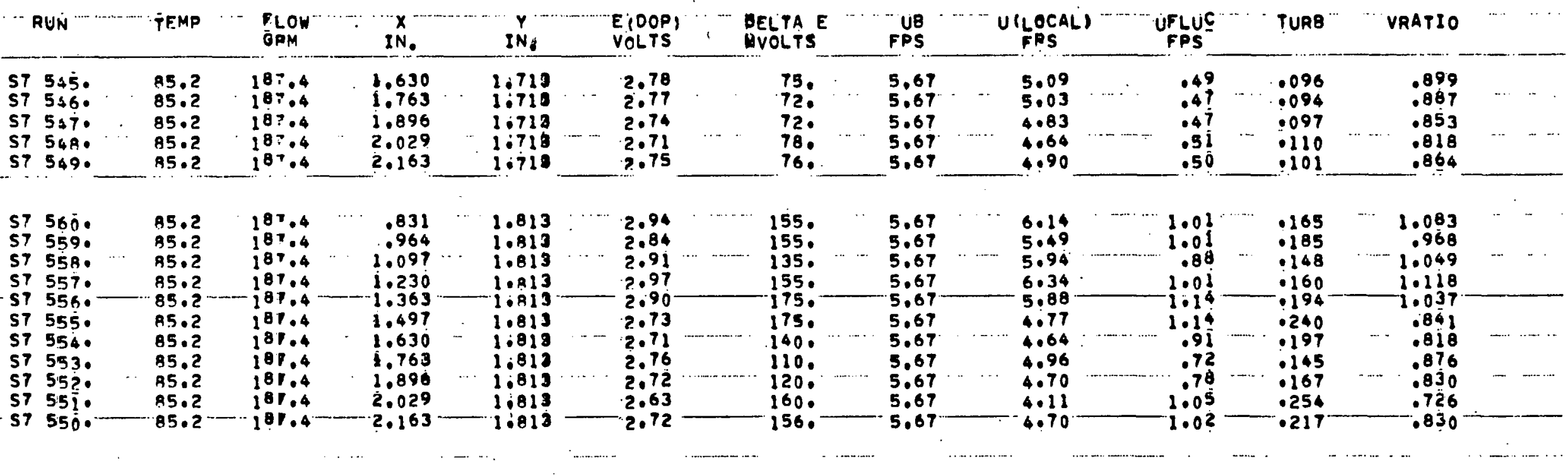




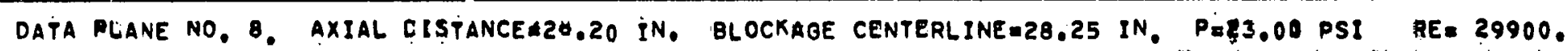

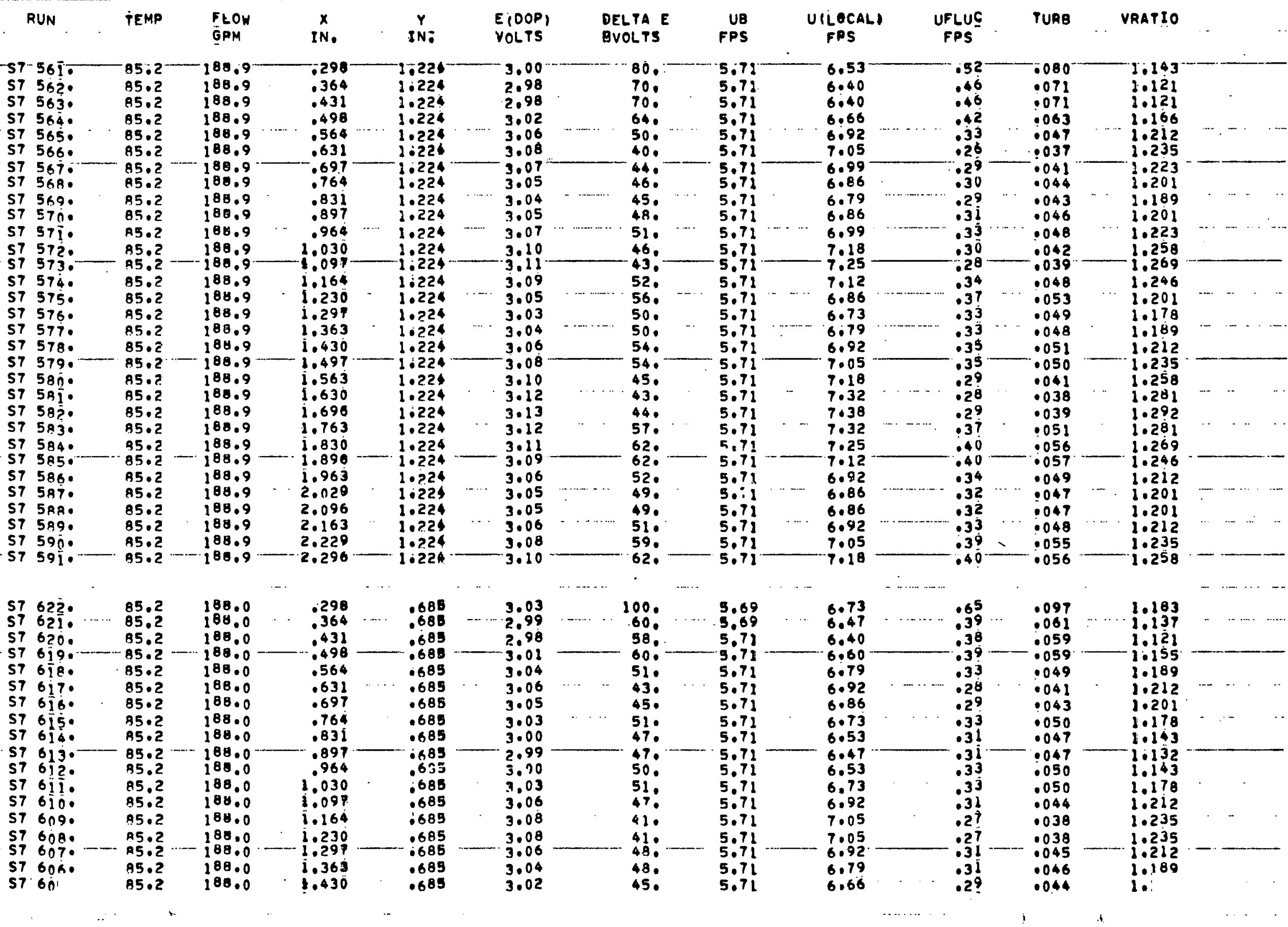




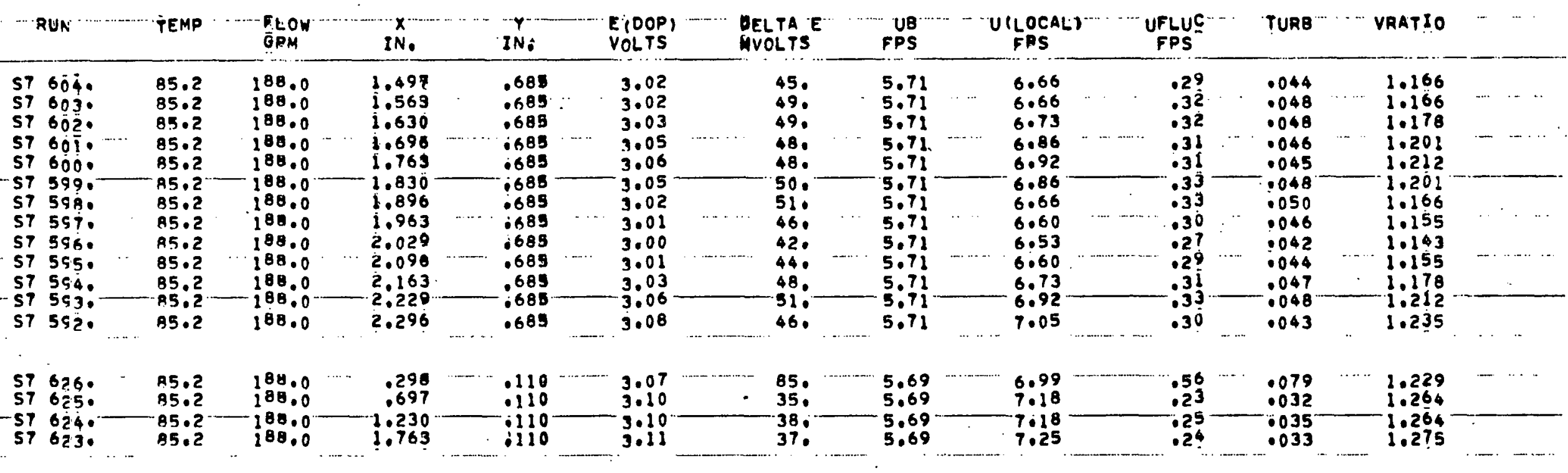


TABLE CHI. TABULATION OR EXRERIMENTAL LOA CATA

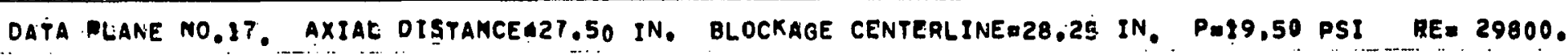

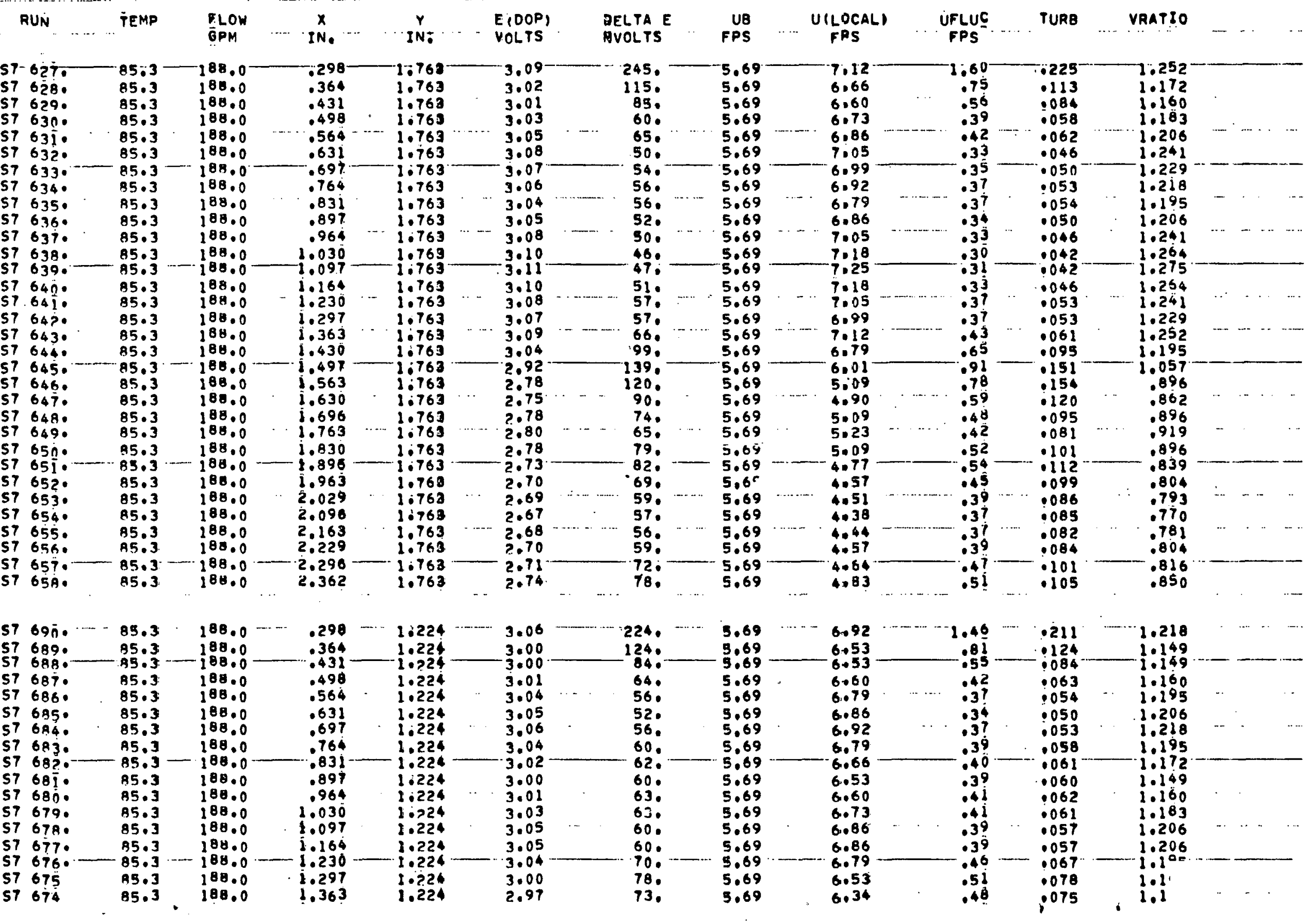




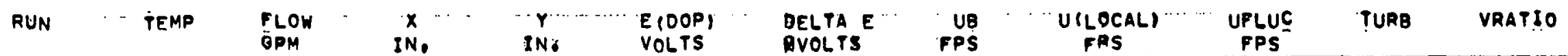

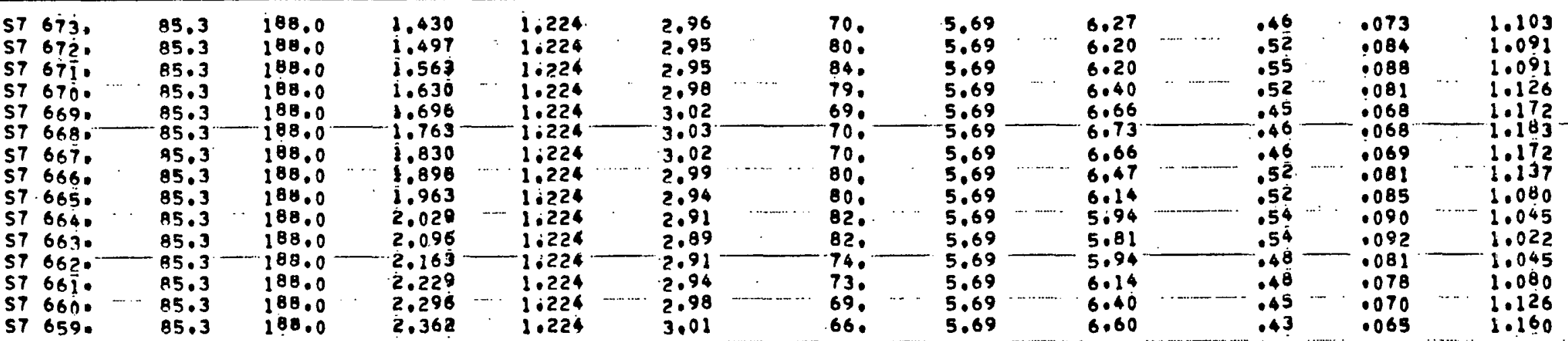

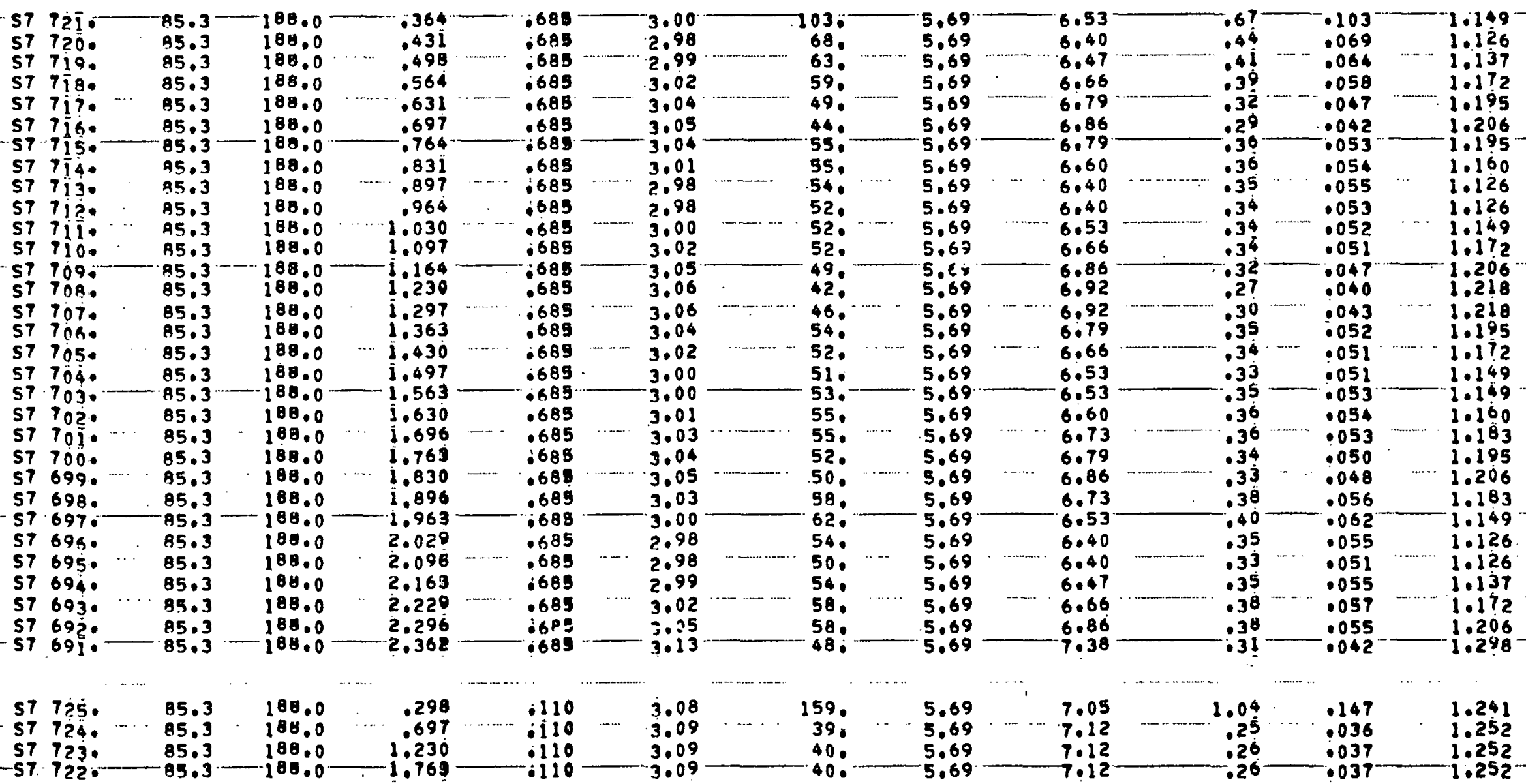


TABLE Cil. TAGULATION OF EXPERIMENTAL LOA DATA

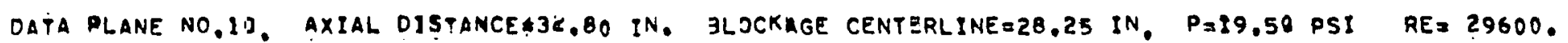

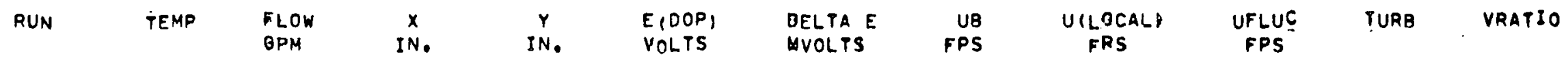

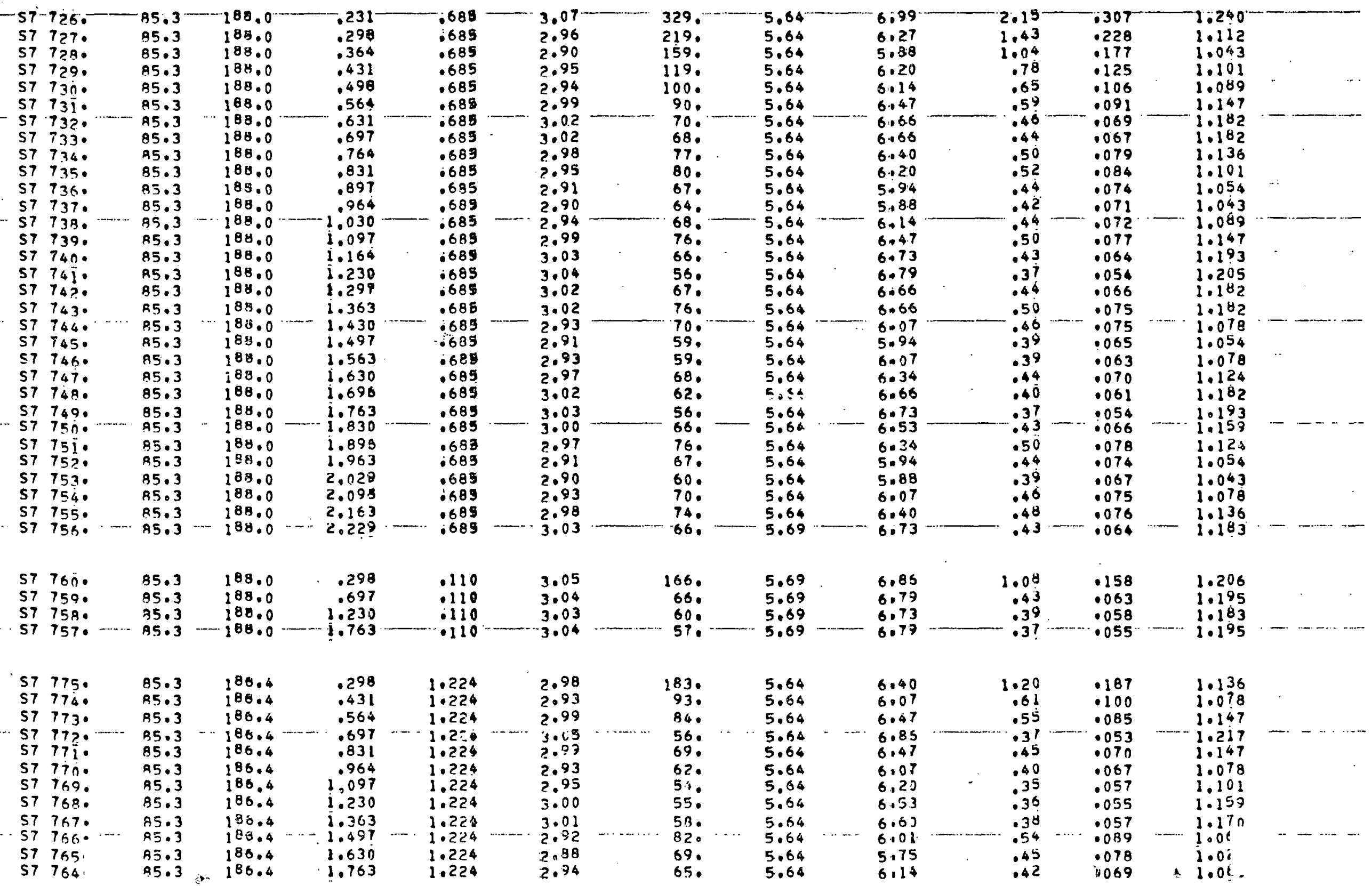




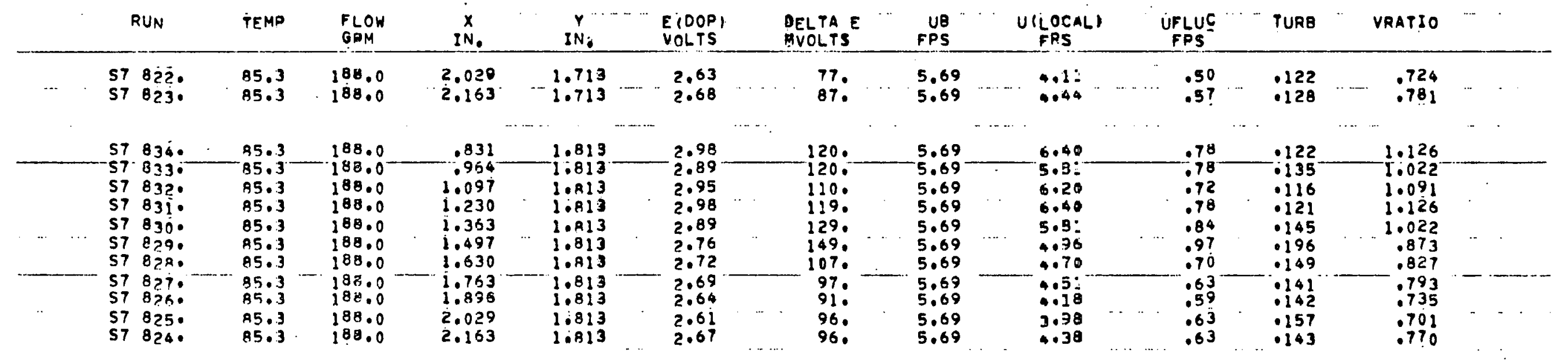


TABLE C'I. TABULATSON OF EXPERIMENTAL LDA DATA

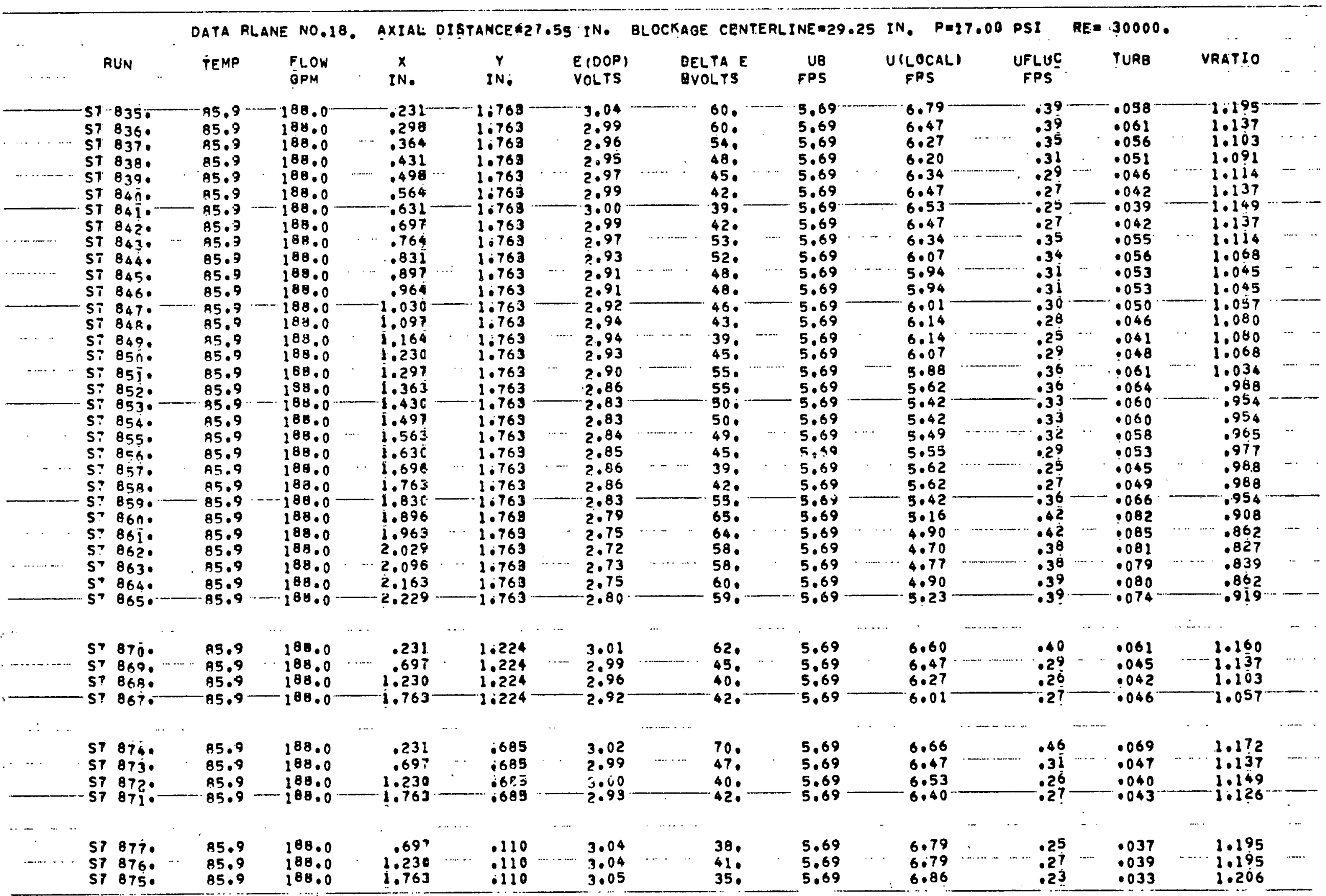


TABLE CEI. TABULATION OF EXPERIMENTAL LOA OATA

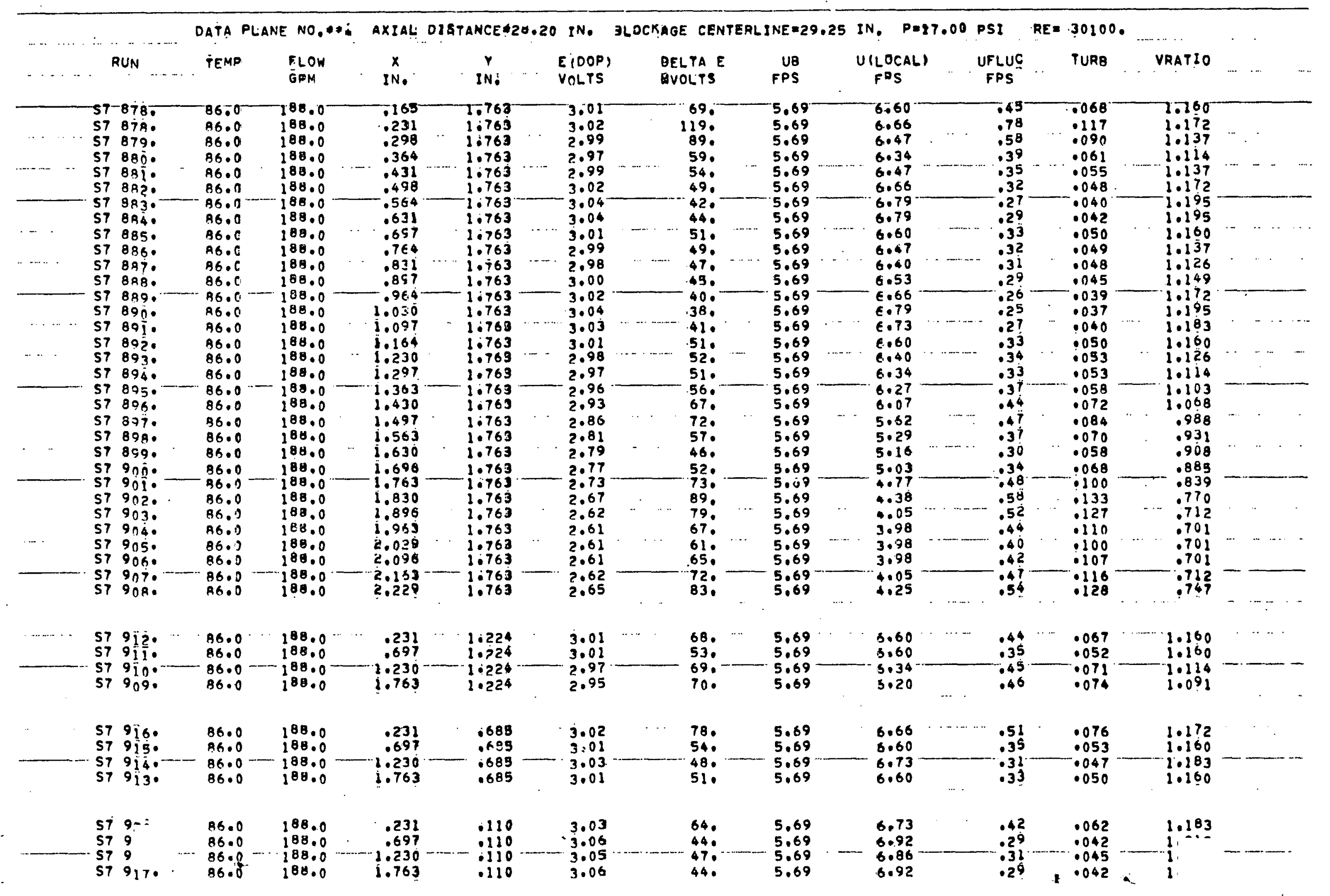


TABLE C-2. Tabulation of Pressure Loss Data $\left(T=85 \pm 4^{\circ} \mathrm{F}\right)$.

\begin{tabular}{|c|c|c|c|c|c|c|c|c|c|}
\hline $\begin{array}{l}\text { Run } \\
\text { No. }\end{array}$ & Configuration & $\begin{array}{l}\text { Flow,F } \\
\text { G.P.M. }\end{array}$ & $\Delta P_{1-2}$ & $\Delta P_{2-3}$ & $\Delta P_{3-4}$ & $\Delta P_{4-5}$ & $\Delta P_{1-3}$ & $\Delta P_{1-5}$ & {$\left[{ }^{\Delta P_{1}} 1-5\right]$ Norm } \\
\hline 1 & Bare Rod & 95.7 & $0: 091$ & 0.051 & 0.098 & 0.033 & 0.142 & 0.280 & -- \\
\hline 2 & $"$ & 139.1 & 0.179 & 0.098 & 0.202 & 0.062 & 0.277 & 0.547 & -- \\
\hline 3 & $"$ & 187.4 & 0.315 & 0.163 & 0.361 & 0.105 & 0.479 & 0.939 & -- \\
\hline 4 & $"$ & 285.9 & 0.703 & 0.348 & 0.792 & 0.217 & 1.046 & 2.056 & -- \\
\hline 5 & $"$ & 377.6 & 1.197 & 0.573 & 1.344 & .0 .363 & 1.768 & 3.478 & -- \\
\hline 6 & $90 \%$ Blockage & 96.0 & 0.095 & 0.063 & 0.106 & 0.033 & 0.157 & 0.296 & 0.294 \\
\hline 7 & $"$ & 139.9 & 0.191 & 0.121 & 0.212 & 0.064 & 0.311 & 0.585 & 0.579 \\
\hline 8 & $"$ & 187.9 & 0.323 & 0.199 & 0.358 & 0.105 & 0.660 & 0.975 & 0.970 \\
\hline 9 & $"$ & 292.6 & 0.733 & 0.431 & 0.800 & 0.231 & 1.151 & 2.182 & 2.092 \\
\hline 10 & $"$ & $\cdot 377.1$ & 1.176 & 0.681 & 1.278 & 0.363 & 1.852 & 3.492 & 3.500 \\
\hline 11 & $70 \% \cdot 81$ ockage & 95.5 & 0.088 & 0.054 & 0.099 & 0.030 & 0.142 & 0.272 & 0.273 \\
\hline 12 & $"$ & 139.6 & 0.177 & 0.106 & 0.199 & 0.060 & 0.283 & 0.542 & .0 .538 \\
\hline 13 & $"$ & 187.4 & 0.309 & 0.182 & 0.349 & 0.103 & 0.491 & 0.941 & 0.941 \\
\hline 14 & $"$ & 281.9 & 0.664 & 0.377 & 0.743 & 0.212 & 1.032 & 1.984 & 2.036 \\
\hline 15 & $"$ & 376.0 & 1.129 & 0.630 & 1.259 & 0.352 & 1.753 & 3.364 & 3.390 \\
\hline
\end{tabular}




\section{DISTRIBUTION}

No. of

Copies

\section{OFFSITE}

A. A. Churm

ERDA Chicágo Patent Group

Chicago Operations Office

9800 South Cass Avenue

Argonne, IL 60439

245 ERDA Technical Information Center for Basic Distribution under NRC-1

51 Supplemental NRC-4. Distribution List

C. G. Howard

Babcock \& Wilcox

Alliance Research Center

1562 Beeson Street

Alliance, $\mathrm{OH} 44601$

C. Morgan

Babcock \& Wilcox

P. 0. Box 1260

Lynchburg, VA 24505

Tom Fernandez

Electric Power Research Institute

3412 Hillview Avenue

P. 0. Box. 10412

Palo Alto, CA 94304

A. Gopalakrishnan

Electric Power Research Institute

3412 Hillview Avenue

P. 0. Box 10412

Palo A1to, CA 94304

J.T.A. Roberts

Electric Power Research Institute

3412 Hillview Avenue

P. 0. Box 10412

Palo Alto, CA 94304
No. of

Copies
S. Neti

University of Kentucky

Department of Mechanical

Engineering

Lexington, KY 40506

Ed Davidson

U.S. Nuclear Regulatory Commission Division of Reactor Safety Research Washington, DC 20555

Lou Shotkin

U.S. Nuclear Regulatory Commission Division of Reactor Safety Research Washington, DC $20555^{\circ}$

S. Fabic

U.S. Nuclear Regulatory Commission Division of Reactor Safety Research Washington, DC 20555

L. S. Tong

U.S. Nuclear Regulatory Commission Division of Reactor Safety Research Washington, DC 20555

D. F. Ross

U.S. Nuclear Regulatory Commission Division of Technical Review Core Performance Branch Washington, DC 20555

H. Sullivan

U.S. Nuclear Regulatory Commission Division of Technical Review Core Performance Branch Washington, DC 20555

T. M. Novak

U.S. Nuclear Kegulatory Commission Division of Technical Review Reactor Systems Branch Washington, DC 20555 
S. Israel

U.S. Nuclear Regulatory Commission Division of Technical Review

Reactor Systems Branch

Washington, DC 20555

D. McPherson

U.S. Nuclear Regulatory Commission Division of Technical Review

Reactor Systems Branch

Washington, DC 20555

J. Hopenfeld

U.S. Energy Research and Development Administration

Components Engineering and Development Branch

Division of Reactor Research and Development.

Washington, DC 20545

H. Cullingford

U.S. Energy Research and Development Administration

Engineering Design and Component Development Branch

Division of Controlled Thermonuclear Rescarch

Vashington, DC 20545

B. Twining

U.S. Energy Research and Development Administration

Systems and Application studies Branch

Division of Controlled Thermonuclear Research

Washington, DC 20545

Pruf: F: Durst

University of Karlsruhe

Karlsruhe,

GERMANY

J. M. Delhaye

CENG

Grenoble,

FRANCE
ONSITE

1 ERDA Richland Operations Office

B. J. Melton

\section{Battelle-Northwest}

J. M. Bates

S. H. Bush

N. E. Carter

R. il. C.ena

J. M. Creer (7)

J. M. Cuta

D. E. Fitzsimmons

C. R. Hann

B. M. Johnson

D. K. Kreid

W. W. Laity

C. A. McMonagle

D. E. Olesen

M. G. Patrick

L. T. Pedersen

D. S. Rowe

C. W. Stewart

A. M. Sutey

D. S. Trent

C. L. Wheeler

R. D. Widrig

F. R. Zaloudek

Technical Information (3)

Technical Publications

(3) $\mathrm{KF} / \mathrm{BH}$ 